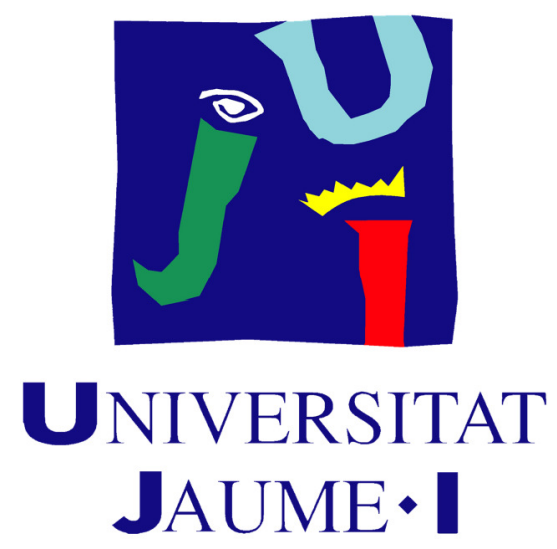

Departamento de Ingeniería Mecánica y Construcción

\title{
Análisis de la distribución de presiones en la mano humana durante el agarre
}

Tesis doctoral

Realizada por: Javier Cepriá Bernal Dirigida por: Dr. Antonio Pérez González Castellón, enero 2016 

A Marisa

A Paula y a Marc 



\section{Agradecimientos}

Hay mucha gente que, en mayor o menor medida han contribuido a que esta tesis haya podido realizarse.

En primer lugar, quiero agradecer a Antonio su dedicación y buenos consejos. No se ha limitado a ser simplemente un director de tesis, sino que ha ido mucho más allá en sus funciones hasta el punto que sin él, este documento no habría sido posible. Sin duda mi perfil investigador futuro se verá marcado por todas las horas que hemos pasado discutiendo resultados.

En segundo lugar, agradezco el apoyo de todos los compañeros de la UJI: a Marta C. Mora y a Verónica Gracia, por sus recomendaciones en el desarrollo de los experimentos; a Jesús por su ayuda en la realización de los mismos; a Salvador por su interés y ánimos; al área de MMCTE, por estar siempre pendientes: Alejandro, Emma, José Manuel, Enrique, Lola y Roberto; a Marian y Rosa, por ser siempre tan eficientes y estar disponibles para cualquier cosa que necesitara; y a todos los voluntarios que participaron en los ensayos: Loles, Victoria, Aurelien, Carmen, Pepe, Francisco Javier, Margarita, Ximo, Vicente, Valeria, Mauro, Ariana, Raquel y Elena.

También quiero agradecérselo a mi familia: a Marisa, incansable en el cuidado de los peques; a Paula, que me pedía jugar al "gatito" (programar en scratch) cada vez que me veía en el pc; a Marc, que me recordaba que existía un mundo más allá del teclado; mis padres, por su apoyo y ánimos; mis suegros y cuñada, siempre dispuestos a cuidar de los peques; y a mi hermano, cuñada y sobrinos, por compartir su alegría.

Y por supuesto, a tantos amigos: Juanjo, Alberto, Benjamín, Apa, Susana, Quique, Carmen, Manolo, David, y un largo etcétera que han hecho más llevadera esta etapa.

Por último, agradezco la financiación de la Fundación Bancaja - Universidad Jaume I, a través del proyecto P1-1B2009-40; y del Ministerio de Ciencia e Innovación a través del proyecto DPI2010-18177.

Muchas gracias a todos/as. 



\section{Resumen}

En esta tesis se presenta un estudio experimental de la dinámica del agarre humano, centrándose en la fuerza durante la manipulación de objetos con el fin de determinar qué fuerza de agarre es necesaria realizar para llevar a cabo ciertas tareas representativas de actividades de la vida diaria, cómo evoluciona dicha fuerza de agarre durante la tarea, cuál es la contribución de las distintas partes de la mano a la misma y cuáles son las presiones desarrolladas en el contacto entre la mano y objeto durante la ejecución de dichas tareas.

Los resultados de la tesis contribuyen a un mejor conocimiento de la dinámica del proceso de agarre, con aplicación en campos tan variados como la robótica, la ergonomía y la ingeniería protésica, ya que un conocimiento profundo de estas características del agarre permite mejorar el diseño de prótesis de los elementos terminales de los manipuladores robóticos y de los robots humanoides, el diseño de objetos y mangos para la manipulación de los mismos y el diseño de prótesis de mano humanas. Además, la tesis ha permitido evaluar las posibilidades prácticas y establecer los protocolos de uso para dos tipos de sensores comerciales utilizables para abordar estudios experimentales sobre el proceso de agarre en condiciones similares a las del agarre humano real.

Metodológicamente, la investigación se desarrolló a través de tres ensayos experimentales en los que se han manipulado objetos durante la realización de diversas tareas por parte de sujetos voluntarios. La mano de los sujetos se instrumentó con sensores de medida poco invasivos, que permiten obtener presión y/o fuerza de contacto en distintas zonas de la misma de forma dinámica, caracterizando de este modo las fuerzas de agarre, la superficie de contacto, la contribución de las distintas zonas de la mano a dicha fuerza de agarre y las presiones realizadas. El nivel de realismo en los objetos y en las tareas realizadas durante los ensayos se incrementó desde el primer ensayo, en el que se manipularon objetos de laboratorio cilíndricos y se ejecutaron tareas muy guiadas, hasta el tercero, en el que se utilizaron objetos cotidianos y se realizaron tareas habituales de la vida diaria. El segundo ensayo fue un paso intermedio entre ambos, realizándose una manipulación con botellas y centrándose principalmente en analizar el efecto de la tarea realizada con un mismo objeto sobre la contribución de las diferentes partes de la mano. 
Adicionalmente, y como paso previo a los ensayos, la tesis analiza los antecedentes relacionados con el objeto de la investigación, incluyendo aspectos como la anatomía de la mano humana, el diseño de prótesis y de manipuladores para robots, la neurofisiología del agarre, la ergonomía aplicada al agarre, las diferentes taxonomías realizadas sobre la postura de agarre y las técnicas y dispositivos existentes para la medida de la fuerza de agarre disponibles actualmente. 



\section{Índice}

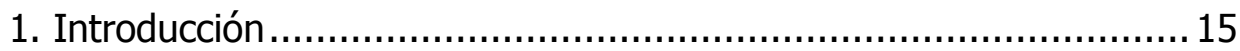

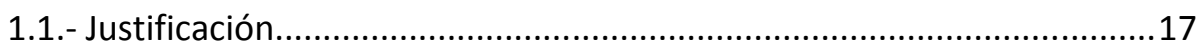

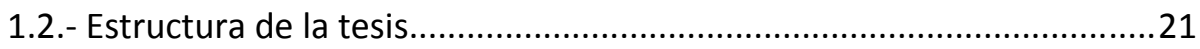

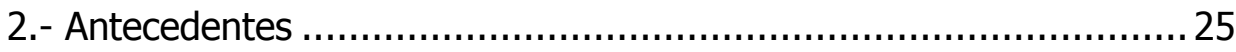

2.1.- Anatomía de la mano humana ...........................................................2

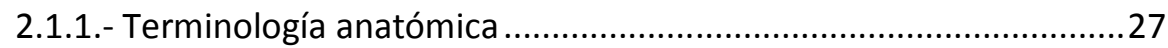

2.1.2.- Huesos de la mano..............................................................................

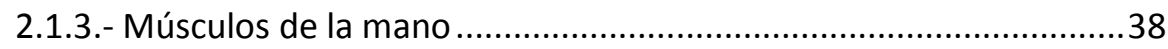

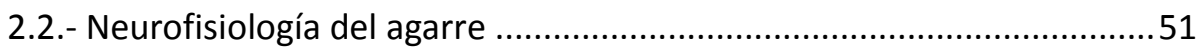

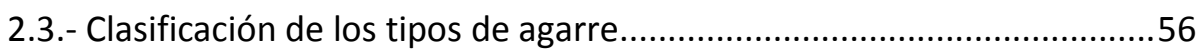

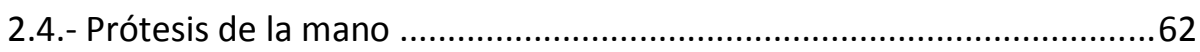

2.5.- Robots manipuladores y manos robóticas ............................................74

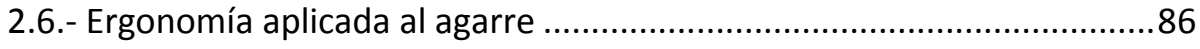

2.7.- Técnicas de medida de fuerza de agarre...............................................8 88

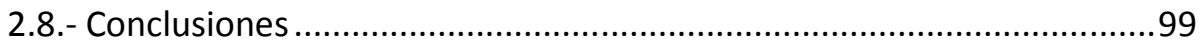

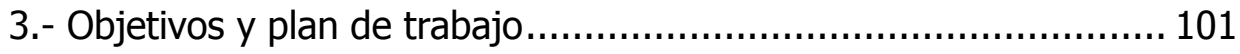

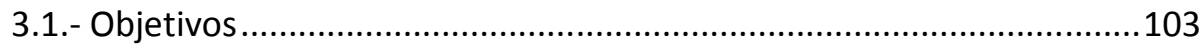

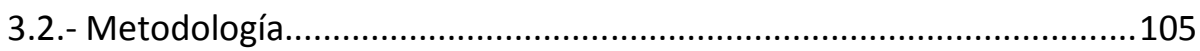

3.2.1.- Instrumentos de medida utilizados ............................................... 105

3.2.2.- Análisis estadísticos utilizados .....................................................110

3.2.3.- Tratamientos de datos realizados en los ensayos ..........................115

3.3.- Terminología empleada en los ensayos..............................................118

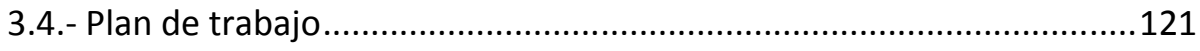

4.- Efecto del diámetro y peso en el agarre de objetos cilíndricos...... 123 


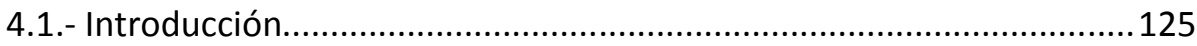

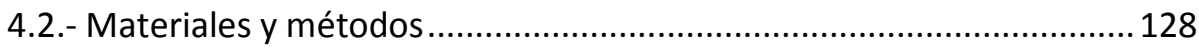

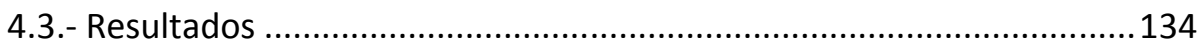

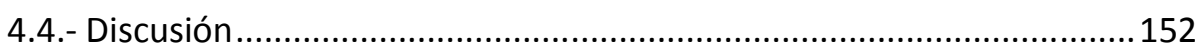

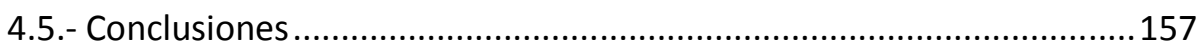

5.- Efecto de la tarea en el agarre en la manipulación de botellas..... 159

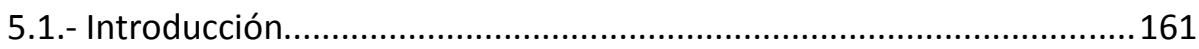

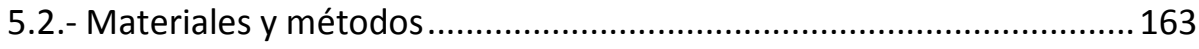

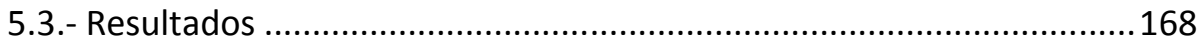

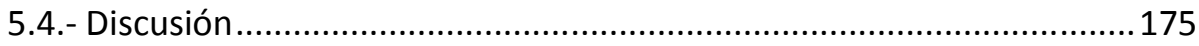

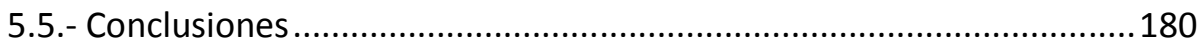

6.- Caracterización del agarre en la realización de tareas cotidianas.. 183

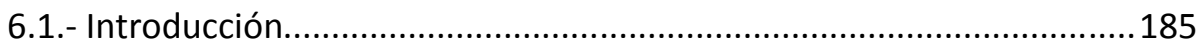

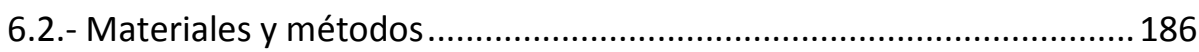

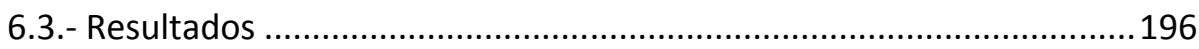

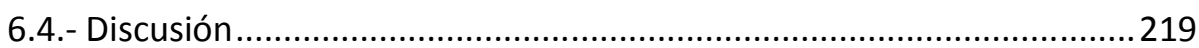

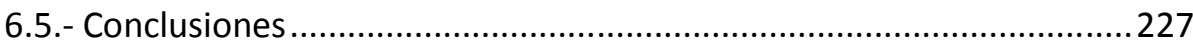

7.- Conclusiones y desarrollos futuros ........................................ 229

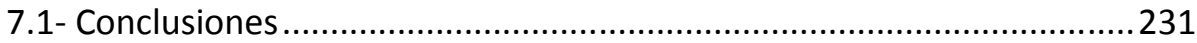

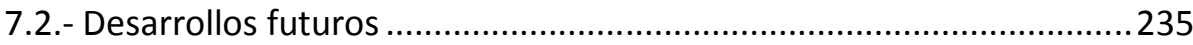

Bibliografía......................................................................... 237 


\section{Abreviaturas utilizadas}

ACP: $\quad$ Abductor corto del pulgar

ADP: $\quad$ Aductor del pulgar

ALP: $\quad$ Abductor largo del pulgar

AM: $\quad$ Abductor del meñique

ANOVA: Análisis de varianza

AVD: $\quad$ Actividades de la vida diaria

CGF: Contribución de cada sensor a la fuerza de agarre

DIP: $\quad$ Articulación interfalángica distal

EC: $\quad$ Extensor común

ECP: $\quad$ Extensor corto del pulgar

El: $\quad$ Extensor propio del índice

ELP: $\quad$ Extensor largo del pulgar

EM: $\quad$ Extensor propio del meñique

FCM: $\quad$ Flexor corto del meñique

FCP: $\quad$ Flexor corto del pulgar

FLP: $\quad$ Flexor largo del pulgar

FP: $\quad$ Flexor profundo

FS: $\quad$ Flexor superficial

gdl: $\quad$ Grados de libertad

GF: $\quad$ Fuerza de agarre

ID1: $\quad$ Primer interóseo dorsal

IF: $\quad$ Articulación interfalángica

IFD: Interfalángica distal

IFP: Interfalángica proximal

IQR: Valor intercuartil.

LU: Lumbrical

MANOVA: Análisis de varianza multivariable

MCC: $\quad$ Articulación metacarpocarpiana

MCF: Articulación metacarpofalángica

MGF: $\quad$ Fuerza de agarre media (experimento de las botellas)

MSFi: Valor medio de fuerza de cada sensor (experimento de las botellas)

OP: $\quad$ Oponente del pulgar

OPM: $\quad$ Oponente del meñique

PC: $\quad$ Componente principal

PCA: $\quad$ Análisis de los componentes principales

PDS: $\quad$ Punto de sincronismo.

PIP: $\quad$ Articulación interfalángica proximal

Q1: $\quad$ Primer cuartil. 
Q3: Tercer cuartil.

RMSE: Error cuadrático medio.

SCD: $\quad$ Variación dentro de las muestras

SCE: $\quad$ Variación entre muestras

SD: $\quad$ Desviación típica

T1: $\quad$ Tarea 1 del experimento de botellas (transporte de botella)

T2: $\quad$ Tarea 2 del experimento de botellas (verter líquido de la botella)

W: $\quad$ Peso 

1. Introducción 



\section{1.- Justificación}

La tesis que se presenta, Análisis de la distribución de presiones en la mano humana durante el agarre, se enmarca dentro del programa de doctorado Proyectos de Innovación Tecnológica en Ingeniería del Producto y Procesos, compartido entre los departamentos de Ingeniería Mecánica y Construcción y de Ingeniería de Sistemas Industriales y Diseño de la Universidad Jaime I de Castellón.

Esta tesis se engloba en la línea de investigación de Biomecánica de la mano humana, abierta por el grupo de Biomecánica y Ergonomía de esta Universidad. El grupo de Biomecánica y Ergonomía empezó sus investigaciones en octubre de 1995 y actualmente sus líneas de investigación principales son: Biomecánica dental, Ergonomía de las herramientas, Ingeniería Emocional, Biomecánica del pie y la ya citada Biomecánica de la mano humana.

Dentro de la línea de biomecánica de la mano humana, el grupo ha trabajado en distintas sublíneas, como son el modelado biomecánico de la mano humana, el uso de dichos modelos para planificación quirúrgica de la mano, la caracterización cinemática y dinámica de la mano a partir de medidas experimentales, la evaluación funcional de la mano durante la manipulación de productos en actividades de la vida diaria y, finalmente el diseño y evaluación de manos artificiales antropomorfas.

En concreto, la presente tesis se enmarca en la sublínea de caracterización de la mano a partir de medidas experimentales. Concretamente se pretende contribuir a un mejor conocimiento de las fuerzas implicadas en el agarre de objetos y en la contribución de las distintas zonas de la mano al mismo. Los resultados obtenidos de este trabajo ayudarán a una mejor caracterización del funcionamiento de la mano y por tanto podrán contribuirán en el futuro para el desarrollo de otras líneas o sublíneas de investigación, como por ejemplo la mejora del diseño de prótesis de mano y manipuladores robóticos, o la mejora ergonómica en el diseño de herramientas manuales y sus mangos o en general de cualquier objeto manipulado.

Como justificación del interés de esta investigación se puede afirmar que la mano humana es uno de los sistemas biomecánicos más complejos del mundo y que su funcionamiento aún no se conoce en profundidad. Su destreza y 
versatilidad para manipular objetos aún no ha sido reproducida completamente por ningún dispositivo artificial. La activación de los músculos durante las tareas de agarre permite a la mano adoptar la forma necesaria para distribuir las fuerzas de contacto de la misma con el objeto durante su manipulación. Una manipulación exitosa se consigue gracias a complejos controles de activación muscular, que se realizan en el sistema nervioso central, facilitada por la retroalimentación táctil y visual conseguida mediante los sentidos y transportada mediante las neuronas aferentes al sistema nervioso central.

El agarre con dispositivos protésicos o con manos antropomorfas robóticas aún no consigue el nivel de destreza de la mano humana, ni siquiera con las modernas prótesis mioeléctricas (Micera, Carpaneto, \& Raspopovic, 2010). Un profundo conocimiento de la distribución de fuerzas en la mano natural durante el agarre no solo mejoraría el control y el diseño mecánico de las prótesis de mano sino también el diseño de los productos desde un punto de vista ergonómico (Kargov, Pylatiuk, Martin, Schulz, \& Döderlein, 2004).

Numerosos estudios previos en la literatura miden la fuerza de agarre total en agarres de potencia. Estos estudios se basan en la utilización de un dinamómetro (generalmente el dinamómetro Jamar (Bohannon, Peolsson, Massy-Westropp, Desrosiers, \& Bear-Lehman, 2006; Peters et al., 2011), aunque existen otros sistemas como el dinamómetro esférico (Chkeir, Jaber, Hewson, \& Duchene, 2012), esfigmomanómetro (G. F. Hamilton, McDonald, \& Chenier, 1992; Ugurlu \& Özdogan, 2013) o el Rolyan (Virgil Mathiowetz, 2002), y se centran en determinar las diferencias entre individuos sanos y patológicos (Rajabally \& Narasimhan, 2013; Roberts et al., 2011; Trampisch, Franke, Jedamzik, Hinrichs, \& Platen, 2012) o la fuerza que ejercen los individuos de edad avanzada (Bohannon, Bear-Lehman, Desrosiers, Massy-Westropp, \& Mathiowetz, 2007).

Otros estudios midieron la fuerza de agarre de la mano durante la manipulación de objetos, aunque la mayoría de ellos se han centrado en el agarre con las puntas de los dedos o han utilizado dispositivos específicos en lugar de objetos cotidianos (Aoki, Niu, Latash, \& Zatsiorsky, 2006; Kinoshita, Kawai, \& Ikuta, 1995; Y.-K. Kong, Lee, Kim, \& Jung, 2011; Kuo et al., 2013; Radwin, Oh, Jensen, \& Webster, 1992; Reilmann, Gordon, \& Henningsen, 2001; 
Análisis de la distribución de presiones en la mano humana durante el agarre

Santello \& Soechting, 2000). La fuerza de agarre y la contribución a las distintas áreas de la mano también han sido estudiadas desde el punto de vista del diseño ergonómico de mangos (Y.-K. Kong, Seo, \& Kang, 2014; Lee, Kong, Lowe, \& Song, 2009; R W McGorry \& Lin, 2007), pero son escasos los estudios que analizan la distribución de fuerzas en el agarre de otro tipo de objetos cotidianos. La mayoría de los estudios que analizan la contribución de las distintas zonas de la mano a la fuerza de agarre han usado objetos cilíndricos porque éstos se pueden envolver fácilmente con sensores de presión laminares, tales como los sistemas de mapeo de presión desarrollados por Tekscan o Fuji Film (Nicholas, Corvese, Woolley, \& Armstrong, 2012; Pataky, Slota, Latash, \& Zatsiorsky, 2012). Algunos estudios que han utilizado objetos cotidianos, tales como botellas, únicamente han tenido en cuenta la posición de la mano y la cinemática de la misma, sin analizar las fuerzas aplicadas (Ansuini, Giosa, Turella, Altoè, \& Castiello, 2008; Crajé et al., 2011; Sartori, Straulino, \& Castiello, 2011). Un estudio reciente utiliza objetos especialmente diseñados, instrumentados con sensores, para simular objetos cotidianos utilizados en tareas de vertido de líquidos, pero únicamente se analiza el agarre con tres dedos (Manis \& Santos, 2015). Además, el hecho de que los sensores tengan una localización específica puede afectar a la forma con la que se manipulan dichos objetos $y$, por tanto, a la fuerza de agarre ejercida. Algunos autores señalan esta falta de estudios sobre la distribución de fuerzas durante el agarre (Pylatiuk, Kargov, Schulz, \& Döderlein, 2006) que puede ser explicada en parte debido a la dificultad de encontrar sensores apropiados.

Por otra parte, hay estudios que demuestran que una correcta retroalimentación sensorial es precisa para prever y regular la fuerza de agarre necesaria (Nowak, Glasauer, \& Hermsdörfer, 2004), por lo que no tener una retroalimentación de contacto adecuada con el objeto como consecuencia de interponer sensores entre la mano y el objeto puede variar la fuerza ejercida en la manipulación del mismo, por lo que los sensores han de ser finos y elásticos para que perturben lo menos posible el contacto natural en el agarre. Además, se debería intentar que el coeficiente de rozamiento sea similar al que presenta la piel humana con el objeto.

Pylatiuk et al. (Pylatiuk et al., 2006) analizaron una manipulación funcional de botellas usando sensores de fuerza especialmente diseñados, situados en la mano, que tenían $9 \mathrm{~mm}$ de diámetro y $3 \mathrm{~mm}$ de espesor. Hermsdörfer et al. 
(Hermsdörfer et al., 2011a) analizaron las fuerzas realizadas durante la manipulación de varios objetos asociadas a actividades cotidianas, pero únicamente midieron las fuerzas de contacto de las puntas de los dedos en el agarre con tres dedos.

El problema de la redundancia motora debida a la producción de fuerza con varios dedos se ha remarcado en estudios previos (V M Zatsiorsky, Li, \& Latash, 1998): la misma fuerza total de agarre se puede realizar con distintas contribuciones de cada uno de los dedos, lo que se conoce como "compartición de fuerzas" o "force sharing". Dicha compartición de fuerzas no se ha estudiado en profundidad en actividades de la vida diaria.

Con el fin de determinar la fuerza de agarre con la mano, se han desarrollado diversos modelos biomecánicos de la misma. Sin embargo, la gran complejidad de la mano hace que esta tarea no sea sencilla. En 2005, Hu et al. (Hu, Osu, Okada, Goodale, \& Kawato, 2005) mostraron un modelo cuantitativo del acoplamiento temporal entre la apertura del agarre y la velocidad de la muñeca. Chang et al (Chang \& Matsuoka, 2006) en 2006 desarrolló un modelo del pulgar. En 2003, Sancho-Bru et al. (Sancho-Bru, Pérez-González, Vergara, \& Giurintano, 2003) presentaron un modelo biomecánico de la mano para los agarres de potencia. Todos estos modelos requieren de datos experimentales en los que basar su validación. Los ensayos llevados a cabo en esta tesis pueden aportar información valiosa para dicha validación. 


\section{2.- Estructura de la tesis}

El contenido de esta tesis se ha organizado en 7 capítulos, además de la bibliografía:

- Capítulo 1: Introducción. Consta de 2 apartados, en los que se justifica la necesidad del estudio realizado en la presente tesis y se indica su estructura.

- Capítulo 2: Antecedentes. Este capítulo consta de 7 apartados. En él, se revisará el estado del arte de diversos aspectos necesarios para el correcto desarrollo de la tesis, para facilitar la lectura de los capítulos posteriores y para un correcto enfoque de los objetivos. La revisión se realiza en términos generales, reservándose para capítulos posteriores las menciones a algunos artículos especialmente relevantes en relación a dichos capítulos y a la discusión de sus resultados.

- Capítulo 3: Objetivos y plan de trabajo. En este capítulo se exponen los objetivos de la tesis, la metodología empleada y la terminología general usada en los ensayos y la redacción de la tesis. Asimismo se describe el plan de trabajo.

- Capítulo 4: Efecto del diámetro y peso en el agarre de objetos cilíndricos. En este capítulo se analiza el agarre durante el transporte de objetos cilíndricos de distintos pesos y diámetros, utilizando diferentes tipos de agarre, con diferente número de dedos implicados.

- Capítulo 5: Efecto de la tarea en el agarre en la manipulación de botellas. En este capítulo se analizan las fuerzas de agarre y su distribución, ejercidas por la mano en el manejo de botellas de distintos tipos y características, con diferentes niveles de llenado y durante la realización de dos tareas diferentes: transporte y vaciado del contenido.

- Capítulo 6. Caracterización del agarre en la realización de tareas cotidianas. En este capítulo se aborda un extenso trabajo experimental de caracterización de las fuerzas de agarre y su distribución en la mano, durante la realización de tareas habituales de la vida diaria con objetos reales de uso cotidiano. Se analizan 21 tareas diferentes que 
involucran fuerzas y tipos de agarre muy variables y representativos de las actividades de la vida diaria.

- Capítulo 7. Conclusiones y desarrollos futuros. En este capítulo se exponen las conclusiones de la tesis y se realiza una propuesta de las posibles líneas futuras de investigación relacionadas.

- Bibliografía. Referencias bibliográficas utilizadas para el desarrollo de la tesis. 


2.- Antecedentes 



\section{1.- Anatomía de la mano humana}

La mano es el órgano terminal de la extremidad superior del ser humano. Por su configuración, es el órgano que presenta una mayor funcionalidad y versatilidad, ya que permite realizar una gran cantidad de movimientos diferentes en distintas configuraciones. Por este motivo, se puede considerar una herramienta universal, ya que, al contrario que ocurre con el resto de mamíferos, la mano humana no se ha especializado en una tarea concreta. Esta no especialización es posible gracias a la capacidad del ser humano de fabricar y utilizar herramientas para efectuar tareas específicas.

La misma fuerza de agarre total puede producirse con distintas configuraciones de posición de los dedos de la mano, lo que conlleva distintas posibilidades de contribución de cada zona de la mano. Este fenómeno se conoce como redundancia motriz, siendo el grupo de Zatsiorsky quien la puso en relieve en 1998 (V M Zatsiorsky et al., 1998).

La anatomía musculo-esquelética de la mano humana se puede dividir en tres entidades: los huesos, los músculos y tendones, y los ligamentos. Está formada por 27 huesos accionados por unos 40 músculos, lo que hace que presente 20 grados de libertad (gdl) (Taylor \& Schwart, 1955).

\subsection{1.- Terminología anatómica}

En la reunión de 1998 del Comité Internacional Federativo de Terminología Anatómica (FICAT, por sus siglas en inglés) se definieron y clasificaron unas 8000 partes anatómicas, divididas en 15 grandes grupos.

La posición anatómica estándar, a partir de la cual localizan todas las estructuras, es la posición en la cual el sujeto se encuentra de pie, con los brazos a los lados, mostrando las palmas de las manos al observador, tal como muestra la figura 2.1. De esta manera, se evitan confusiones al referirse al frente, dorso o lado de un cuerpo. 


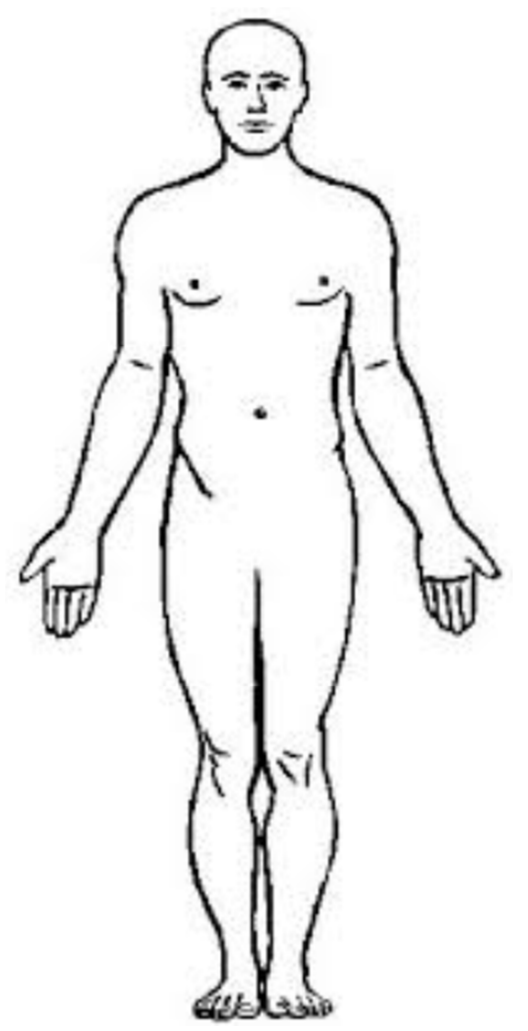

Figura 2.1. Posición anatómica estándar

La anatomía utiliza términos geométricos para definir la localización de todas sus partes, fundamentalmente planos, líneas y regiones. También se usan otros términos geométricos, tales como puntos, ángulos, cuadrantes, etc., y otros no geométricos, como cavidad, conducto o fosa, que dan una idea aproximada de la forma o función de la estructura.

Los planos anatómicos más importantes son tres (figura 2.2):

- Plano frontal: Es un plano vertical paralelo a la posición anatómica anterior que divide el cuerpo en dos partes, la anterior y la posterior. También se llama plano coronal.

- Plano sagital: Es un plano vertical perpendicular a la posición anatómica anterior que divide el cuerpo en dos partes iguales, izquierda y derecha. Es también perpendicular al plano frontal. También es conocido como plano medial. 
- Plano transverso: Es un plano horizontal, paralelo al suelo, que divide el cuerpo en dos partes, superior e inferior.

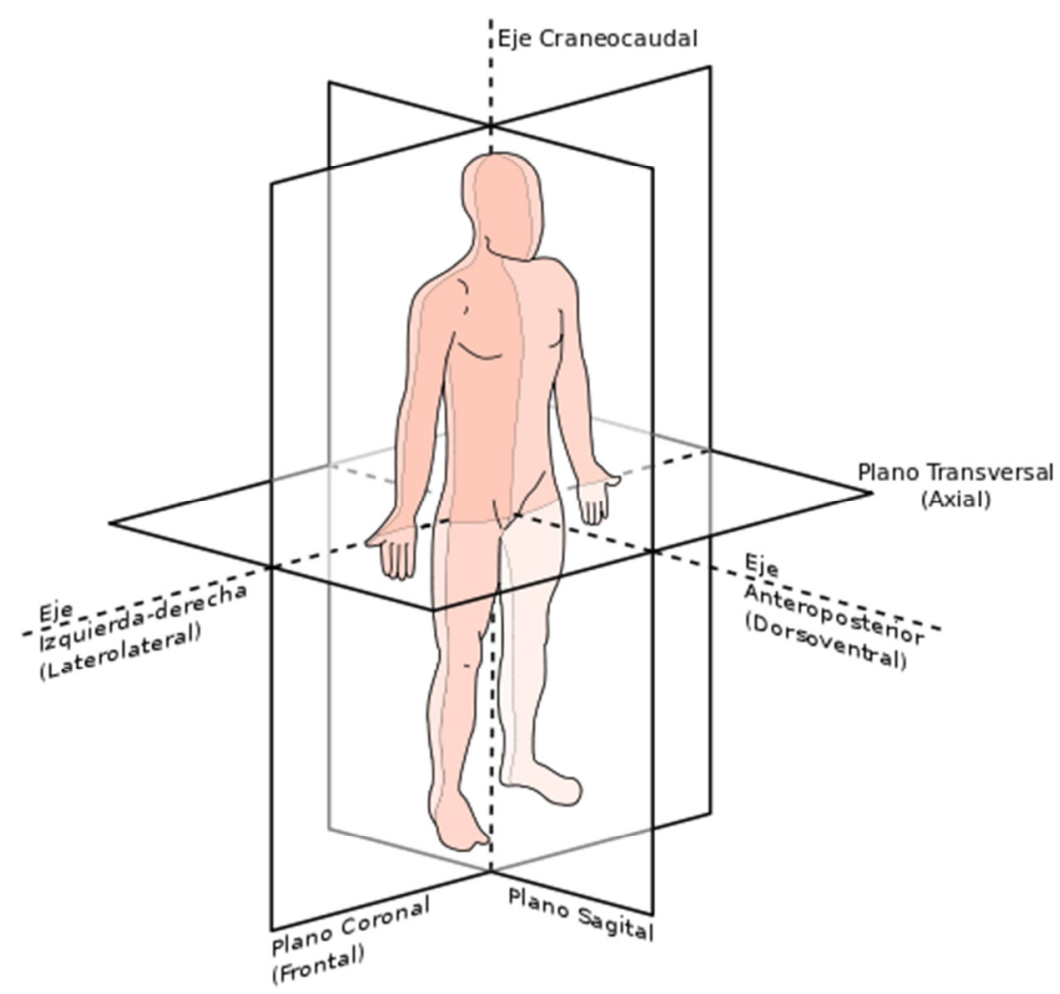

Figura 2.2. Ejes y planos anatómicos más importantes. (Edoarado, 2011)

Existen muchos otros planos, fundamentalmente transversos, de zonas concretas del cuerpo.

Las direcciones en el espacio también tienen una terminología específica, que puede verse en la figura 2.3. En función del órgano que se esté referenciando puede presentar un término u otro, por lo que este apartado se centrará en la terminología utilizada para definir las direcciones de la mano.

La dirección proximal/distal (o apical) se utiliza en los miembros para indicar la mayor o menos proximidad al tronco. Las muñecas serán la parte más proximal de la mano mientras que las puntas de los dedos serán las zonas más distales. 
La dirección dorsal o posterior es la parte que se dirige hacia atrás cuando el sujeto está en posición anatómica. La dirección opuesta es la ventral o anterior. En la mano, la dirección ventral suele llamarse volar o palmar.

La dirección medial es aquella que se dirige hacia el plano medial o línea media en posición anatómica. En la mano suele llamarse cubital, denominándose a la dirección opuesta lateral o radial.

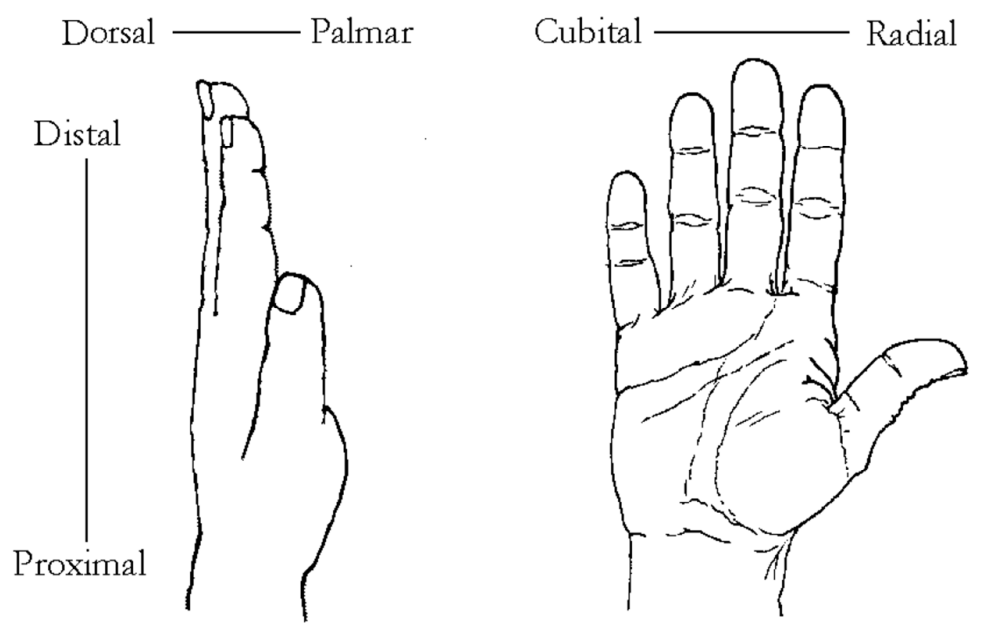

Figura 2.3 Terminología utilizada para describir las posiciones relativas en las tres direcciones espaciales.

Finalmente, los movimientos que se pueden realizar también tienen una nomenclatura específica, que puede verse en la figura 2.4 .

\subsection{2.- Huesos de la mano}

Los huesos forman parte del endoesqueleto en los animales vertebrados. Están compuestos por tejidos duros y blandos, siendo el principal tejido duro el tejido óseo, un tipo especializado de tejido conectivo formado por osteocitos y componentes extracelulares calcificados. Los huesos tienen una cubierta superficial de tejido conectivo fibroso llamado periostio. Sus superficies articulares están cubiertas por tejido conectivo cartilaginoso. Los componentes blandos incluyen a los tejidos conectivos mieloide y el tejido hematopoyético. El hueso también cuenta con vasos y nervios que, respectivamente, irrigan e inervan su estructura. 

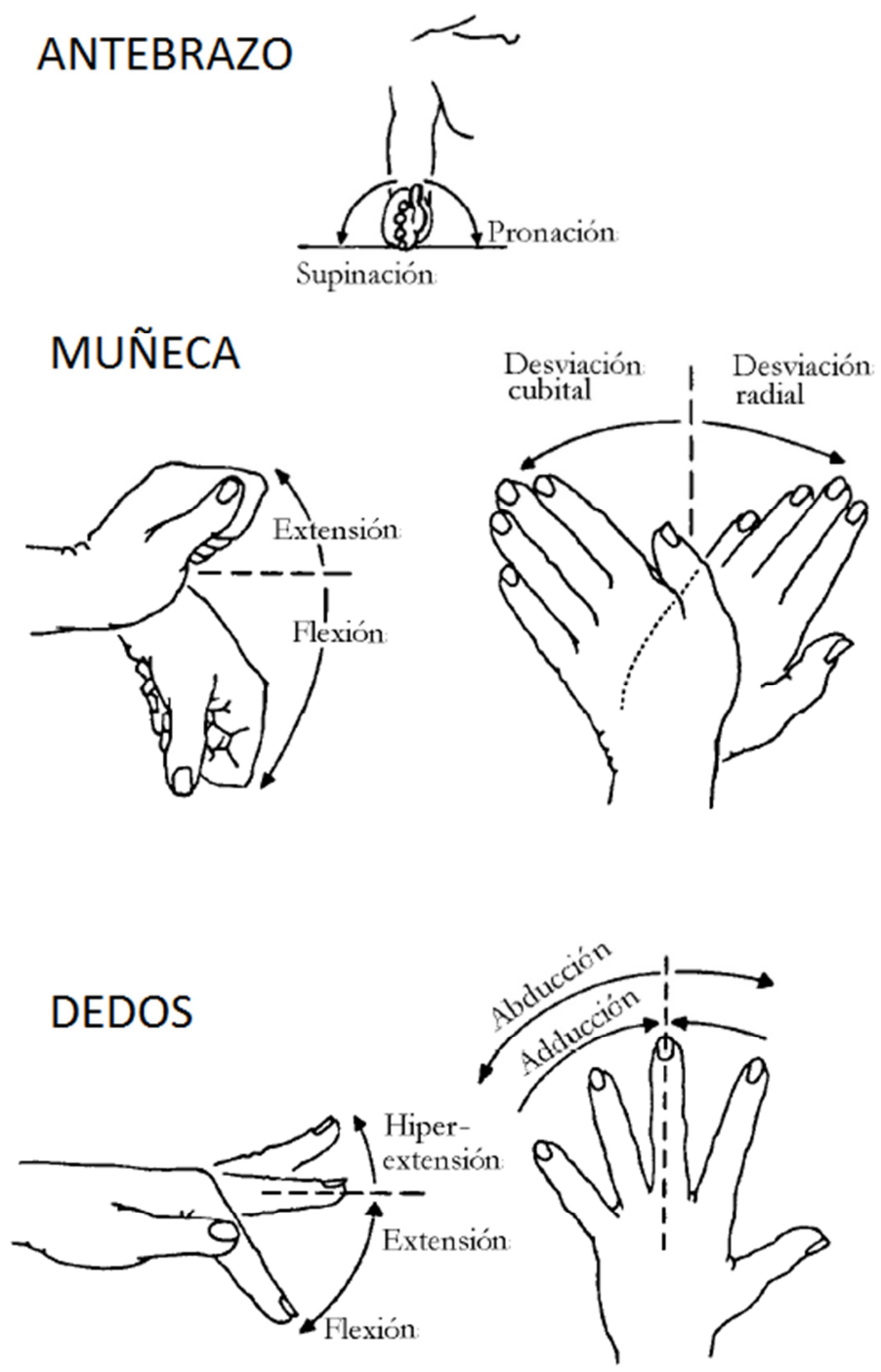

Figura 2.4: Movimientos del antebrazo, muñeca y dedos (Sancho-Bru, 2000)

Las dos funciones principales de los huesos de la mano son la de sostén para el resto de órganos y tejidos, tales como los músculos, la piel y tejidos conectivos; y la de movimiento, que se consigue gracias a los músculos que se insertan en los huesos mediante los tendones.

Como se puede ver en la figura 2.5 , la mano humana tiene un total de 27 huesos divididos en tres grupos: el carpo, los metacarpianos y las falanges, conectándose a la muñeca a través de la palma. 


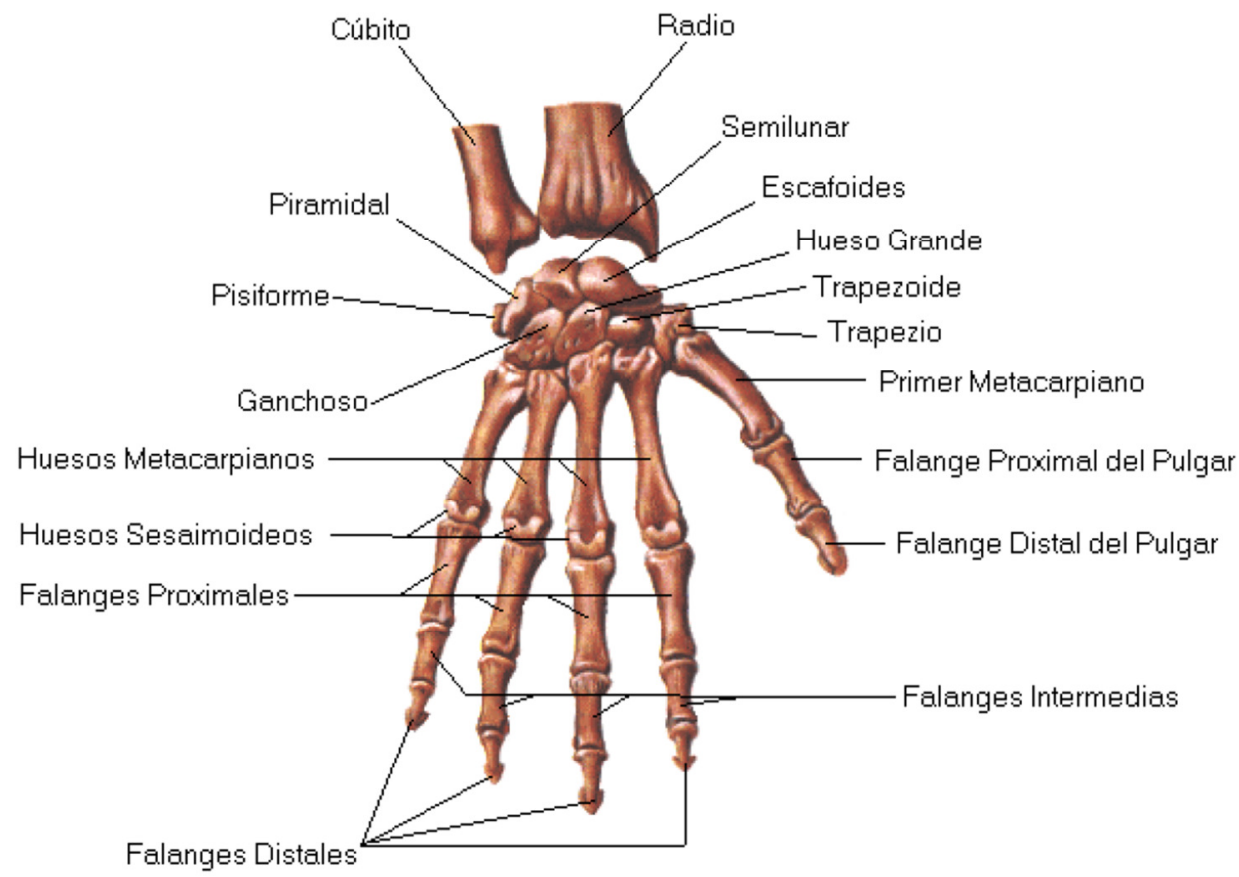

Figura 2.5. Estructura ósea de la mano(Andalucía, n.d.)

El pulgar está formado por dos falanges (distal y proximal), mientras que el resto de dedos tiene tres (distal, intermedia y proximal). El pulgar se une a la palma más cercano a la muñeca que el resto de dedos. Debido a la gran movilidad de su metacarpo, es capaz de efectuar movimientos de cierre y rotación, lo que permite variar la orientación en la que se realiza el movimiento de doblado y extensión del pulgar, pudiendo así oponerlo al resto de dedos. Esto, a su vez, posibilita el agarre tipo pinza, sin el cual la manipulación de objetos sería mucho más pobre. Concretamente, los movimientos que puede realizar el dedo pulgar y su rango son los siguientes (Rouviere \& Delmas, 2005):

- Abducción-extensión (figura 2.6a) que separa el dedo pulgar del eje de la mano, su amplitud es de $35^{\circ}$ a $40^{\circ}$. Este movimiento abre la mano.

- Aducción (figura 2.6b), que aproxima el dedo pulgar al eje de la mano. Su amplitud es de $35^{\circ}$ a $40^{\circ}$. Este movimiento cierra la mano.

- La oposición (figura 2.6c) que combinada con la flexión del dedo pulgar lo conduce al frente del dedo meñique. Se trata de un movimiento de prensión y tiene una amplitud entre $45^{\circ}$ y $60^{\circ}$. 
- La reposición (figura $2.6 \mathrm{~d}$ ), devuelve el dedo pulgar a su posición inicial. Su amplitud es igual que la anterior, entre $45^{\circ}$ y $60^{\circ}$.
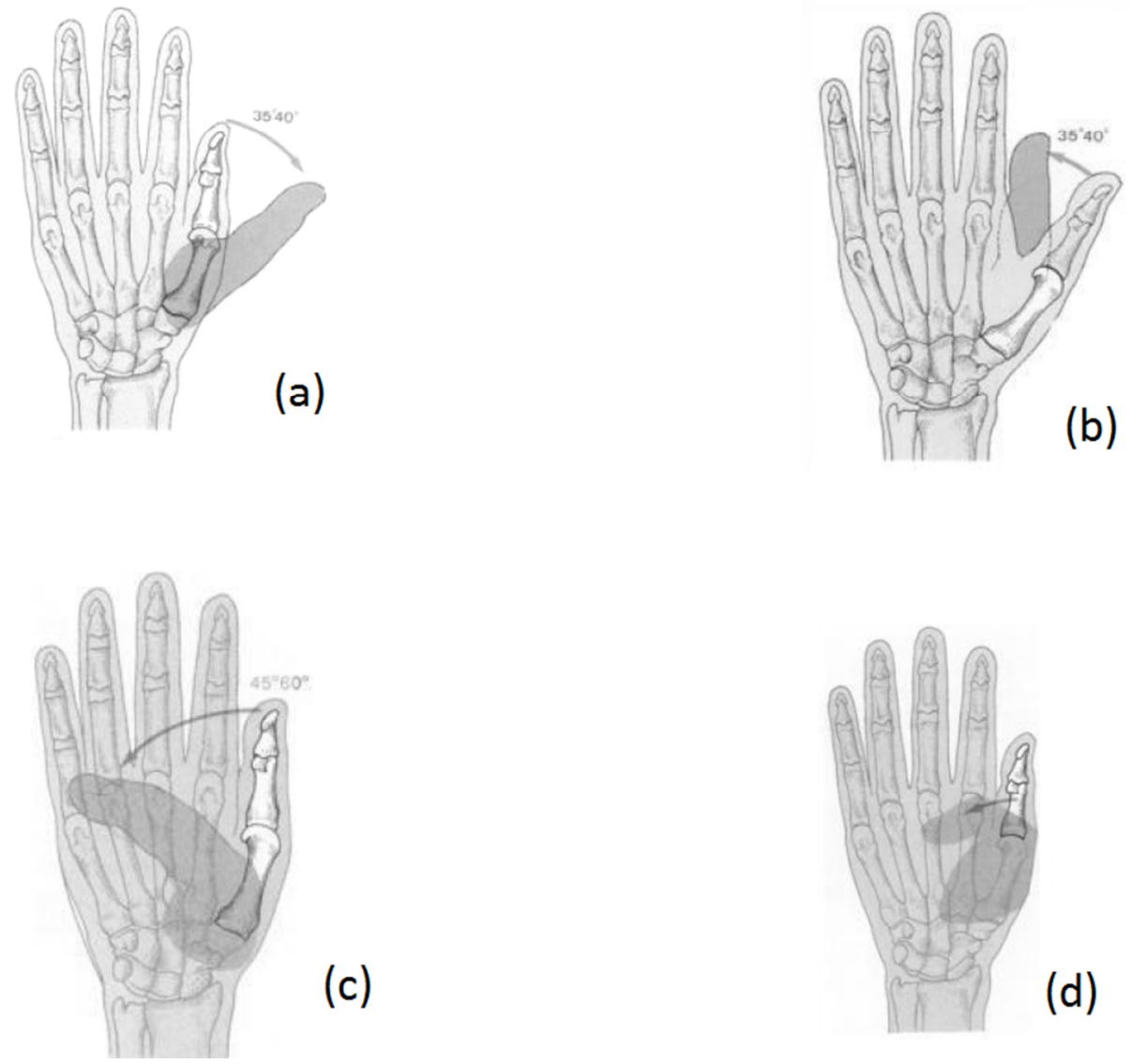

(c)

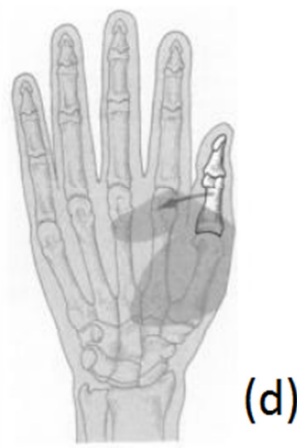

Figura 2.6. Movimientos del dedo pulgar: (a) abducción, (b) aducción, (c) oposición y (d) reposición(Rouviere \& Delmas, 2005)

Los dedos tienen principalmente tres articulaciones (figura 2.7): articulación metacarpofalángica (MCF), que une la falange metacarpiana y la proximal de un dedo o pulgar; articulación interfalángica proximal (PIP), que está localizada entre las falanges media y proximal del dedo; y la articulación interfalángica distal (DIP), ubicada entre las falanges media y distal del dedo (Sancho-Bru, 2000). 


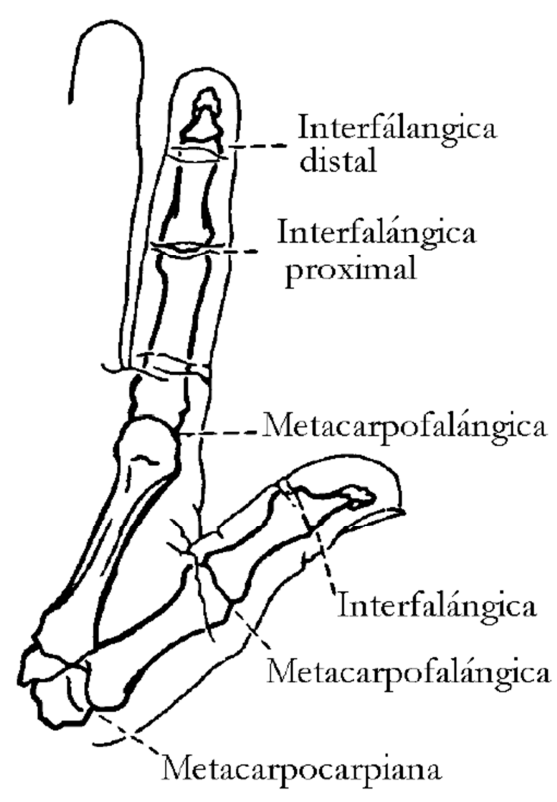

Figura 2.7: articulaciones de la mano (Sancho-Bru, 2000)

La articulación metacarpocarpiana (MCC) del pulgar es del tipo silla de montar, y tiene de movimientos preferentes la flexión-extensión y la abducciónaducción, al igual que la articulación metacarpofalángica (MCF), aunque esta última es de tipo condílea. La articulación interfalángica (IF) es troclear y únicamente tiene la flexión-extensión como movimientos preferentes.

Los dedos índice, medio, anular y meñique están compuestos por cuatro elementos esqueléticos: metacarpo, falange proximal, falange medial y falange distal (figura 2.8) (Sancho-Bru, 2000).

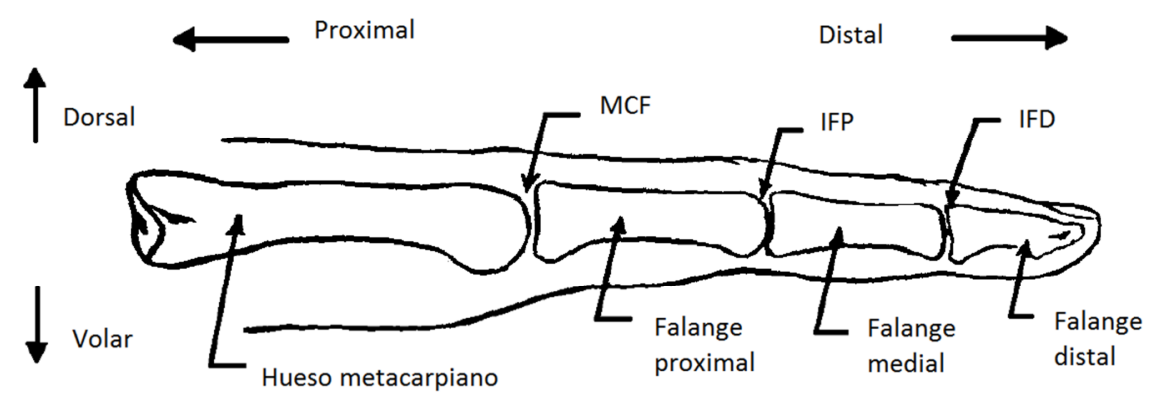

Figura 2.8: Huesos de los dedos y terminología asociada (Sancho-Bru, 2000) 
Las uniones de estos huesos reciben los siguientes nombres, empezando por la articulación entre el carpo (muñeca) y el hueso metacarpiano, y avanzando en sentido distal: metacarpocarpiana (MCC), metacarpofalángica (MCF), interfalángica proximal (IFP) e interfalángica distal (IFD).

Las articulaciones MCC son artroides, por lo que permiten movimientos de flexoextensión de poca amplitud (Kapandji, 1996).

Esta amplitud va en aumento desde el segundo al quinto hueso metacarpiano (normalmente se considera que no hay movimiento relativo entre el segundo y tercer metacarpiano). Los ejes de rotación son oblicuos, lo que explica la tendencia de las cabezas de los metacarpianos a moverse hacia el mismo punto, ayudando el movimiento de oposición del pulgar. Este movimiento también es esencial para producir el arqueo de la mano.

Las articulaciones MCF son de tipo condíleo (figura 2.9). Cada una de estas articulaciones está formada por el contacto entre dos superficies articulares. La superficie proximal corresponde a la cabeza del hueso metacarpiano, que es convexa y cuya sección transversal es aproximadamente rectangular, mientras que la distal es la base de la falange proximal, que es una superficie cóncava que acopla con la concavidad de la superficie de la cabeza del hueso metacarpiano. El rango de flexión en estas articulaciones aumenta en dirección cubital, de forma que en el índice es de $90^{\circ}$ y en el meñique, de $110^{\circ}$. La amplitud de la extensión activa es variable para cada persona, mientras que en la extensión pasiva se puede llegar a los $90^{\circ}$. El rango de abducción-aducción es mayor en extensión, pudiendo obtenerse valores de hasta $30^{\circ}$ en cada dirección. 


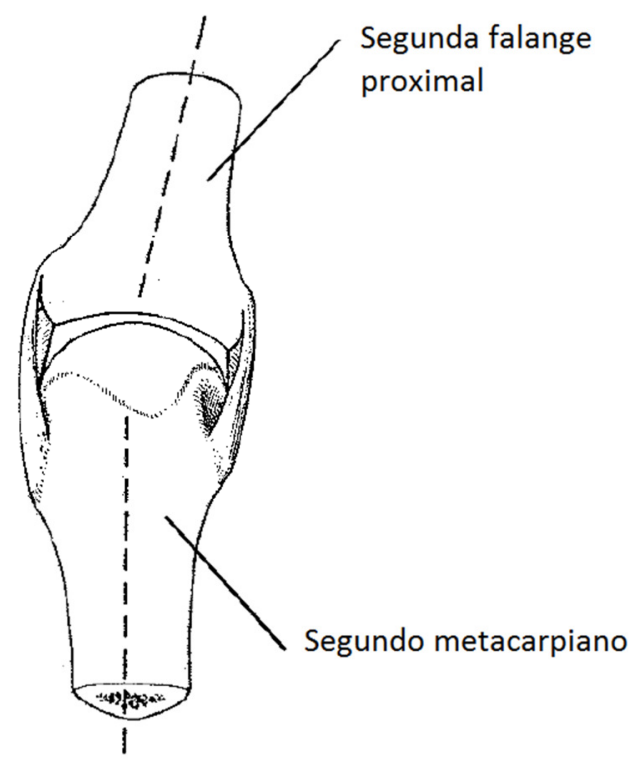

Figura 2.9. Articulación MCF del dedo índice (Dubousset, 1981).

Las articulaciones IFP son de tipo troclear (figura 2.10). Las superficies auriculares se comportan como una polea, que sería la cabeza de la falange, con un único eje transversal alrededor del cual se efectúan los movimientos de flexión-extensión. La superficie proximal de estas articulaciones corresponde a la cabeza de la falange proximal, siendo su forma la de una polea trapezoidal, con aproximadamente el doble de amplitud en la parte palmar que en la dorsal. Tiene dos cóndilos laterales, ligeramente asimétricos, separados por una garganta de poca profundidad (inferior a $1 \mathrm{~mm}$ ). La superficie distal corresponde a las bases de las falanges mediales. Su superficie se adapta a la configuración bicondílea de la cabeza de la falange proximal mediante dos depresiones condíleas y una cresta intercondílea anteroposterior. Como en el caso de la articulación MCF, la distinta curvatura en el plano sagital de la superficie de la cabeza de la falange proximal hace que el movimiento relativo entre las superficies auriculares se realice con mayor proporción en la vertiente palmar, favoreciendo la flexión.

Las articulaciones IFD presentan la misma estructura que las proximales: son articulaciones de tipo troclear (figura 2.11). Estas articulaciones únicamente permiten movimiento de flexoextensión. Su rango de movimientos está entre 
$70^{\circ}$ y $80^{\circ}$, de los cuales entre $10-20^{\circ}$ corresponden a la extensión. La extensión pasiva puede llegar a los $30^{\circ}$.

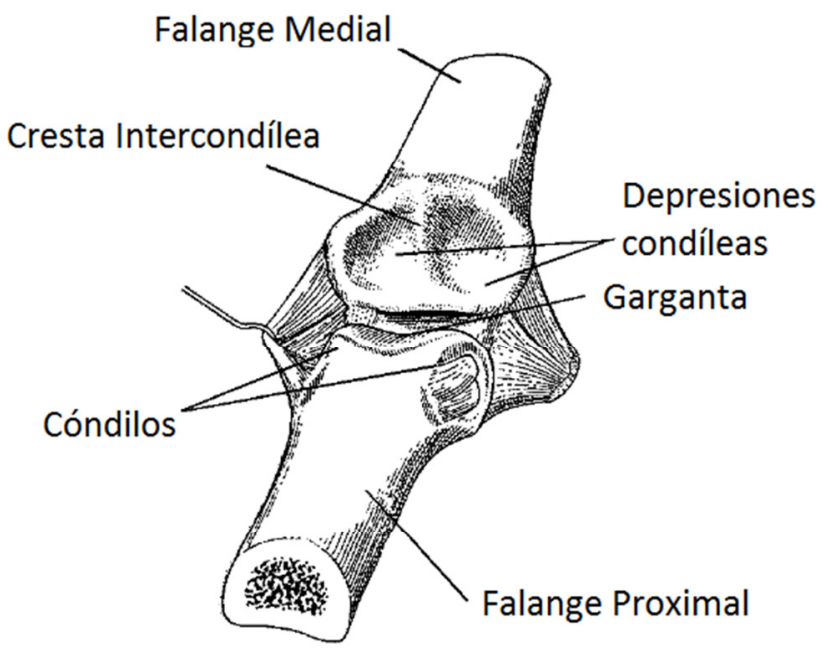

Figura 2.10. Articulación IFP, mostrando las dos cavidades de la base de la falange medial (Dubousset, 1981)

a)

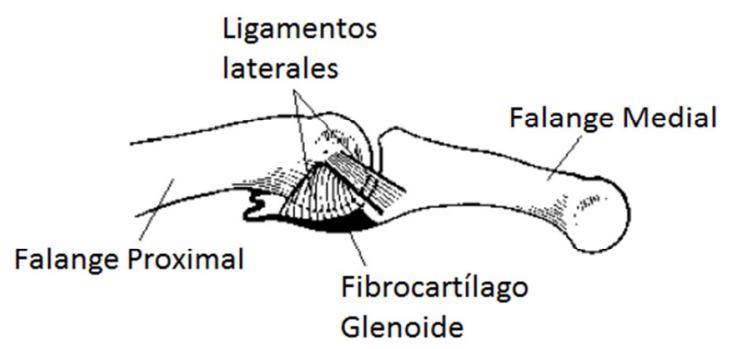

b)

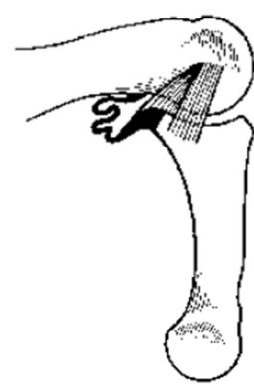

Figura 2.11. Articulación IFP en flexión (a) y extensión (b). (Dubousset, 1981) 


\subsection{3.- Músculos de la mano}

Los músculos son órganos que, mediante su contracción, son capaces de transmitir una fuerza de tracción a su tendón, produciendo así un momento sobre las articulaciones en cuyos huesos actúa. Un tendón es una cuerda fibrosa en la que finalizan las fibras de los músculos y que sirven de unión entre los músculos y los huesos u otras estructuras.

Por otra parte, un ligamento es cualquier banda fibrosa de elevada resistencia que conecta los huesos, bien directamente, o bien mediante su unión a un tendón y que, por tanto, limita sus movimientos.

El control de los movimientos de la mano se realiza básicamente por la acción de dos sistemas de músculos y tendones. Es posible abrir la mano principalmente gracias a la acción de los músculos extensores extrínsecos (situados en el antebrazo), aunque también intervienen los músculos intrínsecos de la mano (músculos pequeños situados completamente dentro de la mano). Por otro lado, es posible cerrar la mano por la acción de los músculos flexores extrínsecos, pero también en este caso hay cierta intervención de los músculos intrínsecos de la mano (Fischer, 1969).

El número de músculos no se puede concretar ya que hay músculos que pueden estar ausentes, es decir, hay sujetos que no presentan estos músculos. La ausencia de dichos músculos no implica una mala funcionalidad de la mano. Algo similar ocurre con los ligamentos, de manera que puede variar de una persona a otra al haber algunos ausentes.

Además, algunos músculos se dividen en dos o más secciones, no estando claro si son un único músculo o varios. Por este motivo, suele decirse que la mano está compuesta por unos 40 músculos, 9 de los cuales se encuentran en el pulgar. Estos músculos son los siguientes (figuras 2.12 y 2.13 ): 


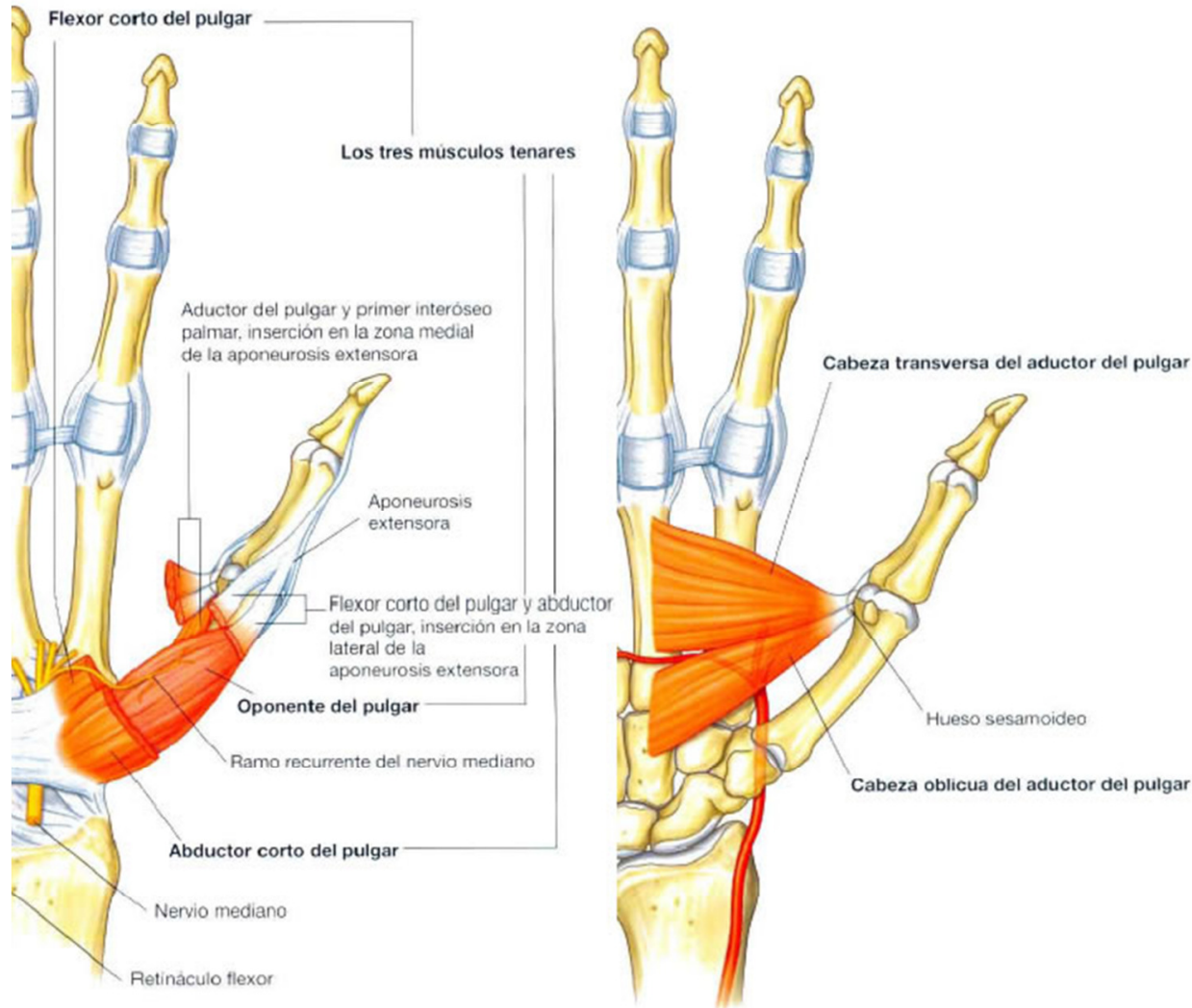

Figura 2.12: Vista dorsal de los músculos del pulgar (Salazar, n.d.)

- Abductor corto del pulgar ( $A C P)$ : Es un músculo pequeño y débil en comparación con el resto de músculos, aunque su acción es esencial para conseguir la oposición del pulgar durante el agarre. Parece más grande de lo que es en realidad debido a que el músculo oponente del pulgar se encuentra debajo de él, empujándolo y aumentando el brazo del tendón sobre la articulación MCC. Este músculo tiene forma de abanico. Sus fibras empiezan en el carpo (sobre el trapecio y el escafoides), atraviesan las articulaciones MCF y MCC y su tendón aplanado inserta sobre el tubérculo radial de la base de la falange proximal (Brand \& Hollister, 1992). El músculo es relativamente débil ya que la acción de abducción no suele realizarse para vencer cargas externas, sino para situar al pulgar en la posición más idónea para la acción a realizar. Sus músculos antagonistas son el extensor largo del pulgar y, en menor medida, el aductor del pulgar. 


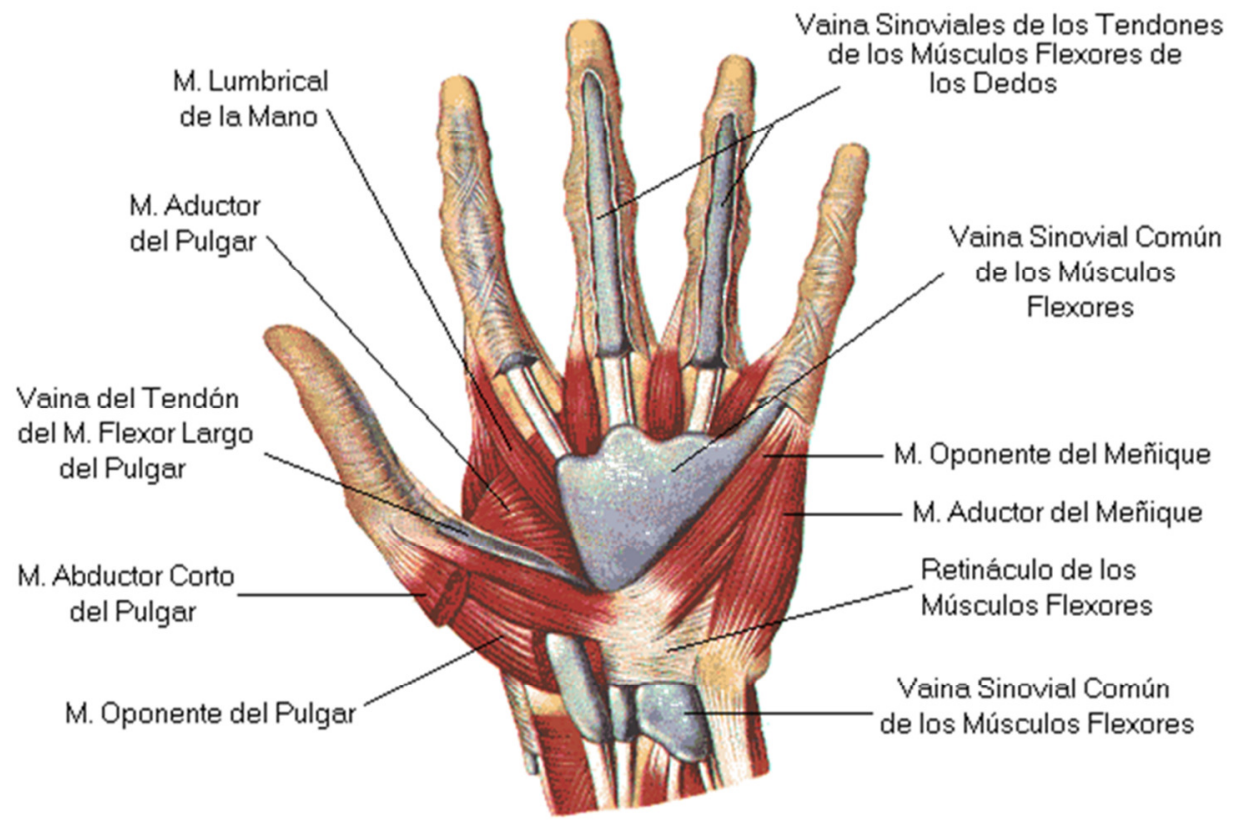

Figura 2.13: Vista dorsal de los músculos del pulgar (MEC, n.d.)

- Flexor corto del pulgar (FCP): Se trata de un músculo en forma de tirante, con fibras musculares que tienen su origen en el carpo, atraviesan las articulaciones MCC y MCF y acaban insertándose sobre el sesamoide radial y el tubérculo radial de la base de la falange proximal. Algunas fibras se extienden hasta el aparato extensor del pulgar por su vertiente radial.(Zancolli \& Cozzi, 1993). Produce la flexión en la MCC y en la MCF, con un componente de pronación en ésta última articulación. Se utiliza en las acciones de pinzamiento (junto con el aductor del pulgar) debido a su potencia y porque, además, su disposición le otorga un gran brazo de palanca sobre la articulación MCC en esta tarea (Brand \& Hollister, 1992).

- Oponente del pulgar (OP): Este músculo se encuentra debajo del ACP y del FCP. Sus fibras tienen el origen en el carpo, insertándose a lo largo de la cara radial del hueso metacarpiano. Su principal función es la oposición, aunque también puede producir pronación a causa de su inserción excéntrica sobre el hueso metacarpiano, importante a la hora de estabilizar la articulación MCC bajo esfuerzos torsionales. Es 
más potente que el ACP, aunque es difícil de cuantificar debido a la gran variabilidad de sus fibras (Brand \& Hollister, 1992).

- Aductor del pulgar (ADP): Es un músculo con forma de abanico. Se pueden diferenciar dos masas musculares, con distinta orientación de las fibras (transversales y oblicuas). Las fibras de la masa transversal tienen su origen sobre la cara volar del tercer metacarpiano, mientras que las de la masa oblicua lo tienen más proximal, con fibras provenientes del carpo y del tercer metacarpiano. Todas las fibras atraviesan la articulación MCC, con brazos de palanca sustancialmente diferentes, para acabar insertándose mayormente en la base de la falange proximal, y sobre el mecanismo extensor. Así, el ADP interviene en la extensión de la articulación IF (Imaeda, An, \& W.P., 1992), pero su acción principal es la retroposición del pulgar. Mientras que los músculos ACP, ALP y OP mantienen el pulgar en la posición correcta de rotación y oposición para producir la acción de pinzamiento, es el ADP (junto con el FCP) el que soporta la fuerza durante el agarre. Tanto el ADP como el FCP son dos músculos potentes, con brazos de palanca sobre la articulación MCC superiores a los de cualquier músculo de la articulación de la mano (Brand \& Hollister, 1992).

- Primer interóseo dorsal (ID1): Sus fibras musculares tienen origen en las caras contiguas de los dos primeros metacarpianos, y su tendón inserta totalmente en la base de la falange proximal del dedo índice, en su cara radial, actuando tanto en el dedo pulgar como en el índice. A diferencia que el resto de músculos del pulgar, no comprime la articulación MCC sino que la expande. Su línea de acción es casi paralela al eje de flexión-extensión y la mayor parte de las fibras se originan cerca del eje de abducción - aducción, de manera que no proporciona potencia en el agarre, por lo cual es obviado frecuentemente en los estudios del pulgar (Brand \& Hollister, 1992). Su función es la de contrarrestar el efecto de los músculos flexores durante el agarre de potencia y el agarre de precisión bidigital pulgaríndice.

- Abductor largo del pulgar (ALP): Se trata de un músculo extrínseco, situado en la capa más profunda de los músculos del antebrazo. Tiene un tendón que cruza la muñeca por la cara radial, el cual 
frecuentemente se ramifica presentando varias inserciones (Valentin, 1981). El tendón principal cruza la articulación MCC y se inserta en la vertiente radial de la base del primer metacarpiano, pero otras ramificaciones se pueden insertar en los huesos carpianos. Además de producir la abducción y la extensión de la articulación MCC, también es abductor y flexor de la muñeca. Es un músculo potente y muy importante para mantener la configuración en forma de arco del pulgar durante el pinzamiento (Brand \& Hollister, 1992).

- Extensor corto del pulgar (ECP): Es también un músculo extrínseco, situado en la misma capa de músculos del antebrazo que el ALP. Su tendón es delgado, y comparte el mismo túnel que el ALP para cruzar la muñeca, haciéndolo inmediatamente dorsal a este. Atraviesa dorsalmente las articulaciones MCC y MCF para acabar insertándose en la base de la falange proximal. Sus acciones sobre la muñeca y la articulación MCC son similares a las del ALP, con quien está íntimamente asociado, aunque su importancia es relativa, ya que es lo único que aporta es la extensión independiente de la junta MCF, lo que es menos importante que la posibilidad de flexionarla independientemente (Brand \& Hollister, 1992).

- Flexor largo del pulgar (FLP): Las fibras de este músculo extrínseco empiezan sobre el radio y la membrana interósea del antebrazo, siendo uno de los pocos músculos del brazo que normalmente es completamente independiente del resto y que, además, realiza una acción que no puede ser realizada por otro músculo, que es la flexión de la articulación IF. Su tendón es el más radial de todos los tendones del túnel carpiano. Después de atravesar la muñeca, cruza volarmente las articulaciones MCC, MCF (pasando entre los dos sesamoides) e IF, de manera que produce la flexión de IF, además de la flexión de las articulaciones MCF y MCC, pero con menor proporción que el FCP y el ADP.

- Extensor largo del pulgar (ELP): Este músculo extrínseco se origina sobre el cúbito y la membrana interósea. Su tendón recorre longitudinalmente el dorso del antebrazo para atravesar la muñeca, de donde emerge con un acusado cambio de dirección. Es el músculo extensor de la articulación IF, ayudando también en la extensión de la articulación MCF. Sobre la articulación MCC actúa tanto como extensor 
como aductor, siendo el brazo de palanca para la aducción más grande a medida que aumenta la supinación del primer metacarpiano, a la vez que disminuye el brazo de palanca de extensión (Brand \& Hollister, 1992).

En la tabla 2.a se puede ver un resumen de las acciones que realiza cada músculo en cada articulación (fuerte, media o débil):

Tabla 2.a: Acción de los músculos sobre las distintas articulaciones del pulgar (FI: flexión, Ex: extensión, Ab: abducción, Ad: aducción; XXX: fuerte, XX: media, X: débil)

\begin{tabular}{|c|c|c|c|c|c|c|c|c|c|c|}
\cline { 2 - 11 } \multicolumn{1}{c|}{} & \multicolumn{4}{c|}{ MCC } & \multicolumn{5}{c|}{ MCF } & \multicolumn{3}{c|}{ IF } \\
\hline Músculo & $\mathrm{Fl}$ & $\mathrm{EX}$ & $\mathrm{Ab}$ & $\mathrm{Ad}$ & $\mathrm{FI}$ & $\mathrm{EX}$ & $\mathrm{Ab}$ & $\mathrm{Ad}$ & $\mathrm{FI}$ & $\mathrm{EX}$ \\
\hline $\mathrm{ACP}$ & $\mathrm{XX}$ & & $\mathrm{XX}$ & & & & $\mathrm{XXX}$ & & & $\mathrm{X}$ \\
\hline $\mathrm{FCP}$ & $\mathrm{XX}$ & & $\mathrm{X}$ & & $\mathrm{XX}$ & & $\mathrm{X}$ & & & \\
\hline OP & $\mathrm{XX}$ & & $\mathrm{XX}$ & & & & & & & \\
\hline ADP & $\mathrm{XXX}$ & & & $\mathrm{XXX}$ & & & & $\mathrm{XXX}$ & & $\mathrm{X}$ \\
\hline $\mathrm{ID} 1$ & $\mathrm{XX}$ & & & $\mathrm{X}$ & & & & & & \\
\hline ALP & & $\mathrm{XX}$ & $\mathrm{XXX}$ & & & & & & & \\
\hline ECP & & $\mathrm{XX}$ & $\mathrm{XXX}$ & & & $\mathrm{XXX}$ & & & & \\
\hline FLP & $\mathrm{XX}$ & & & & $\mathrm{XXX}$ & & & & $\mathrm{XXX}$ & \\
\hline ELP & & $\mathrm{XXX}$ & & $\mathrm{XX}$ & & & & $\mathrm{X}$ & & $\mathrm{XXX}$ \\
\hline
\end{tabular}

La flexión en el resto de los dedos se realiza fundamentalmente por dos músculos: el flexor superficial (FS) y el flexor profundo (FP). Estos dos músculos extrínsecos originan la fuerza de agarre de los dedos, ya que producen la flexión de los mismos. EL FS empieza en el antebrazo y se divide en cuatro partes, de las que salen sus respectivos tendones hacia cada uno de los dedos (figura 2.14). Pese a esta división, el FS actúa como un único músculo, ya que existe un tendón en el antebrazo que conecta estas divisiones entre ellas (Brand \& Hollister, 1992). Por el otro extremo, cada una de estas divisiones tienen un tendón que cruzan el carpo y divergen hacia sus respectivos dedos. Por otro lado, el FP también se divide en 4 partes que tampoco son totalmente independientes, sino que existen conexiones entre ellas en el antebrazo y sobre la región del túnel carpiano (Brand \& Hollister, 1992). De cada una de las masas musculares sale un tendón que atraviesa la muñeca y se dirige a cada uno de los dedos. 


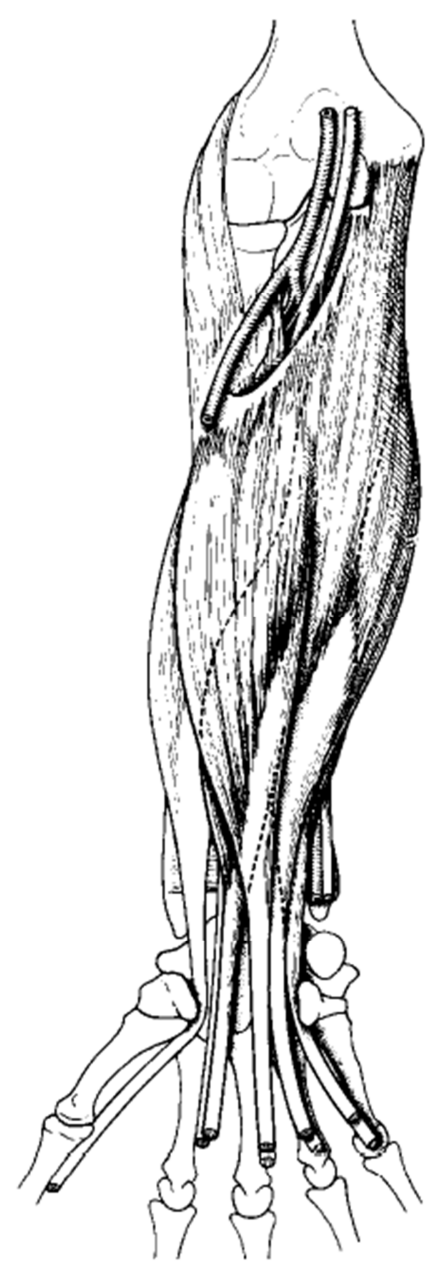

Figura 2.14. Vista dorsal del antebrazo, mostrando el flexor superficial de los dedos, con los cuatro tendones divergentes hacia cada uno de los dedos.(Valentin, 1981)

El túnel carpiano es un sistema de retención de los tendones flexores de todos los dedos y del nervio mediano. Está formado por los huesos del carpo y por el ligamento anterior del carpo. Los tendones flexor superficial y flexor profundo discurren conjuntamente desde que emergen del túnel carpiano, estando siempre el profundo en una posición más interna que el superficial. Sobre la zona superficial de la mano se puede observar como el músculo lumbrical tiene su origen en el tendón del FP. 
La extensión de los dedos se realiza gracias a una red de tendones tan compleja que todavía no está clarificada la anatomía de la misma. En la extensión de los dedos intervienen músculos intrínsecos y extrínsecos, siendo los extrínsecos el extensor común (EC) y los extensores propios del índice y meñique (figura 2.15). Los músculos intrínsecos son los interóseos y lumbricales (Sancho-Bru, 2000).

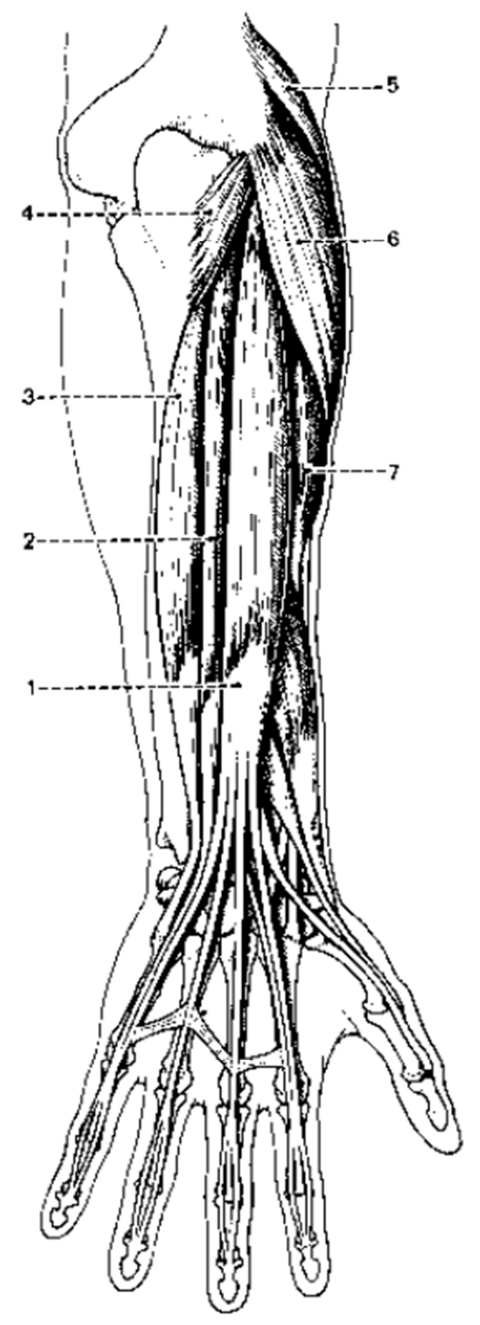

Figura 2.15. Vista dorsal del antebrazo mostrando el extensor común a lo largo de todo su recorrido, junto con los tendones extensores (Valentin, 1981) (1) EC, 2) EM, 3) Extensor cubital del carpo, 4) Anconeous, 5) Braquio-radial, 6) Extensor largo del carpo, 7) Extensor corto radial del carpo 
Aunque existe un tendón EC para cada uno de los dedos, éste está reforzado en el índice y el meñique por un tendón propio sobre la cara cubital (Tubiana \& Valentin, 1964). Además, hay que señalar que la configuración y multiplicidad de estos tendones varía en la zona comprendida desde su origen en la unión musculotendinosa hasta el paso sobre la articulación MCF (Schenck, 1964; Von Schroeder \& Botte, 1995). De hecho, la distribución más común es un tendón EC y un tendón propio (EI) para el índice; un único tendón EC para el dedo medio; un doble tendón EC para el anular; y un doble tendón propio, sin ningún tendón EC, para el meñique (EM) (Schenck, 1964).

Aun así, hay personas que en el índice tienen un doble tendón El (16\%), o bien un doble $(28 \%)$ o triple (16\%) tendón EC; que en el anular tienen un único (12\%) o triple (16\%) tendón EC; o que en el meñique tienen un único $(19 \%)$ o doble (26\%) tendón EC (Schenck, 1964).

El EC empieza en el antebrazo, en la parte más distal del húmero, como una única masa muscular, para dividirse posteriormente en cuatro partes, aunque esta separación es incompleta, ya que existen una serie de conexiones fibrosas entre las distintas masas musculares. Además, en la cara dorsal de la mano, sobre los metacarpos, existen otras conexiones entre los tendones de estos músculos, lo que hace que los movimientos de extensión de los distintos dedos sean interdependientes, por lo que en ocasiones se considera al EC como un único músculo con cuatro tendones. La configuración del EC en su recorrido por el dedo es compleja, ya que se trata de una complicada red de fibras que conectan el EC con los músculos intrínsecos y con otras estructuras de la mano (huesos, vainas, etc.).

El músculo lumbrical (LU) empieza y acaba sobre dos tendones, teniendo su origen sobre el FP, pasando volarmente sobre el ligamento transversal metacarpiano, e insertándose en el mecanismo extensor, sobre la banda lateral radial, acercándose al dedo con un ángulo de aproximadamente $40^{\circ}$ (Smith, 1975). Normalmente hay cuatro lumbricales, de sección circular, presentando a veces una inserción en la base de la falange proximal. Los puntos de inserción del tercer y cuarto lumbrical son variables. De hecho, en ocasiones no existe el tercer lumbrical (Eyler \& Markee, 1954). El primer y segundo lumbrical empiezan sobre la cara radial de los tendones FP mientras que el tercer y cuarto tienen su origen sobre los tendones FP adyacentes 
(Zancolli \& Cozzi, 1993). Los músculos lumbricales favorecen la extensión IF producida por el tendón EC mediante la estabilización de la falange proximal, impidiendo la hiperextensión, además de tener un efecto extensor directo(Zancolli \& Cozzi, 1993). Pueden causar flexión de la articulación MCF cuando las articulaciones IF están en extensión total (Ranney, Wells, \& Dowling, 1987). Además, pueden causar desviación radial de las articulaciones MCF, pero su poder de desviación radial es inferior al de los interóseos. Asimismo, es el único músculo capaz de relajar el tendón de su antagonista. Cuando el LU se contrae, estira en sentido proximal la banda lateral, produciendo la extensión de la articulación IFP, estirando a la vez el tendón FP en sentido distal, relajándolo y por tanto disminuyendo su acción sobre la flexión de la articulación IFD (Smith, 1975).

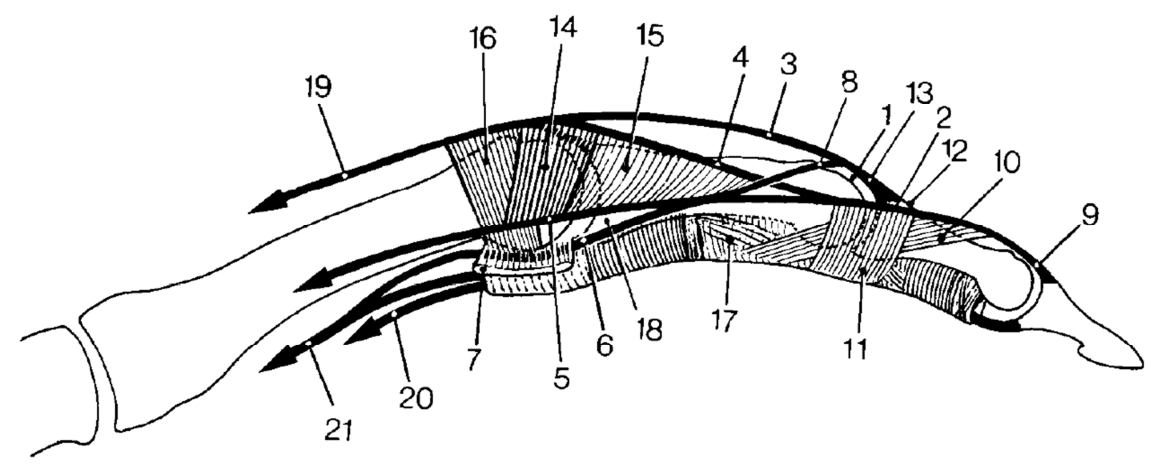

Figura 2.16. Esquema del mecanismo extensor y sus conexiones (Tubiana, 1981). (1) Tendón extensor central, 2) Tendón extensor lateral, 3) Banda central del EC, 4) Banda lateral del EC, 5) Interóseo, 6) Lumbrical, 7) Ligamento transversal metacarpiano, 8) Banda central del interóseo, 9) Tendón extensor terminal, 10) Ligamento retinacular oblicuo, 11) Ligamento retinacular transversal, 12) Ligamento triangular, 13) Tendón extensor central, 14) Fibras transversales de la aponeurosis, 15) Fibras oblicuas, 16)Banda sagital, 17) Vaina fibrosa de los tendones flexores, 18) Inserción del interóseo en la base de la primera falange, 19) Tendón del EC, 20) Tendón del FS, 21) Tendón del $F P$ )

Por lo que acontece a los músculos interóseos, existen dos grupos: los volares o los palmares, y los dorsales. La diferenciación es debida según sea su origen sobre los metacarpianos. Además, se suele hablar de interóseos proximales 
(insertan en la base de la falange proximal) y distales (insertan sobre el mecanismo extensor, en una posición más distal que los anteriores). Hay cuatro interóseos dorsales (ID) y tres interóseos volares (IV).

Además del EC, el índice y el meñique tienen músculos extensores propios: el extensor propio del índice (EI) y el del meñique (EM). El El permite la extensión independiente del dedo índice mientras el resto de dedos está flexionado (produciéndose así la acción de señalar). Tiene un tendón largo que se inserta en la cara cubital del EC del dedo índice, con lo que se confunde sobre la articulación MCF (Wehbé, 1995).

La región hipotenar está compuesta por tres músculos intrínsecos que actúan sobre el meñique: el flexor corto del meñique (FCM), el abductor del meñique (AM) y el oponente del meñique (OPM). La posición de estos músculos puede verse en la figura 2.17. El FCM está ausente en muchos casos (Fahrer \& Tubiana, 1981) y cuando está es una masa muscular cilíndrica con un diámetro inferior a los $2 \mathrm{~mm}$. Se origina sobre el ligamento anular y sobre la apófisis unciforme y se inserta, junto con el AM, sobre el tubérculo cubital de la base de la falange proximal del meñique.
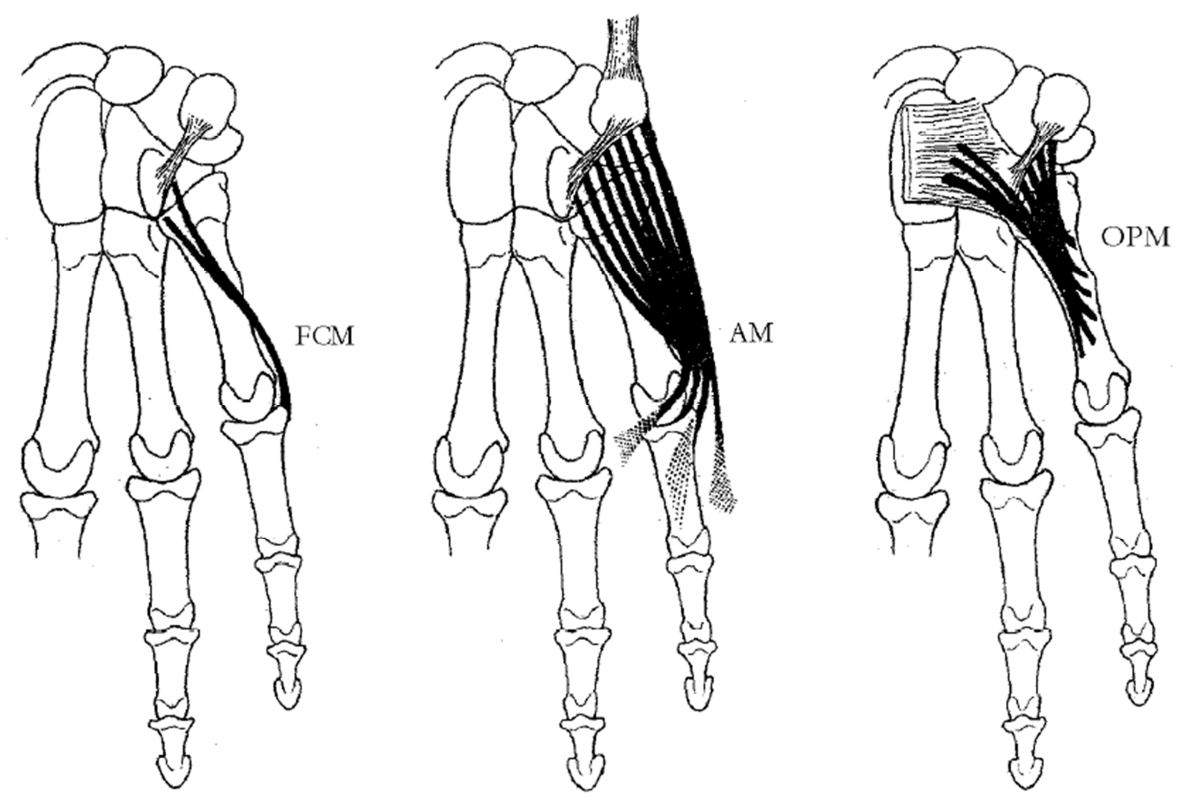

Figura 2.17. Vista palmar de los músculos de la región hipotenar (Fahrer \& Tubiana, 1981) 
El OPM tiene su origen sobre el borde inferior del ligamento anular y la apófisis unciforme y se inserta sobre la cara interna del quinto metacarpiano, de forma similar al OPP en el pulgar. El OPM flexiona el quinto metacarpiano sobre el carpo, a la vez que le otorga una componente de rotación longitudinal de supinación. El FCM y el AM flexionan la falange proximal y produce abducción. EL AM se puede considerar un equivalente del ID sobre el meñique.

Los músculos de la palma configuran diferentes protuberancias en la misma, definiendo zonas con las que se establece contacto entre el objeto y la mano durante la manipulación. Estas zonas se denominan (figura 2.18) eminencia hipotenar, eminencia tenar y seno palmar distal.

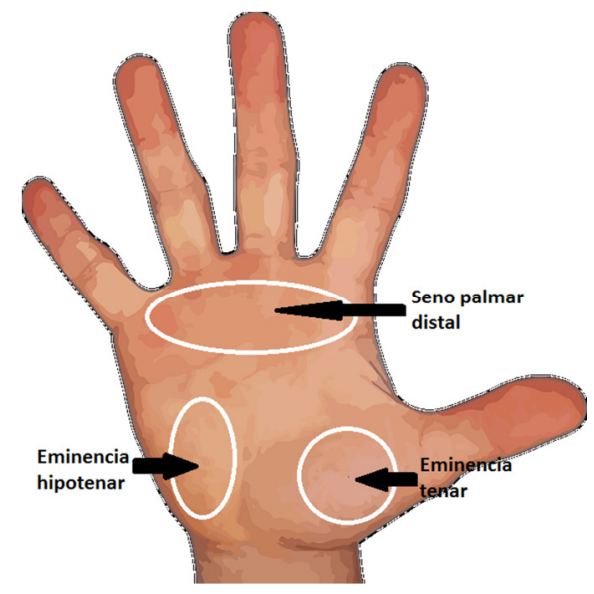

Figura 2.18. Localización de las eminencias hipotenar y tenar y seno palmar distal

En la tabla 2.b se puede ver un resumen de las acciones que realiza cada músculo en cada articulación (fuerte, media o débil): 
Tabla 2.b: Acción de los músculos sobre las distintas articulaciones de los dedos de la mano (FI: flexión, Ex: extensión, Ab: abducción, Ad: aducción; XXX: fuerte, XX: media, X: débil)

\begin{tabular}{|c|c|c|c|c|c|c|c|c|c|c|}
\cline { 2 - 11 } \multicolumn{1}{c|}{} & \multicolumn{1}{c|}{ MCC } & \multicolumn{4}{c|}{ MCF } & \multicolumn{3}{c|}{ IFP } & \multicolumn{2}{c|}{ IFD } \\
\hline Músculo & $\mathrm{FI}$ & $\mathrm{EX}$ & $\mathrm{FI}$ & $\mathrm{EX}$ & $\mathrm{Ab}$ & $\mathrm{Ad}$ & $\mathrm{FI}$ & $\mathrm{EX}$ & $\mathrm{FI}$ & $\mathrm{EX}$ \\
\hline FP & $\mathrm{X}$ & & $\mathrm{XXX}$ & & & & $\mathrm{XXX}$ & & $\mathrm{XXX}$ & \\
\hline FS & $\mathrm{X}$ & & $\mathrm{XXX}$ & & & & $\mathrm{XXX}$ & & & \\
\hline EC & & $\mathrm{X}$ & & $\mathrm{XXX}$ & & & & & $\mathrm{XXX}$ & $\mathrm{XXX}$ \\
\hline LU & & & $\mathrm{X}$ & & $\mathrm{XX}$ & $\mathrm{XX}$ & & $\mathrm{X}$ & & $\mathrm{X}$ \\
\hline ID & & & $\mathrm{X}$ & & $\mathrm{XX}$ & & & $\mathrm{X}$ & & $\mathrm{X}$ \\
\hline IV & & & $\mathrm{X}$ & & & $\mathrm{XX}$ & & $\mathrm{X}$ & & $\mathrm{X}$ \\
\hline EI & & $\mathrm{X}$ & & $\mathrm{XXX}$ & & & & $\mathrm{XXX}$ & & $\mathrm{XXX}$ \\
\hline EM & & $\mathrm{X}$ & & $\mathrm{XXX}$ & & & & $\mathrm{XXX}$ & & $\mathrm{XXX}$ \\
\hline FCM & $\mathrm{XX}$ & & $\mathrm{XX}$ & & $\mathrm{XX}$ & & $\mathrm{XX}$ & & & \\
\hline AM & $\mathrm{XX}$ & & $\mathrm{XX}$ & & $\mathrm{XX}$ & & $\mathrm{XX}$ & $\mathrm{X}$ & & $\mathrm{X}$ \\
\hline OPM & $\mathrm{XX}$ & & & & & & & & & \\
\hline
\end{tabular}




\section{2.- Neurofisiología del agarre}

En cualquier acción o conducta de todo organismo vivo está presente el sistema nervioso, actuando como sistema de control del sistema músculoesquelético. Cualquier cambio en el desarrollo del organismo es resultado de modificaciones funcionales de dicho sistema nervioso. La neurofisiología se encarga de desvelar cómo funciona este complicado sistema y cómo produce la variedad de modelos de conducta que manifiestan los organismos. En el caso del agarre, los estudios neurofisiológicos sobre este proceso ayudan a desvelar las claves de la interacción entre los sentidos, el sistema nervioso aferente, el sistema nervioso central, el sistema nervioso eferente y el sistema músculoesquelético durante el agarre y manipulación.

Numerosos trabajos han estudiado la regulación de la fuerza muscular ejercida cuando un objeto se eleva de una mesa, desde los primeros experimentos realizados por Johansson y Westling (Johansson \& Westling, 1984; Westling \& Johansson, 1984a). Estos estudios han permitido definir las diferentes fases del proceso de agarre de un objeto apoyado en una superficie: fase de precarga, en la que se configura el agarre; fase de carga en la que se produce un incremento paralelo de la fuerza normal al objeto y de la fuerza tangencial que se opone a la gravedad; fase de transición en la que el objeto se desplaza desde su superficie de apoyo a la posición deseada; fase estática en la que el objeto se mantiene estático y las fueras tienden a mantenerse aproximadamente constantes; fase de reposición en la que se mueve el objeto para acercarlo de nuevo a la superficie de apoyo; fase de descarga en la que se reducen las fuerzas hasta perder el contacto de la mano con el objeto (figura 2.19) (Jones \& Lederman, 2006). 


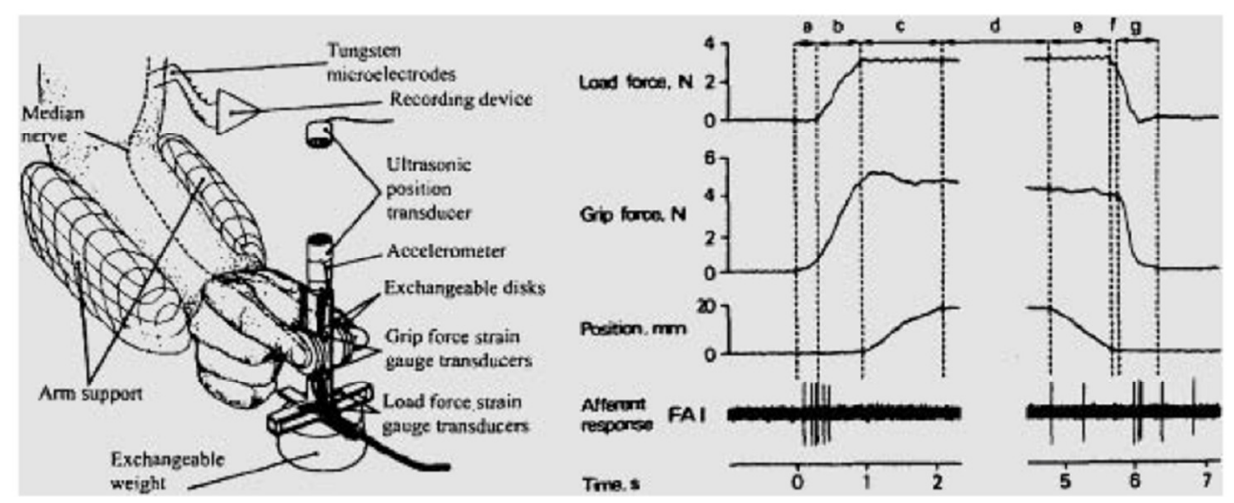

Figura 2.19. Ilustración del experimento de Westling and Johansson (Westling \& Johansson, 1984a), donde se aprecian las diferentes fases durante el agarre, con indicación de las curvas de fuerza de agarre, fuerza tangencial, posición y señal del sistema aferente. Las fases son: a) precarga, b) carga, c) transición, d) estática, e) reposición, g) descarga. (Jones \& Lederman, 2006)

Se ha demostrado que durante la fase estática, en la que la carga se mantiene debido a la aducción de las puntas de los dedos, la fuerza de agarre se escala de forma precisa para prevenir por un lado que el objeto resbale y por otro que el objeto se rompa debido a una fuerza excesiva, aparte de no ser tan elevada que produzca una fatiga muscular innecesaria (Jones \& Lederman, 2006). Cuando un sujeto está a punto de elevar una carga, se estima el peso del objeto y el resto de fuerzas de inercia que van a tener que vencerse a partir de la experiencia previa y se adecua la fuerza de agarre en función de ese valor (Augurelle, Smith, Lejeune, \& Thonnard, 2003). Esta adecuación del valor no se ve afectada al realizar acciones como andar, saltar, mover el brazo incluso utilizar un agarre con dos manos (J R Flanagan, Wing, Allison, \& Spenceley, 1995; J. Randall Flanagan, Burstedt, \& Johansson, 1999; JR R Flanagan \& Tresilian, 1994). Cuando la carga cambia de forma inesperada, se modifica inmediatamente el agarre para evitar que se caiga (Grichting, Hediger, Kaluzny, \& Wiesendanger, 2000).

La fuerza de agarre mínima para manipular un objeto depende de factores cuantificables tales como el peso del objeto, el coeficiente de rozamiento entre la mano y el objeto, la superficie de contacto, la tarea concreta que se realizará con el objeto (traslados y/o giros), la velocidad de manipulación, etc. Sin embargo, al operar con un objeto, la fuerza de agarre que se realiza 
siempre es mayor a la necesaria, ya que se aplica un margen de seguridad para evitar que el objeto deslice y se caiga. Este margen de seguridad no es el mismo para todos los sujetos, ni para cada sujeto al realizar tareas distintas, ya que depende de factores subjetivos (Lowe, 2001; Na Jin Seo, 2009; Westling \& Johansson, 1984a).

Pilon et al. determinaron que los sujetos, en función de las características del objeto percibidas, anticipaban la fuerza que debían hacer en el agarre para manejarlos (Pilon, De Serres, \& Feldman, 2007). Esto hace que los objetos que parecen más pesados, se traten como si fueran realmente más pesados.

Un factor esencial para prever la fuerza de agarre necesaria y adecuarla durante la manipulación de un objeto es la recepción de información de los sentidos (Monzée et al., 2003). Nowak et al. (Nowak et al., 2004) registraron la fuerza de agarre durante el manejo de un objeto para cuatro sujetos, uno de los cuales era insensible a la vista y al tacto. Aunque los cuatro sujetos realizaron aceleraciones estadísticamente iguales en los objetos agarrados $(y$, por tanto, produjeron inercias similares durante los movimientos verticales y horizontales), el sujeto que no percibía realimentación de sus sentidos utilizaba fuerzas innecesariamente elevadas para el peso y la inercia producida por el objeto.

El equipo de Flanagan determinó que al elevar un objeto utilizando un agarre tipo pinza de precisión con las puntas de los dedos pulgar e índice, el peso percibido dependía de la textura de la superficie del objeto, de manera que cuanto más suave era la textura de la superficie, más pesado parecía el objeto, con lo que se aumentaba el coeficiente de seguridad en el agarre para evitar que el objeto se deslizara (J R Flanagan et al., 1995). En un estudio posterior, concluyó que la percepción de que la carga era mayor no era exclusiva de las cargas gravitacionales, sino que se cumplía para todo tipo de cargas ( $\mathrm{R}$ Flanagan \& Wing, 1997).

La necesidad de tener retroalimentación sensorial durante la manipulación hace que sea complicado el registro de las medidas en la fuerza de agarre, siendo posibles dos opciones: construir un objeto lo más parecido posible al objeto real que se quiere estudiar con los sensores incluidos, lo que es una opción costosa en tiempo y dinero y que no siempre da resultados fiables porque el objeto nunca será exactamente igual al objeto real; o utilizar un 
objeto real, en cuyo caso medir la fuerza de agarre implica intercalar algún tipo de sensor entre la piel y el objeto sobre el que se quiere medir la fuerza.

Hay varios estudios del efecto sobre la fuerza que tiene operar un objeto con guantes. El equipo de Shih realizó un ensayo en el que 10 sujetos realizaban una tarea con uno, dos, tres o ningún guante de látex. La tarea consistió en levantar tres pesos diferentes (100 g, $150 \mathrm{~g}$ y $200 \mathrm{~g}$ ) utilizando un agarre de tipo pinza con los dedos pulgar e índice. La conclusión fue que a medida que se añadían más guantes, era necesario realizar una fuerza de agarre mayor, aunque no fue concluyente el motivo, pudiendo ser que variaba el coeficiente de rozamiento entre ambas superficies (Shih, Vasarhelyi, Dubrowski, \& Carnahan, 2001). Tsaousidis y Freivalds realizaron un experimento en el que comprobaron cómo afectaba un guante de cuero sobre el momento máximo que se podía realizar, la fuerza máxima de agarre y la realización en un agarre tipo pinza (Tsaousidis \& Freivalds, 1998). Sus resultados muestran que la fuerza de agarre máxima se ve afectada, aunque puede ser, al igual que en el caso de Shih, debido al cambio del coeficiente de rozamiento. Otro estudio de Rock et al. determinó el efecto del material de los guantes. Para ello, los sujetos del experimento realizaron un agarre de fuerza máxima y otro de precisión de tipo pinza utilizando tres dedos (pulgar, índice y medio) y con cuatro configuraciones de la mano: desnuda, con un guante de nitrilo, uno de cuero y otro de vinilo. El resultado muestra que los guantes afectan a la fuerza máxima que se puede realizar pero que la fuerza en el agarre de precisión no era estadísticamente diferente entre la mano desnuda, la mano vestida con el guante de vinilo y la vestida con el guante de nitrilo (Rock, Mikat, \& Foster, 2001), lo que implica que los guantes finos no afectan de forma importante en los agarres de precisión que emplean contracciones musculares voluntarias inferiores a la máxima.

Diversos estudios se han centrado en el aprendizaje ocasionado por sucesivas repeticiones de la misma tarea al manipular un objeto. Mathiowetz et al. realizaron un ensayo sobre 27 sujetos que efectuaron un agarre de potencia, otro tipo pinza con pulgar e índice, otro de pinza lateral y otro de pinza palmar usando pulgar, índice y medio, utilizando un dinamómetro Jamar y un dinamómetro de pinza. Su conclusión fue que las correlaciones menores entre sujetos se obtenían si se realizaba solamente un intento o se tomaba el valor mayor de un grupo de tres intentos totales (V Mathiowetz, Weber, Volland, \& 
Kashman, 1984), mientras que la repetibilidad mejoraba al tomar la media de tres intentos. En oposición a estos resultados, Hamilton et al. realizaron un ensayo con 33 sujetos que usaron el dinamómetro Jamar de manera que se tomaron los resultados de un único intento, la media de dos intentos, la media de tres intentos y el valor más alto de tres intentos. Realizar un único intento daba resultados menos repetibles que el resto, pero aun así los resultados obtenidos fueron estadísticamente no significativos (A. Hamilton, Balnave, \& Adams, 1994). A una conclusión similar llegó Coldham et al., que realizaron un estudio sobre 66 sujetos en el que comprobaron que se obtenían resultados estadísticamente similares de fuerza de agarre máxima en el dinamómetro Jamar tanto si el ensayo se repetía una vez como si los sujetos realizaban tres repeticiones para cada ensayo (Coldham, Lewis, \& Lee, 2006). 


\section{3.- Clasificación de los tipos de agarre.}

Como consecuencia de la anatomía de la mano, de las características de los objetos manipulados y de la propia neurofisiología asociada al proceso de manipulación las personas adoptamos diferentes configuraciones de la mano para coger los objetos y asegurar su estabilidad. El número de posturas de agarre es virtualmente infinito, pero con el fin de facilitar su estudio se suele hablar de diferentes patrones o tipos de agarre, usando para ello diversas taxonomías. Entenderemos por tipo de agarre en este contexto a cada una de los posibles patrones posturales estáticos de la mano con los cuales un objeto puede ser mantenido de forma segura (Feix, Pawlik, Schmiedmayer, Romero, \& Kragi, 2009).

El diseño de una mano antropomórfica ha de cumplir la dualidad entre la complejidad de la mano y las tareas que se supone que ha de cumplir. En general, las manos sofisticadas con muchos gdl son hábiles pero plantean requisitos significativos en términos de control.

La mayoría de las taxonomías del agarre se han realizado con el objetivo de comprender qué tipos de agarres humanos se utilizan más comúnmente en las tareas cotidianas para utilizarlas para el diseño de manos protésicas y robotizadas (Feix et al., 2009).

Según Human Grasping Database, existen 22 taxonomías de agarre diferentes (Human Grasping Database, 2007), lo que denota que no hay consenso en la literatura existente en la clasificación de los tipos de agarres humanos que se pueden realizar, por lo que en este apartado se expondrán algunas existentes y se definirá la taxonomía utilizada en la presente tesis.

La primera taxonomía del agarre fue presentada por Schlesinger en 1919. En ella se describían únicamente 7 tipos de agarres (Schlesinger, 1919). Estos tipos de agarres dependían más de la tarea que se realizaba que del tamaño y forma del objeto. La primera distinción entre agarre de potencia y agarre de precisión la realizó Napier en 1956 (Napier, 1956), completando la taxonomía en un trabajo posterior. Los agarres de potencia son aquellos en los que se va a realizar una cantidad de fuerza significativa. Para conseguirla, los dedos se flexionan alrededor del objeto en una dirección y el pulgar envuelve el objeto en la dirección opuesta, proporcionando la fuerza de oposición necesaria para 
mantener el objeto en contacto con la palma y los dedos. Los agarres de precisión se caracterizan porque tienden a mantener el objeto fundamentalmente mediante las puntas de los dedos y el pulgar, implica músculos intrínsecos y extrínsecos, no interviene la palma y las articulaciones proximales (MCC y MCF) o no se mueven o se mueven con un ángulo pequeño. Esta distinción entre agarre de potencia y de precisión se ha tenido en cuenta desde ese trabajo para realizar ulteriores clasificaciones.

En 1980, Kamakura (Kamakura, Matsuo, Ishii, Mitsuboshi, \& Miura, 1980) presentó una taxonomía con 14 tipos de agarre que incluía, además de los agarres de potencia y de precisión, el agarre intermedio, que es un tipo de agarre de transición entre el de potencia y el de precisión.

La taxonomía más conocida fue la propuesta por Cutkosky en 1989 (M. R. Cutkosky, 1989), que completaba la iniciada por el mismo autor en 1986 (M. Cutkosky \& Wright, 1986). En ella se describen 16 tipos de agarre (figura 2.20). En ella se muestra que la selección de la configuración de los dedos respecto del objeto depende tanto de la forma del objeto como de la tarea que se pretende realizar, aunque no se clarifica totalmente la correspondencia entre las tareas y el tipo de agarre.

A partir de la de Cutkosky se han realizado diferentes taxonomías, destacando la de Kapandji, completada en 2006 (Kapandji, 2006), que describe 26 tipos de garre, aunque hay muchas otras (Clarkson, 2000; Exner, 2001; C. M. Light, Chappell, Kyberd, \& Ellis, 1999; Colin M. Light, Chappell, \& Kyberd, 2002a; Tyldesley \& Grieve, 1996). 


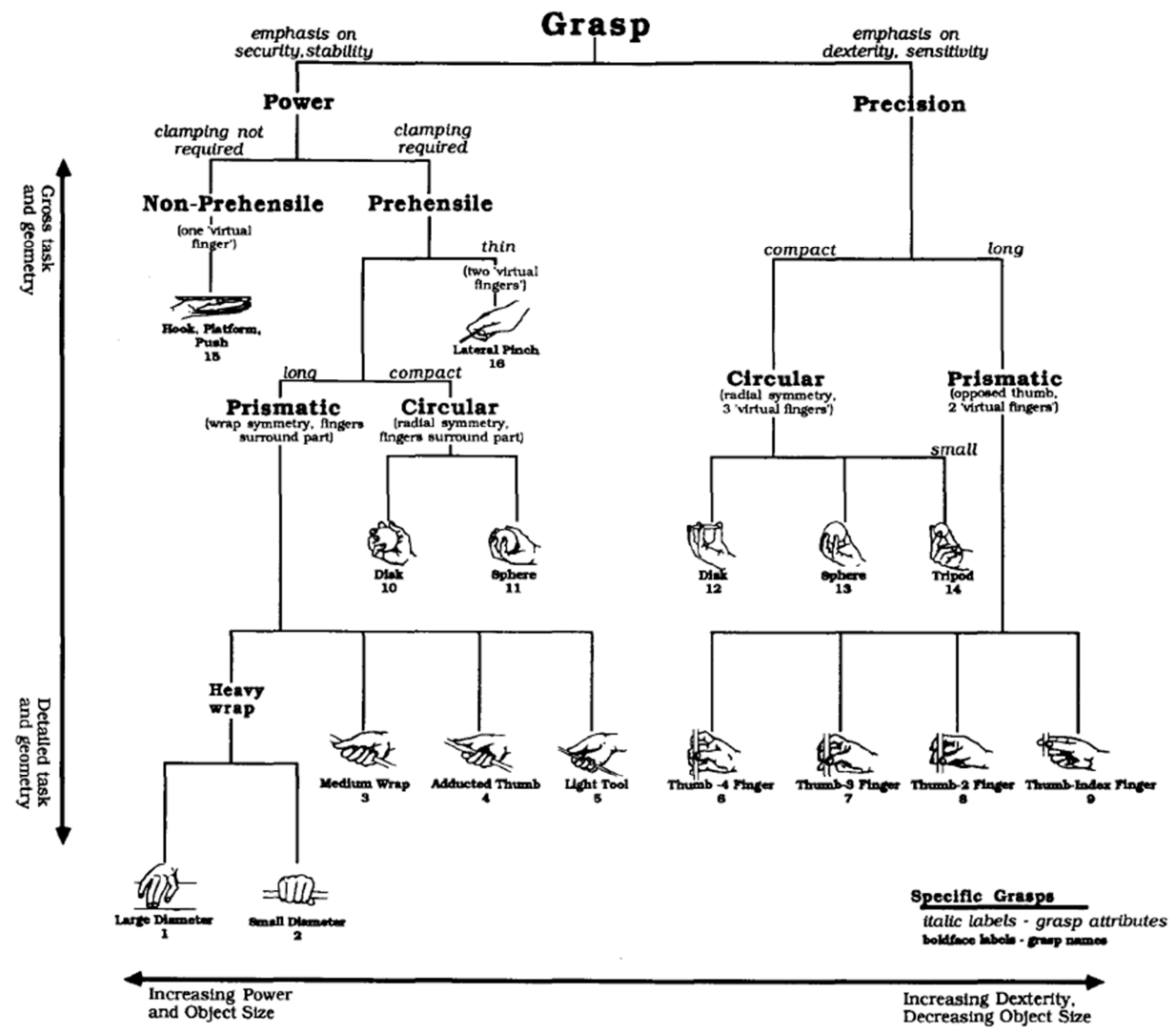

Figura 2.20. Taxonomía de Cutkosky (M. R. Cutkosky, 1989)

La taxonomía de Cutkosky no permite identificar todos los tipos de agarre, ya que se han llegado a describir 33 tipos distintos (Feix et al., 2009), pero una clasificación con tantos tipos de agarre puede resultar poco clara al haber agarres que puedan pertenecer a dos tipos similares en función de pequeños matices. Por este motivo, para la presente tesis se ha definido una taxonomía de agarre propia, que se detalla a continuación. El nombre de los agarres en este apartado se dará tanto en inglés como en castellano, ya que en algunos casos es difícil encontrar una traducción apropiada y son términos ampliamente utilizados en la literatura.

En total se han definido 11 tipos de agarre (figura 2.21):

- Cilíndrico (cylindrical): es un tipo de agarre de potencia en el que interviene la palma y los dedos (incluido el pulgar), principalmente las 
falanges proximales e intermedias. Todos los dedos están flexionados alrededor del objeto que normalmente forma un ángulo recto con el antebrazo, con lo que se asegura un contacto total y una gran fuerza de agarre. El pulgar envuelve el objeto y, generalmente, se solapa con los otros dedos. Este es el agarre típico cuando se manejan herramientas tales como martillos, sierras, hachas, etc.

- Oblicuo (oblique): agarre de potencia en el que, a diferencia del cilíndrico, el objeto no forma un ángulo recto con el antebrazo, lo que conlleva que la contribución del pulgar en este tipo de agarre sea inferior a la del agarre cilíndrico. Este tipo de agarre se da cuando se manejan objetos cilíndricos o cuasi-cilíndricos de manera que no formen un ángulo recto con el antebrazo cuando se agarran, como por ejemplo las limas o la plancha de ropa.

- Gancho (hook): es un tipo de agarre de potencia que hace referencia a la forma que adquieren los dedos al ejecutarlo. Pueden intervenir desde el índice hasta el meñique, con una posición flexionada alrededor del objeto, colocando la mano en forma de gancho (de ahí el nombre del agarre). Normalmente el pulgar no se utiliza. La articulación MCF está extendida y las IFP e IDP tienen una cierta flexión. Este agarre se utiliza al coger un maletín o al abrir un cajón.

- Esférico (spherical): agarre de potencia en el que todos los dedos, incluido el pulgar, se colocan en abducción alrededor de un objeto y, a diferencia del agarre cilíndrico, los dedos se encuentran separados. Es el tipo de agarre que se efectúa al sujetar una pelota o al desenroscar una tapa de un bote cilíndrico de un diámetro elevado.

- Lumbrical (lumbrical o extension): agarre de precisión en el que las articulaciones MCF están flexionadas y las IFP e IDP están en extensión. El pulgar se encuentra en oposición. Este tipo de agarre se suele utilizar para sujetar objetos horizontales, como platos o bandejas, aunque también se da cuando se coge un libro apoyado en vertical.

- Agarre intermedio de precisión - potencia (Intermediate powerprecision): Es un tipo de agarre de precisión en el que se manejan objetos con un peso medio. Se da cuando se manejan objetos como un mando a distancia o el auricular de un teléfono. 
- Pinza, pellizco (pinch): En este agarre de precisión únicamente se utilizan las yemas de los dedos, motivo por el cual también es conocido como "pad to pad" (yema a yema). Las articulaciones MCF e IFP de los dedos se flexionan, el pulgar hace un movimiento de abducción y las IDP permanecen en extensión de manera que junten las yemas de los dedos con la del pulgar. Este agarre se realiza al coger objetos pequeños y realizar tareas de precisión con ellos, como por ejemplo poner una moneda dentro de una hucha. Normalmente se conoce como "pinch" cuando interviene únicamente el pulgar y el índice. Si hay más dedos implicados, se suele llamar pinza especial (special pinch).

- Pinza lateral (lateral prehension o lateral pinch): En este agarre de precisión, la yema del dedo pulgar en extensión presiona el objeto que se está sujetando contra la superficie lateral radial del dedo índice. Es típico cuando se maneja una llave o se coge una tarjeta.

- No prensil (non-prensile): Tipo de agarre en el que no interviene el pulgar. Se da, por ejemplo, cuando se cierra una tapa con la palma de la mano.

- Lateral (side to side): Este tipo de agarre de precisión se caracteriza por no utilizar la yema de los dedos. Requiere la aducción de dos dedos, generalmente el índice y el medio. Es un agarre débil que no permite mucha precisión. Su uso más común es para sujetar un cigarrillo. 


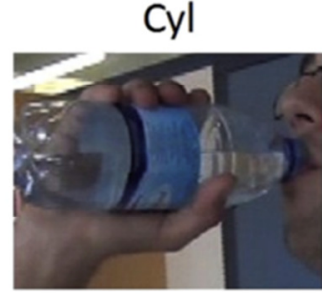

Lum

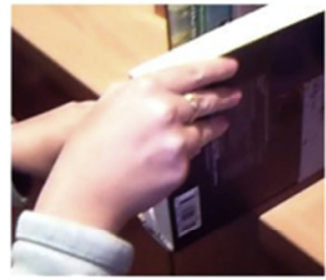

LatP

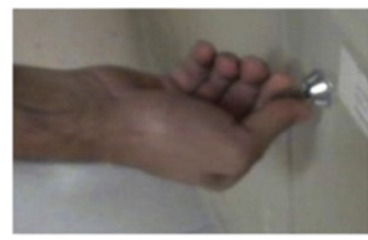

StS

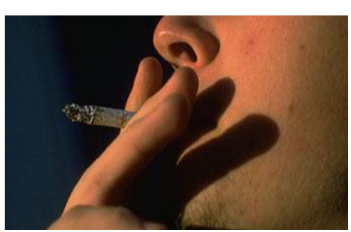

$\mathrm{Obl}$

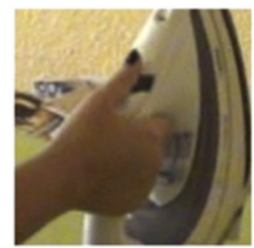

IntPP

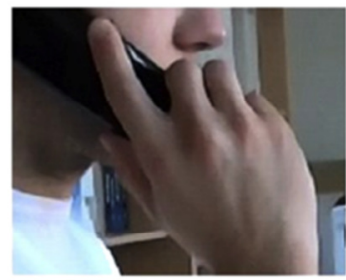

$\mathrm{SpP}$

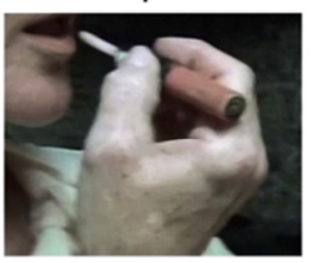

Sph

Hook

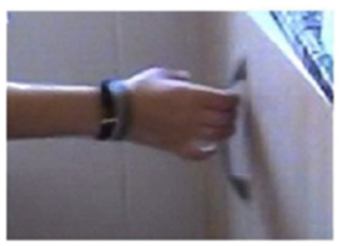

Pinch

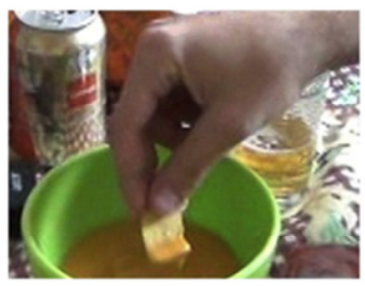

NonP
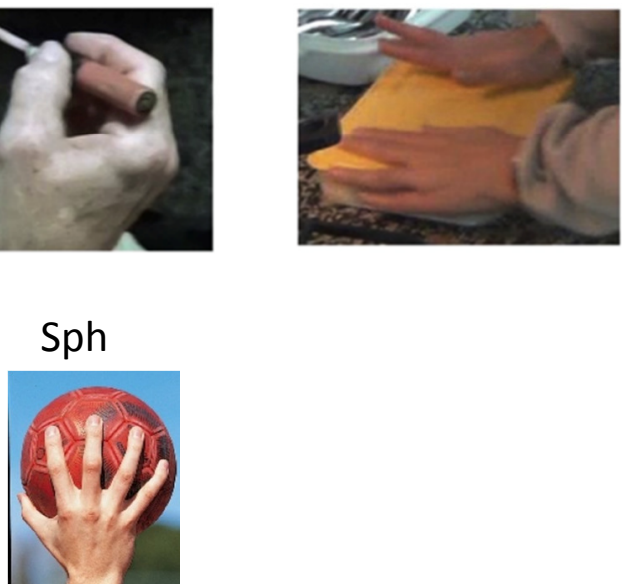

Figura 2.21. Tipos de agarres (Cyl: Cilíndrico; Obl: Oblicuo; Hook: Gancho; Lum: Lumbrical; IntPP: Intermedio de precisión - potencia; Pinch: Pinza; LatP: Pinza lateral; SpP: Pinza especial; NonP: No prensil; StS: Lateral; Sph: Esférico). 


\section{4.- Prótesis de la mano}

Una prótesis es un elemento fabricado con el fin de mejorar o reemplazar una función, una parte o un miembro completo del cuerpo humano afectado. Su implantación presenta también un aspecto psicológico, al crear una percepción de totalidad al recobrar la movilidad y aspecto que se tenía antes de la amputación. El avance en el diseño de las prótesis ha estado ligado directamente con el avance en los materiales empleados para la construcción de prótesis, así como del desarrollo tecnológico y del entendimiento de la biomecánica del cuerpo humano (Dorador, Ríos, Flores, \& Juárez, 2004)

Mason et al. (Mason \& Salisbury, 1985) determinaron que, teóricamente, para evitar que un objeto deslice durante el agarre mediante una mano con dedos rígidos y duros se necesitan un mínimo de 9 gdl. Esto se debe a que se necesitan al menos 3 dedos para restringir totalmente el movimiento de un objeto.

Si se realiza una clasificación en base a su funcionalidad, existen dos tipos de prótesis: las prótesis estéticas y las prótesis funcionales (Quinayás Burgos, 2010).

Las prótesis estéticas (figura 2.22) también se llaman prótesis pasivas, ya que no permiten realizar agarres funcionales, ocupándose únicamente del aspecto estético, de donde toman su nombre. Habitualmente, están compuestas por tres materiales: PVC rígido, látex flexible o silicona. Estos materiales son ligeros y requieren poco mantenimiento. Tienen menos piezas móviles que otras opciones protésicas (Bowers, 2002)

Las prótesis funcionales proveen cierta movilidad, intentando suplir las funciones del miembro natural amputado. Según su principio de funcionamiento, éstas se pueden clasificar en mecánicas, eléctricas, neumáticas, mioeléctricas e híbridas. 

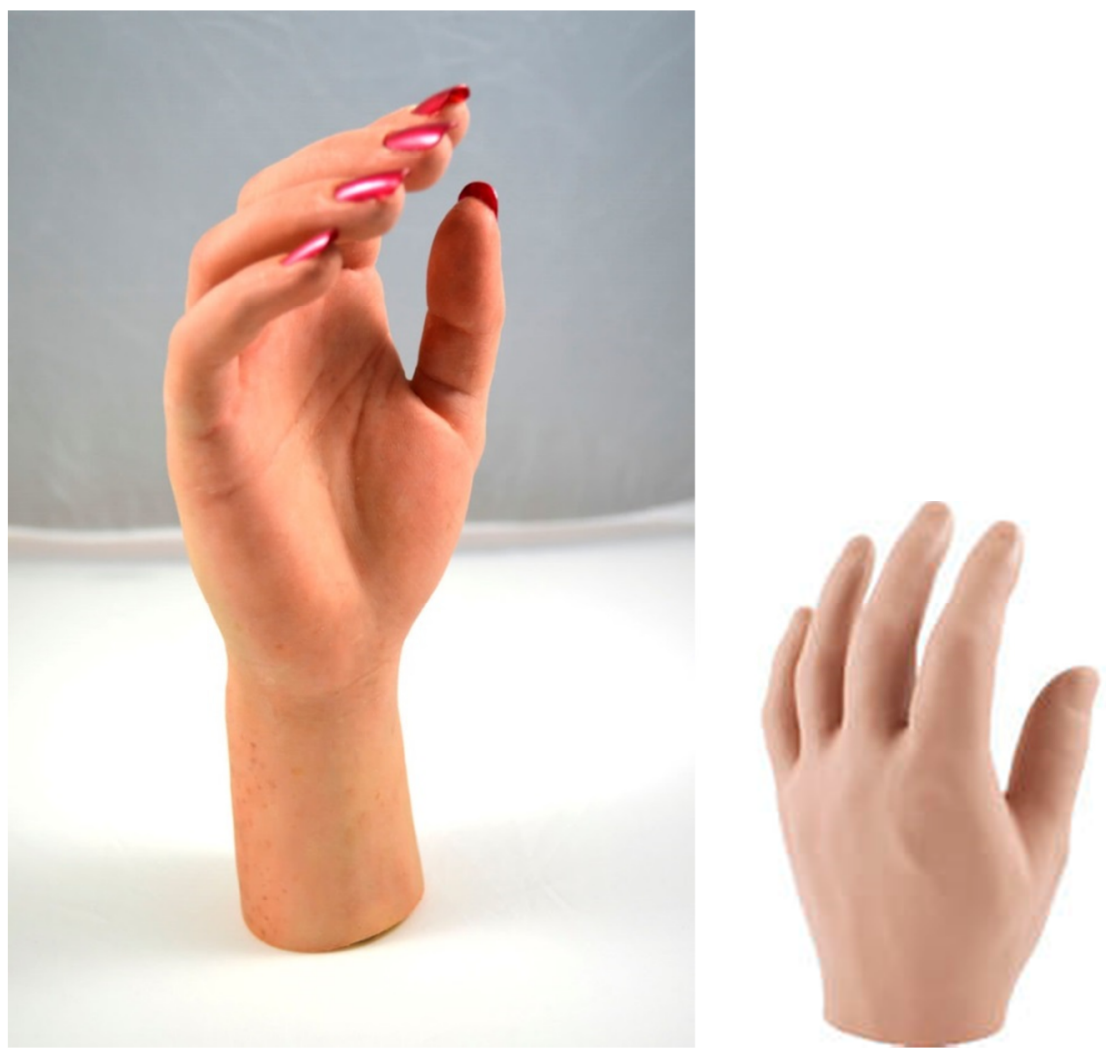

Figura 2.22: Prótesis estéticas de la mano (Medicallexpo, n.d.-b)

Las prótesis mecánicas (figura 2.23) son dispositivos que controlan la apertura y cierre mediante un arnés sujeto alrededor de los hombros, pecho y parte del brazo, controlado por el usuario. Su funcionamiento se basa en la extensión de una liga mediante el arnés para su apertura, consiguiendose el cierre mediante un resorte activado con la relajación del músculo. Estos elementos se recubren con un guante para dar una apariencia más estética, aunque esto limita el agarre a objetos relativamente grandes y redondos, ya que el guante estorba al querer sujetar objetos pequeños (Quinayás Burgos, 2010). 


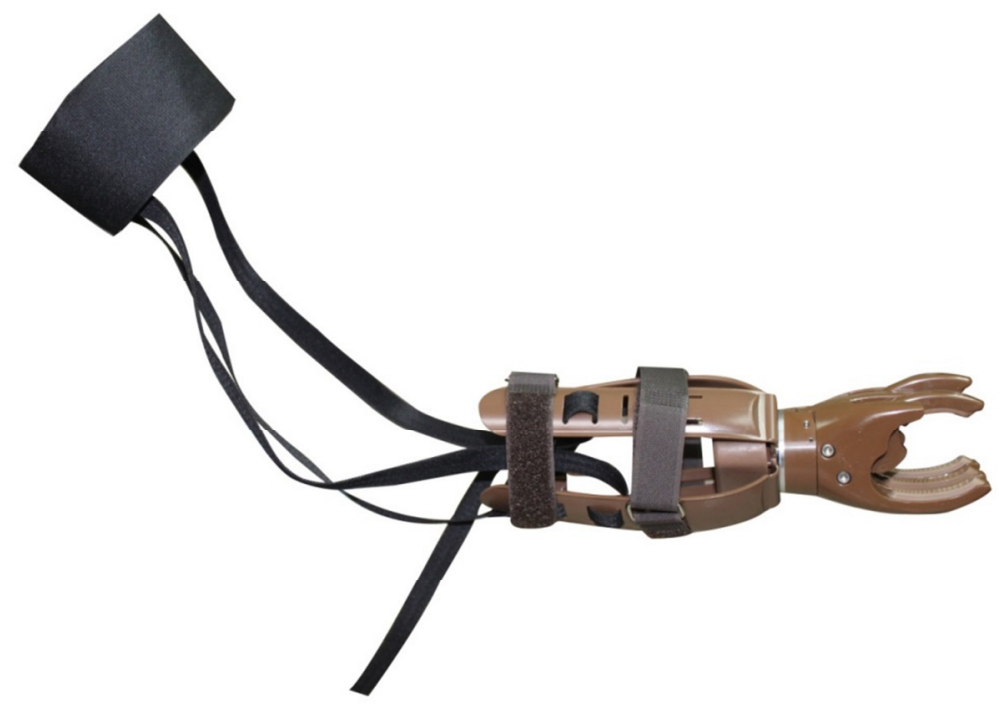

Figura 2.23: Prótesis mecánica ((Junta de beneficencia, n.d.))

Las prótesis eléctricas (figura 2.24) utilizan motores en el dispositivo terminal, muñeca o codo con una batería recargable. Se controlan mediante un servocontrol, control con interruptor de arnés o control con botón pulsador. Para acoplar la prótesis se usa un socket, que es un eslabón intermedio entre la prótesis y el muñón de manera que se logra la suspensión de éste por una succión. Son prótesis caras de adquirir y de mantener, y presentan otras desventajas como no poder utilizarse en un medio húmedo y el elevado peso que alcanza la prótesis.

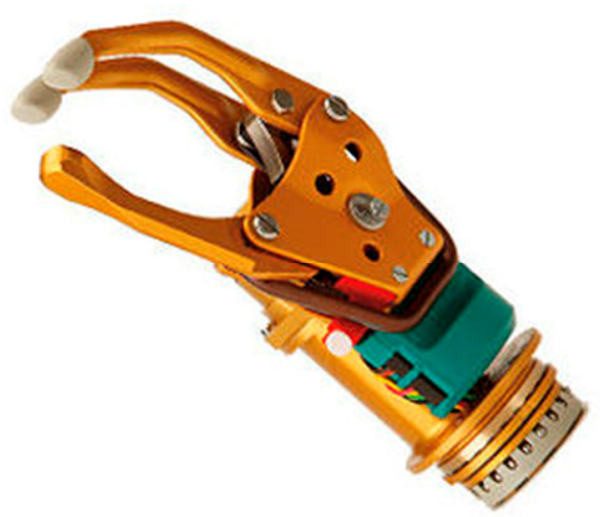

Figura 2.24: Mano eléctrica Myo Hand de la empresa Otto Bock (Bock, n.d.) 
Las prótesis neumáticas (figura 2.25) son accionadas por aire comprimido que utilizan músculos neumáticos como actuadores, con lo que tienen una elevada potencia específica. Un músculo neumático está compuesto por un tubo interior de caucho cubierto por una capa de fibras trenzadas de forma helioidal. Uno de sus extremos es la entrada de aire y el otro, el punto de conexión, de manera que cuando entra aire en el tubo interior y aumenta la presión, el músculo neumático se hincha y se contrae, produciendo el movimiento (Shadow Robot, n.d.). Estas prótesis consiguen una elevada fuerza de agarre con un peso moderado.

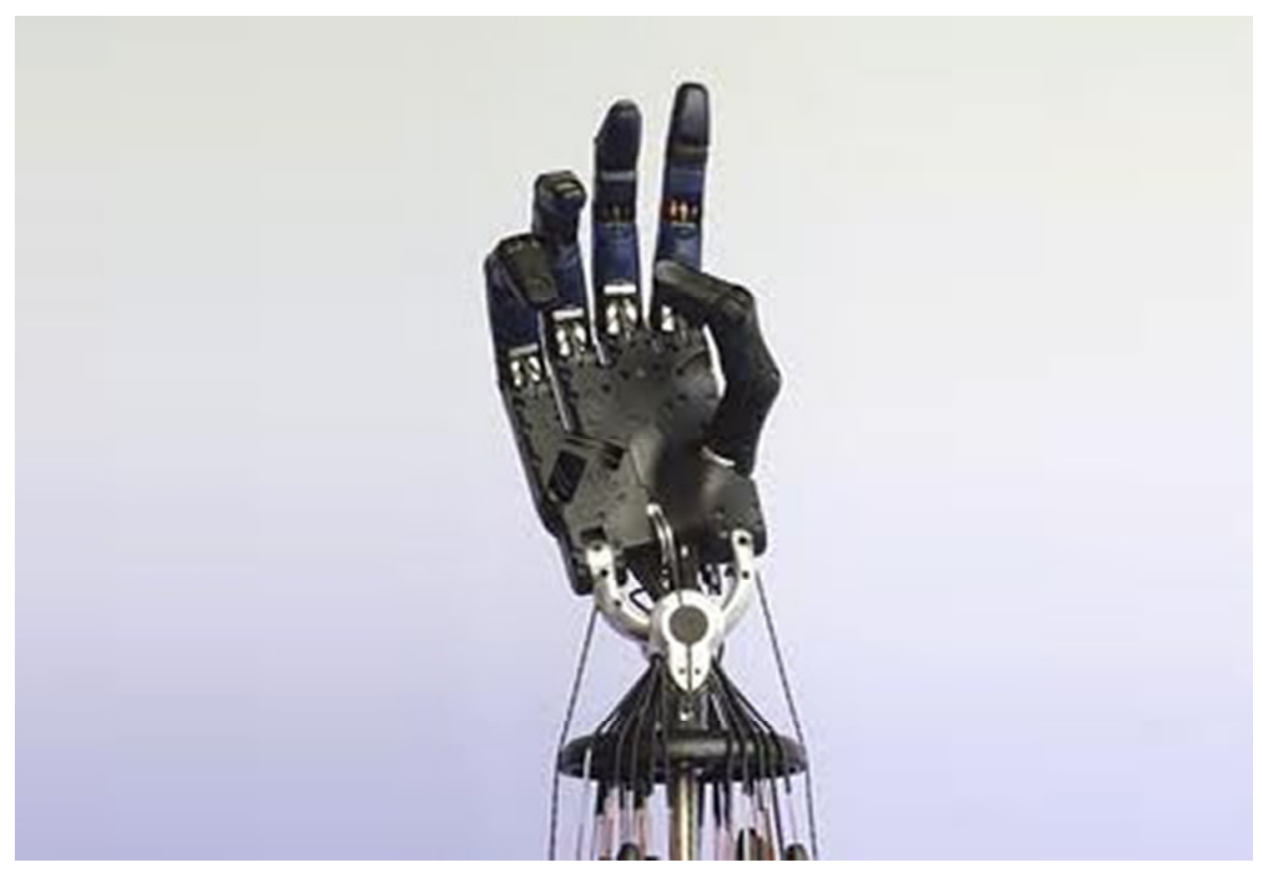

Figura 2.25: mano Shadow (robotnik, n.d.)

Otra opción protésica son las prótesis hibridas (figura 2.26), que combinan la acción del cuerpo con el accionamiento por electricidad en una sola prótesis. En su gran mayoría, las prótesis híbridas sirven para individuos que tienen amputaciones o deficiencias transhumerales. Normalmente utilizan un codo accionado por el cuerpo y un dispositivo terminal controlado de forma mioeléctrica. Este dispositivo terminal puede ser un gancho o una mano. Este gancho o mano puede recubrirse con un guante para mejorar la estética de la prótesis (Quinayás Burgos, 2010). 


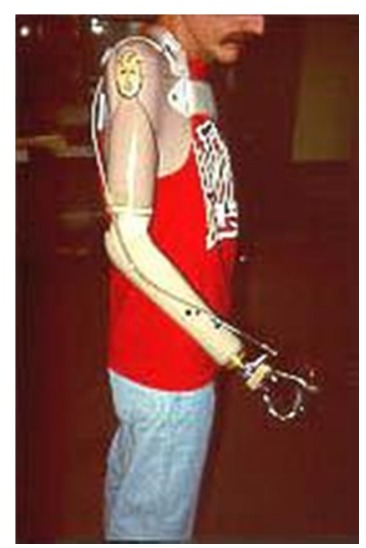

Figura 2.26: Prótesis híbrida (Bioinstrumentación, n.d.).

Las prótesis mioeléctricas (figura 2.27) son prótesis electrónicas muy populares debido al alto grado de rehabilitación que presentan, ya que aunan el mejor aspecto estético, gran fuerza y velocidad de prensión. El control mioeléctrico se basa en aprovechar la pequeña señal eléctrica (de 5 a $20 \mathrm{uV}$ ) producida al querer contraer un músculo mediante electrodos superficiales conectados a la piel. Únicamente requieren que el usuario flexione sus músculos para operarla y que no tienen arnés de suspensión. Su principal desventaja es que necesitan una batería que requiere mantenimiento (Quinayás Burgos, 2010).

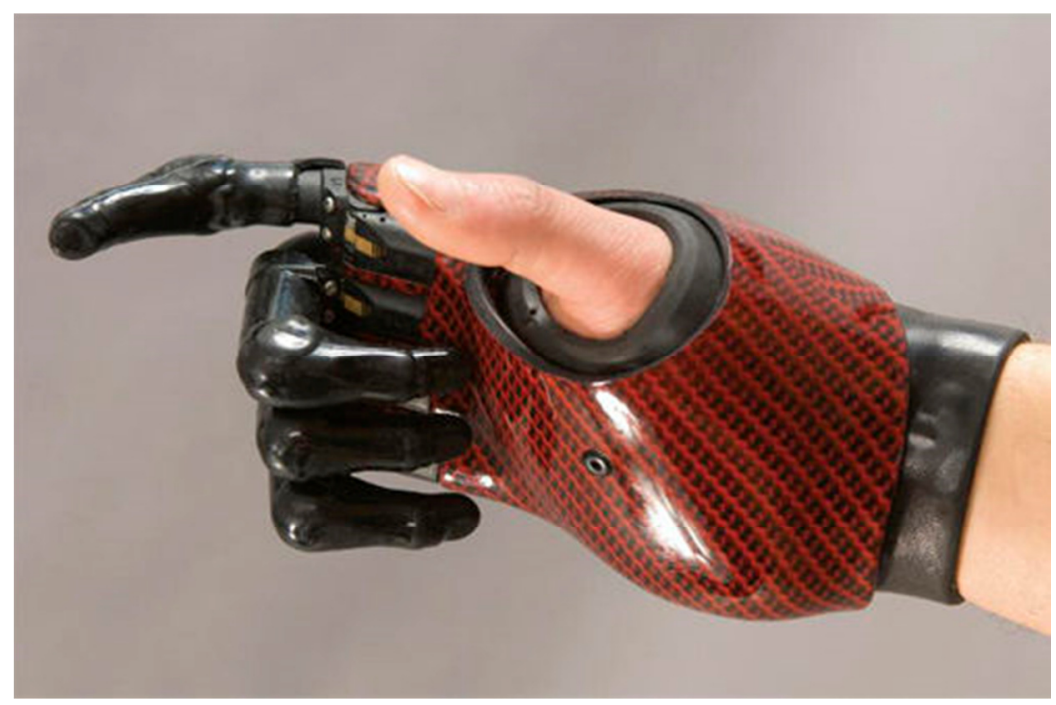

Figura 2.27: Prótesis mano parcial de mano multiarticulada y mioeléctrica (Medicallexpo, n.d.-a) 
En los últimos años se están desarrollando prótesis biónicas, muy avanzadas mecánicamente, resistentes a los agentes externos y con una apariencia similar a la mano humana. Belter et al. (Belter, Segil, Dollar, \& Weir, 2013) determinaron una serie de características que debían cumplir estas prótesis:

- El peso total de la mano protésica (considerando todos los factores: baterías, guante cosmético, etc.) ha de ser inferior a 500 g. Esto es debido a que una mano humana pesa alrededor de $400 \mathrm{~g}$ (Chandler, Clauser, McMconville, Reynolds, \& Young, 1975).

- Los diseños cinemáticos simples y robustos son preferibles a los diseños anatómicamente más correctos.

- Ha de permitir la aducción del pulgar, ya que ésta permite el agarre lateral.

- Con el fin de reducir el peso, son más recomendables los motores sin escobillas.

- Se recomienda una fuerza de agarre tipo pinza de al menos $65 \mathrm{~N}$ durante el agarre palmar.

En 2009 se presentó la prótesis I-LIMB (figura 2.28), que fue la primera mano biónica disponible comercialmente, desarrollada por la empresa Touchbionics. Tiene $6 \mathrm{gdl}$ y consta de 5 dedos que pueden funcionar y ser articulados de forma independiente. Se controla con un sistema mioeléctrico con entrada de dos señales musculares para abrir y cerrar los dedos de la mano, siendo muy intuitiva para el paciente.
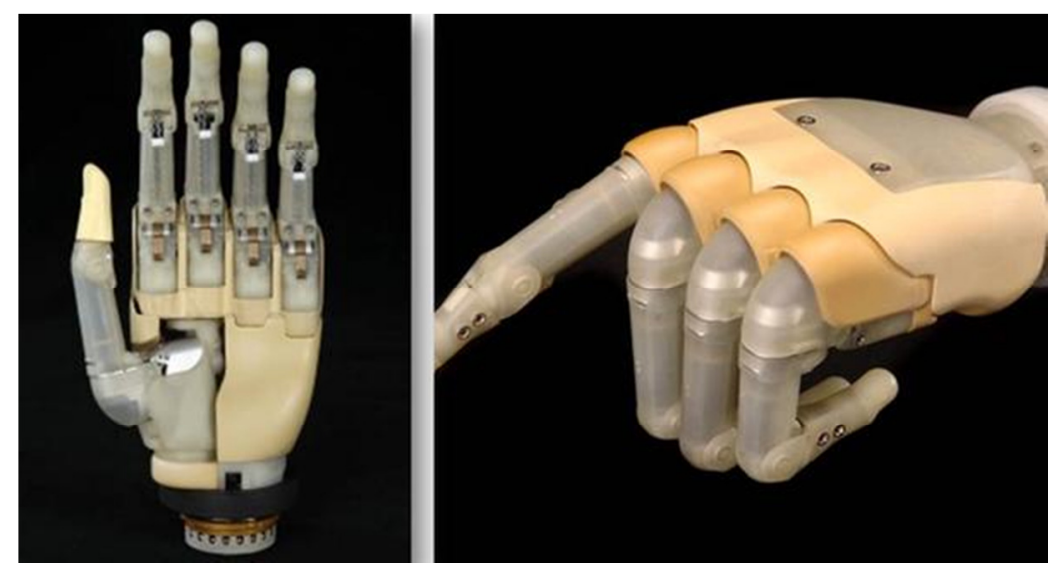

Figura 2.28: Prótesis I-LIMB (Touch Bionics, n.d.) 
Posteriormente, Touch Bionics ha presentado modelos mejorados, que son más rápidos, permiten una mayor fuerza de agarre, etc. Son los modelos ILIMB Pulse, I-LIMB Quantum, I-Limb Ultra Revolution (figura 2.29). Estas manos tienen 12 formas de agarre.

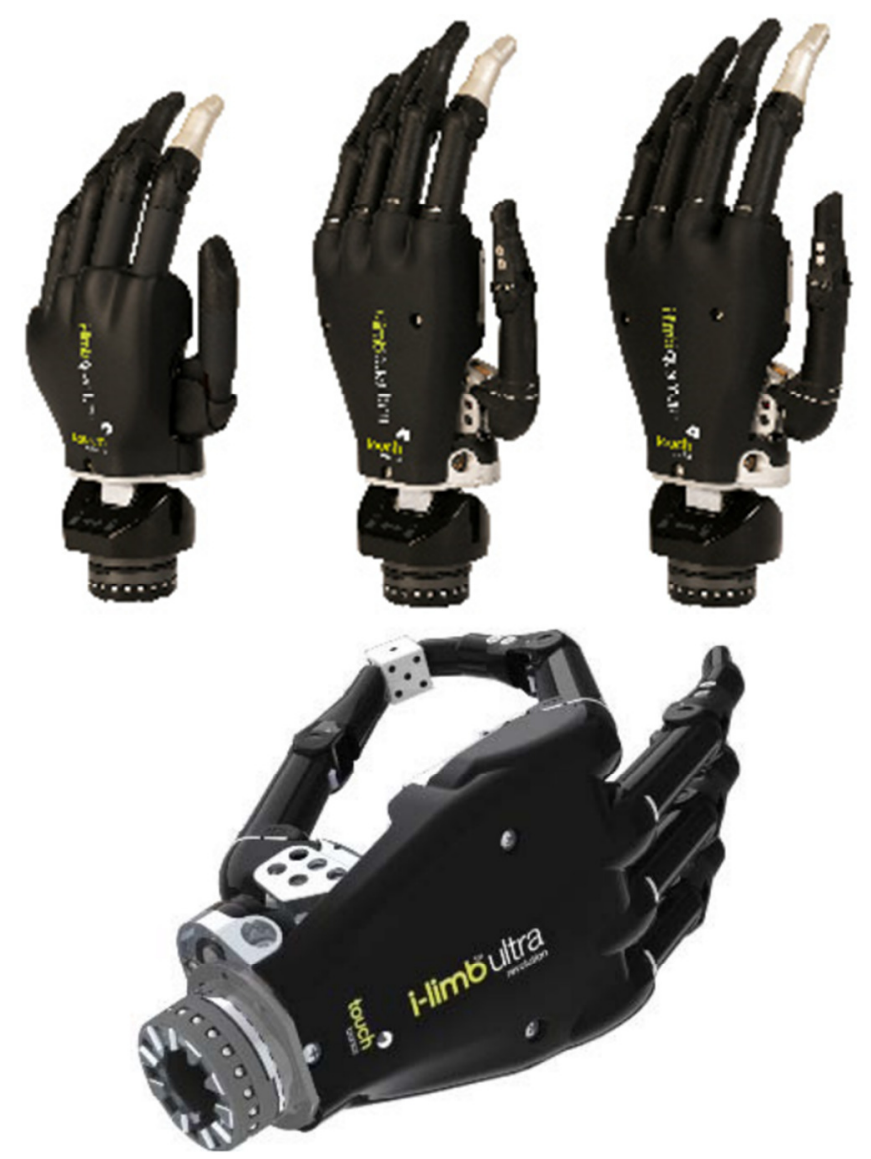

Figura 2.29. I-Limb Pulse, I-LIMB Ultra Revolution (Touch Bionics, n.d.).

La empresa Vincent Systems presentó en 2010 la mano Vincent Hand (figura 2.30). Tiene 11 articulaciones y 6 actuadores que permiten los $6 \mathrm{gdl}$ de sus cinco dedos (Belter et al., 2013). 


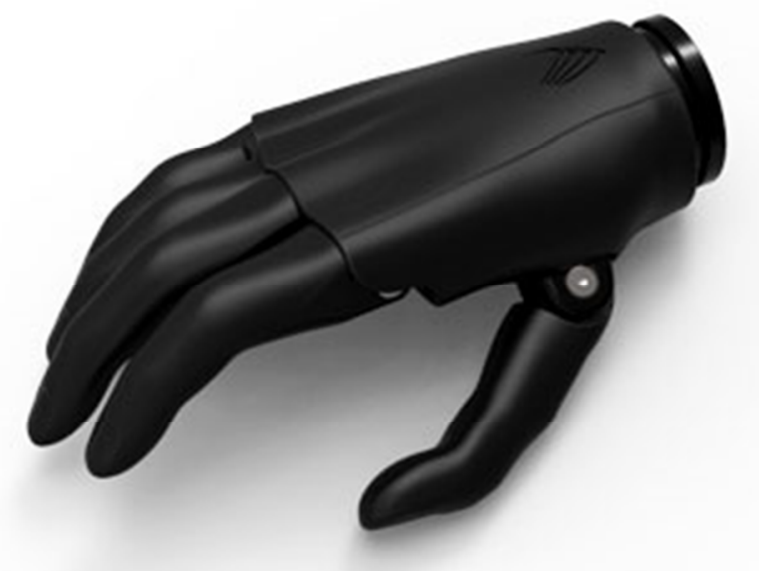

Figura 2.30: Prótesis Vincent Hand (Vincent Systems, 2011)

La empresa Otto Bock comercializa otra mano biónica, la prótesis Michelangelo (figura 2.31). Tiene seis gdl y es resistente al agua hasta los tres metros de profundidad.

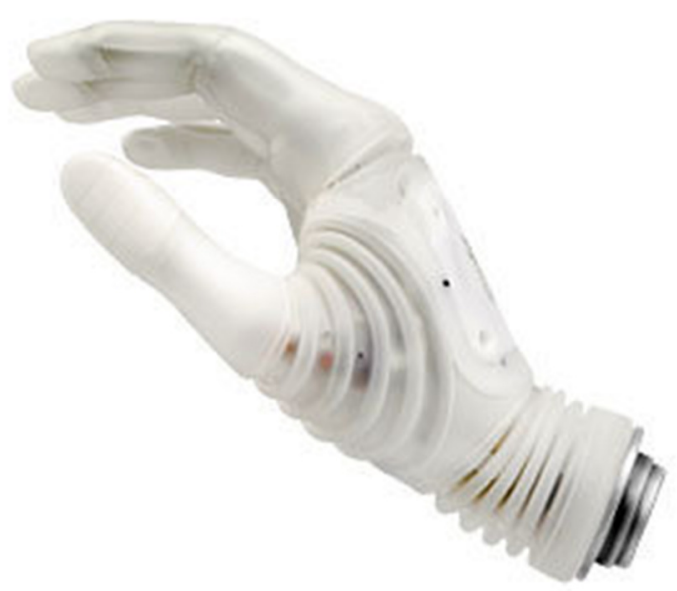

Figura 2.31. Mano Michelangelo (Otto Bock, n.d.) 
La empresa Bebionic también tiene una línea de manos protésicas mioeléctricas (figura 2.32). Los modelos han ido evolucionando desde las Bebionic hand, Bebionic hand v2 y la más reciente Bebionic hand 3, que consta de 14 tipos de agarre.

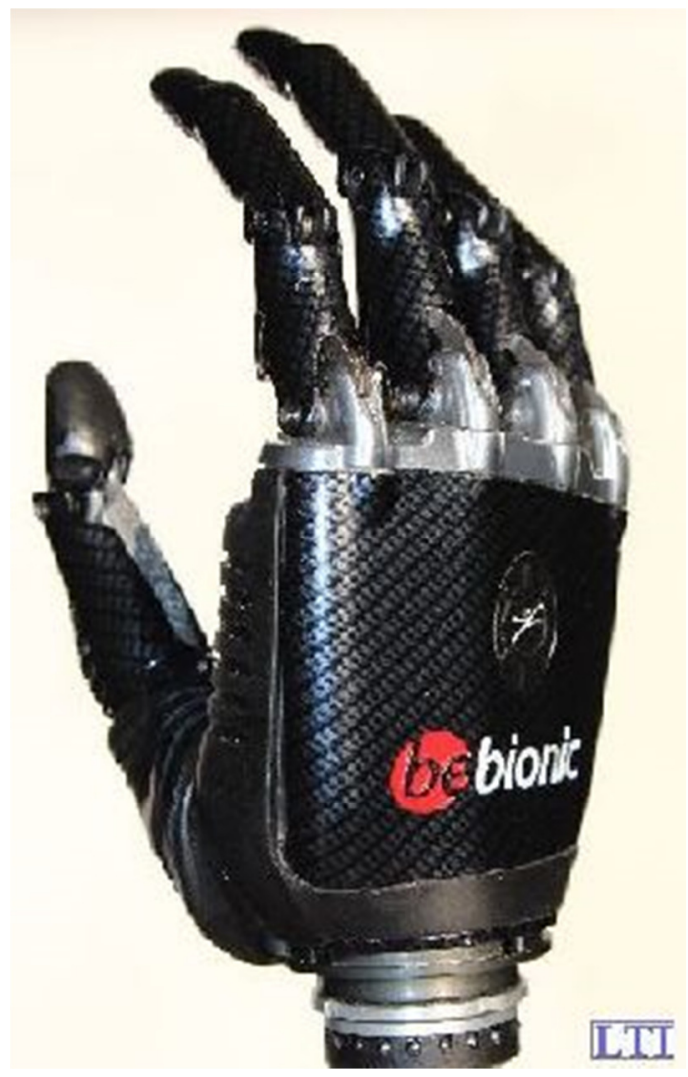

Figura 2.32. Mano bebionic (Bebionic, n.d.)

La mano Myo, fabricada por Centri, es otra opción de mano mioeléctrica. Consta de 2 actuadores que le proporcionan los dos grados de libertad (figura 2.33).

Aunque estas prótesis de mano presentan una buena movilidad, no pueden igualar la destreza de la mano humana, por lo que en ocasiones es necesario poner otros elementos terminales para realizar ciertas actividades, tales como jugar al baloncesto, esquiar o ir en bicicleta. (figura 2.34). Por este motivo es necesario continuar desarrollando prótesis más avanzadas que permitan realizar cualquier actividad con un único elemento terminal. 


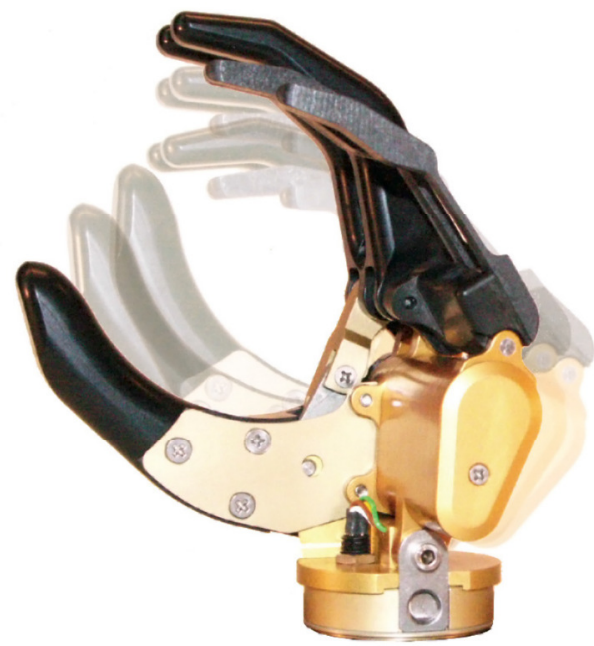

Figura 2.33. Mano Myo, de Centri (Centri, 2014)
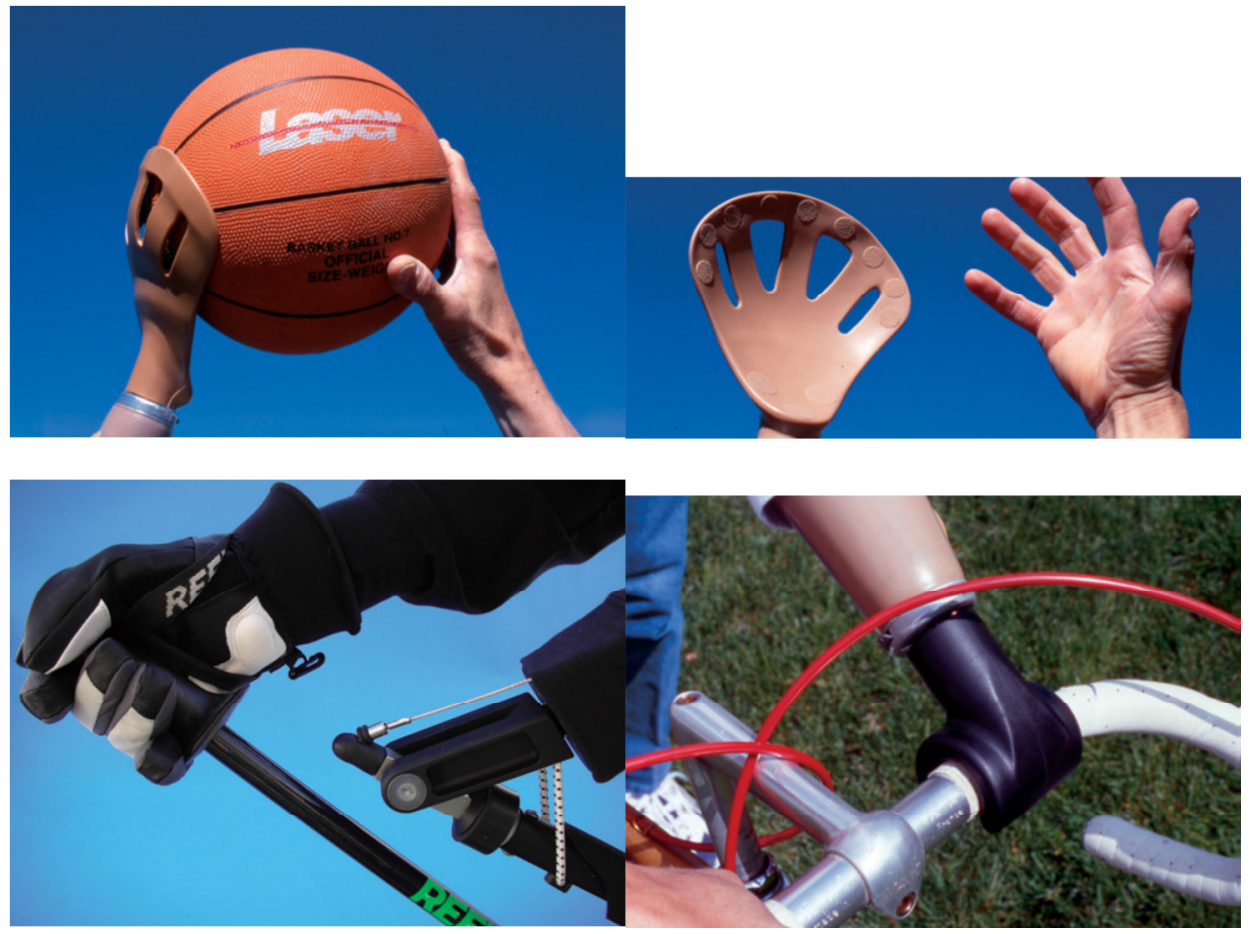

Figura 2.34. Distintos elementos terminales para actividades especificas (jugar al baloncesto, esquiar, ir en bicicleta) (EMO, 2014). 
A pesar del desarrollo reciente de prótesis con una mayor complejidad mecánica y un mayor grado de antropomorfismo, la principal limitación para su uso extensivo, aparte del coste, radica en el control de las mismas (Micera et al., 2010). En los humanos el sistema nervioso periférico recoge la información sensorial exteroceptiva y la propioceptiva a través del sistema aferente y la envía al sistema nervioso central, que la procesa, y envía señales nerviosas a los músculos apropiados mediante el sistema nervioso eferente para conseguir el agarre. Todo ello se realiza con una rapidez y precisión asombrosas y $\sin$ apenas esfuerzo mental, tras años de entrenamiento en la infancia. Este es sin duda el punto clave y de mayor complejidad para conseguir emular el agarre humano con un dispositivo mecánico. Algunos de los factores que dificultan el control del agarre en un ambiente humano son la amplia variedad de objetos y tareas, su diferente rigidez, peso, rugosidad y apariencia, las variaciones en su posición y orientación y la condiciones ambientales variables en las que debe realizarse el agarre (Kemp, Edsinger, \& Torres-Jara, 2007). Los algoritmos de control deben utilizar la información sensorial disponible (muchas veces reducida) y procesarla para finalmente enviar señales adecuadas a los actuadores que deben realizar el agarre, todo ello en tiempo real. Sin embargo la dificultad radica en determinar cuáles son las señales apropiadas para que los actuadores realicen el agarre de forma segura y eficiente. Un mejor conocimiento de la biomecánica del agarre y el diseño de algoritmos de control y/o aprendizaje adecuados son fundamentales para resolver esta incógnita. El uso de redes neuronales (Ascari, Bertocchi, Corradi, Laschi, \& Dario, 2009; Molina-Vilaplana \& López-Coronado, 2007; Mora, Sancho-Bru, \& Perez-Gonzalez, 2012), la aplicación de sinergias durante el agarre (Vinjamuri et al., 2011) y el aprendizaje por demostración (Argall et al., 2009; Ekvall \& Kragic, 2004) son algunos de los métodos propuestos para acometer este problema de control, aunque queda mucho trabajo para alcanzar este objetivo. En el caso de las manos protésicas, al propio problema de control, se une el de la interpretación adecuada de la señal obtenida de los músculos residuales con electromiografía superficial para enviar las señales de control adecuadas a los actuadores (Micera et al., 2010; Parker, Englehart, \& Hudgins, 2006). Aunque las manos antropomorfas incluyen más grados de libertad que los manipuladores tradicionales de un sólo grado de libertad, el reto principal sigue siendo cómo conseguir controlar simultáneamente dichos grados de libertad de forma no secuencial. Uno de los problemas en las 
prótesis es la limitación en las señales musculares disponibles y otro la capacidad del usuario para controlar simultáneamente dichos grados de libertad de una forma natural y sin un esfuerzo mental excesivo. En los últimos años, con el fin de abrir otras opciones en los métodos de control de prótesis, también se está investigando en sistemas alternativos a la electromiografía superficial para conectar las señales cerebrales a los actuadores del miembro protésico (brain-machine interfaces), como electrocorticografías (ECoG) (Pistohl, Schulze-Bonhage, Aertsen, Mehring, \& Ball, 2012), electroencefalografías (Agashe \& Contreras-Vidal, 2013), electromiografía intramuscular (Weir et al., 2009) o movimiento de los ojos (Duvinage, Castermans, \& Dutoit, 2011). 


\section{5.- Robots manipuladores y manos robóticas}

Los brazos robóticos manipuladores son dispositivos que imitan los movimientos del brazo humano para realizar un trabajo específico. En función de la tarea asignada, presentan un efector final u otro (Nof, 1999). Estos efectores adoptan una forma diferente en función de la operación a realizar (Olier Caparroso, Avilés, \& Hernández Bello, 1999). Las manos robóticas son accionadas por dispositivos con transformación energética de origen eléctrico, hidráulico o neumático. Estas manos normalmente se utilizan en robots humanoides o robots industriales, y están pensadas para cumplir tareas específicas. Aunque industrialmente son muy utilizados los efectores con dos dedos o pinzas, en los últimos 10 años se están desarrollando dispositivos robóticos con múltiples dedos (Ceccarelli, Nava, Jáuregui, Parada, \& Carbones, 2004).

Además, en el presente siglo se han empezado a desarrollar robots humanoides, que requieren la implementación de habilidades de manipulación, lo que es un campo complejo en la robótica. Un problema crucial en la manipulación robótica es la elección de las fuerzas de agarre para evitar o minimizar el riesgo de que se escape el objeto que se está cogiendo, sin dañarlo. (Bicchi, 2000; Laschi et al., 2000).

Según Bicchi et al., los tres requisitos funcionales de la mano mecánica son la destreza manipulativa, la robustez en el agarre y la operatividad humana. La destreza manipulativa es la capacidad de la mano de manipular objetos y recolocarlos según las necesidades de la tarea. La robustez en el agarre es la capacidad de mantener el agarre del objeto que se está manipulando a pesar de las perturbaciones (fuerzas inesperadas, estimación errónea de las características del objeto, etc.), de manera que no se ejerza tanta fuerza que el agarre dañe el objeto manipulado. Por último, la operatividad humana es un interfaz fácil y amigable con el operador humano, bien sea un programador para la tarea autónoma de un robot o una persona con una prótesis. (Bicchi, 2000).

Actualmente los manipuladores robóticos son ampliamente utilizados en los procesos industriales. Entre las tareas más comunes que éstos realizan se encuentra el manejo de objetos calientes, peligrosos, muy pesados o en procesos monótonos y alienantes (Bolton, 2010). Es muy importante diseñar 
estos sistemas con una arquitectura abierta o modular, con el fin de que puedan adaptarse para poder realizar varias tareas (Simanca, Avilés, \& Calle, 2005).

La primera mano mecánica basada en el modelo de la mano humana la desarrollo Frank Skinner en 1957. Este diseño sujetaba objetos con formas básicas como triangulares, rectangulares, cilíndricas y esféricas (Nof, 1999).

En 1982 se diseñó la mano robótica Stanford-JPL (figura 2.35), que posee 9 gdl con dos dedos y un pulgar oponente. La mano es actuada por 12 servomotores DC. Sus articulaciones son actuadas por alambres recubiertos de teflón.(BROCK et al., 2005)

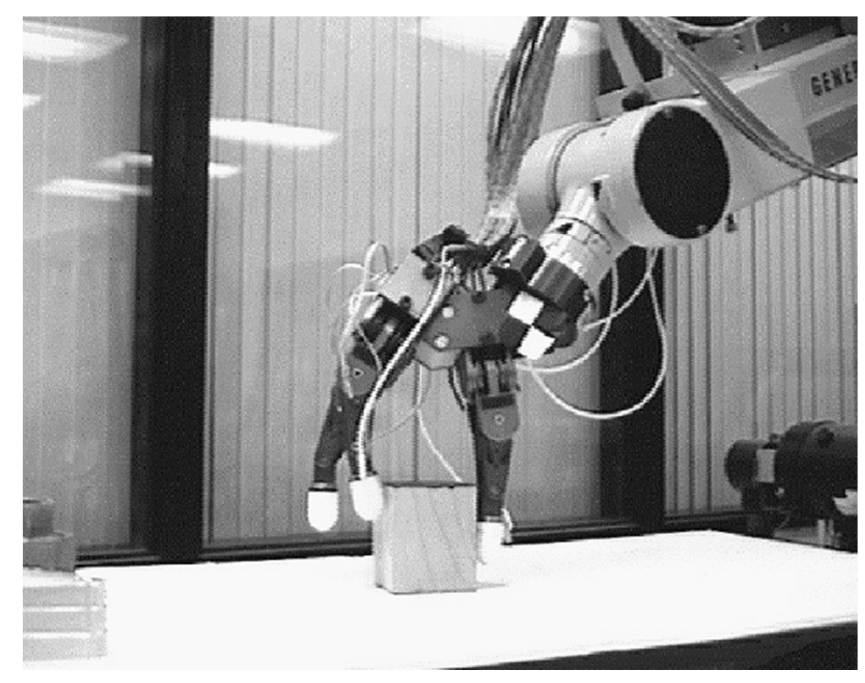

Figura 2.35: Mano Stanford/JPL (Buckley, n.d.)

En 1984 se desarrolló la mano robótica UTAH-MIT (figura 2.36), de características antropomórficas y compuesta por un pulgar y tres dedos con cuatro gdl cada uno. Este modelo permite una manipulación bastante precisa de los objetos, ya que las articulaciones están accionadas mediante tendones operados por un cilindro neumático. (BROCK et al., 2005) 


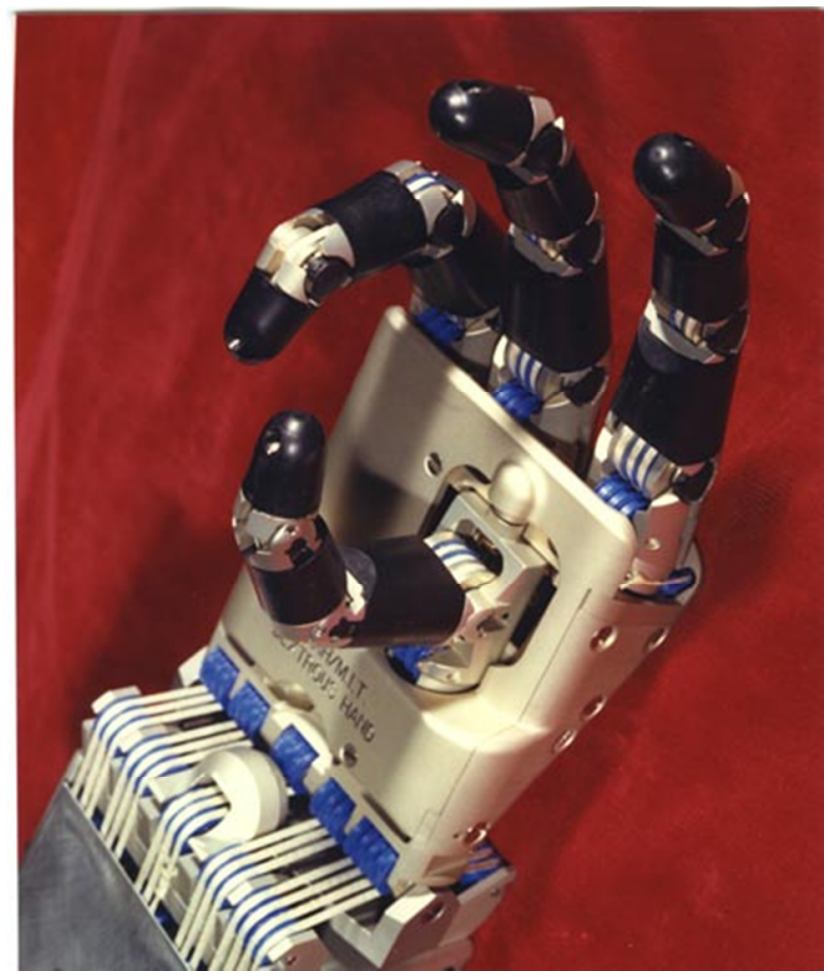

Figura 2.36: Mano UTAH-MIT (Computer History, n.d.)

En 1998 se presentó la DLR-Hand, una mano robótica multiarticulada con sensores de par, fuerza y posición en cada uno de sus cuatro dedos (Butterfass, Hirzinger, Knoch, \& Liu, 1998). En 2001 se presentó la mano DLR-Hand II (figura 2.37), que era una evolución de la DLR-Hand. Implementaba una estructura de esqueleto abierto de forma que se mejoraba el acceso a los sensores y circuitos de la mano, además de estar equipada con actuadores más potentes y con sensores de fuerza y par de $6 \mathrm{gdl}$ en cada dedo. (Butterfass, Grebenstein, Liu, \& Hirzinger, 2001)

En 2001 se presenta también la mano Gifu Hand, desarrollada con cinco dedos multiarticulados actuados mediante servomotores instalados en cada una de sus 20 articulaciones, que determinan su posición mediante un encoder magnético montado en cada una de las articulaciones. Cada punta de los dedos tiene un sensor de fuerza y de par. En 2002 se presenta la mejora de este diseño, la Gifu Hand II (figura 2.38), con la principal novedad de los 
sensores táctiles situados en la palma de la mano con 624 puntos de detección. (Kawasaki, Komatsu, \& Uchiyama, 2002)

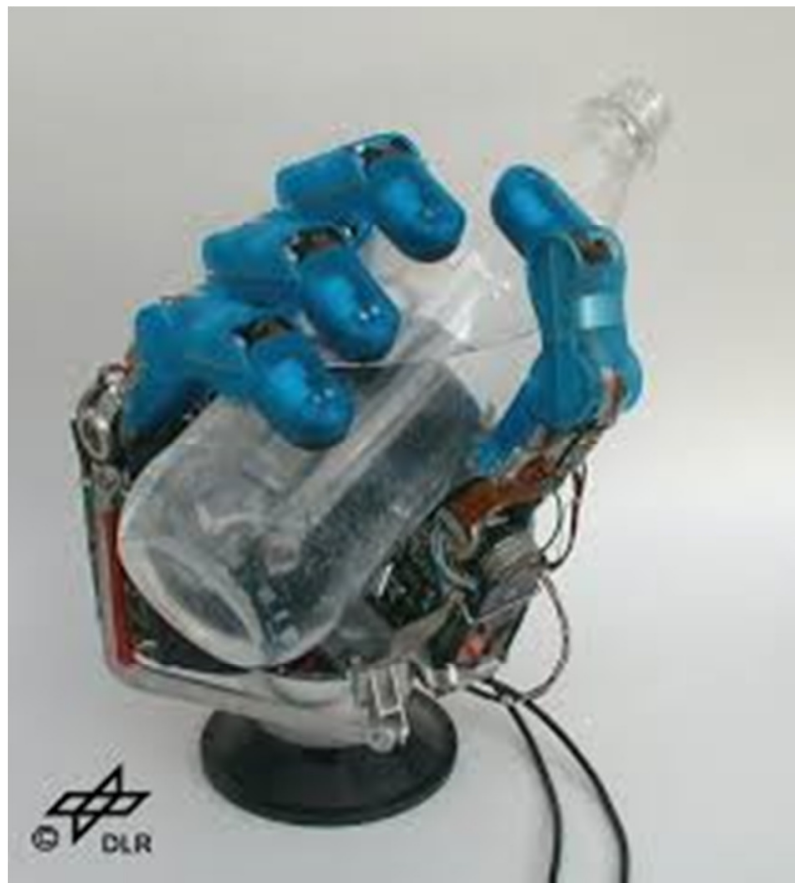

Figura 2.37: Mano DLR-Hand II. (DLR, n.d.)

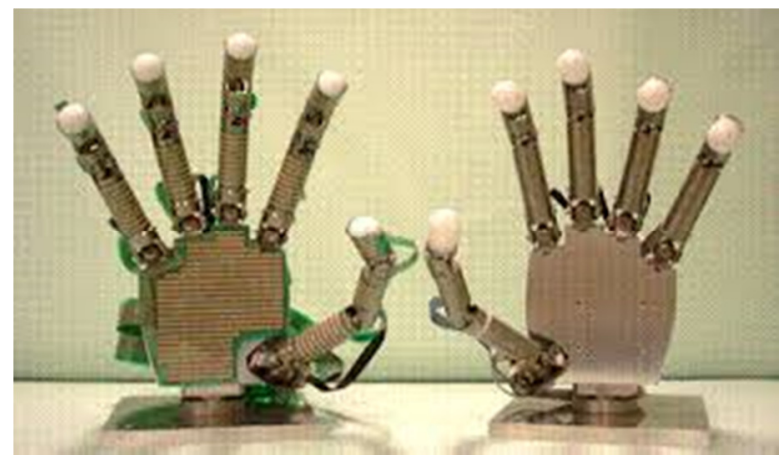

Figura 2.38. Gifu hand II (RSJ, n.d.)

En 1999 se presentó la mano con la que se instrumentaría el Robonaut (Lovchik \& Diftler, 1999), un robot astronauta diseñado principalmente pos los laboratorios de investigación de la NASA y que tenía como función principal la 
de ayudar a realizar tareas en el espacio que podrían ser peligrosas para el ser humano. Consta únicamente de una cabeza, un torso y dos brazos, por lo que carece de piernas. Está pensado para ser controlado a distancia, es decir, no se plantea como un robot con inteligencia artificial. (Bluethmann et al., 2003).

Su mano (figura 2.39) está compuesta por cinco dedos y 12 gdl; la muñeca presenta $2 \mathrm{gdl}$ adicionales. Se acciona mediante 14 motores de CC sin escobillas y está equipada con 43 sensores. Podía ejercer una fuerza de $20 \mathrm{lbf}$ (unos $90 \mathrm{~N}$ ) y un momento de 30lbf-in (unos $3.4 \mathrm{Nm}$ ).

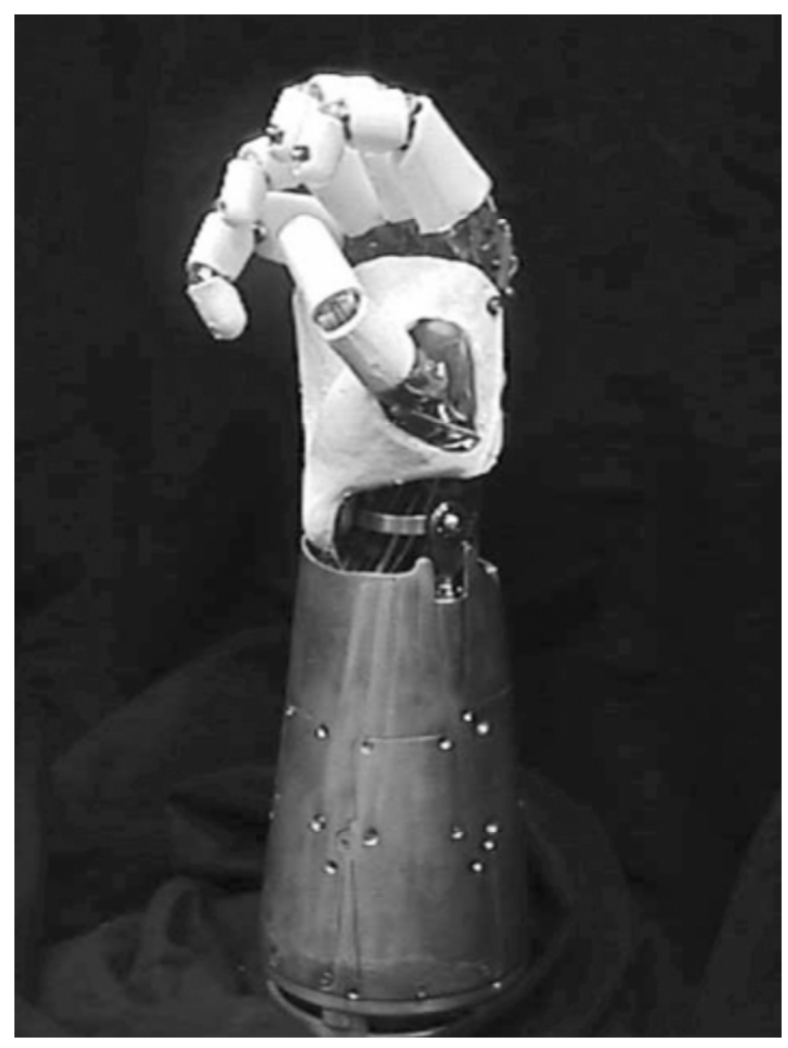

Figura 2.39: Mano del Robonaut (Lovchik \& Diftler, 1999)

Posteriormente la NASA en colaboración con General Motors desarrollaron la segunda serie de Robonaut (R2A y R2B), conocida formalmente como R2 (figura 2.40). En febrero de 2011, en la misión STS-133, se trasladó a la Estación Espacial Internacional. Esta nueva generación de Robonaut se equipó con una mano mejorada: la punta de sus dedos puede realizar una fuerza de empuje de $2.25 \mathrm{~kg}$ (unos $22 \mathrm{~N}$ ) a una velocidad de $200 \mathrm{~mm} / \mathrm{s}$. Además, es capaz 
de realizar tareas tan complejas como enroscar un tornillo y manejar una gran cantidad de herramientas (Bridgwater et al., 2012).

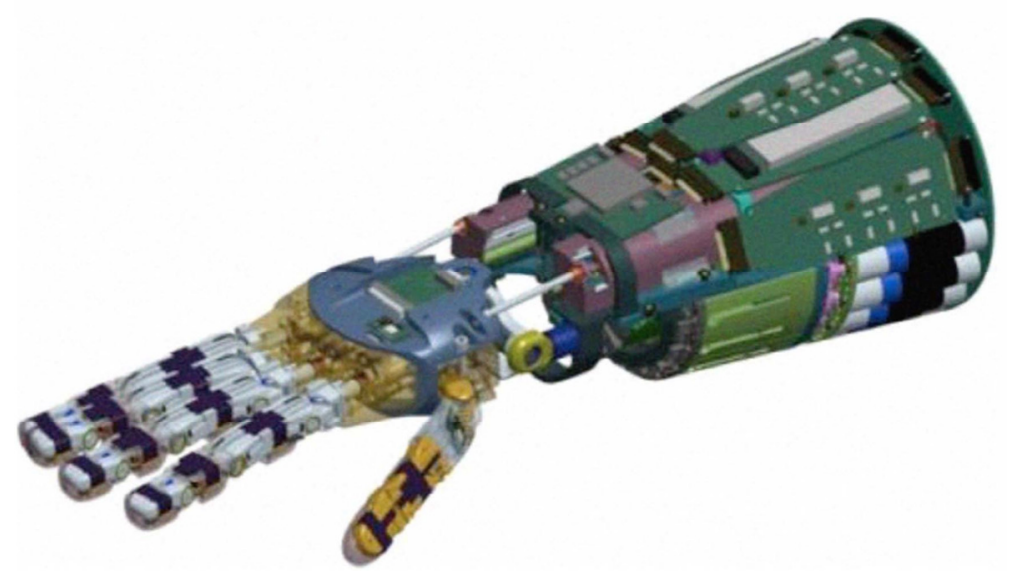

Figura 2.40: Mano del Robonaut 2 (Bridgwater et al., 2012)

Otro tipo de robot humanoide son los HRP, acrónimo de "Humanoid Robotics Project". (Hirukawa et al., 2004). Este tipo representa la totalidad de cuerpo humano. Los primeros modelos fueron de la serie HRP-1 (figura 2.410), y datan de 1997. Se trataba de robots humanoides de $130 \mathrm{~kg}$ de peso y $160 \mathrm{~cm}$ de alto y $60 \mathrm{~cm}$ de ancho, que tenían un total de $28 \mathrm{gdl}$, aunque su mano era de tipo pinza, teniendo un único gdl (abrir/cerrar la pinza) cada una de ellas.

Un año después, en 1998, se desarrolló el HRP-2P (figura 2.42), de 58 kg y 154 $\mathrm{cm}$ de alto por $65 \mathrm{~cm}$ de ancho. Tenía un total de $30 \mathrm{gdl}$, pero su mano continuaba siendo una pinza, con lo que únicamente tenía un gdl en cada una de ellas, al igual que el modelo anterior. El HRP-2 es una evolución del modelo anterior, realizada en 2002, que permite un mejor control y mayor velocidad y autonomía. Su mano continua siendo una pinza, pero es capaz de realizar acciones tan complejas como manejar un yo-yo (Mombaur \& Sreenivasa, 2010).

En 2005 aparece el HRP-3P, con $65 \mathrm{~kg}$ de peso, $160 \mathrm{~cm}$ de altura y una anchura de $66.4 \mathrm{~cm}$. Tiene un total de $36 \mathrm{gdl}$ y presenta una mano totalmente distinta, con $3 \mathrm{gdl}$, en la que el primer dedo imita al pulgar y tiene un gdl, mientras que 
el otro componente intenta representar a los dedos índice, medio, anular y meñique trabajando como una única entidad y tiene 2 gdl. Estos dedos permiten envolver el objeto a coger $y$, además, realizar un agarre de potencia. Aunque mejora la capacidad de agarre de la mano del HRP-2, éste aún está muy limitado, ya que le resulta difícil realizar tareas tales como apretar un conductor eléctrico. (Kaneko, Harada, Kanehiro, Miyamori, \& Akachi, 2008).

La evolución del HRP-3P, el HRP-3, se presenta en 2007. Se trata de un robot de $68 \mathrm{~kg}, 160.6 \mathrm{~cm}$ de altura y una anchura de $66.4 \mathrm{~cm}$. Tiene un total de 42 gdl y consta de una mano con tres dedos y 6 gdl cada una (figura 2.43). El primer dedo, que imita el pulgar, tiene 2 gdl. Una de sus articulaciones está dispuesta en la base y se utiliza para encarar el pulgar con el segundo y tercer dedo. La otra unión está dispuesta en el medio del pulgar y se utiliza para la flexión y la extensión. Construyéndolo de esta manera, se consigue que pueda formar la misma pinza que en modelos anteriores. El segundo dedo, que imita al índice, tiene $3 \mathrm{gdl}$. En su base hay dos articulaciones rectangulares, una de las cuales permite la flexión-extensión y la otra la abducción-aducción. Este diseño del segundo dedo consigue que se pueda manipular el gatillo de una herramienta eléctrica (figura 2.44) o apretar un interruptor. La tercera articulación está en medio del tercer dedo y permite la flexoextensión (Kaneko et al., 2008).

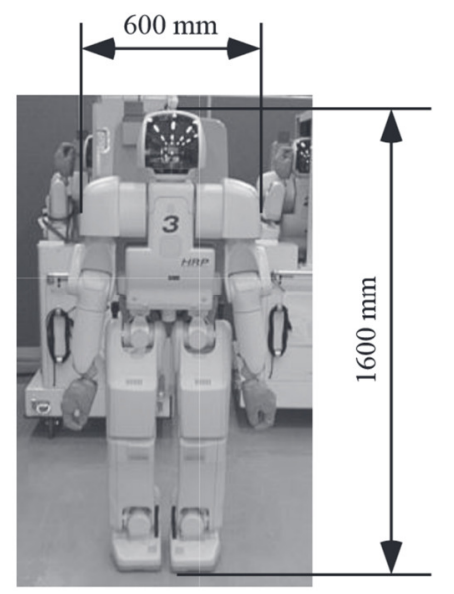

Figura 2.41: HRP-1 (Hirukawa et al., 2004) 


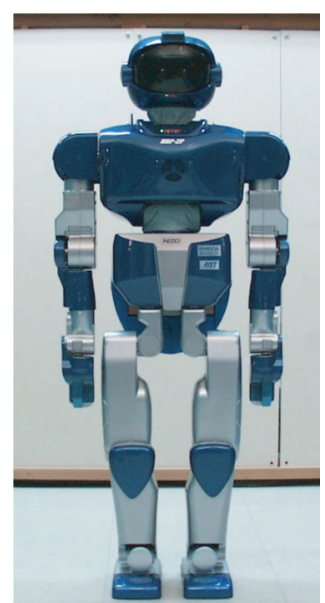

Figura 2.42: HRP-2P (Hirukawa et al., 2004)

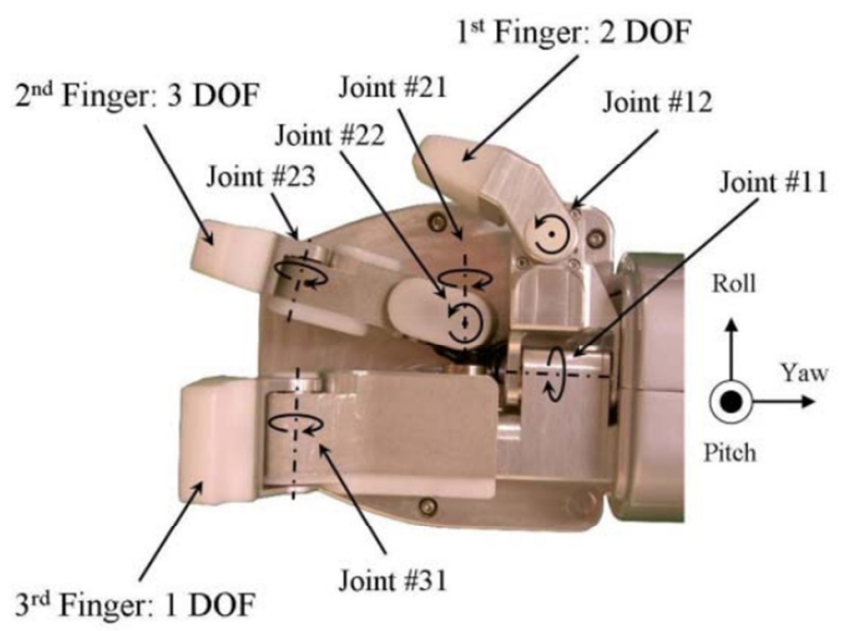

(a) Pitch axis view

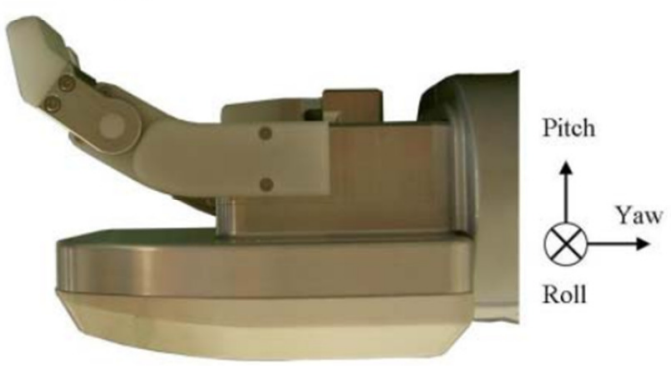

Figura 2.43: Mano de 3 dedos y $6 \mathrm{gdl}$ del HRP-3 (Kaneko et al., 2008) 


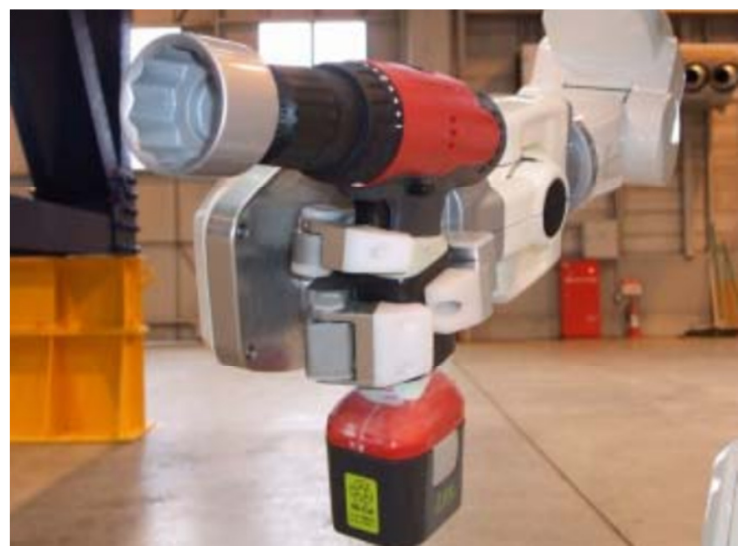

Figura 2.44: Mano del HRP-3 manejando un taladro eléctrico (Kaneko et al., 2008)

En 2009 aparece el modelo HRP-4C , que intenta asemejar en apariencia a una joven japonesa, con lo que se hace especial énfasis en la estética (figura 2.45) (Kaneko, Kanehiro, Morisawa, Tsuji, et al., 2011). Su altura es de $158 \mathrm{~cm}$ y tiene un peso de $43 \mathrm{~kg}$, con un total de $42 \mathrm{gdl}$. Sus manos tienen 5 dedos pero únicamente $2 \mathrm{gdl}$ cada una, abducción-aducción del pulgar y flexión-extensión de los otros cuatro dedos (figura 2.46) (Kaneko, Kanehiro, Morisawa, Tsuji, et al., 2011). El modelo HRP-4 surge en 2010 con el principal objetivo de reducir costes frente al modelo HRP-4. Tiene una altura de $151,4 \mathrm{~cm}$ y un peso de 39 $\mathrm{kg}$. Para reducir costes, pasa de los $42 \mathrm{gdl}$ del anterior modelo a únicamente 34, si bien las manos continúan teniendo $2 \mathrm{gdl}$, iguales a los del modelo HRP4C (Kaneko, Kanehiro, Morisawa, Akachi, et al., 2011) (figura 2.47)

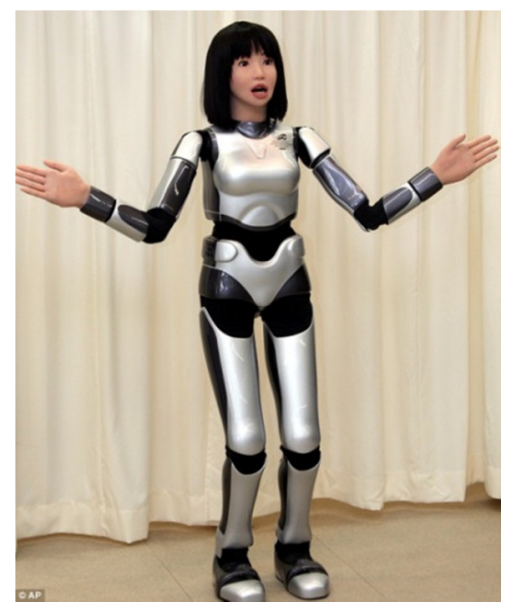

Figura 2.45: $H R P-4 C(H R P$, n.d.) 


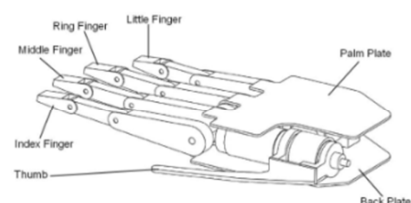

(a) Mano

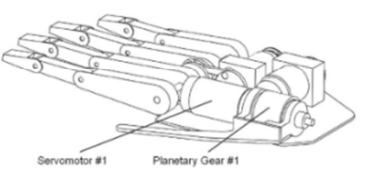

(b) Pulgar en postura de abducción

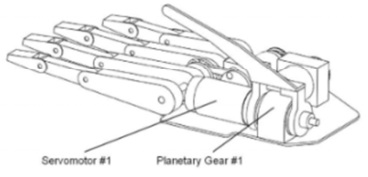

(c) Pulgar en postura de aducción

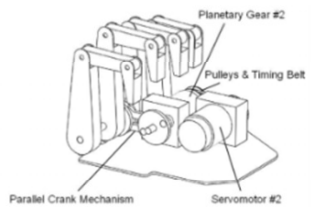

(e) Cuatro dedos flexionados

Figura 2.46: Muestra de los dos gdl de la mano del HRP-4C: a) Mano en posición inicial;

b) Pulgar en abducción; c) Pulgar en aducción; d) Dedos en extensión; e) Dedos en flexión (Kaneko, Kanehiro, Morisawa, Tsuji, et al., 2011)

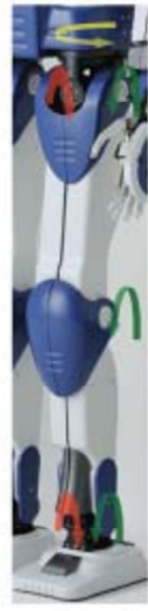

Leg (ea.) 6 D.O.F.

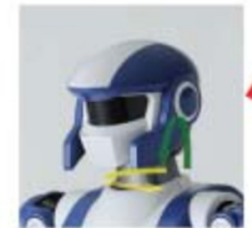

Head 2 D.O.F.

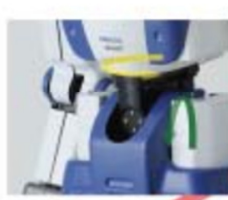

Waist 2D.O.F.
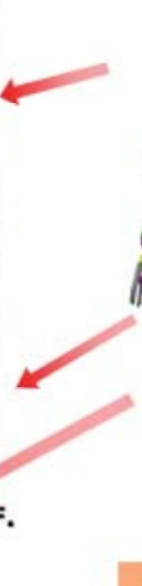
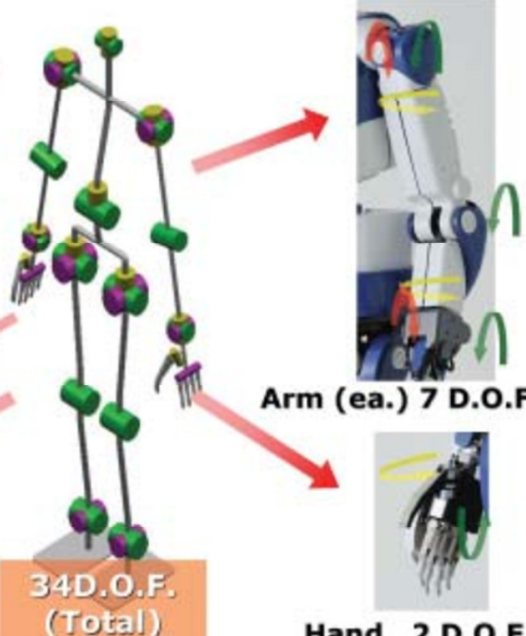

Hand 2 D.O.F.

Figura 2.47: Configuración de los gdl del HRP-4 ((Kaneko, Kanehiro, Morisawa, Akachi, et al., 2011))

A modo de resumen, la tabla 2.c muestra las características más importantes en los distintos modelos HRP. 
Tabla 2.c: Características de los robots humanoides HRP

\begin{tabular}{|c|c|c|c|c|c|c|c|}
\hline Modelo & Año & $\begin{array}{c}\text { Altura } \\
(\mathrm{cm})\end{array}$ & $\begin{array}{c}\text { Peso } \\
(\mathrm{kg})\end{array}$ & $\begin{array}{c}\text { Gdl } \\
\text { totales }\end{array}$ & $\begin{array}{c}\text { Gdl } \\
\text { mano }\end{array}$ & $\begin{array}{c}\text { Número } \\
\text { de dedos }\end{array}$ & $\begin{array}{c}\text { Tipo de } \\
\text { mano }\end{array}$ \\
\hline HRP-1 & 1997 & 160 & 130 & 28 & 1 & 2 & Pinza \\
\hline HRP-2P & 1998 & 154 & 58 & 30 & 1 & 2 & Pinza \\
\hline HRP-2 & 2002 & 154 & 58 & 30 & 1 & 2 & Pinza \\
\hline HRP-3P & 2005 & 160 & 65 & 36 & 3 & 2 & Multidedo \\
\hline HRP-3 & 2007 & 160.6 & 68 & 42 & 6 & 3 & Multidedo \\
\hline HRP-4C & 2009 & 158 & 43 & 42 & 2 & 5 & $\begin{array}{c}\text { Estética } \\
\text { humana }\end{array}$ \\
\hline HRP-4 & 2010 & 151,4 & 39 & 34 & 2 & 5 & $\begin{array}{c}\text { Estética } \\
\text { humana }\end{array}$ \\
\hline
\end{tabular}

En 2008, Gaiser et al. presentaron la mano robótica FRH-4 (figura 2.48). Se trataba de una mano antropomórfica hidráulica con cinco dedos y que permite la precisión de un robot manipulador. Al ser hidráulica, tiene una potencia específica elevada. Además, está equipada con sensores de posición en sus 11 articulaciones y con sensores de contacto, lo que le permite tener retroalimentación en el agarre. (Gaiser et al., 2008).

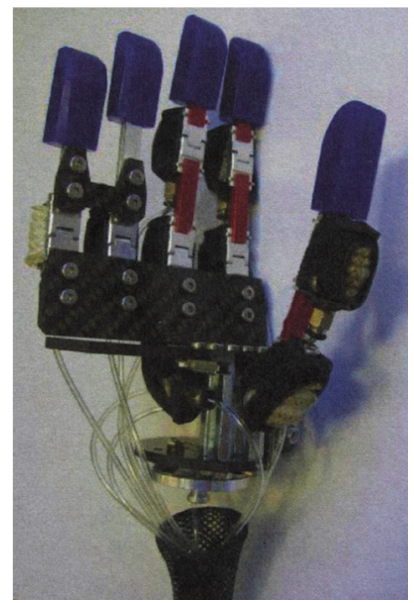

Figura 2.48: Mano robótica FRH-4 (Gaiser et al., 2008)

Entre los últimos avances presentados en este tipo de sistemas vale la pena resaltar que se centran en la inteligencia artificial y la cognitiva, lo que permite que los sistemas robóticos sean cada vez más sofisticados, haciendo que la 
habilidad y capacidad de agarre sea cada vez más similar a la mano humana, por lo que los nuevos sistemas son conocidos como biomiméticos y bioinspirados. (Mattar, 2013). La mejor comprensión del agarre característico de la mano ha permitido desarrollar algoritmos de control que permiten regular la fuerza que ha de ejercer cada dedo para conseguir un agarre firme en condiciones tanto estáticas como dinámicas (Carbone \& González, 2011).

Como se ha enfatizado, las manos robóticas más recientes se equipan con sensores táctiles de alta precisión por todo el sistema para proporcionar continuamente información sobre la magnitud y las fuerzas en los puntos de contacto entre la mano robótica y el objeto manipulado(Yousef, Boukallel, \& Althoefer, 2011). Además, se están desarrollando manos teleoperadas por medio de guantes maestros que las guían inalámbricamente.(Zaid \& Yaqub, 2012). 


\section{6.- Ergonomía aplicada al agarre}

La ergonomía es la disciplina que se encarga del diseño de los lugares de trabajo, herramientas y tareas, de modo que coincidan con las características fisiológicas, anatómicas, psicológicas y las capacidades del trabajador, buscando la optimización de los tres elementos del sistema (humano, máquina y ambiente), para lo cual elabora métodos de estudio de la persona, de la técnica y de la organización (Vern, 1992).

Uno de los aspectos más analizados dentro del campo ergonómico en relación al proceso de agarre es la caracterización de las fuerzas de agarre en los mangos de herramientas y/o máquinas que deben ser manipulados. Debido a la gran cantidad de enfermedades profesionales ocasionadas por el mal agarre de las herramientas, es importante conocer cómo afecta el diseño de los mangos en la fuerza de agarre y la contribución de las distintas zonas de la mano a la misma. La caracterización de la fuerza de agarre utilizada al realizar las acciones con mangos de herramientas o máquinas es necesaria para optimizar el diseño de dichos mangos y evitar las lesiones en la extremidad superior (Eksioglu, 2004; McDowell, Wimer, Welcome, Warren, \& Dong, 2012).

Evers et al. identificaron 6 factores de confort en el uso de herramientas manuales: funcionalidad, postura y músculos, irritación y dolor en manos y dedos, irritación en la superficie de la mano, características del mango, y estética. Estos factores se clasificaron en tres grupos: funcionalidad, interacción física y apariencia. Las principales conclusiones que obtuvieron fueron que los mismos descriptores están relacionados en la comodidad e incomodidad en el manejo de herramientas manuales; los descriptores de funcionalidad están mayormente relacionados en la comodidad del uso de herramientas manuales seguidos de los descriptores de interacción física; y que los descriptores estéticos son secundarios en la comodidad del manejo de herramientas manuales. (Kuijt-Evers, Groenesteijn, De Looze, \& Vink, 2004)

El equipo de Seo ha realizado diversos estudios acerca de cómo afecta la forma y tamaño de los mangos en la fuerza de agarre. En 2008 realizaron un estudio acerca de cómo afectaba el diámetro de un objeto (entre 38 y $83 \mathrm{~mm}$ ) a la fuerza de agarre máxima que se podía ejercer, obteniendo una fórmula del diámetro óptimo que debía tener el objeto en función de la amplitud del 
agarre interior y de la longitud de la mano (Na Jin Seo \& Armstrong, 2008). En un trabajo posterior, estudiaron cómo afectaba que la forma de los mangos fuera elíptica en la distribución de fuerzas de agarre, concluyendo que con esta forma de mango se conseguían fuerzas normales de agarre un $58 \%$ superiores y momentos máximos un $25 \%$ superiores que con mangos cilíndricos (N.J. Seo \& Armstrong, 2011).

En 2005, Kong et al. (Y. K. Kong \& Lowe, 2005) realizaron un estudio con mangos cilíndricos de aluminio de distinto diámetro (entre 25 y $50 \mathrm{~mm}$ ) para determinar el diámetro óptimo del mango de una herramienta para realizar la máxima fuerza. El resultado fue que el diámetro debía ser el 19,7\% de la longitud de la mano.

Además del diámetro óptimo de confort, también se ha estudiado la apertura óptima en el agarre (Blackwell, Kornatz, \& Heath, 1999). Eksioglu estudió la apertura óptima durante el agarre en función del tamaño de la mano, con el fin de evitar lesiones debidas a la realización de un fuerza de agarre excesiva (Eksioglu, 2004). 


\section{7.- Técnicas de medida de fuerza de agarre.}

Uno de los principales objetivos para caracterizar el agarre es determinar la fuerza que se está realizando en el mismo, así como la presión y la superficie de contacto.

Existen varios tipos de fuerza de agarre que se pueden evaluar. En ocasiones se pretende medir la fuerza máxima de agarre que es capaz de realizar un sujeto; en otras, lo que se pretende es conocer la fuerza, presiones y zonas de contacto de la mano con el objeto manipulado de forma cotidiana. En medicina, la evaluación del resultado final después de lesiones en las extremidades superiores a menudo incluye la medida de la fuerza máxima de agarre para obtener así una evaluación objetiva (BACORN \& KURTZKE, 1953; Frykman, 1967; Lidstrom, 1959).

Para medir la fuerza de agarre máxima lo habitual es utilizar un dinamómetro. Se han diseñado varios instrumentos para este propósito, aunque en los primeros que se utilizaron se detectó que los resultados obtenidos estaban relacionados con el instrumento utilizado para medir la fuerza (Kellor, Frost, Silberberg, Iversen, \& Cummings, 1971; Schmidt \& Toews, 1970; Thorngren \& Werner, 1979). El dinamómetro ideal debería tener las siguientes características (Solgaard, Kristiansen, \& Jensen, 1984):

- Las lecturas deberían ser reproducibles.

- Debería tener la misma precisión independientemente de si la fuerza de agarre es alta o baja.

- Debería ser apropiado para cualquier tamaño de mano.

- Su uso debería ser cómodo para el sujeto.

- Debería ser pequeño y fácilmente transportable.

Los primeros instrumentos utilizados fueron el dinamómetro de muelle de acero y el vigorímetro Martin. El dinamómetro de muelle de acero (figura 2.49) es un instrumento pequeño y manejable, pero muy incómodo para la mayoría de los sujetos.

El vigorímetro Martin (figura 2.50) es un instrumento de precisión (Thorngren $\&$ Werner, 1979) pero requiere de pelotas de distinto tamaño para que se ajuste a las distintas tallas de mano. 


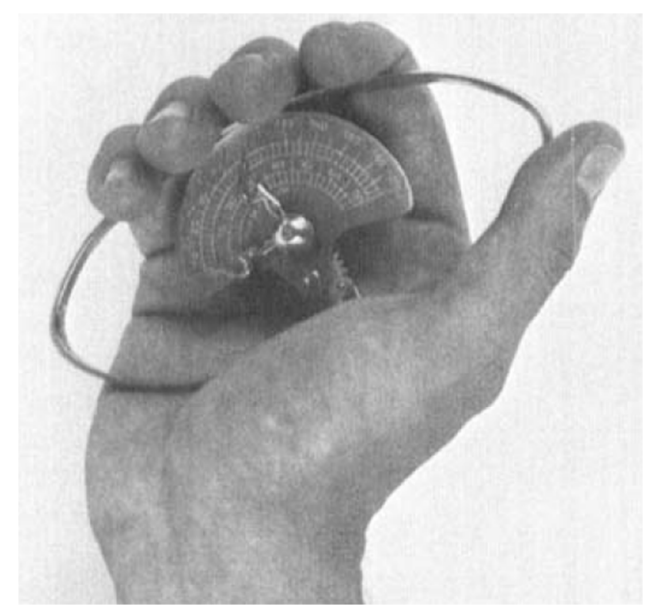

Figura 2.49: Dinamómetro de muelle de acero

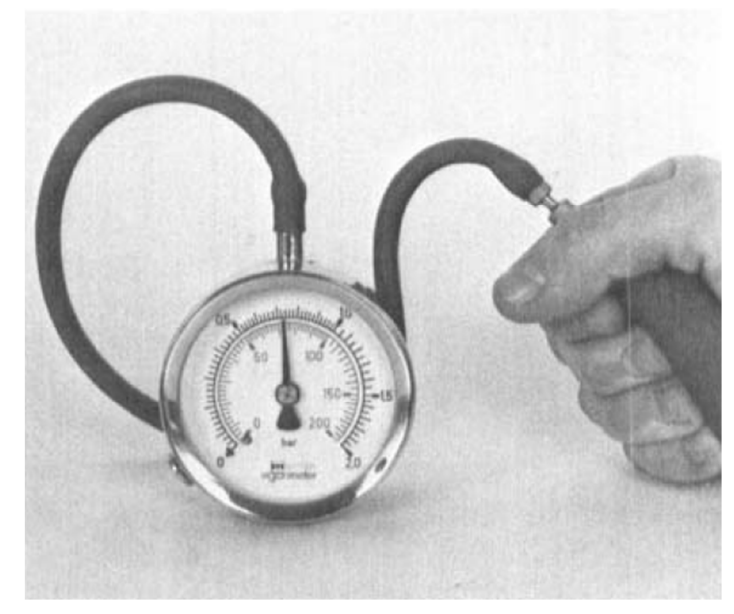

Figura 2.50: Vigorímetro Martin

A principios de los años 80 apareció un instrumento denominado My-Gripper (figura 2.51), pequeño y manejable, cómodo para los pacientes y que se podía utilizar independientemente del tamaño de la mano.

En un estudio realizado en 1984 por Solgaard et al. entre estos tres instrumentos (dinamómetro de muelle de acero, vigorímetro Martin y MyGripper) (Solgaard et al., 1984), se concluyó que el dinamómetro de muelle de acero no era apropiado para uso clínico debido a su falta de precisión, al contrario que el vigorímetro Martin y My-Gripper, que eran instrumentos adecuados en cuanto a su precisión. 


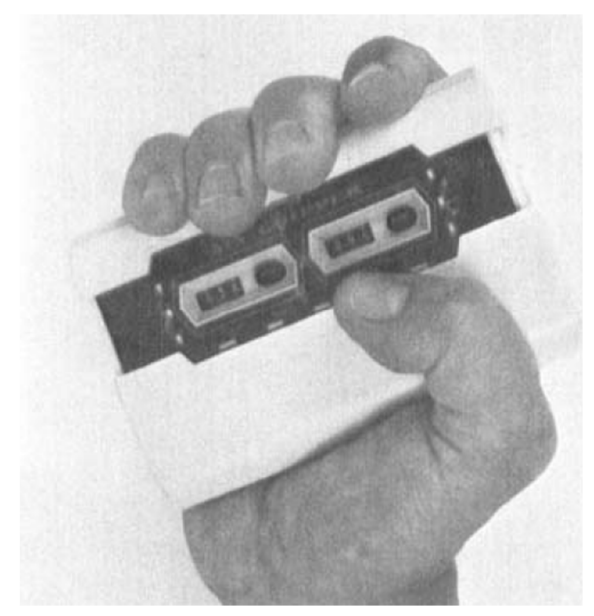

Figura 2.51: My-Gripper

Actualmente, para medir la fuerza máxima que puede ejercer un sujeto, lo habitual es usar un dinamómetro Jamar (figura 2.52), tal como demuestra la gran cantidad de ensayos que se encuentran en la literatura que utilizan este dinamómetro (Bohannon et al., 2006; Massy-Westropp, Rankin, Ahern, Krishnan, \& Hearn, 2004; Torres Coscoyuela, González del Pino, Yáñez Calvo, \& Bartolomé del Valle, 1999). La postura en la que se realiza el test de fuerza también es importante (Balogun, Akomolafe, \& Amusa, 1991), por lo que es necesario estandarizarla en las medidas.

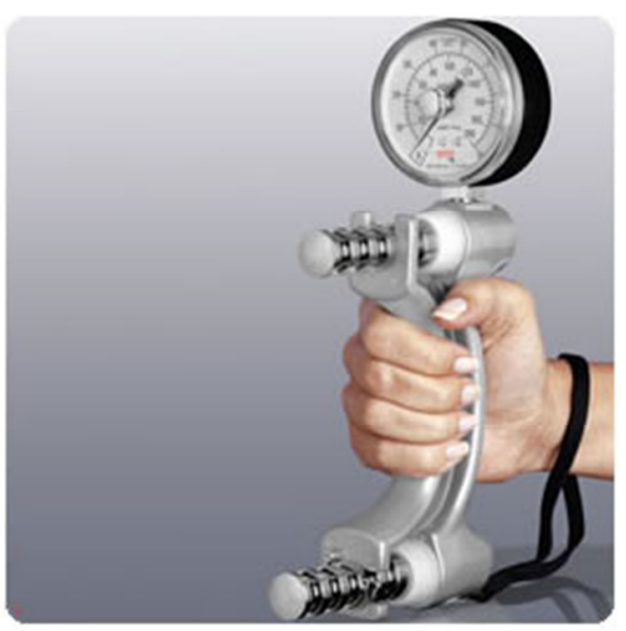

Figura 2.52. Dinamómetro Jamar 
El dinamómetro Jamar se utiliza para la evaluación inicial y permanente de la fuerza de prensión de las personas. A partir de estas pruebas, es posible determinar si un sujeto experimenta una disfunción en la mano, ya que este instrumento mide la fuerza de la mano y el antebrazo cuando los individuos aplican una fuerza isométrica apretando dos asas hidráulicas. Un aneroide o un indicador digital muestra la cantidad de fuerza aplicada.

Cabe destacar que el dinamómetro Jamar es ajustable al tamaño de la mano del individuo para asegurar que dicho individuo pueda ejercer su fuerza de agarre máxima, al poder asirlo cómodamente. El dinamómetro Jamar tiene dos asas de metal de diseño ergonómico apiladas una encima de la otra y separadas por un muelle hidráulico. La distancia que separa las asas se puede establecer en uno de los cinco ajustes, haciendo el dispositivo adecuado independientemente del tamaño de la mano.

Si el indicador de medida es una aneroide, éste generalmente consta de dos agujas: una que mide la fuerza en libras o kilogramos, volviendo automáticamente a cero una vez se cesa de hacer la fuerza; y otra que se queda en posición de retención señalando la fuerza pico ejercida, para facilitar la lectura, y retorna a cero de forma manual. De forma similar, si el indicador es digital, en la pantalla se puede ver la fuerza que se está realizando en ese instante y un registro de la fuerza pico de esa prueba. Los valores típicos del rango de medida son entre los 0 y 90 kilogramos (0 y 200 libras).

La forma de operar correctamente un dinamómetro Jamar es ajustarlo al tamaño de la mano del sujeto. El sujeto ha de ponerse de pie para manipularlo y ha de cogerlo con el brazo de pruebas extendido cómodamente a su lado, aunque también puede flexionarse el codo un ángulo de $90^{\circ}$.

Si lo que se pretende es medir la fuerza realizada durante la manipulación de un objeto, es necesario que tanto la acción como el objeto manipulado sea lo más parecido a la acción y método que se lleva a cabo de forma natural. Para ello, una opción es construir objetos con sensores de la misma forma que el objeto a ensayar, como McGorry que fabricó un objeto con forma de cuchillo (figura 2.53) para medir la fuerza durante el cortado de un filete de carne. (R. W. McGorry, 2001; Raymond W. McGorry, Dowd, \& Dempsey, 2003) 


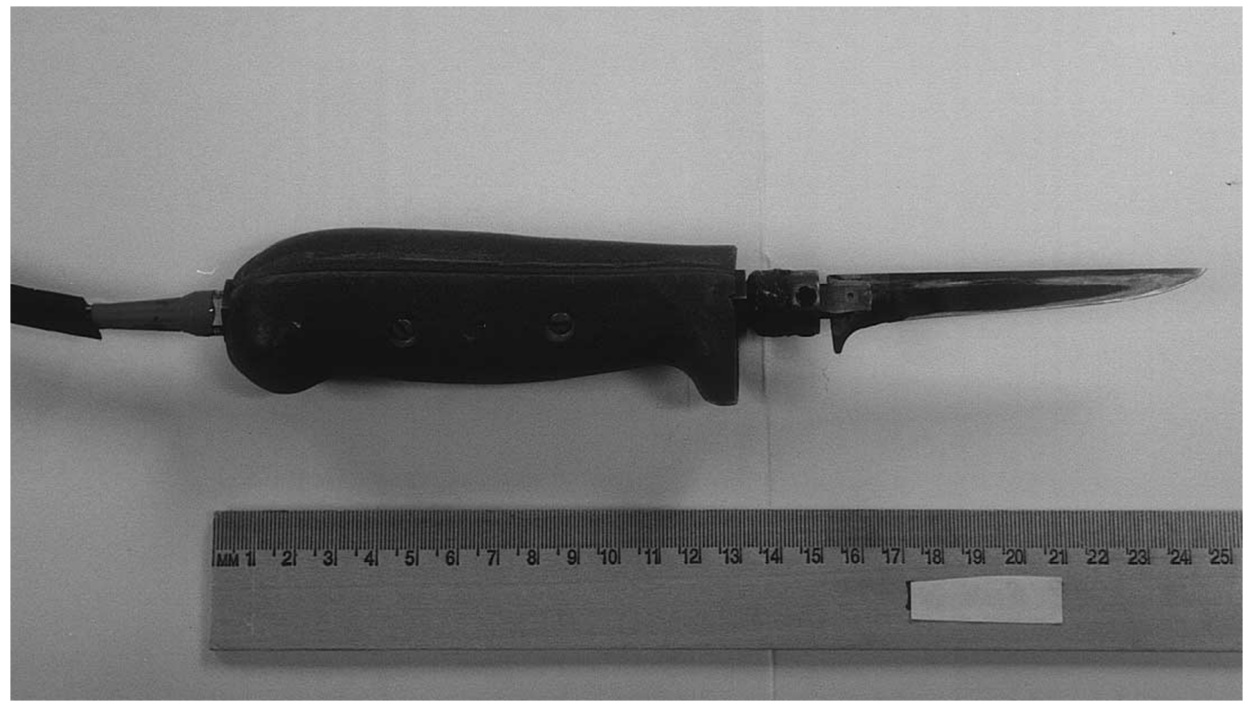

Figura 2.53: Cuchillo para medir la fuerza de corte (R. W. McGorry, 2001)

Este sensor tenía una buena linealidad $\left(r^{2}=0.999\right)$ con poca histéresis. El rango de trabajo era superior a los $700 \mathrm{~N}$ para las fuerzas de agarre y superior a 28 $\mathrm{Nm}$ y $16 \mathrm{Nm}$ para los dos momentos aplicados en los ejes. Además se trataba de un diseño flexible, que permitía modificarlo para medir las fuerzas de agarre efectuadas al manipular otras herramientas.

Wimer et al. (Wimer, Dong, Welcome, Warren, \& McDowell, 2009) desarrollaron un dinamómetro cilíndrico de $40 \mathrm{~mm}$ de diámetro (figura 2.54) cuyos resultados no presentaban una relación fiable con los resultados que se obtendrían utilizando un dinamómetro Jamar, con lo que concluyeron que este último no era apropiado para obtener resultados con el fin de mejorar los mangos cilíndricos de las herramientas.

Se trataba de un cilindro cuyo vástago estaba separado longitudinalmente en seis partes iguales fabricadas en aluminio. La fuerza se medía mediante un par de galgas medidoras de tensión instaladas en las ranuras en la parte cercana a la base del dispositivo en la que se ensamblaban los seis brazos del cilindro, que también era de aluminio. Para registrar y procesar las señales de las galgas se utilizó una tarjera acondicionadora de galgas de tensión (National Instruments SC-2043-SG). Las señales resultantes se introdujeron en otra tarjeta de adquisición de datos (National Instruments PCI-MIO-16XE-10) instalada en un ordenador. 


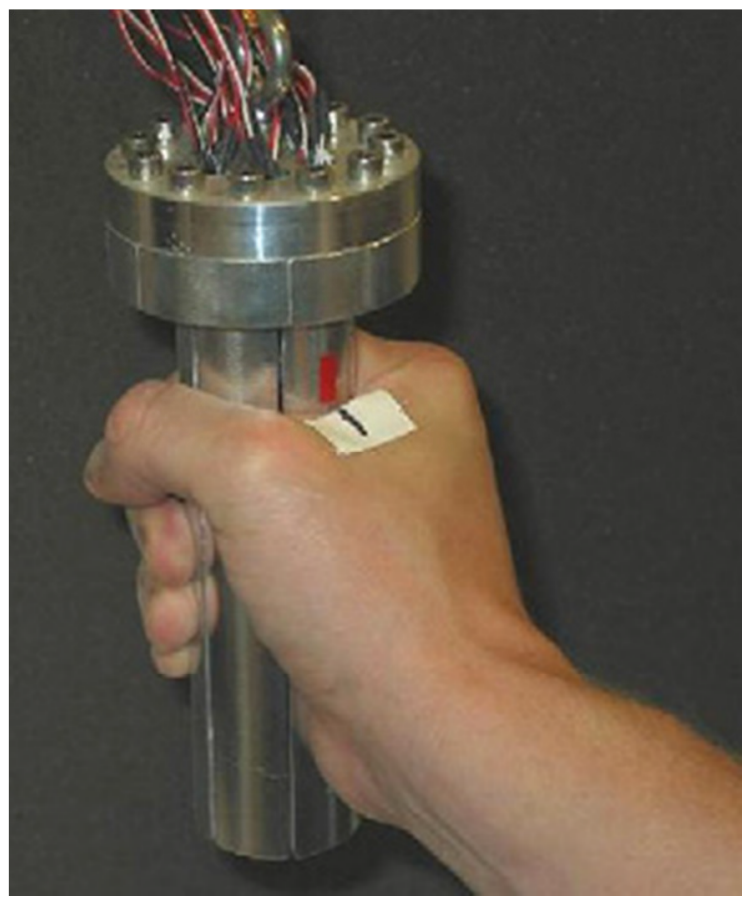

Figura 2.54: Dinamómetro cilíndrico (Wimer et al., 2009)

En 2012, Shin et al. (Shin et al., 2012) desarrollaron un dinamómetro digital (figura 2.55) para medir la fuerza ejercida en el agarre lateral. Consistía en una galga extensométrica que permitía una variación en su resistencia eléctrica muy rápida y un dispositivo de medida de la fuerza ejercida por dos dedos, que utilizaba un método de sensor de potencia que permitía medidas con una precisión de 10 gramos y una frecuencia de muestreo de $1.25 \mathrm{~Hz}$. Compararon los resultados mediante un calibre hidráulico Preston (figura 2.56) y concluyeron que ambos medían fuerzas similares y que por tanto podía utilizarse cualquiera de los dos para realizar esa medición.

La medida de fuerza de agarre mediante dinamómetros está limitada a objetos artificiales que no siempre consiguen que el agarre se realice como se agarraría un objeto real. Fabricar objetos propios que simulen los objetos reales y que capturen la fuerza de agarre y las presiones en su manipulación resulta muy costoso en términos de tiempo y dinero. Una alternativa es intercalar un sensor entre la mano y el objeto a manipular. 


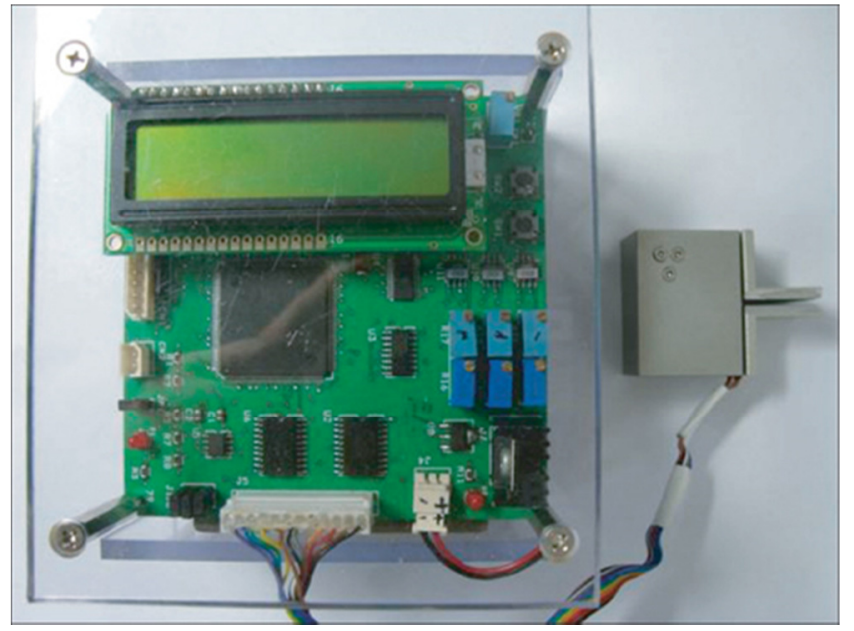

Figura 2.55 : Dinamómetro digital de pinza (Koreamed, 2012)

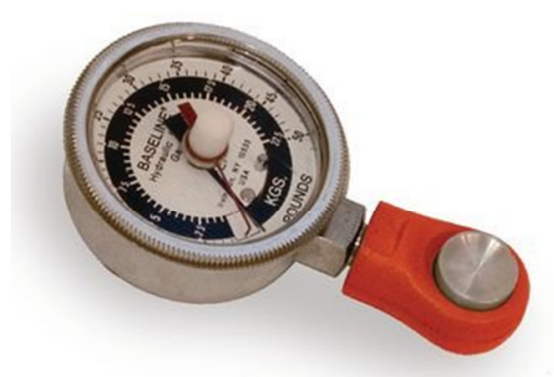

Figura 2.56: Calibre hidráulico Preston(Amazon, 2013)

Los sensores de fuerza finos y flexibles sirven para medir las fuerzas de agarre cuando las células de carga no son apropiadas, ya que pueden adaptarse fácilmente sobre superficies curvas. Además, son ligeros, por lo que pueden acoplarse directamente sobre la mano; sobre un guante que posteriormente vestirá la mano sobre la que se quiera medir la fuerza de agarre; o sobre el mango del objeto o la superficie de agarre. Diversos autores han estudiado las capacidades de varios de estos sensores (Bachus, DeMarco, Judd, Horwitz, \& Brodke, 2006; Buis \& Convery, 1997; Ferguson-Pell, Hagisawa, \& Bain, 2001; Hsiao, Guan, \& Weatherly, 2002; Polliack et al., 2000; D. C. Wilson, Niosi, Zhu, 
Oxland, \& Wilson, 2006; D. R. Wilson, Apreleva, Eichler, \& Harrold, 2003; Woodburn \& Helliwell, 1996)

Respecto a los sensores pensados para recubrir objetos, dos de los más utilizados son el TekScan system (I-Scan, TekScan, Inc., South Boston, MA) y el Fuji Film Prescale Pressure Measuring System (Fuji Photo Film Co. Ltd., Tokyo, Japan).

El sensor Fuji Film (figura 2.57) consiste en una lámina fina con la que se recubre el objeto o mango que se desea estudiar. Ha sido utilizado en varios estudios (Bachus et al., 2006; D. C. Wilson et al., 2006; D. R. Wilson et al., 2003). Comercialmente, existen 8 modelos que permiten varias escalas de sensibilidad. Los del rango menor permiten medir presiones entre 0.05 y 0.2 $\mathrm{MPa}$. Los de mayor rango, permiten la medida de presiones entre 130 y 300 MPa (Fuji, n.d.). Sensores similares a éste son comercializados también por otras empresas como Tekscan, Inc. El modo de utilización es enrollarlo alrededor del objeto del que se quiere medir la presión de contacto en el agarre, por lo que las formas más susceptibles donde puede ser utilizado son los objetos cilíndricos. Permite medir presiones de contacto desde 0.05 hasta $300 \mathrm{MPa}$. Cuando se aplica presión, se queman unas pequeñas microburbujas contenidas dentro del film, de forma que muestran los distintos grados de presión a través de la densidad del color, lo que corresponde al valor de la presión y la distribución de presiones. Estas láminas son fáciles de usar, pero como contrapartida son de un único uso, sólo sirven para presiones estáticas y únicamente muestran el valor más alto aplicado. Además el tratamiento posterior de los resultados requiere el uso de sistemas de tratamiento automático de imágenes. 


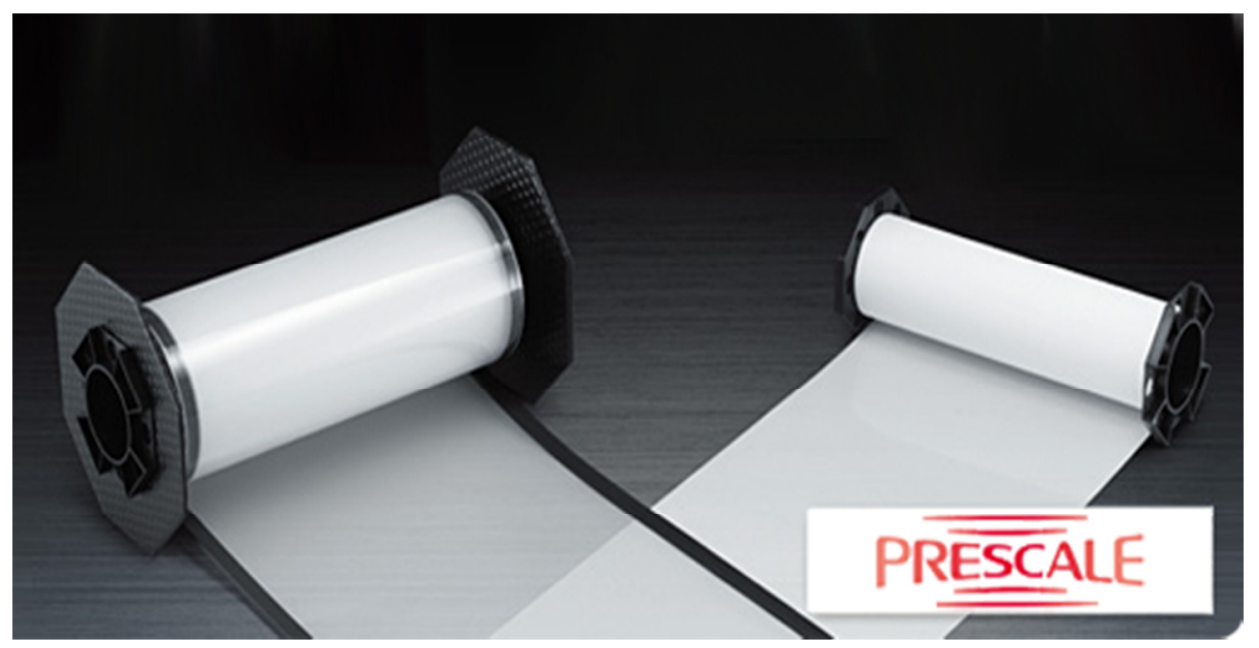

Figura 2.57. Sensor Fuji Film (Fuji, n.d.)

El sensor I-Scan (figura 2.58) consiste en una matriz recubierta de tinta semiconductora que crea una resistencia eléctrica en la intersección de los puntos que permite conocer la presión realizada en las diversas zonas. Ha sido utilizado en varios estudios (Brodke et al., 2001; Davitt, Beals, \& Bachus, 2001; Greis, Scuderi, Mohr, Bachus, \& Burks, 2002; Momberger, Morgan, Bachus, \& West, 2000)

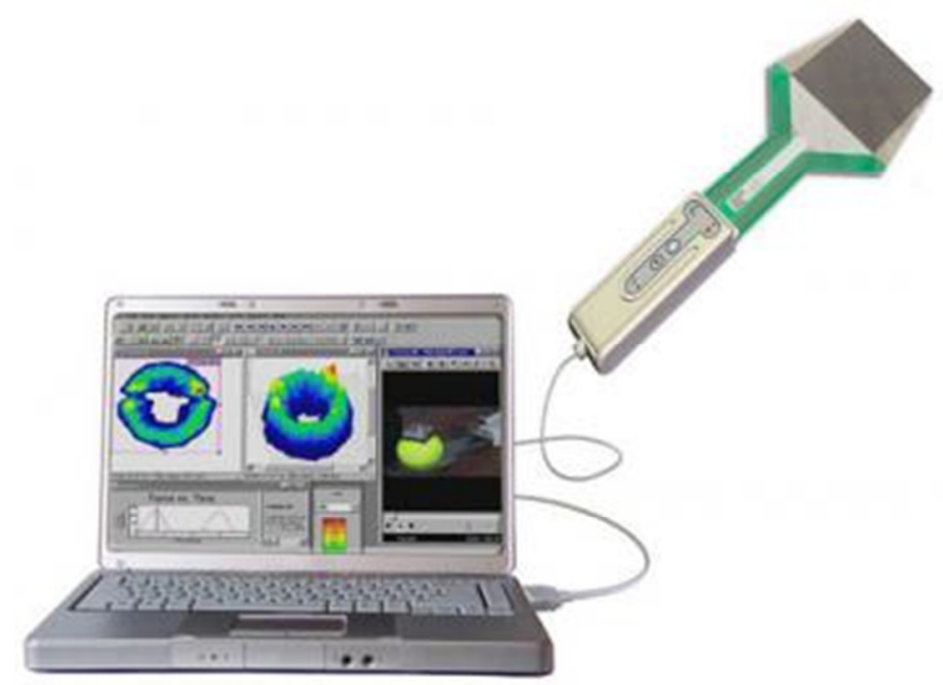

Figura 2.58. Sensor I-Scan (TekScan, n.d.) 
Tal como señalan Drewniak et al. (Drewniak, Crisco, Spenciner, \& Fleming, 2007), existen diversos estudios que demuestran que entre estos dos sensores laminares, el sensor I-Scan es mejor que el Fuji Film, ya que permite la captura de datos continua en tiempo real, es más fino y puede ser reutilizado y esterilizado (Agins, Harder, Lautenschlager, \& Kudrna, 2003; Bachus et al., 2006; DeMarco, Rust, \& Bachus, 2000; Harris, Morberg, Bruce, \& Walsh, 1999; Matsuda, Williams, Whiteside, \& White, 1995; D. R. Wilson et al., 2003).

La alternativa a recubrir el objeto a manipular con el sensor es vestir la mano que va a realizar el agarre con el sensor o con una prenda (generalmente un guante) que tenga adherida el sensor. El principio de funcionamiento de estos sensores puede ser resistivo o capacitivo.

Un ejemplo de sensor capacitivo es el Finger TPS (Pressure profiles Systems, Los Angeles, CA), que es un sistema inalámbrico (con una frecuencia de muestreo de $40 \mathrm{~Hz}$ ) compuesto de ocho sensores de fuerza finos. Dichos sensores consisten en una matriz de sensores de presión capacitivos. La figura 2.59 muestra una mano con el conjunto de sensores colocados, en los que hay cinco sensores en las falanges distales de cada dedo, incluido el pulgar, dos sensores adicionales en las falanges proximales del índice y del dedo medio y un sensor en la palma de la mano. El sistema registra la fuerza total en cada sensor. El error de precisión del sistema es inferior al 5\% y el error de repetibilidad, inferior al $1 \%$, según el fabricante.

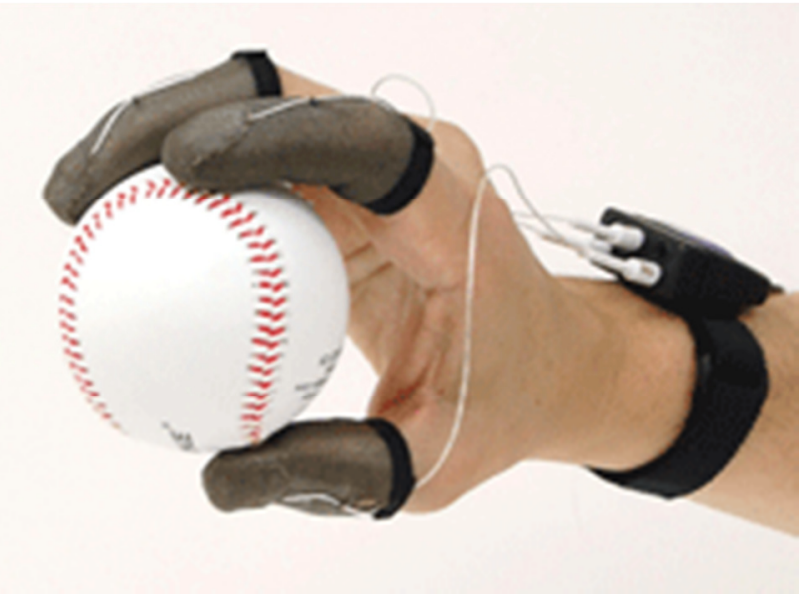

Figura 2.59: Sensor Finger TPS (Pressure profiles Systems, Los Angeles, CA) instrumentado en una mano derecha 
Respecto a los sensores resistivos, un ejemplo es el Grip 4256E, de Tekscan Inc. (figura 2.60), que tiene 18 zonas sensibles con un total de 349 sensores resistivos individuales, con una densidad de 6.2 sensores $/ \mathrm{cm}^{2}$. El sistema mide la presión en cada uno de dichos sensores. El fabricante recomienda coserlo a un guante para facilitar la colocación del sensor. Este sensor no tiene una frecuencia de muestreo predeterminada, ya que se puede modificar mediante el software adjunto.

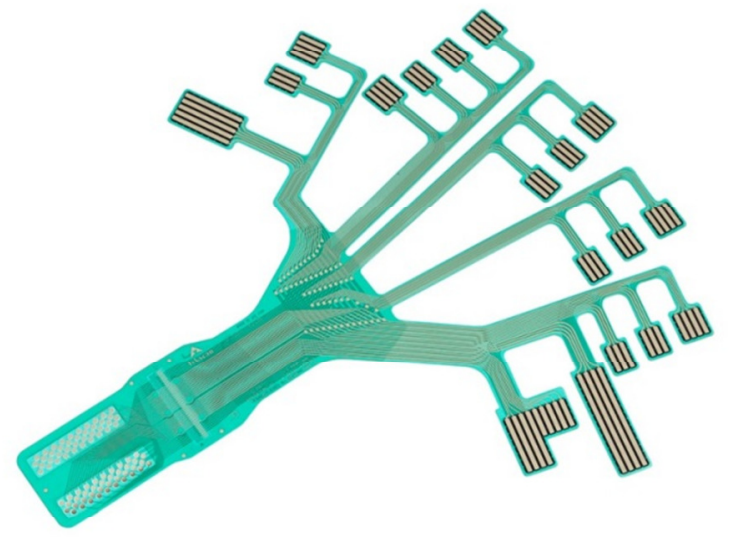

Figura 2.60. Sensor Grip 4256E, de Tekscan Inc.

En los experimentos realizados en la presente tesis se han utilizado el sensor Finger TPS y el Grip 4256E. Estos dos últimos sensores se detallarán en el apartado 3.2, donde se incluirán más características de los mismos. 


\section{8.- Conclusiones}

En este capítulo se han expuesto los estudios previos realizados para abordar los objetivos de esta tesis. Cabe destacar las siguientes conclusiones:

- La anatomía de la mano es muy compleja, ya que consta de 27 huesos conectados por articulaciones de distinto tipo, configurando un sistema mecánico con más de 20 grados de libertad, que es accionado por alrededor de 40 músculos. Las variaciones anatómicas entre sujetos pueden implicar diferentes tamaños musculares e incluso variación en el número de músculos, así como variabilidad en las orientaciones de las articulaciones y en el tamaño de los huesos, sin que ello implique una mala funcionalidad de la mano. Esta variabilidad permite hipotetizar que cabe esperar repartos de la fuerza de agarre entre las diferentes zonas de la mano cambiantes entre sujetos para una misma tarea u objeto manipulado.

- El proceso de agarre durante el levantamiento y reposición de un objeto sobre una superficie puede caracterizarse mediante la definición de una serie de fases típicas: precarga, carga, transición, estática, reposición y descarga.

- Los estudios neurofisiológicos del proceso de agarre indican que los sujetos predicen la fuerza necesaria que van a necesitar para sujetar un objeto en función de las características aparentes del mismo, de manera que objetos con apariencia de ser más pesados hacen que el sujeto tienda a realizar fuerzas de agarre mayores.

- La repetibilidad de los ensayos de agarre puede verse afectada por cambios en la calidad de la retroalimentación sensorial visual y táctil, así como por el entrenamiento del sujeto en una misma tarea, por lo que este aspecto deberá considerarse en el diseño de los experimentos en esta tesis. El uso de guantes delgados puede afectar a la fuerza máxima de agarre que un sujeto puede realizar, aunque hay estudios que indican poco efecto en las fuerzas de agarre en la manipulación por debajo de las capacidades musculares máximas del sujeto.

- Pese a que existen prótesis de mano muy avanzadas, actualmente no hay ninguna que permita realizar las mismas funciones que la mano 
humana sana. De forma similar, ningún robot manipulador ni elemento terminal de extremidad superior de robot humanoide puede ejecutar las mismas acciones que la mano humana. La principal limitación radica en el control de un número tan elevado de grados de libertad y en la reducida información sensorial. La mejora del control de estos manipuladores pasa por un mejor conocimiento de la dinámica del proceso de agarre, para reducir el número de acciones de control dependientes del sistema nervioso central del sujeto, incrementado la parte de control automático embebida en el dispositivo.

- El diseño ergonómico de mangos en herramientas y en máquinas pasa por un mejor conocimiento de la distribuciones de presiones en el agarre. Una gran cantidad de enfermedades profesionales asociadas a estas operaciones se debe a un mal diseño de los mangos o a un mal agarre de las herramientas.

- A pesar de que las posturas de agarre alcanzables por la mano humana son virtualmente infinitas, se han realizado numerosos intentos de clasificar dichas posturas en un grupo de patrones o tipos de agarre característicos. Estas taxonomías facilitan la comparación de agarres aparentemente similares realizados con diferentes objetos o en diferentes tareas al tiempo que ayudan a utilizar un lenguaje común en la comunicación de la investigación del proceso de agarre. En esta tesis se empleará una clasificación con 11 tipos de agarre principales: cilíndrico, oblicuo, lumbrical, intermedio de precisión-potencia, pinza, pinza lateral, pinza especial, no prensil, lateral y esférico. 
3.- Objetivos y plan de trabajo 



\section{1.- Objetivos}

El objetivo principal que se pretende alcanzar con el desarrollo de la presente tesis es contribuir a una mejor caracterización de la dinámica del agarre de objetos por la mano humana. Para ello se plantea una metodología centrada en la experimentación sobre sujetos instrumentados con sensores específicos de medida de fuerza o presión de contacto. Respecto a los trabajos previos en este campo, la principal aportación que se plantea es el diseño de experimentos en condiciones de agarre lo más similares posible a las actividades habituales de la vida diaria y con medida de fuerza de contacto en la mayor superficie posible de la mano. Se pretende conseguir información sobre fuerzas totales de agarre y contribución de cada zona de la mano a dichas fuerzas de agarre, así como valores de presiones de contacto empleadas. Los resultados que se obtengan permitirán contribuir a la mejora del diseño de prótesis de mano humana, de manipuladores robóticos y al diseño ergonómico de objetos y mangos.

Para conseguir este objetivo general se plantean los siguientes objetivos parciales:

- Analizar los trabajos previos existentes relacionados con el agarre humano, para conocer las implicaciones de interés de la investigación en diferentes campos (diseño de prótesis de mano, agarre con robots manipuladores antropomorfos, ergonomía de productos y herramientas) y enfocar la investigación hacia cubrir posibles limitaciones o lagunas de los trabajos previos, así como para poder revisar los resultados de esta tesis en comparación con otros trabajos previos similares.

- Poner a punto metodologías y técnicas de medida experimental adecuadas para investigaciones futuras en este campo, así como comparar diferentes sensores comerciales disponibles en el grupo de investigación para medida de fuerzas de contacto entre mano y objeto manipulado.

- Analizar la fuerza de agarre y distribución de presiones en la mano durante el agarre de objetos de diferentes formas y pesos habituales de las actividades de la vida diaria. Estudiar el efecto de las 
características del objeto y la tarea en la fuerza realizada y la contribución de las diferentes partes de la mano. 


\section{2.- Metodología}

\subsection{1.- Instrumentos de medida utilizados}

Para conseguir cumplir los objetivos de la presente tesis, se han realizado tres ensayos para caracterizar la dinámica del agarre. En estos ensayos se han utilizado dos sensores diferentes, el Grip 4256E y el Finger TPS.

\section{Grip 4256E}

El Grip 4256E, de Tekscan Inc. (figura 3.1) es un sensor permite obtener información en cada instante de la presión, superficie de contacto y fuerza ejercida durante el agarre, lo que permite obtener con un tratamiento adecuado de los datos medidos, valores tales como la presión media y máxima y la fuerza de agarre de cada zona de la mano.
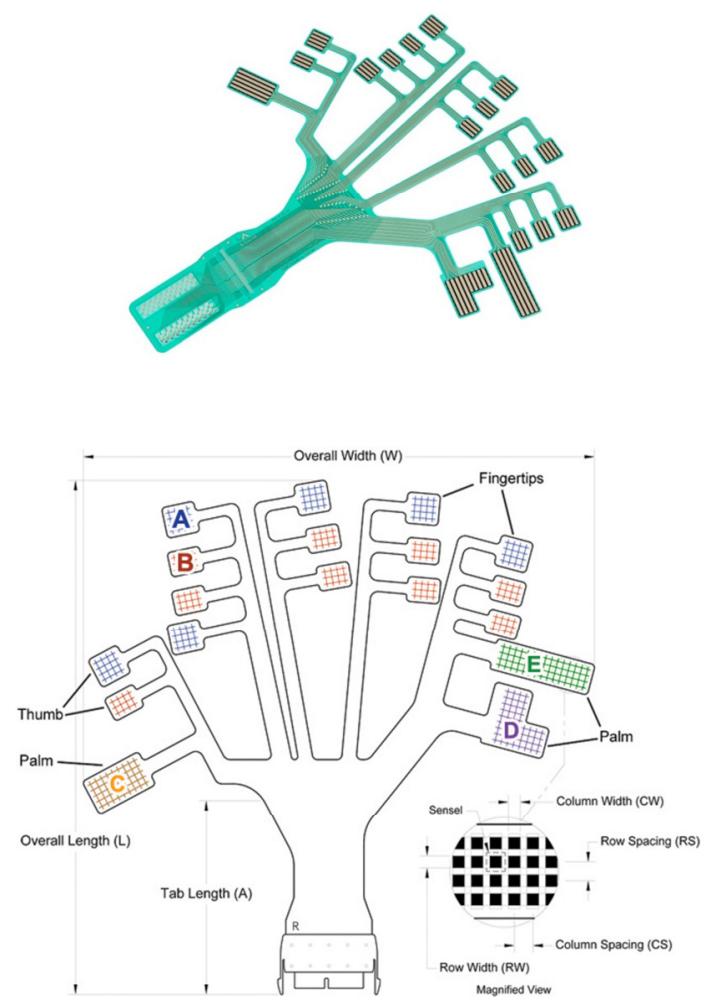

Figura 3.1. Sensor Grip 4256E 
Consta de 18 zonas sensibles con un total de 349 elementos sensores individuales cuadrados, con una densidad aproximada de unos 6.2 elementos sensores por $\mathrm{cm}^{2}$, abarcando las principales zonas de contacto de la mano con los objetos durante el agarre. El principio de funcionamiento del sensor es resistivo y su espesor aproximado es $0.1 \mathrm{~mm}$. La frecuencia máxima de adquisición es de $750 \mathrm{~Hz}$ y la presión máxima de medida es de 517 kPa, pudiendo seleccionarse la sensibilidad del sensor a través del software de adquisición, para niveles de presión máxima de 517, 345, 172 y 86 kPa.

Se puede colocar directamente sobre la mano, aunque el fabricante recomienda coserlo a un guante para facilitar la colocación del sensor. En los ensayos de esta tesis, se cosió en un guante de algodón que posteriormente vestía el sujeto que realizaba el ensayo (figura 3.2). Una vez puesto el guante sobre la mano del sujeto, se recubría el mismo con otro guante transparente delgado de polietileno de baja densidad para proteger el sensor y, encima de este, se colocaba otro guante de látex para fijar la posición del sensor, evitar el contacto directo con el objeto a manipular y asegurar un coeficiente de rozamiento más constante en el contacto mano-objeto.

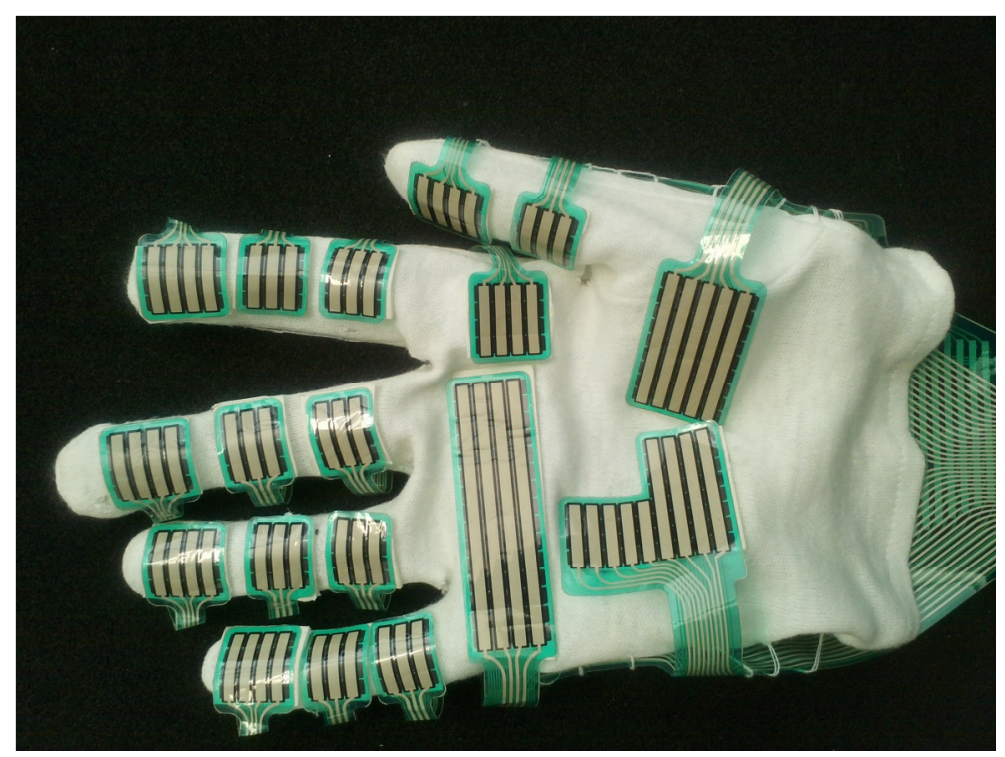

Figura 3.2. Sensor Grip 4256E cosido a un guante de algodón.

Una vez colocado el sensor en el sujeto, el sensor se conecta a un hub que se fija al brazo y que transfiere la información al ordenador a través de un puerto 
USB (figura 3.3). La frecuencia de muestreo se puede modificar hasta $750 \mathrm{~Hz}$. Su validez, precisión y facilidad de uso y calibración había sido comprobada en trabajos previos, (Pataky et al., 2012; Pérez-González et al., 2011).

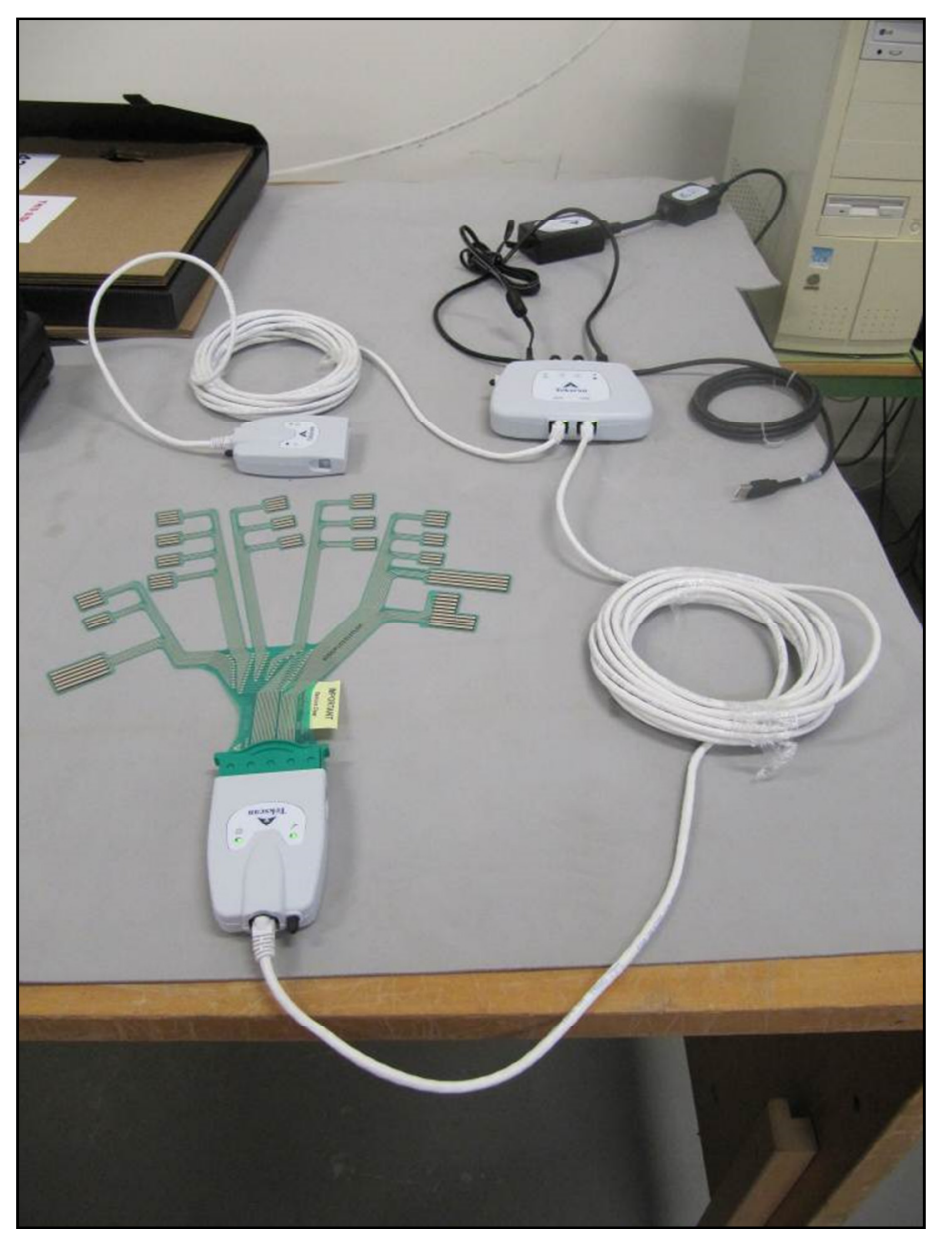

Figura 3.3. Conexión del sensor Grip $4256 E$

Cuando el sensor se utiliza en la mano, consta de 17 zonas sensibles diferenciadas en lugar de 18 , ya que dos de ellas, situadas en la palma, se consideran conjuntamente para abarcar una mayor zona de la palma. Esto no va en detrimento de la precisión del sensor, ya que la localización concreta de cada sensor donde se produce el contacto sigue indicándose. Estas 17 zonas sensibles se muestran en la figura 3.4. A estas zonas nos hemos referido en los ensayos como $\mathrm{Si}$, siendo $\mathrm{i}=1,2, \ldots, 17$. 


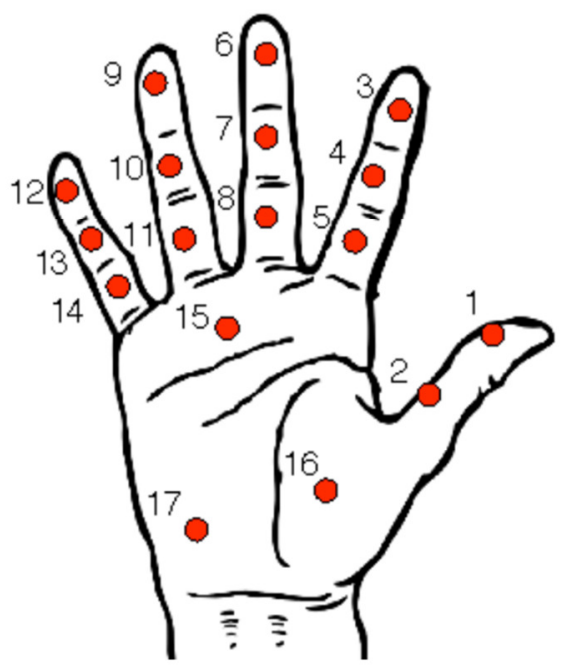

Figura 3.4. Zonas sensibles al estar instrumentada la mano con el Grip $4256 E$

Para utilizar este sensor de forma apropiada, es necesario calibrarlo y tararlo antes de los ensayos. La calibración se realizó con un dinamómetro, realizando una fuerza conocida sobre las distintas zonas del sensor, ya montado sobre el guante pero sin estar colocado en la mano. La información de dicha calibración se guarda en un archivo que es posible cargar antes del inicio del ensayo.

Otra operación necesaria es el taraje. Esto consiste en poner las presiones registradas a cero antes de iniciar la tarea, con el fin de asegurar que al inicio de cada tarea el sensor no marcase ninguna presión producida por alguna arruga del guante.

\section{Finger TPS}

El Finger TPS, de Pressure Profiles Systems, Los Angeles, CA, (figura 3.5) permite registrar la fuerza de contacto ejercida en cada instante durante un agarre en cada zona concreta de la mano vestida con el sensor.

El principio de funcionamiento del sensor es capacitivo y su espesor final es de unos 2 a $3 \mathrm{~mm}$. La frecuencia máxima de adquisición es de $40 \mathrm{~Hz}$. Los sensores se conectan a un hub que se fija sobre el brazo y que transfiere la información al ordenador vía inalámbrica o bien mediante un cable USB. 


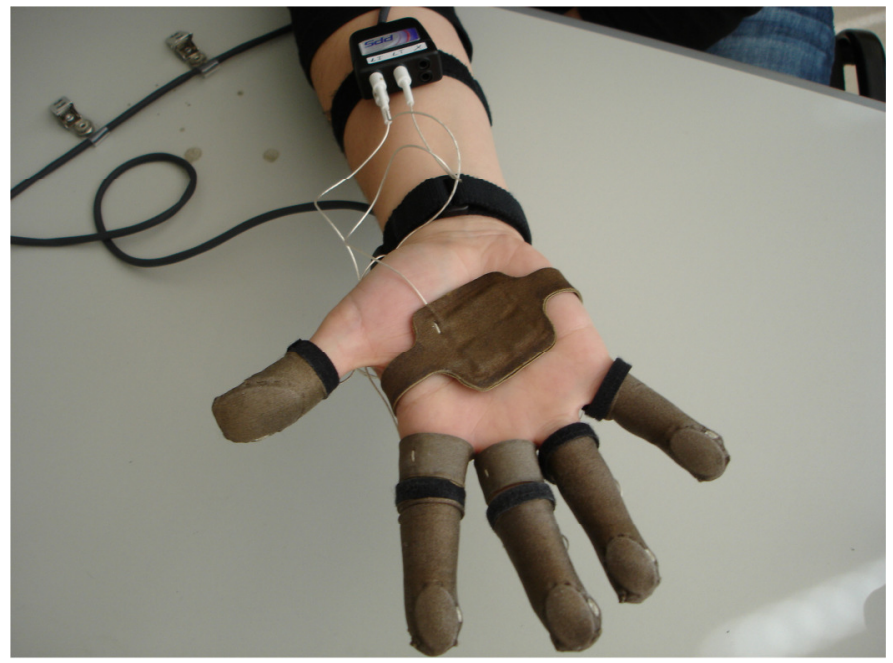

Figura 3.5.: Sensor Finger TPS (Pressure profiles Systems, Los Angeles, CA) instrumentado en una mano derecha

El sistema utilizado en esta tesis consta de 8 sensores que se colocan directamente sobre la mano, tal como puede verse en la figura 3.5. De los 8 sensores, 5 se colocan en las falanges distales de cada dedo, incluido el pulgar (denominados en nuestros ensayos como Index, Middle, Ring, Little y Thumb); 2 sensores adicionales se sitúan en las falanges proximales de los dedos índice y medio (Index2 y Middle2); y un último sensor ubicado en la palma de la mano (Palm). Con el fin de proteger el sensor durante el ensayo y uniformizar el coeficiente de rozamiento con el objeto, se usó un guante de látex sobre la mano una vez colocados los sensores.

Al inicio de cada experimento se colocaban los sensores sobre la mano del sujeto y se realizaba la calibración del dispositivo utilizando el procedimiento recomendado por el fabricante, que consistía en presionar una célula de carga proporcionada conjuntamente al sistema hasta alcanzar una fuerza de referencia de $12 \mathrm{~N}$. Según el fabricante, el error de precisión del sistema es inferior al $5 \%$ y el error de repetibilidad, inferior al $1 \%$.

Ambos sistemas de medida, Finger TPS y Grip 4256E fueron comparados en un trabajo previo del grupo de investigación, confirmando la validez de ambos para la medida en ensayos de agarre. La figura 3.6 muestra una comparativa 
de las fuerzas de agarre medidas con ambos sensores en un mismo experimento de transporte de un bote cilíndrico.

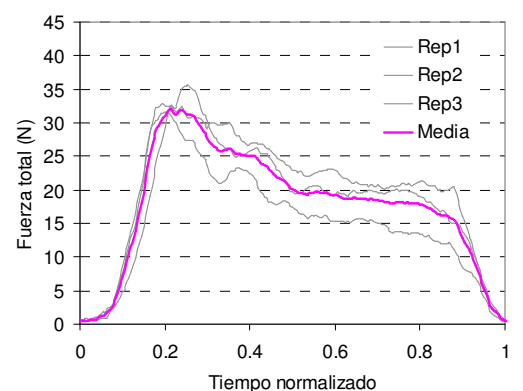

(a)

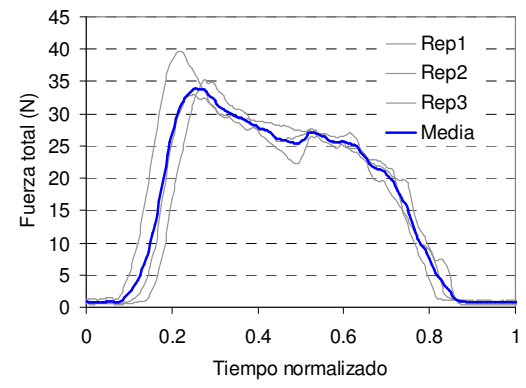

(b)

Figura 3.6. Fuerza en el experimento de levantar un bote cilíndrico con sistema Grip (a) $y$ Finger TPS (b)

\subsection{2.- Análisis estadísticos utilizados}

\subsubsection{1.-Análisis de varianza (ANOVA)}

Es un método estadístico de análisis de datos que permite contrastar la hipótesis nula de que las medias de $K$ poblaciones $(K>2)$ son iguales, frente a la hipótesis alternativa de que por lo menos una de las poblaciones difiere de las demás en cuanto a su valor esperado. Este contraste es fundamental en el análisis de resultados experimentales, en los que interesa comparar los resultados de $\mathrm{F}$ factores con respecto a la variable dependiente o de interés. El tamaño de las poblaciones es $\mathrm{n}$.

Un ANOVA necesita el cumplimiento de tres supuestos:

- Las $\mathrm{K}$ poblaciones tienen una distribución de probabilidad de la variable dependiente correspondiente a cada factor de tipo normal.

- Los $\mathrm{F}$ factores sobre las que se aplican los tratamientos son independientes.

- Las poblaciones tienen todas la misma varianza.

El ANOVA se basa en la descomposición de la varianza total de los datos con respecto a la media global, que bajo el supuesto de que la hipótesis nula es 
cierta es una estimación de la varianza obtenida a partir de toda la información muestral, en dos partes:

- Variación dentro de las muestras o intragrupos (SCD): cuantifica la dispersión de los valores de cada muestra con respecto a sus medias correspondientes.

- Variación entre muestras o intergrupos (SCE): cuantifica la dispersión de las medias de las muestras respecto a la media global.

Cuando la hipótesis nula es cierta los cocientes SCE/(K-1) y SCD/(n-K) son dos estimadores insesgados de la varianza poblacional y el cociente entre ambos se distribuye según una $\mathrm{F}$ de Snedecor con K-1 grados de libertad en el numerador y $\mathrm{n}-\mathrm{K}$ grados de libertad en el denominador. Por tanto, si la hipótesis nula es cierta, es de esperar que el cociente entre ambas estimaciones sea aproximadamente 1 , de forma que se rechazará si difiere significativamente de 1. La cantidad de la que difiere de uno para decidir si los resultados son estadísticamente diferentes dependen del intervalo de confianza (C) que se seleccione, siendo este generalmente del $95 \%$. El valor $p$ que se obtiene para cada factor tras realizar un ANOVA es igual a 1-C, siendo $C$ el intervalo de confianza en el que no se cumple la hipótesis nula. Por tanto, para un intervalo de confianza usual del $95 \%$, la hipótesis nula no se cumplirá si $p<0.05$, lo que significará que dentro de las poblaciones hay al menos una estadísticamente distinta a las demás.

Los valores obtenidos con los distintos ANOVAS realizados en esta tesis se presentarán de dos maneras: bien con una tabla en la que se mostrarán todos los valores obtenidos del ANOVA (Factor, Suma de cuadrados, Grados de libertad, Cuadrado medio, $\mathrm{F}$ de Snedecor y valor de $\mathrm{p}$ ); o bien mostrando únicamente el valor de $\mathrm{p}$ cuando se realice el ANOVA sobre múltiples zonas de la mano, con el objetivo de simplificar los resultados.

Una variación del ANOVA es el MANOVA (análisis de la varianza multivariable). En este caso, en lugar de haber una única variable dependiente, hay varias. El MANOVA se ha utilizado cuando se ha tomado la contribución a la fuerza de agarre de las distintas zonas de la mano como variable dependiente.

Todos los ANOVAS y MANOVAS de esta tesis se han realizado empleando Matlab. Para ello se ha empleado la función 'anovan' y 'manova1', 
respectivamente, usando en ambos casos el nivel de significación o confianza por defecto de alpha $=0.05$.

\subsubsection{2. - Análisis post-hoc de Tukey.}

Tal como se ha visto en el apartado anterior, mediante un ANOVA se determina que existen diferencias entre las medias pero no se puede conocer el valor de las medias de los factores que difieren entre sí. Para conseguirlo es necesario realizar un procedimiento adicional llamado prueba de medias.

Existe una gran cantidad de prueba de medias, siendo algunas de ellas las debidas a Tukey, Duncan-Newman, Dunnett, etc. En los ensayos realizados para redactar esta tesis, se ha utilizado el método de Tukey para complementar el ANOVA ya que presenta los resultados más conservadores (García-Villapando, Castillo-Morales, Ramírez Guzmán, Rendón-Sánchez, \& Larqué-Saavedra, 2001). Un análisis realizado por Einot y Gabriel de los procedimientos de comparación múltiple más utilizados también concluyó que el método de Tukey era el más recomendable debido a su simplicidad y por disponer intervalos de confianza (Einot \& Gabriel, 1975).

El método de Tukey permite identificar subconjuntos homogéneos de medias que son estadísticamente iguales entre sí. Esta prueba se efectúa con experimentos que implican un elevado número de comparaciones, y ha de realizarse conjuntamente con el ANOVA.

Para realizar la prueba de Tukey, en primer lugar se ha de calcular el comparador de Tukey $(w)$ a partir de la fórmula siguiente:

$$
w=q x \sqrt{\frac{R M S E}{r}}
$$

Donde q es un valor que se obtiene de la tabla de Tukey: horizontalmente se colocan los gdl de los tratamientos y verticalmente los gdl del error. Existen tablas únicamente para niveles de significancia del $5 \%$ y del $1 \%$. RMSE es el error cuadrático medio obtenido a partir del ANOVA. $r$ es el número de repeticiones. Si la diferencia entre dos promedios es mayor que el comparador se concluye que los dos promedios no son iguales, considerándose iguales en caso contrario. Se utiliza el mismo comparador para todos los pares de promedios que se comparan. 
En los distintos ensayos realizados se mostrará el análisis de Tukey mediante una gráfica, estando centrada en el valor medio del factor estudiado y mostrando los valores del intervalo para cada factor. Si existe intersección en los intervalos de dos pares de factores, implica que sus valores medios no son estadísticamente diferentes.

Los análisis de Tukey de esta tesis se han realizado en Matlab, empleando la función 'multcompare' con la estructura de salida 'stats' obtenida del análisis ANOVA con 'anovan'.

\subsubsection{3. - Análisis de los componentes principales (PCA).}

Cuando se recoge información sobre una muestra de datos, lo más frecuente es tomar el mayor número posible de variables. Esto hace que el número de posibles coeficientes de correlación sea elevado, lo que dificulta visualizar la relación entre las variables. Por tanto, se hace necesario reducir el número de variables.

Es importante resaltar que el concepto de mayor información se relaciona con el de mayor variabilidad o varianza: cuanto mayor sea la variabilidad de los datos, se considera que existe mayor información.

El análisis de componentes principales (principal components analysis, PCA) es una técnica estadística de síntesis de la información o reducción de la dimensión (del número de variables). Ante un conjunto de datos con muchas variables, el PCA tiene como objetivo transformar el conjunto original de variables en otro conjunto de nuevas variables incorreladas entre sí (es decir, que no tengan repetición ni redundancia en la información) llamado conjunto de componentes principales.

Las nuevas variables son combinaciones lineales de las anteriores y se van construyendo según el orden de importancia en cuanto a la variabilidad total que recogen de la muestra. El objetivo es conseguir un número de nuevas variables inferior al número de variables originales que recojan la mayor parte de información o variabilidad de datos. Estas nuevas variables son los componentes principales (principal components, PC).

Para el cálculo de los PC, se considera una serie de variables $\left(\mathrm{x}_{1}, \mathrm{x}_{2}, \ldots, \mathrm{x}_{\mathrm{p}}\right)$ sobre un grupo de objetos o individuos y se trata de calcular, a partir de ellas, un 
nuevo conjunto de variables $y_{1}, y_{2}, \ldots, y_{p}$, incorreladas entre sí, cuyas varianzas vayan decreciendo progresivamente. Cada $y_{j}$ (donde $j=1,2, \ldots, p$ ) es una combinación lineal de las $x_{1}, x_{2}, \ldots, x_{p}$ originales, es decir, $y_{j}=a_{j 1} x_{1}+a_{j 2} x_{2}+\ldots+$ $a_{j p} x_{p}=a_{j}{ }^{\prime} \mathbf{x}$, siendo $a_{j}{ }^{\prime}$ el vector de coeficientes para la nueva variable $y_{j}$.

Como lo que se desea es maximizar la varianza, la forma más sencilla de calcular los coeficientes es considerar los coeficientes $a_{i j}$ mayores que mantengan la ortogonalidad de la transformación, lo que implica que el módulo del vector $\mathbf{a}_{\mathrm{j}}$ ' sea unitario. Así, el primer componente se calcula eligiendo $a_{1}$ de modo que $y_{1}$ tenga la mayor varianza posible, sujeta a la restricción de que $\mathbf{a}_{1} \mathbf{a}_{1}=1$. El segundo componente principal se calcula obteniendo $\mathrm{a}_{2}$ de modo que la variable obtenida, $\mathrm{y}_{2}$, esté incorrelada con $\mathrm{y}_{1} ; \mathrm{y}$ así sucesivamente para el resto de variables, calculándolas de manera que estén incorreladas con las anteriores. El método usual para obtener los coeficientes es el de los multiplicadores de Lagrange.

Los coeficientes pueden tomar valores entre -1 y 1 , por lo que un valor cercano a 0 implica que la variable original no tiene correlación con el PC; un valor positivo significa que la variable original tiene correlación positiva con el PC, es decir, que su presencia está relacionada con el PC; si los coeficientes tienen valor negativo tiene correlación negativa, es decir, indican que su ausencia o disminución de valor explica ese nuevo PC.

El análisis de los resultado de un PCA debe efectuarse para cada caso concreto en función de los valores obtenidos por los coeficientes. Dentro de un PC, los coeficientes elevados en valor absoluto indican qué variables originales son determinantes para él, por lo que pueden agruparse como una única entidad o nuevo PC. Así, la interpretación de los factores del PCA ha de ser deducida tras observar la relación de los factores con las variables iniciales.

Los análisis de componentes principales de esta tesis se han realizado en Matlab, empleando la función 'princomp'.

\subsubsection{4. - Matriz de correlación.}

Es una matriz cuadrada y simétrica constituida por los coeficientes de correlación entre las variables, de manera que el elemento $r_{i j}$ de la matriz corresponde al coeficiente de correlación entre las variables $i$ y $j$. Todos los 
términos de la diagonal de la matriz serán 1 , ya que el coeficiente de correlación de una variable consigo misma es 1.

El coeficiente de correlación es una medida de la variación lineal entre dos variables aleatorias cuantitativas, es decir, es un índice que puede utilizarse para medir el grado de relación de dos variables. Para calcular el coeficiente de correlación se emplea la fórmula siguiente:

$$
\rho_{X, Y}=\frac{\sigma_{X Y}}{\sigma_{X} \sigma_{Y}}
$$

siendo $\rho_{X, Y}$ el coeficiente de correlación; $\sigma_{X Y}$ la covarianza de $X, Y ; \sigma_{X}$ la desviación típica de la variable $X ; y \quad \sigma_{Y}$ la desviación típica de la variable $Y$.

\subsection{3.- Tratamientos de datos realizados en los ensayos}

\subsubsection{1.- Filtrado de datos}

Esta técnica permite reducir el rizado de los datos adquiridos mediante los distintos sensores en los diferentes ensayos. Dicho rizado está ocasionado por la frecuencia de muestreo y las perturbaciones durante el agarre de los objetos. Dado que se quieren eliminar las perturbaciones y éstas se producen a una elevada frecuencia, el filtro que se ha de emplear es paso-bajo.

Para todos los ensayos de esta tesis se ha utilizado un filtro paso-bajo de 0-20 $\mathrm{Hz}$ de desfase temporal nulo, apropiado para reducir el rizado sin perder información en los datos de entrada y sin desfasar la señal en el tiempo.

Para implementarlo se ha utilizado la función de Matlab filtfilt, que tiene la forma $y=$ filftfilt $(B, A, x)$, donde $\mathbf{x}$ es el vector de entrada; $y$ el vector de salida; $y$ A y B son los coeficientes del filtro digital. La figura 3.7 muestra un ejemplo de la señal sin filtrar y la señal filtrada.

\subsubsection{2. - Eliminación de valores atípicos}

En el ensayo descrito en el capítulo 6 de esta tesis se han eliminado valores considerados atípicos. Para decidir qué valores se encontraban anormalmente alejados y que podían deberse a un error en la medida, se ha utilizado el rango intercuartil. Este método consiste en eliminar los valores atípicos leves, es decir, aquellos que son menores que $Q_{1}-1.5 \cdot I Q R$ o mayores que $Q_{3}+$ 
1.5.IQR., siendo $Q_{1}$ y $Q_{3}$ el primer y tercer cuartil, respectivamente, e IQR, el valor intercuartil.

El valor de los cuartiles $Q_{1}$ y $Q_{3}$ se realizó utilizando el método 1 . Según este método, para obtener el primer cuartil se utiliza la mediana para dividir los valores ordenados en dos mitades. $Q_{1}$ es la mediana de la primera mitad de los valores y $Q_{3}$, la mediana de la segunda mitad de los valores.

Para implementar la rutina que elimina los valores atípicos se ha utilizado la función de Matlab iqr, que tiene la forma $Y=\operatorname{iqr}(X)$, siendo $X$ el intervalo de valores e $Y$ el valor IQR de ese intervalo. Los valores $Q_{1}$ y $Q_{3}$ se han obtenido con la función prctile, que tiene la forma $Y=\operatorname{prctile}(X, P)$, siendo $X$ el intervalo de valores, $P$ el valor de porcentaje e $Y$ el valor que se encuentra en el percentil $P$ del intervalo $X . Q_{1}$ se ha obtenido asignando a $P$ el valor 25 y $Q_{3}$, asignándole el valor 75 .

\subsubsection{3. - Normalización del tiempo}

Cuando se comparan resultados de un mismo ensayo para distintos sujetos, se observa que el tiempo empleado por todos ellos no es exactamente el mismo, sino que varía ligeramente. Para facilitar el promediado de resultados entre sujetos ha sido necesario normalizar la escala de tiempos para poder sincronizar las tareas y poder comparar los resultados entre varios sujetos o entre repeticiones del mismo sujeto. Esto permite visualizar los resultados y obtener conclusiones de forma más clara.

Para ello se ha definido el tiempo normalizado como una escala de tiempo obtenida a partir de la medición de tiempo de la tarea en la que el instante inicial de la tarea es 0 y el final, 1 para todos los casos. Es una magnitud adimensional.

\subsubsection{4.- Normalización de la fuerza}

De forma similar a la normalización del tiempo, ha sido necesario normalizar la fuerza para poder comparar los resultados obtenidos entre distintos sujetos o entre repeticiones del mismo sujeto.

La fuerza normalizada es una medida de fuerza en la que 0 implica ausencia de fuerza y 1 es la fuerza máxima realizada por el sujeto durante el ensayo. La fuerza se normaliza para poder observar las tendencias en la misma tarea para 
Análisis de la distribución de presiones en la mano humana durante el agarre

distintas repeticiones del mismo sujeto o para sujetos diferentes, independientemente de que uno realice una fuerza superior a otro. Así, se puede comprobar si se realizan aumentos o descensos de fuerza en el mismo momento, si en el mismo instante se dan las fuerzas máximas, etc. Es una magnitud adimensional. 


\section{3.- Terminología empleada en los ensayos}

Hay ciertos términos que se repiten en los tres ensayos realizados en la presente tesis, por lo que en este apartado se explicarán con el fin de evitar una repetición innecesaria de términos en todos los capítulos. Aun así, cierta terminología específica de cada ensayo está expuesta en los capítulos correspondientes a dichos ensayos.

La terminología común empleada en todos los ensayos es la siguiente:

- Agarre: En la presente tesis se utiliza este término para referirse a la configuración de la mano durante la manipulación de un objeto, que implica una postura y unas fuerzas de contacto entre la mano y el objeto, aunque en ocasiones no se coja el objeto, como en el caso de los agarres no prensiles o cuando se realizan acciones tales como teclear un número de teléfono.

- Ensayo: Experimentación que se realiza con el fin de obtener conclusiones sobre algún aspecto del agarre.

- Experimento: Parte de un ensayo que se analiza por separado para considerar particularidades del mismo.

- Tarea: Cada una de las distintas operaciones que se realizan con un objeto que se está manipulando dentro de un ensayo.

- Factor: Cada uno de los parámetros independientes que se modifican durante un mismo ensayo con el fin de determinar su efecto sobre el agarre.

- Repetición: Se refiere a cada una de las ejecuciones de una misma tarea con unos mismos factores por parte de un sujeto.

- Etapa: Cada una de las partes en las que se divide la tarea de la vida diaria que se va a realizar.

- Escenario: Lugar donde se realiza la tarea incluyendo la definición de las posiciones relativas entre el sujeto y el objeto manipulado.

- Fase de precarga: Es el intervalo de tiempo durante el agarre en el que los dedos se están colocando para iniciar el agarre.

- Fase de carga: Es el intervalo de tiempo durante el agarre en el que se produce un aumento paralelo en la fuerza de agarre normal a la 
superficie del objeto y la fuerza de carga tangencial a la superficie hasta que la fuerza de carga supera a la gravedad.

- Fase de transición: Es el intervalo de tiempo durante el agarre de un objeto en el que se mueve de un lugar a otro.

- Fase de descarga: Es el intervalo de tiempo durante el agarre que se da cuando se suelta el objeto.

- Tiempo normalizado: Es una escala de tiempo obtenida a partir de la medición de tiempo de la tarea en la que el instante inicial de la tarea es 0 y el final, 1 para todos los casos. Es una magnitud adimensional.

- Fuerza normalizada: Es una medida de fuerza en la que 0 implica ausencia de fuerza y 1 es la fuerza máxima realizada por el sujeto durante el ensayo. Es una magnitud adimensional.

- Sincronización: Para poder comparar los resultados entre distintos sujetos, es necesario armonizar los resultados, de manera que cada instante de la gráfica para cada sujeto corresponda al mismo instante de ejecución de la tarea.

- Fuerza registrada de cada sensor $\left(\mathrm{SF}_{\mathrm{i}}\right)$ : $\mathrm{Es}$ la fuerza registrada por cada sensor en cada instante cuando se manipula un objeto. Es una fuerza normal a la superficie y se mide en $\mathrm{N}$.

- Fuerza de agarre (grip force, GF): Es la suma escalar de todas las $\mathrm{SF}_{\mathrm{i}}$ definiéndose para cada instante. Por tanto, se trata de una fuerza normal a la superficie. Se mide en $\mathrm{N}$.

$$
G F=\sum_{i} S F_{i}
$$

- Valor medio de la fuerza de cada sensor (mean sensor force, $\mathrm{MSF}_{\mathrm{i}}$ ): Es la fuerza media registrada por el sensor $\mathbf{i}$ durante el agarre del objeto en un intervalo de tiempo determinado. Se mide en $\mathrm{N}$.

$$
M S F_{i}=\frac{\int_{t 1}^{t 1+\Delta t} S F_{i} \cdot d t}{\Delta t}
$$

- Fuerza de agarre media (mean grip force, MGF): Es la suma de todos los $\mathrm{MSF}_{\text {. }}$. Se mide en $\mathrm{N}$.

$$
M G F=\sum_{i} M S F_{i}
$$

- Contribución de cada sensor a la fuerza de agarre (contribution to grip force, $\mathrm{CGF}_{\mathrm{i}}$ ): Es la razón entre la fuerza registrada en cada sensor $\left(\mathrm{SF}_{\mathrm{i}}\right)$ y la fuerza de agarre (GF). Es un parámetro adimensional, que se puede 
expresar como porcentaje (\%). Puede definirse para un instante determinado:

o como promedio en un intervalo:

$$
C G F_{i}(t)=\frac{S F_{i}}{G F}
$$

$$
C G F_{i}=\frac{\int_{t 1}^{t 1+\Delta t} C G F_{i}(t) \cdot d t}{\Delta t}
$$

- Agarre libre: Agarre realizado por el sujeto sin que haya recibido ninguna indicación sobre la forma en la que ha de realizarlo. 


\section{4.- Plan de trabajo}

Se han realizado varias tareas para alcanzar los objetivos fijados de la presente tesis. En un primer lugar, tal como viene reflejado en el capítulo 2 de antecedentes, se ha realizado una búsqueda exhaustiva de la literatura, con el fin de examinar el trabajo previo existente en cuanto a los estudios de diseño de prótesis de mano, de robots manipuladores, neurofisiología y ergonomía. También se ha estudiado la anatomía de la mano humana y las distintas clasificaciones de los tipos de agarre, así como los dispositivos y métodos utilizados para medir las magnitudes en el agarre de objetos.

A partir de este estudio previo, se definieron tres ensayos para aumentar la profundidad en el conocimiento de ciertos aspectos del agarre que no se encontraban totalmente desarrollados en la literatura. Los ensayos se diseñaron de manera que en el primero se usaron de objetos de laboratorio y tareas muy guiadas para llegar al último en el que se utilizan objetos cotidianos y se realizan actividades de la vida diaria. El segundo ensayo es un paso intermedio entre ambos.

En un primer ensayo, se comprobó de qué manera afectaba el peso y el diámetro de un objeto a algunas características del agarre, tales como la fuerza de agarre y la contribución de cada zona de la mano a la misma. Para ello se utilizaron cilindros de laboratorio de distintos pesos y diámetros, que se manipularon mediante agarres de distintos tipos (tres agarres de precisión de tipo pinza con 2, 3 y 5 dedos; un agarre cilíndrico de potencia; y un agarre libre que sirvió como patrón para comparar los resultados de los otros agarres prescritos). Por tanto, además de poder comprobar de qué manera afecta el diámetro y el peso del objeto, también se sacaron conclusiones sobre las variaciones producidas en función del tipo de agarre.

En el segundo ensayo se quiso comprobar el efecto sobre la fuerza de agarre que tenía el cambiar la tarea realizada sobre el objeto a manipular. Además, se consideró conveniente no utilizar un objeto abstracto como un cilindro de laboratorio, sino un objeto de uso cotidiano. De esta manera, para este segundo ensayo se realizaron dos tareas diferentes, utilizando para ello cuatro tipos de botellas. Las tareas que se realizaron con éstas fue la de transportarlas de un punto de la mesa a otro y la de vaciar el contenido de la botella en un 
recipiente. Las botellas eran de distintas formas y materiales, y además se realizaron los ensayos con dos niveles distintos de llenado, con lo que aparte de la tarea, se pudo estudiar otros factores como el peso y material de la botella.

En el tercer y último ensayo se realizaron diversas actividades de la vida diaria para comprobar algunas características del agarre de los objetos ejecutores mientras se realizaba la tarea. Mediante este ensayo se obtuvieron valores característicos en la manipulación de objetos cotidianos que permiten mejorar el diseño de una prótesis de mano o del elemento terminal de un brazo robótico cuya funcionalidad esté basada en realizar este tipo de tareas.

Por último, se obtuvieron las conclusiones y se expusieron las líneas de investigación futuras que surgían como resultado de estos ensayos. 
4.- Efecto del diámetro y peso en
el agarre de objetos cilíndricos 



\section{1.- Introducción}

En muchas actividades de la vida diaria se utiliza el agarre cilíndrico, ya que una gran cantidad de objetos y mangos tienen una forma cilíndrica o cuasicilíndrica. Algunos ejemplos de estos objetos los encontramos en herramientas tales como martillos, limas o serruchos; objetos cotidianos como vasos, botellas o volantes; y mangos de útiles como sartenes, ollas, etc. En función de los requerimientos de fuerza y precisión el agarre empleado será de potencia, en el que no solo los dedos sino también la palma contactará con el objeto manipulado; o de precisión, en el que el contacto se producirá únicamente en las falanges.

Un conocimiento profundo de los agarres efectuados sobre este tipo de objetos permite optimizar el tamaño de los mangos para maximizar la fuerza de agarre, así como mejorar el diseño de las prótesis de mano y de los robots manipuladores en un agarre tan habitual.

Numerosos autores han realizado estudios acerca del agarre cilíndrico, aunque muchos de dichos estudios presentan algunas limitaciones que se analizan a continuación. Una gran parte de los trabajos previos analizan únicamente la fase de agarre estático sobre un objeto en lugar de considerar una tarea representativa de las actividades cotidianas, como por ejemplo el transporte de un punto a otro. Por otra parte, en muchos estudios previos el sujeto debía realizar agarres prescritos en el experimento, por lo que los resultados no permiten analizar la forma en que el sujeto realizaría dicho agarre de forma libre. Finalmente, la información de fuerzas de contacto entre el objeto y la mano suele ser limitada, bien por tratarse de objetos sensorizados que únicamente registran un valor global de fuerza de agarre o bien porque se utilizan sensores puntuales con información limitada sobre la distribución espacial de la fuerza de agarre. Por tanto, sería interesante que se evaluara la contribución a la fuerza de agarre realizada por las distintas zonas de la mano, en función del tamaño y peso del objeto agarrado y para distintos tipos de agarre, tanto agarres prescritos, como elegidos libremente por el sujeto.

Algunos de los trabajos que han analizado la fuerza de contacto en el agarre de objetos cilíndricos se han realizado sobre un único objeto y forzando un tipo de agarre previamente seleccionado (Bourbonnais, Frak, Pilon, \& Goyette, 2008; 
Kargov et al., 2004; Pataky et al., 2012). Kargov et al. (Kargov et al., 2004) obtuvieron datos sobre distribución de esfuerzos en varios puntos de la mano para un agarre de potencia sobre una única botella, empleando pequeños sensores discretos de fuerza colocados en diferentes puntos de la mano. Sin embargo, estos sensores no cubrían la totalidad de la mano, por lo que este método tenía el inconveniente de que gran parte de la fuerza no era registrada.

En 2004, Edgren et al. (Edgren, Radwin, \& Irwin, 2004) utilizaron 5 cilindros de distinto diámetro (entre 1 y 3 pulgadas) para determinar cómo afectaba a la fuerza máxima que podía ejercer un sujeto en el agarre. Sin embargo, en este estudio se utilizó únicamente un tipo de agarre, el cilíndrico de potencia, en el que no sólo los dedos sino también la palma tienen contacto con el cilindro. Kong et al. (Y. K. Kong \& Lowe, 2005), en 2005, realizaron también un estudio del diámetro óptimo para la realización de la máxima fuerza de agarre con un objeto cilíndrico en función del diámetro. Para ello utilizaron cilindros de aluminio de distinto diámetro y concluyeron que el diámetro óptimo de una herramienta era del $19,7 \%$ de la longitud de la mano. En este estudio no se tuvieron en cuenta factores como los distintos tipos de agarre ni el peso del objeto manipulado, sino que el experimento únicamente se centró en la fuerza máxima de agarre realizable.

El grupo de Zatsiorsky ha analizado en numerosos trabajos (Aoki et al., 2006; Budgeon, Latash, \& Zatsiorsky, 2008; Savescu, Latash, \& Zatsiorsky, 2008; Vladimir M Zatsiorsky \& Latash, 2008) la distribución de fuerzas en agarres tipo pinza prismáticos, aunque los objetos considerados eran montajes de laboratorio con sensores de fuerza, específicamente diseñados para medir la fuerza en la falange distal de cada dedo, y no objetos cotidianos.

Domalain et al., en 2008 (Domalain, Vigouroux, Danion, Sevrez, \& Berton, 2008a) analizaron el efecto del diámetro y del peso en objetos cilíndricos, utilizando discos de distintos diámetros y pesos. El agarre de los discos se efectuó con dos dedos (índice y pulgar), por lo que, aun cuando el objeto era cilíndrico, el agarre era de tipo pinza. El grupo de Seo (Na Jin Seo \& Armstrong, 2008) determinó la relación entre la fuerza de agarre y la fuerza normal en un cilindro. Para ello utilizó mangos de varios diámetros (entre 38 y $83 \mathrm{~mm}$ ) sobre los que los sujetos realizaron la fuerza de agarre máxima. 
Análisis de la distribución de presiones en la mano humana durante el agarre

Como consecuencia de los estudios previos, se ha podido establecer dos comportamientos típicos en el agarre multidedo (Kuo et al., 2013; Martin, Latash, \& Zatsiorsky, 2009; McDonnell, Ridding, Flavel, \& Miles, 2005; V M Zatsiorsky, Li, \& Latash, 2000). Por un lado, se determinó que durante el agarre se produce sinergia entre los dedos, de modo que la acción voluntaria que produce un dedo para aumentar la fuerza de agarre produce una acción involuntaria o esclava en el resto de dedos (efecto conocido como enslaving). El segundo es el efecto de compensación del error, según el cual la reducción o anulación de fuerza de agarre en un dedo tiene como consecuencia un incremento de fuerza de agarre en los otros dedos para mantener la estabilidad en el agarre (efecto conocido como error compensation).

En este capítulo se expone el ensayo realizado para analizar la fuerza total de agarre empleada para mover un objeto cilíndrico utilizando distintos tipos de agarre con el objetivo de analizar experimentalmente cómo afecta el tipo de agarre, y el peso y diámetro del objeto manipulado, a la fuerza total de agarre y a las presiones de contacto en las distintas zonas de la mano. También se pretende analizar si en el agarre libre de objetos cilíndricos para su transporte, determinados tamaños o pesos de los mismos determinan una transición en la forma de agarre empleada, tanto por el número de dedos implicados en el agarre, como por las zonas de los mismos que intervienen.

Para ello, se utilizaron un total de 7 cilindros de distintos diámetros y pesos, que se trasladaron sobre una mesa. Para su manipulación se realizaron varios tipos de agarre: tres de tipo pinza, con dos dedos (pulgar e índice); tres dedos (pulgar, índice y medio); y cinco dedos sin utilizar la palma; un agarre de tipo cilíndrico de potencia, con los cinco dedos y la palma en contacto con el cilindro; y un agarre libre, es decir, sin dar ninguna indicación al sujeto de cómo lo ha de efectuar. 


\section{2.- Materiales y métodos}

En el experimento participaron 6 sujetos diestros, 3 hombres y 3 mujeres entre 22 y 45 años, con longitud de mano media 176.4 mm (desviación típica 10.9 $\mathrm{mm}$ ), sin patologías previas en el miembro superior, después de leer y firmar un consentimiento escrito. El protocolo del experimento cumplía con la Declaración de Helsinki y fue aprobado por el comité ético de la universidad.

La tarea que realizaron los sujetos fue transportar siete cilindros rígidos (figura 4.1), de distintos pesos y diámetros, entre dos puntos de una mesa. El peso y diámetro de cada cilindro se muestra en la tabla 4.a. Como se puede ver, se emplearon cuatro cilindros con el mismo peso (469 g) y distinto diámetro y cuatro con el mismo diámetro $(50 \mathrm{~mm})$ y distinto peso. El cilindro $c 3$ pertenece a los dos grupos, con un peso de $469 \mathrm{~g}$ y un diámetro de $50 \mathrm{~mm}$. El orden de los ensayos se aleatorizó para cada sujeto.

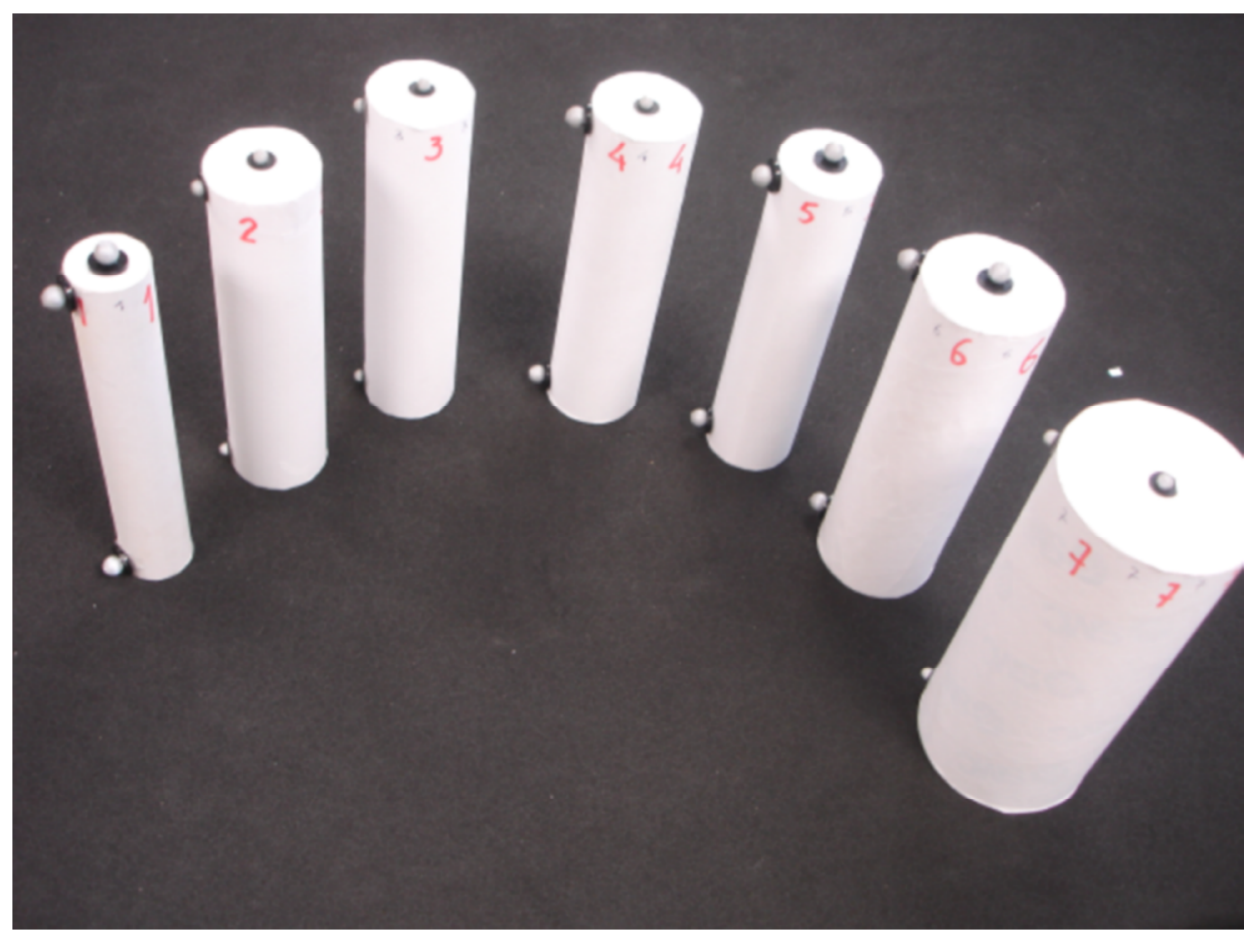

Figura 4.1. Cilindros empleados en el ensayo 
Análisis de la distribución de presiones en la mano humana durante el agarre

Tabla 4.a. Características de los cilindros empleados en el ensayo: diámetro (d), peso (W), altura (h).

\begin{tabular}{|c|c|c|c|c|c|c|c|}
\hline Cilindro & $\mathrm{c1}$ & $\mathrm{c} 2$ & $\mathrm{c3}$ & $\mathrm{c4}$ & $\mathrm{c5}$ & $\mathrm{c6}$ & $\mathrm{c7}$ \\
\hline $\mathrm{d}(\mathrm{mm})$ & 35 & 50 & 50 & 50 & 50 & 65 & 90 \\
\hline $\mathrm{W}(\mathrm{g})$ & 469 & 193 & 469 & 780 & 1117 & 469 & 469 \\
\hline $\mathrm{h}(\mathrm{mm})$ & 210 & 210 & 210 & 210 & 210 & 210 & 210 \\
\hline
\end{tabular}

Para realizar el ensayo, el sujeto se sentaba en una silla de altura regulable, frente a una mesa en la que se encontraba el cilindro a trasladar, de tal modo que la altura de la mesa coincidiera con el nivel del codo. Cuando el operador daba la orden de inicio, el sujeto, usando su mano derecha, agarraba el cilindro apoyado sobre la mesa con su eje vertical, lo levantaba y lo trasladaba hasta una nueva posición sobre la mesa separada $150 \mathrm{~mm}$ en dirección anterior, dejándolo nuevamente apoyado sobre su eje vertical (figura 4.2).

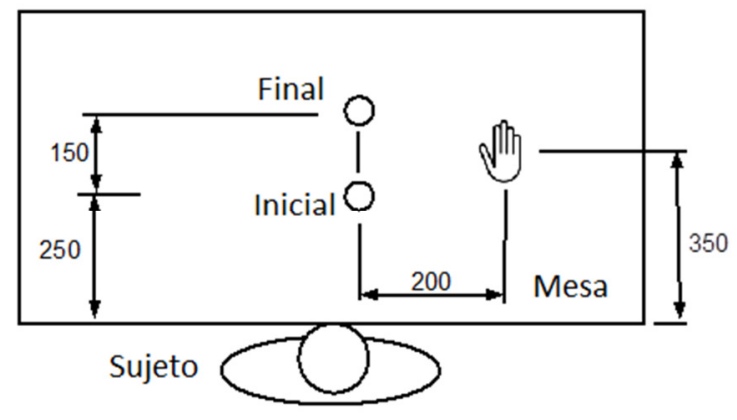

Figura 4.2. Imagen vista superior de la mesa y las posiciones (cotas en $\mathrm{mm}$ ).

No se dio ninguna indicación especial al sujeto sobre el levantamiento del cilindro respecto a la mesa durante el traslado, ni sobre la fuerza que debía hacer sobre él, indicándose únicamente el tipo de agarre en cada caso. Se repitió el ensayo con cada cilindro para cinco agarres diferentes. Inicialmente se hacía un agarre libre seleccionado por el sujeto, referenciado como "lib", en el que no se daba ninguna restricción en el agarre, y posteriormente con agarres prescritos en los que debía utilizar 2 dedos, 3 dedos, 5 dedos y un agarre cilíndrico de potencia, en el que se pedía que la palma también contactara con el objeto, referenciados como "2D", "3D", "5D" y "cil", respectivamente. 
Para el agarre 2D, se indicó al sujeto que debía utilizar únicamente el dedo pulgar y el índice; para el agarre 3D, debía utilizar el pulgar, índice y medio; para el 5D, debía utilizar todos los dedos pero no debía contactar la palma de la mano con el cilindro manipulado; por último, para el agarre cil, se le pidió que sujetara el cilindro como el mango de un martillo, intentando que contactara tanto los dedos como la palma de la mano con la superficie del objeto. Para cada combinación de cilindro y tipo de agarre se realizaron 3 repeticiones consecutivas, precedidas de otras 3 repeticiones de familiarización no registradas.

Para registrar los datos, la mano del sujeto se instrumentó con el sensor Grip 4256 E de Tekscan Inc. descrito en el capítulo 3 utilizando una frecuencia de muestreo de $50 \mathrm{~Hz}$. Para facilitar la colocación el sensor se montó cosido sobre un guante de algodón siguiendo las recomendaciones del fabricante (figura 4.3).

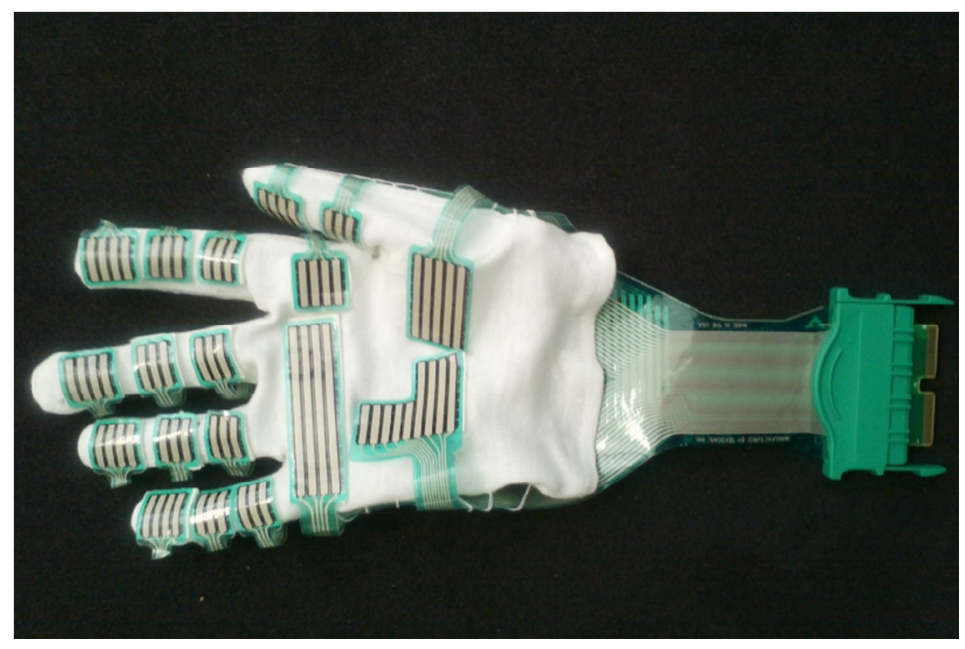

Figura 4.3. Sensor GRIP 4256E (TEKSCAN) montado sobre un guante de algodón.

Una vez puesto el guante sobre la mano del sujeto, se recubría el mismo con otro guante fino de polietileno de baja densidad para proteger el sensor y finalmente uno de látex para fijar la posición del sensor, evitar el contacto directo con el objeto a manipular y asegurar un coeficiente de rozamiento más constante en el contacto mano-objeto (figura 4.4). Las dos zonas sensibles situadas en el seno palmar distal se consideraron como una sola zona para los análisis, definiéndose por tanto 17 zonas o regiones de contacto (figura 4.5). 
Aunque los sujetos perdían sensibilidad en los dedos al vestir dos guantes, estudios previos indican que no se debería ver estadísticamente afectada la fuerza de agarre realizada (Rock et al., 2001).

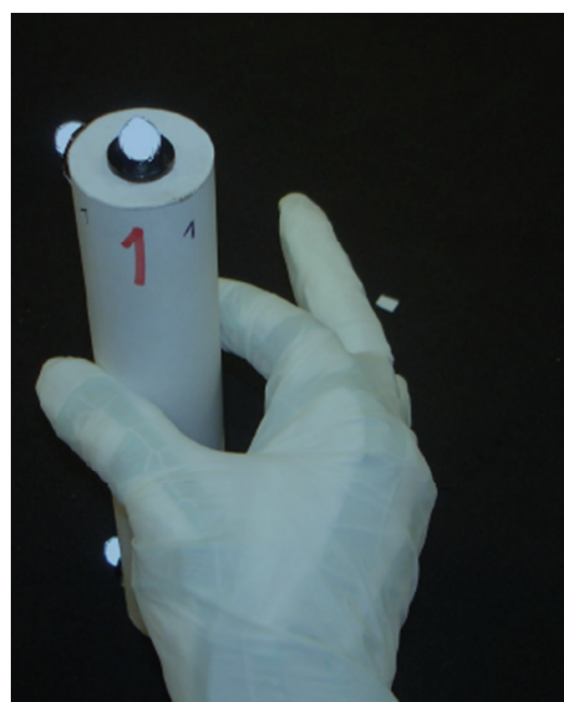

Figura 4.4: Montaje del sensor en la mano durante el agarre 2D sobre el cilindro c1.

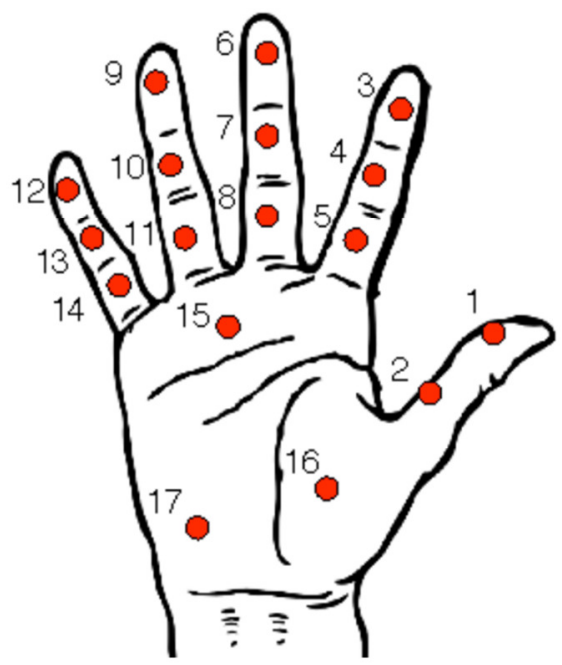

Figura 4.5: Zonas definidas en la mano a partir de las medidas del sensor 
Para un mejor análisis de los resultados, se realizó un procesado de los datos experimentales. En primer lugar, los datos se filtraron utilizando un filtro pasobajo $(0-20 \mathrm{~Hz})$ de primer orden de desfase temporal nulo, para reducir el rizado de las medidas experimentales. Posteriormente, los datos correspondientes a las tres repeticiones de un mismo ensayo se sincronizaron, teniendo en cuenta los momentos de inicio y fin del agarre. Para ello se utilizó como referencia de sincronización los instantes de máxima derivada positiva (fase de carga) y de máxima derivada negativa (fase de descarga) en la fuerza de agarre total (GF). El tiempo se normalizó de 0 a 1, fijándose los instantes de máxima derivada de fuerza de las fases de carga y descarga en 0.3 y 0.7 , respectivamente.

La fase de transición se definió entre los instantes de tiempo normalizado 0.4 y 0.6 , siendo este el intervalo utilizado para el cálculo del valor medio de la fuerza de cada sensor $i\left(M_{S F}\right)$.

Los datos de la fuerza de agarre media durante la fase de transición (MGF) de los diferentes experimentos se analizaron utilizando un ANOVA, con el fin de determinar el efecto de sujeto, cilindro y tipo de agarre empleado, en el valor de MGF. Los factores independientes del ANOVA fueron, por tanto, el sujeto que realizaba la tarea (Sujeto, "Suj"), el cilindro (Cilindro, "Cil") y el tipo de agarre (Tipo de agarre, "TipA") siendo MGF la variable dependiente del ANOVA. Para analizar de una forma más precisa cómo afecta la variación del diámetro y del peso, en algunos análisis se desglosó el experimento en dos partes: el experimento EP, en el que se consideraron únicamente los cilindros en los que variaba el peso, con el mismo diámetro (c2, c3, c4, c5); y el experimento $E D$, en el que se consideraron aquellos cilindros en los que variaba el diámetro, con igual peso (c1, c3, c6, c7). En estos casos se empleó como factor en el ANOVA el diámetro del cilindro (Diámetro, "Dia") y el peso del cilindro (Peso, "Pes"). Asimismo se realizó un posterior análisis post-hoc de Tukey a partir de los ANOVAs para detectar posibles agrupamientos entre los diferentes niveles de los factores. Además, se realizó un ANOVA del experimento ED sobre la MGF considerando únicamente el agarre $2 \mathrm{D}$, con los factores Sujeto y Diámetro, con el fin de comparar los resultados obtenidos con los conseguidos por Domalain et al. en un ensayo previo similar (Domalain et al., 2008a). 
Análisis de la distribución de presiones en la mano humana durante el agarre

La repetibilidad de las medidas en las tres repeticiones se comprobó mediante el error cuadrático medio (RMSE) en un ANOVA sobre MSF con el factor 'Sujeto $x$ Cilindro x Tipo de Agarre x Sensor'.

Además de la MGF se analizó también la contribución de cada sensor a la fuerza de agarre (CGF) en el mismo intervalo de la fase de transición (entre tiempos normalizados 0.4 y 0.6 ), con el fin de conocer la distribución de la fuerza de agarre entre las distintas zona de la mano. Se realizaron ANOVAS similares a los realizados sobre MGF, utilizando en este caso CGF $_{\mathrm{i}}$ como variable dependiente y manteniendo los mismos factores independientes que en el ANOVA sobre MGF. En estos ANOVAS también se realizó el análisis posthoc de Tukey.

Con el fin de determinar posibles patrones o sinergias en la distribución de las fuerzas de agarre en la mano, se realizó también un análisis de componentes principales (PCA). Como en este ensayo se realizaron agarres con distinto número de dedos resulta difícil realizar un PCA considerando de forma independiente las distintas zonas de la mano, por lo que se realizó el PCA definiendo como agrupaciones 4 zonas: falanges distales, falanges mediales, falanges proximales y palma.

Además, se realizó un análisis de coeficientes de correlación entre el agarre libre y los demás tipos de agarre para cada uno de los cilindros, con el fin de discernir qué tipo de agarre guiado (2D, 3D, 5D o cil) se asemeja más al agarre libre.

En todos los casos, el tratamiento de los datos se hizo empleando Matlab. 


\section{3.- Resultados}

La figura 4.6 muestra un ejemplo de resultado de fuerza total de agarre obtenida para las tres repeticiones de uno de los tratamientos del ensayo, una vez procesado para la sincronización temporal de las tres repeticiones y filtrado del ruido. Se observa una pendiente elevada alrededor del instante normalizado 0.3 , correspondiente a un incremento brusco de la fuerza debido al establecimiento del agarre (fase de carga), y una pendiente negativa elevada alrededor del instante normalizado 0.7 , correspondiente al descenso brusco de la fuerza al finalizar el agarre y depositar el cilindro sobre la mesa (fase de descarga). Puede apreciarse también cómo la fuerza inicial de agarre no es nula al inicio ni al final del ensayo, lo que se atribuye a la resolución y deriva de los sensores del equipo de medida, resultando un error cercano a $1 \mathrm{~N}$ en la fuerza total.

El error de repetibilidad medio asociado a las 3 repeticiones de cada combinación de factores, obtenido a partir del RMSE del ANOVA sobre MSF con el factor 'Sujeto x Cilindro x Tipo de agarre x Sensor', fue de $0.54 \mathrm{~N}$.

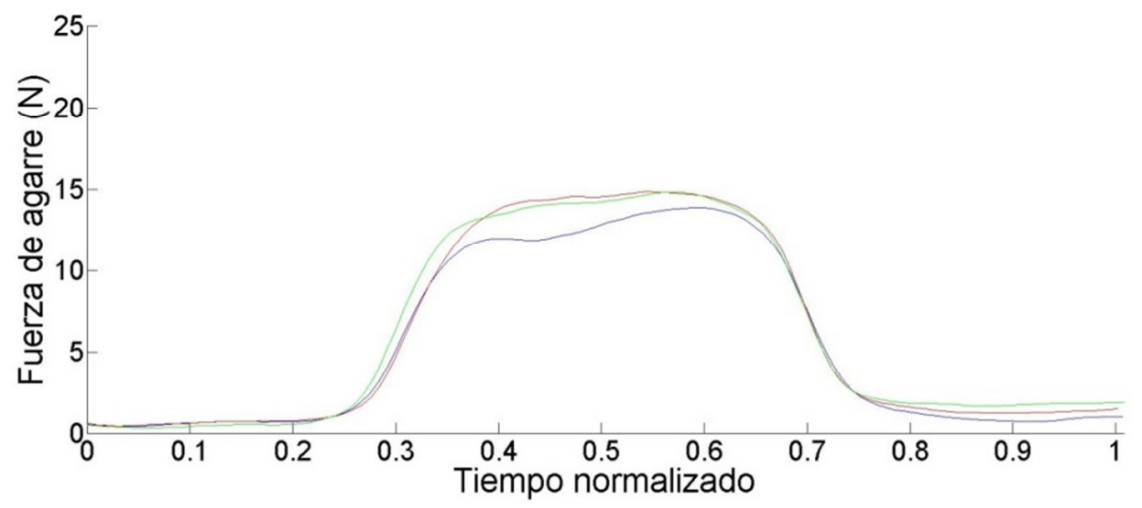

Figura 4.6. Ejemplo de resultado de fuerza total de agarre (sujeto 1, cilindro c6, agarre 3D)

La tabla 4.b muestra los resultados del ANOVA sobre la fuerza total de agarre (MGF) para el experimento EP, utilizando como factores 'Sujeto', 'Tipo de agarre' y 'Peso'. Se observa que todos los factores afectaban significativamente a la fuerza total de agarre ( $p<0.05$ en todos los casos). El tipo de agarre ("TipA") es el parámetro que explica la mayor varianza en los 
datos, como se observa por su mayor valor del cuadrado medio, seguido por el peso. Las interacciones dobles entre factores también son estadísticamente significativas.

La tabla 4.c muestra los resultados similares para el ANOVA sobre MGF para el experimento ED, utilizando como factores 'Sujeto', 'Tipo de agarre' y 'Diámetro'. Se observa igualmente que todos los factores afectaban significativamente a la fuerza total de agarre. El tipo de agarre ("TipA") vuelve a ser el parámetro que explica la mayor varianza en los datos, como se observa por su mayor valor del cuadrado medio, seguido por el sujeto, siendo mejor la varianza asociada al diámetro. Las interacciones dobles entre factores también son estadísticamente significativas.

Tabla 4.b: Resultados del ANOVA sobre MGF para el experimento EP

\begin{tabular}{cccccc}
\hline Factor & $\begin{array}{c}\text { Suma de } \\
\text { cuadrados }\end{array}$ & $\begin{array}{c}\text { Grados de } \\
\text { libertad }\end{array}$ & $\begin{array}{c}\text { Cuadrado } \\
\text { medio }\end{array}$ & F & P \\
\hline Suj & 11252.1 & 5 & 2250.4 & 46.37 & 0.0000 \\
Pes & 11990 & 3 & 3996.7 & 82.35 & 0.0000 \\
TipA & 52174.7 & 4 & 13043.7 & 268.75 & 0.0000 \\
Suj x Pes & 2124.3 & 15 & 141.6 & 2.92 & 0.0002 \\
Suj x TipA & 7973.7 & 20 & 398.7 & 8.21 & 0.0000 \\
Pes x TipA & 4667.3 & 12 & 388.9 & 8.01 & 0.0000 \\
Error & 27664.2 & 570 & 48.5 & & \\
Total & 140753.7 & 629 & & & \\
\hline
\end{tabular}

Tabla 4.c: Resultados del ANOVA sobre la MGF para el experimento ED

\begin{tabular}{cccccc}
\hline Factor & $\begin{array}{c}\text { Suma de } \\
\text { cuadrados }\end{array}$ & $\begin{array}{c}\text { Grados de } \\
\text { libertad }\end{array}$ & $\begin{array}{c}\text { Cuadrado } \\
\text { medio }\end{array}$ & F & P \\
\hline Sujeto & 12178.1 & 5 & 2435.6 & 42.03 & 0.0000 \\
Diámetro & 787.2 & 3 & 262.4 & 4.53 & 0.0038 \\
TipA & 48121.3 & 4 & 12030.3 & 207.61 & 0.0000 \\
Suj x Diam & 4229.9 & 15 & 282.0 & 4.87 & 0.0000 \\
Suj x TipA & 7973.7 & 20 & 398.7 & 6.88 & 0.0000 \\
Diam x TipA & 8398.8 & 12 & 699.9 & 12.08 & 0.0000 \\
Error & & 570 & 57.9 & & \\
Total & & 629 & & & \\
\hline
\end{tabular}


Con el fin de observar posibles agrupamientos entre niveles para un mismo factor, se realizaron análisis post-hoc de Tukey, cuyos resultados se muestran gráficamente en las figuras 4.5, 4.6, 4.7 (experimento EP) y figuras 4.8, 4.9, 4.10 (experimento ED).

En el ensayo EP, la figura 4.5 muestra dos grupos de sujetos estadísticamente diferentes. La figura 4.6 revela que a medida que aumenta el peso, es necesaria una mayor MGF para trasladar los cilindros. La figura 4.7 pone de manifiesto que en los agarres 2D y 3D se hace una fuerza que no es significativamente diferente. El agarre Cil es en el que se efectúa una mayor fuerza de agarre, mientras que el agarre libre se realiza con una fuerza media intermedia entre la del 5D y la de Cil.

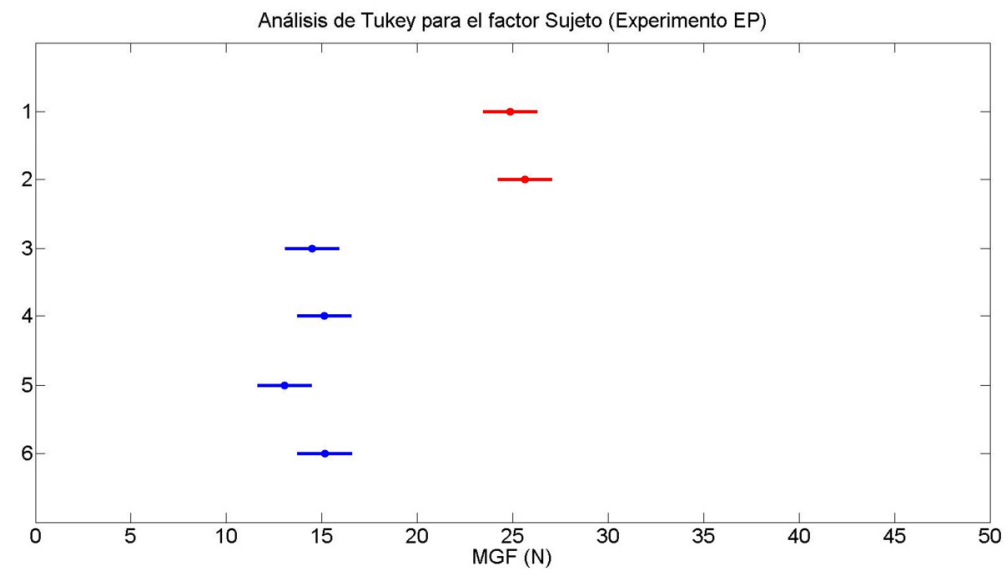

Figura 4.5: Tukey para el factor sujeto, experimento EP 


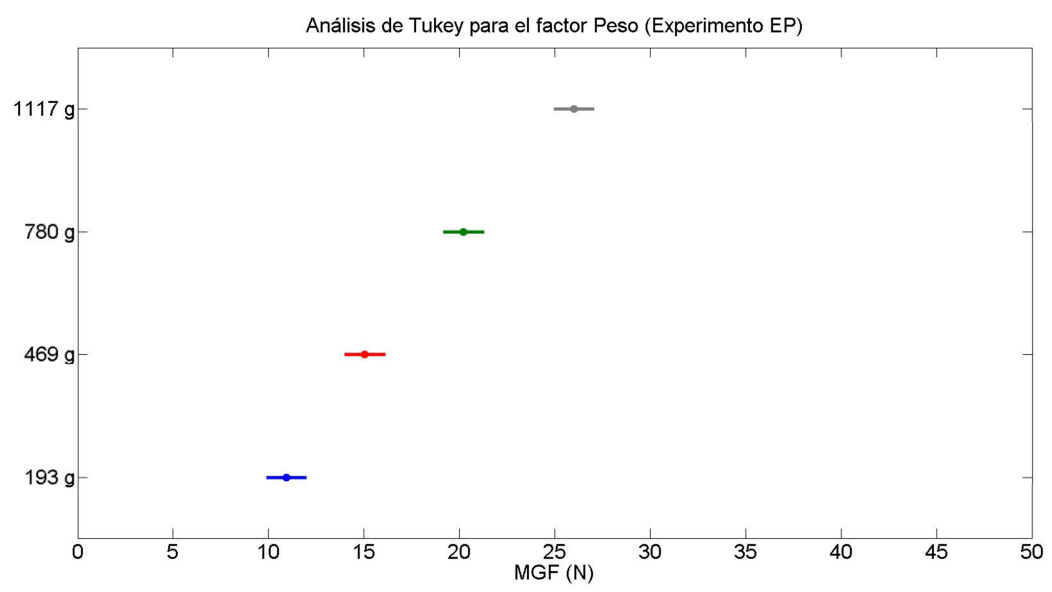

Figura 4.6: Tukey para el factor peso, experimento EP

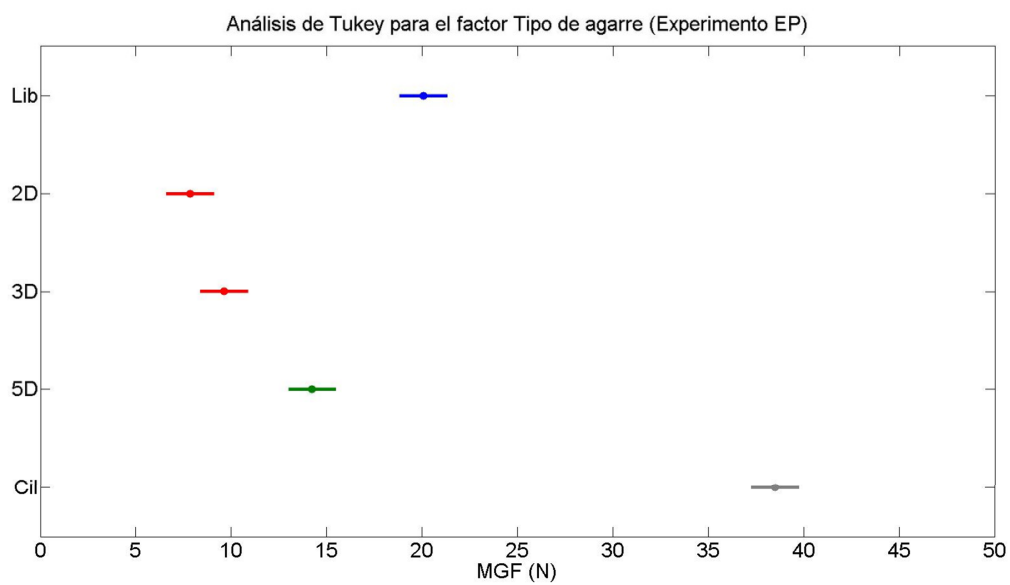

Figura 4.7: Tukey para el factor tipo de agarre, experimento EP

Respecto al experimento ED, la figura 4.8 muestra tres agrupamientos entre individuos, repitiéndose el agrupamiento entre el sujeto 1 y 2 que se daba en el experimento EP, mientras que el sujeto 3 presenta un comportamiento medio diferente a los sujetos 4,5 y 6 , a diferencia de los que ocurría en el experimento EP. La figura 4.9 pone de manifiesto que hay dos agrupamientos respecto al diámetro de los cilindros, con los de diámetro de $50 \mathrm{~mm}, 65 \mathrm{~mm}$ y $90 \mathrm{~mm}$ formando un grupo y el de $35 \mathrm{~mm}$ como único elemento del segundo grupo. Por último, la figura 4.10 muestra resultados similares a los que se observaban en la figura 4.7 , siendo los agarres $2 \mathrm{D}$ y $\mathbf{3 D}$ los que requieren 
menos fuerza. El agarre Cil vuelve a ser el que utiliza una mayor fuerza de agarre. El agarre libre se sitúa en un valor medio de fuerza de agarre similar al 5D.

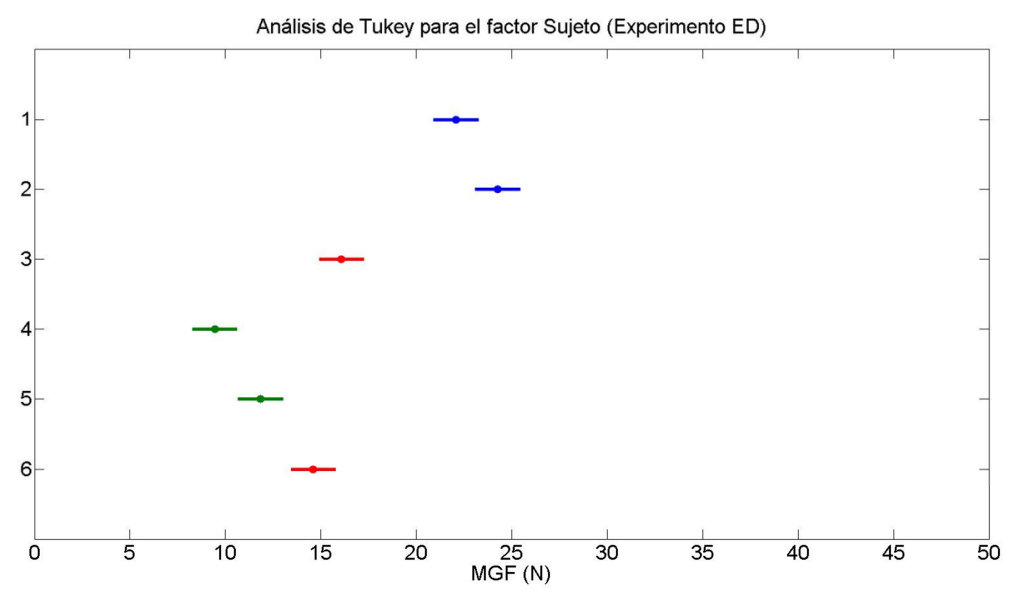

Figura 4.8: Tukey para el factor sujeto, experimento ED

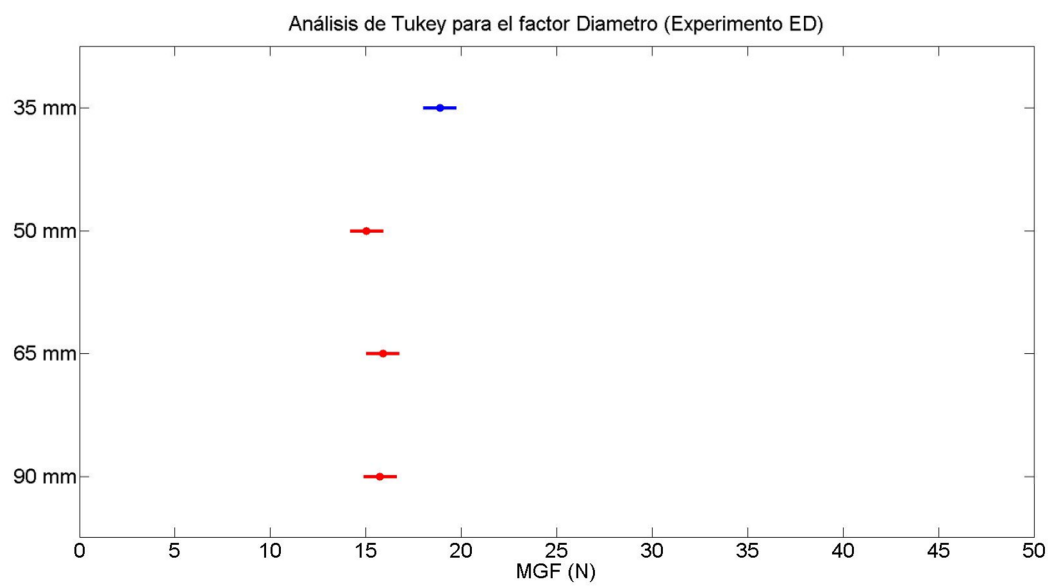

Figura 4.9: Tukey para el factor diámetro, experimento ED 


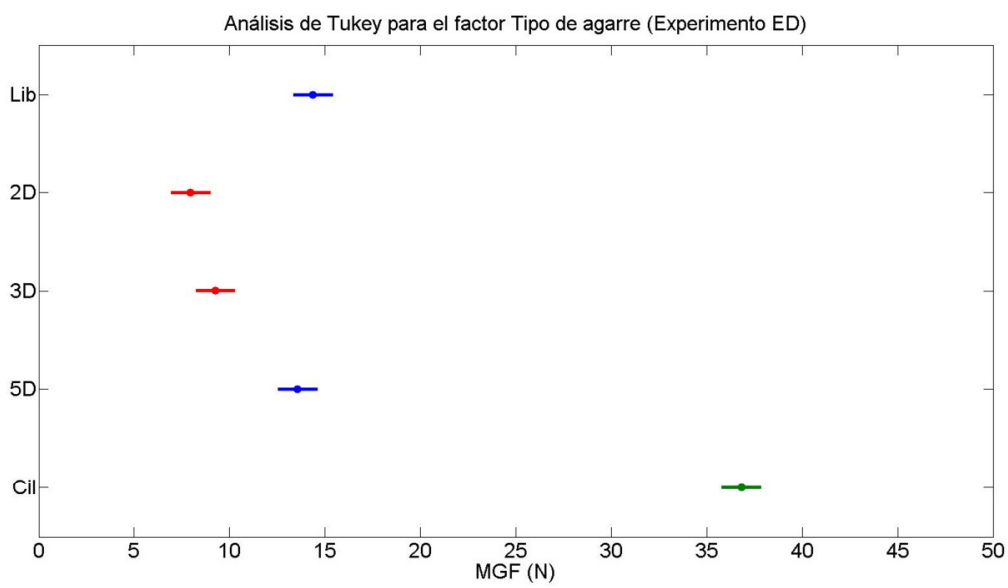

Figura 4.10: Tukey para el factor tipo de agarre, experimento ED

La tabla 4.d muestra los resultados del ANOVA correspondiente al experimento $E D$ realizado sobre la $M G F$, restringido únicamente el agarre $2 D$, con los factores 'Diámetro' y 'Sujeto'. Se observa que ambos factores son significativos en la fuerza de agarre, con una mayor varianza asociada al sujeto. El análisis de Tukey (figura 4.11) muestra que el diámetro de $90 \mathrm{~mm}$ exige las mayores fuerzas de agarre y el de $35 \mathrm{~mm}$ las menores, no siendo significativa la diferencia entre las fuerzas medias empleadas para los cilindros de 50 y 65 $\mathrm{mm}$.

Tabla 4.d: Resultados del ANOVA sobre la MGF, para el experimento ED, considerando únicamente el agarre $2 D$

\begin{tabular}{cccccc}
\hline Factor & $\begin{array}{c}\text { Suma de } \\
\text { cuadrados }\end{array}$ & $\begin{array}{c}\text { Grados de } \\
\text { libertad }\end{array}$ & $\begin{array}{c}\text { Cuadrado } \\
\text { medio }\end{array}$ & F & P \\
\hline Suj & 1460.68 & 5 & 292.136 & 155.24 & 0.0000 \\
Diam & 491.45 & 3 & 163.816 & 87.05 & 0.0000 \\
Suj x Diam & 509.48 & 15 & 33.965 & 18.05 & 0.0000 \\
Error & 90.33 & 48 & 1.882 & & \\
Total & 2551.94 & 71 & & & \\
\hline
\end{tabular}




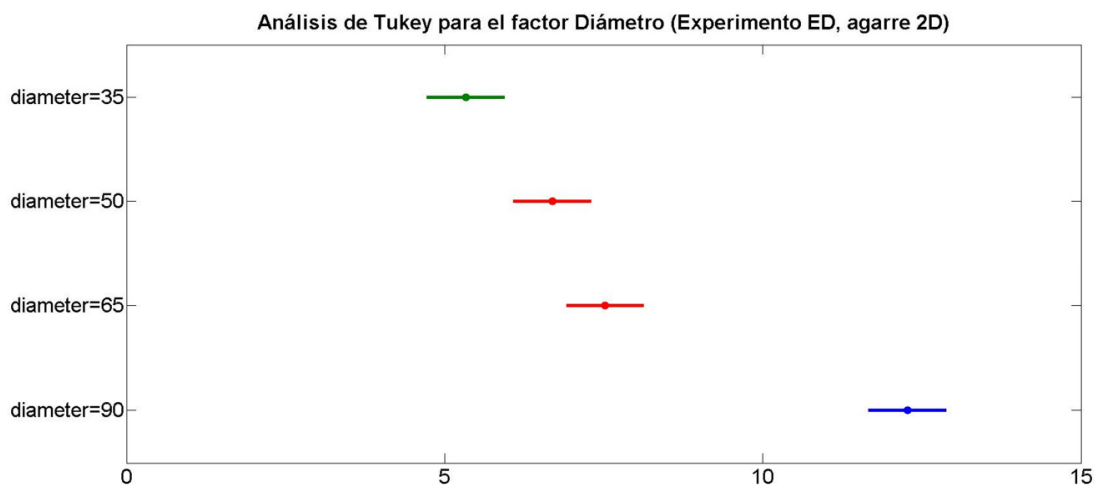

Figura 4.11. Análisis post-hoc de Tukey para el factor Diámetro, experimento ED, teniendo en cuenta solamente el agarre $2 D$.

El error de repetibilidad asociado a las 3 repeticiones de cada combinación de factores, obtenido a partir del RMSE del ANOVA del MSF con el factor 'Sujeto $x$ Cilindro x Tipo de agarre $x$ Sensor', fue de 0.54 N.

Las tablas 4.e a 4.i muestran la CGF promedio de cada sensor, para cada uno de los cilindros, según el tipo de agarre realizado.

Tabla 4.e. CGF (\%) para el agarre 2D.

\begin{tabular}{|c|c|c|c|c|c|c|c|}
\hline CIL & c1 & c2 & c3 & c4 & c5 & c6 & c7 \\
\hline AGARRE & 2D & 2D & 2D & 2D & 2D & 2D & 2D \\
\hline MGF (N) & 6.3 & 4.5 & 7.5 & 10.6 & 12.9 & 8.7 & 13.2 \\
\hline S1 & 26.7 & 29.5 & 29.9 & 21.8 & 22.7 & 31.5 & 32.3 \\
\hline S2 & 4.2 & 5.4 & 5.6 & 4.7 & 7.5 & 7.2 & 6.1 \\
\hline S3 & 40.4 & 32.0 & 38.6 & 39.0 & 41.7 & 35.1 & 45.3 \\
\hline S4 & 8.2 & 10.9 & 10.5 & 13.9 & 13.4 & 12.2 & 3.0 \\
\hline S5 & 3.7 & 2.9 & 2.5 & 2.3 & 2.8 & 1.5 & 2.3 \\
\hline S6 & 0.2 & 0.0 & 0.2 & 0.3 & 0.0 & 0.0 & 0.2 \\
\hline S7 & 0.7 & 0.7 & 0.6 & 0.9 & 0.9 & 0.8 & 0.4 \\
\hline S8 & 2.2 & 1.4 & 2.4 & 2.1 & 2.3 & 2.2 & 1.0 \\
\hline S9 & 0.7 & 0.6 & 0.2 & 0.3 & 0.2 & 0.3 & 0.1 \\
\hline S10 & 0.0 & 0.0 & 0.1 & 0.0 & 0.0 & 0.3 & 0.0 \\
\hline S11 & 0.0 & 0.1 & 0.0 & 0.0 & 0.1 & 0.2 & 0.0 \\
\hline S12 & 2.5 & 1.4 & 1.2 & 0.9 & 1.1 & 1.2 & 0.8 \\
\hline
\end{tabular}


Análisis de la distribución de presiones en la mano humana durante el agarre

\begin{tabular}{|l|l|l|l|l|l|l|l|}
\hline S13 & 0.4 & 1.5 & 1.9 & 1.0 & 0.6 & 0.8 & 1.7 \\
\hline S14 & 1.3 & 2.0 & 1.3 & 1.1 & 1.4 & 1.7 & 1.3 \\
\hline S15 & 0.5 & 4.7 & 2.7 & 9.0 & 1.0 & 2.4 & 3.9 \\
\hline S16 & 5.6 & 5.9 & 2.3 & 2.1 & 3.4 & 2.6 & 1.4 \\
\hline S17 & 2.7 & 0.9 & 0.2 & 0.4 & 0.8 & 0.1 & 0.1 \\
\hline
\end{tabular}

Tabla 4.f. CGF (\%) para el agarre 3D.

\begin{tabular}{|c|c|c|c|c|c|c|c|}
\hline CIL & c1 & c2 & c3 & c4 & c5 & c6 & c7 \\
\hline AGARRE & 3D & 3D & 3D & 3D & 3D & 3D & 3D \\
\hline MGF (N) & 7.8 & 5.9 & 9.1 & 11.3 & 15.7 & 10.0 & 13.3 \\
\hline S1 & 27.9 & 31.4 & 32.8 & 24.3 & 22.1 & 33.4 & 35.5 \\
\hline S2 & 4.2 & 5.6 & 3.9 & 4.7 & 8.0 & 5.1 & 4.8 \\
\hline S3 & 25.8 & 20.1 & 21.5 & 26.5 & 28.7 & 22.4 & 23.6 \\
\hline S4 & 3.8 & 4.2 & 3.7 & 3.4 & 4.0 & 4.3 & 1.8 \\
\hline S5 & 1.0 & 2.5 & 1.8 & 0.8 & 1.5 & 0.7 & 0.4 \\
\hline S6 & 17.8 & 19.5 & 21.8 & 26.6 & 22.0 & 20.2 & 21.1 \\
\hline S7 & 5.2 & 4.1 & 5.2 & 1.4 & 0.7 & 4.4 & 1.8 \\
\hline S8 & 2.2 & 1.4 & 1.2 & 3.5 & 2.3 & 1.4 & 2.2 \\
\hline S9 & 0.3 & 0.4 & 0.4 & 0.5 & 0.3 & 0.4 & 0.4 \\
\hline S10 & 0.0 & 0.0 & 0.0 & 0.1 & 0.1 & 0.1 & 0.1 \\
\hline S11 & 0.0 & 0.0 & 0.0 & 0.0 & 0.1 & 0.0 & 0.2 \\
\hline S12 & 1.6 & 1.5 & 1.0 & 1.3 & 1.1 & 1.2 & 1.0 \\
\hline S13 & 0.9 & 1.0 & 0.9 & 0.7 & 0.7 & 0.7 & 0.9 \\
\hline S14 & 1.0 & 1.5 & 0.7 & 1.3 & 1.1 & 0.9 & 1.3 \\
\hline S15 & 0.3 & 1.2 & 1.6 & 0.9 & 3.6 & 1.3 & 3.4 \\
\hline S16 & 4.6 & 4.3 & 2.4 & 3.4 & 2.8 & 0.6 & 1.3 \\
\hline S17 & 3.4 & 1.2 & 0.9 & 0.6 & 0.8 & 2.9 & 0.4 \\
\hline
\end{tabular}


Capítulo 4. Efecto del diámetro y peso en el agarre de objetos cilíndricos

Tabla 4.g. CGF (\%) para el agarre 5D.

\begin{tabular}{|c|c|c|c|c|c|c|c|}
\hline CIL & c1 & c2 & c3 & c4 & c5 & c6 & c7 \\
\hline AGARRE & $5 \mathrm{D}$ & $5 \mathrm{D}$ & $5 \mathrm{D}$ & $5 \mathrm{D}$ & $5 \mathrm{D}$ & $5 \mathrm{D}$ & $5 \mathrm{D}$ \\
\hline MGF (N) & 14.36 & 10.5 & 13.0 & 15.0 & 18.3 & 13.7 & 13.1 \\
\hline S1 & 16.8 & 24.4 & 22.4 & 17.0 & 13.9 & 23.5 & 28.9 \\
\hline S2 & 3.5 & 3.9 & 3.8 & 3.1 & 4.4 & 6.0 & 5.1 \\
\hline S3 & 9.6 & 9.6 & 11.6 & 12.5 & 12.7 & 13.0 & 11.8 \\
\hline S4 & 3.7 & 3.0 & 3.4 & 4.2 & 3.6 & 3.3 & 1.1 \\
\hline S5 & 0.5 & 1.8 & 0.7 & 0.8 & 0.5 & 0.5 & 0.6 \\
\hline S6 & 4.3 & 3.6 & 5.4 & 6.0 & 9.3 & 4.9 & 8.8 \\
\hline S7 & 2.1 & 1.4 & 1.4 & 1.3 & 2.8 & 0.8 & 0.7 \\
\hline S8 & 2.0 & 1.7 & 0.7 & 1.0 & 0.5 & 0.4 & 0.3 \\
\hline S9 & 4.4 & 6.1 & 6.2 & 7.0 & 6.2 & 5.0 & 8.0 \\
\hline S10 & 0.4 & 0.1 & 0.1 & 0.1 & 0.2 & 0.1 & 0.1 \\
\hline S11 & 0.0 & 0.0 & 0.1 & 0.1 & 0.1 & 0.1 & 0.1 \\
\hline S12 & 17.8 & 15.1 & 18.8 & 22.5 & 22.6 & 17.3 & 17.1 \\
\hline S13 & 5.5 & 7.1 & 2.2 & 5.0 & 3.3 & 7.2 & 5.4 \\
\hline S14 & 8.3 & 9.7 & 7.3 & 7.1 & 8.0 & 7.2 & 7.1 \\
\hline S15 & 8.8 & 3.6 & 5.4 & 3.9 & 3.7 & 1.8 & 1.3 \\
\hline S16 & 9.1 & 5.8 & 5.9 & 5.2 & 4.9 & 4.2 & 1.8 \\
\hline S17 & 3.2 & 2.2 & 3.3 & 2.9 & 2.5 & 3.9 & 1.2 \\
\hline
\end{tabular}

Tabla 4.h. CGF (\%) para el agarre cil.

\begin{tabular}{|c|c|c|c|c|c|c|c|}
\hline CIL & c1 & c2 & c3 & c4 & c5 & c6 & c7 \\
\hline AGARRE & cil & Cil & cil & cil & cil & cil & cil \\
\hline MGF (N) & 52.56 & 27.06 & 34.68 & 42.87 & 49.42 & 36.1 & 23.8 \\
\hline S1 & 3.1 & 12.4 & 11.6 & 11.2 & 8.4 & 21.4 & 32.9 \\
\hline S2 & 7.5 & 11.4 & 10.1 & 9.8 & 8.5 & 10.3 & 8.7 \\
\hline S3 & 2.1 & 3.7 & 5.1 & 3.9 & 4.1 & 5.4 & 5.2 \\
\hline S4 & 2.3 & 2.0 & 2.6 & 2.5 & 2.5 & 1.3 & 0.5 \\
\hline S5 & 6.1 & 3.8 & 3.3 & 3.5 & 3.8 & 2.5 & 1.7 \\
\hline S6 & 5.4 & 5.1 & 7.2 & 6.6 & 8.3 & 6.7 & 6.6 \\
\hline S7 & 2.6 & 1.7 & 1.4 & 1.5 & 1.7 & 0.9 & 0.5 \\
\hline S8 & 2.2 & 1.2 & 1.3 & 1.0 & 0.9 & 0.4 & 0.1 \\
\hline S9 & 7.5 & 8.3 & 7.8 & 9.0 & 8.6 & 8.5 & 9.9 \\
\hline
\end{tabular}


Análisis de la distribución de presiones en la mano humana durante el agarre

\begin{tabular}{|l|c|c|c|c|c|c|c|}
\hline S10 & 0.7 & 0.0 & 0.9 & 1.4 & 1.6 & 1.0 & 0.4 \\
\hline S11 & 0.0 & 0.0 & 0.1 & 0.1 & 0.1 & 0.1 & 0.1 \\
\hline S12 & 13.3 & 12.4 & 10.9 & 13.0 & 11.7 & 13.4 & 12.5 \\
\hline S13 & 3.1 & 3.1 & 3.8 & 3.6 & 3.6 & 3.6 & 5.6 \\
\hline S14 & 3.5 & 3.5 & 2.9 & 2.5 & 2.1 & 2.0 & 2.0 \\
\hline S15 & 17.5 & 17.1 & 19.2 & 17.1 & 14.7 & 13.0 & 9.1 \\
\hline S16 & 14.4 & 7.2 & 5.4 & 7.0 & 11.3 & 3.9 & 1.7 \\
\hline S17 & 7.5 & 6.2 & 5.4 & 5.6 & 7.2 & 4.7 & 1.6 \\
\hline
\end{tabular}

Tabla 4.i. CFG para el agarre lib.

\begin{tabular}{|c|c|c|c|c|c|c|c|}
\hline CIL & c1 & c2 & c3 & c4 & c5 & c6 & c7 \\
\hline AGARRE & lib & Lib & lib & lib & lib & lib & lib \\
\hline MGF (N) & 15.24 & 8.01 & 12.30 & 23.41 & 36.53 & 12.86 & 17.06 \\
\hline S1 & 25.3 & 26.61 & 22.58 & 20.8 & 17.5 & 33.8 & 38.9 \\
\hline S2 & 4.3 & 9.2 & 7.1 & 10.5 & 7.5 & 6.0 & 6.5 \\
\hline S3 & 4.9 & 5.4 & 5.6 & 5.9 & 6.0 & 6.4 & 5.8 \\
\hline S4 & 7.5 & 3.8 & 6.0 & 5.7 & 5.5 & 4.3 & 1.6 \\
\hline S5 & 3.9 & 3.9 & 1.9 & 2.4 & 2.5 & 1.6 & 1.1 \\
\hline S6 & 7.1 & 2.8 & 3.8 & 7.2 & 9.9 & 7.5 & 11.3 \\
\hline S7 & 1.3 & 1.9 & 1.9 & 1.5 & 2.6 & 1.6 & 0.9 \\
\hline S8 & 2.5 & 2.2 & 1.2 & 1.3 & 1.6 & 0.8 & 0.4 \\
\hline S9 & 3.4 & 4.6 & 5.1 & 6.0 & 6.1 & 5.1 & 7.1 \\
\hline S10 & 0.2 & 0.5 & 0.5 & 0.3 & 1.0 & 0.2 & 0.3 \\
\hline S11 & 0.1 & 0.4 & 0.4 & 0.2 & 0.1 & 0.1 & 0.1 \\
\hline S12 & 13.0 & 14.1 & 15.7 & 12.6 & 10.5 & 15.0 & 13.4 \\
\hline S13 & 1.5 & 2.3 & 2.0 & 1.5 & 2.9 & 2.2 & 2.4 \\
\hline S14 & 5.7 & 6.5 & 6.2 & 3.2 & 3.1 & 5.1 & 4.1 \\
\hline S15 & 9.2 & 2.7 & 3.1 & 10.6 & 10.9 & 3.5 & 4.1 \\
\hline S16 & 5.8 & 7.8 & 12.1 & 3.8 & 5.7 & 2.9 & 0.5 \\
\hline S17 & 3.5 & 4.3 & 4.3 & 5.8 & 5.9 & 3.3 & 1.1 \\
\hline
\end{tabular}

Las tablas 4.j y 4.k resumen las tablas 4.e-i, ya que muestran la contribución de los diferentes sensores agrupadas por dedos y por zonas (como suma de CGF de los sensores en dichos dedos o zonas), para los distintos tipos de agarre (promedio para todos los cilindros). Entre paréntesis se indica el intervalo de confianza al $95 \%$. 
Capítulo 4. Efecto del diámetro y peso en el agarre de objetos cilíndricos

Tabla 4.j. Media e intervalo de confianza al 95\% (entre paréntesis) de la contribución media de cada dedo (suma de CGF, en \%) para cada tipo de agarre.

\begin{tabular}{|c|c|c|c|c|c|c|}
\hline Tipo de agarre & Pulgar & Índice & Medio & Anular & Meñique & Palma \\
\hline Lib & $\begin{array}{c}33.87 \\
(28.47-39.27)\end{array}$ & $\begin{array}{c}13.24 \\
(11.41-15.07)\end{array}$ & $\begin{array}{c}10.30 \\
(8.21-12.39)\end{array}$ & $\begin{array}{c}6.10 \\
(5.13-7.08)\end{array}$ & $\begin{array}{c}20.52 \\
(18.30-22.74)\end{array}$ & $\begin{array}{c}15.96 \\
(11.23-20.69)\end{array}$ \\
\hline 2D & $\begin{array}{c}33.59 \\
(30.06-37.11)\end{array}$ & $\begin{array}{c}51.76 \\
(48.64-54.89)\end{array}$ & $\begin{array}{c}2.78 \\
(2.26-3.29)\end{array}$ & $\begin{array}{c}0.46 \\
(0.26-0.66)\end{array}$ & $\begin{array}{c}3.87 \\
(3.33-4.41)\end{array}$ & $\begin{array}{c}7.54 \\
(5.20-9.88)\end{array}$ \\
\hline 3D & 34.81 & 28.91 & 26.61 & 0.47 & 3.22 & 5.98 \\
& $(31.42-38.21)$ & $(26.58-31.25)$ & $(24.71-28.51)$ & $(0.36-0.58)$ & $(2.86-3.58)$ & $(4.88-7.07)$ \\
\hline 5D & 25.33 & 15.68 & 8.61 & 6.46 & 31.70 & 12.22 \\
& $(20.79-29.87)$ & $(14.46-16.92)$ & $(6.93-10.28)$ & $(5.57-7.33)$ & $(30.09-33.30)$ & $(8.28-16.17)$ \\
\hline Cil & 24.02 & 9.87 & 9.18 & 9.56 & 19.10 & 28.28 \\
& $(16.19-31.84)$ & $(8.94-10.80)$ & $(8.11-10.26)$ & $(8.77-10.35)$ & $(18.25-19.94)$ & $(21.55-35.01)$ \\
\hline
\end{tabular}

Tabla 4.k. Media e intervalo de confianza al 95\% (entre paréntesis) de la contribución media de cada zona de la mano (suma de CGF, en \%) para cada tipo de agarre.

\begin{tabular}{|c|c|c|c|c|}
\hline Tipo de agarre & Falanges distales & Falanges medias & Falanges proximales & Palma \\
\hline Lib & $\begin{array}{c}58.24 \\
(50.63-65.85)\end{array}$ & $\begin{array}{c}9.31 \\
(7.63-10.99)\end{array}$ & $\begin{array}{c}16.49 \\
(13.99-18.98)\end{array}$ & $\begin{array}{c}15.96 \\
(11.23-20.69)\end{array}$ \\
\hline 2D & $\begin{array}{c}68.38 \\
(64.13-72.63)\end{array}$ & $\begin{array}{c}12.23 \\
(9.33-15.14)\end{array}$ & $\begin{array}{c}11.84 \\
(10.87-12.80)\end{array}$ & $\begin{array}{c}7.54 \\
(5.20-9.88)\end{array}$ \\
\hline 3D & 76.64 & 7.74 & 9.63 & 5.98 \\
& $(74.11-79.17)$ & $(5.88-9.61)$ & $(8.14-11.12)$ & $(4.88-7.07)$ \\
\hline 5D & 63.53 & 10.22 & 14.03 & 12.22 \\
& $(58.34-68.74)$ & $(8.79-11.63)$ & $(12.76-15.29)$ & $(8.28-16.17)$ \\
\hline Cil & 46.51 & 8.23 & 16.98 & 28.28 \\
& $(37.60-55.43)$ & $(7.33-9.12)$ & $(14.99-18.97)$ & $(21.55-35.01)$ \\
\hline
\end{tabular}

La figura 4.12 es una presentación gráfica de los mismos datos expuestos en las tablas 4.e - $k$ pero desglosados para los experimentos EP y ED, mostrando la contribución de los distintos dedos y zonas de la mano a la MGF, permitiendo calibrar el efecto del peso y del diámetro del cilindro. Las figuras 4.12a y 4.12b muestran la comparación de la contribución entre dedos (a) y zonas distales-proximales (b) a la fuerza de agarre para los cilindros con el mismo diámetro pero distinto peso (experimento EP). Se observa que el aumento de peso del cilindro implica un leve incremento porcentual de la contribución de los dedos índice y medio a costa de un decremento porcentual de la participación en el pulgar (figura 4.12a). Por otra parte, el aumento del diámetro del cilindro implica un incremento en la contribución a la fuerza de agarre de la zona distal de los dedos, reduciéndose la contribución de la palma (figuras $4.12 \mathrm{c}$ y $4.12 \mathrm{~d}$ ). 


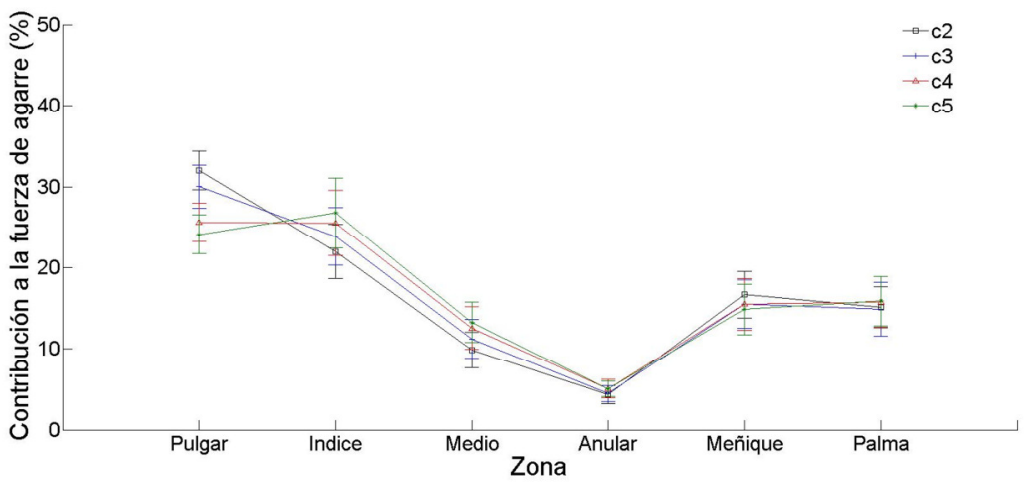

(a)

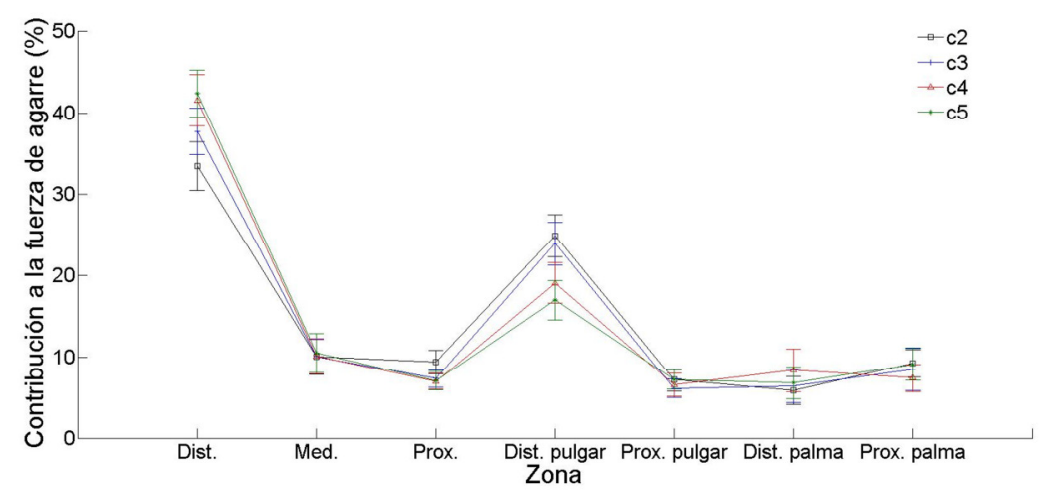

(b)

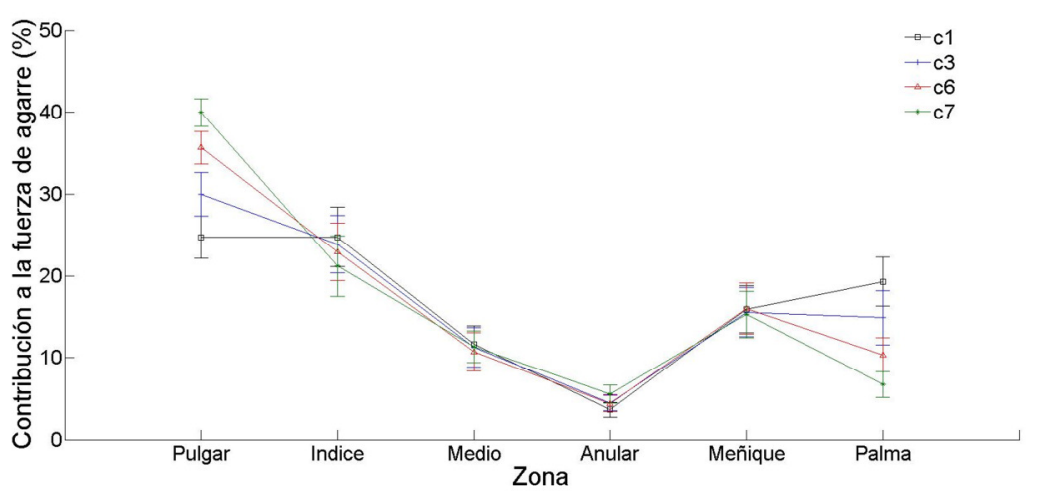

(c) 


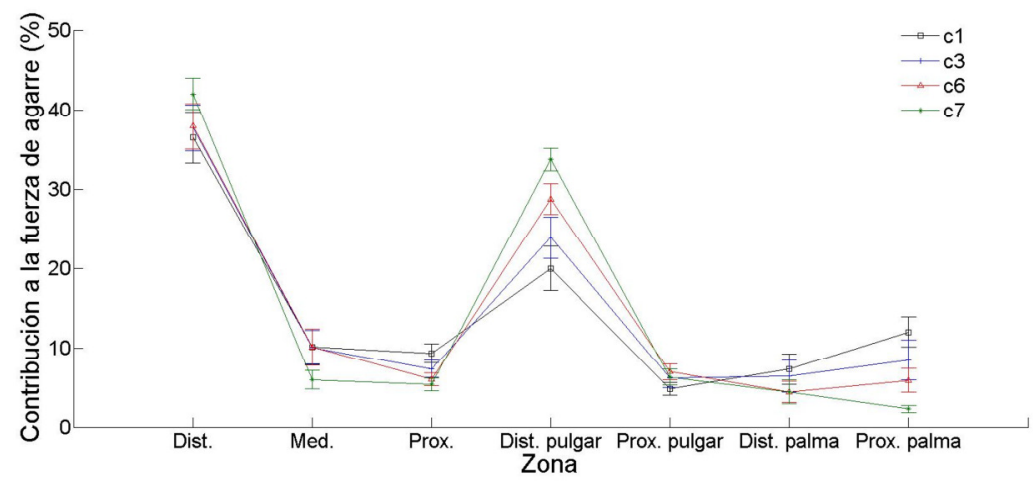

(d)

Figura 4.12. Media e intervalo de confianza (95\%) de la contribución porcentual a la fuerza de agarre en función de la zona, por dedos y palma $(a, c)$ y por posición distalproximal para pulgar, resto de dedos y palma $(b, d)$, en función del cilindro agrupados para el experimento $\operatorname{EP}(a, b)$ y experimento $E D(c, d)$, para todos los sujetos y tipos de agarre.

La figura 4.13 muestra las presiones medias en las distintas zonas sensibles, para cada tipo de agarre.

Los resultados de los ANOVAS realizados sobre la contribución de cada una de las 17 zonas sensibles del sensor $\left(\mathrm{CGF}_{\mathrm{i}}\right)$ indican que mayoritariamente el efecto de todos los factores considerados (Sujeto, Diámetro, Peso y Tipo de agarre) es significativo sobre la contribución porcentual de cada una de estas zonas a la fuerza total de agarre (tablas 4.1 y $4 . \mathrm{m}$ ), excepto quizá el efecto del peso, que resulta no significativo en muchos de los sensores.
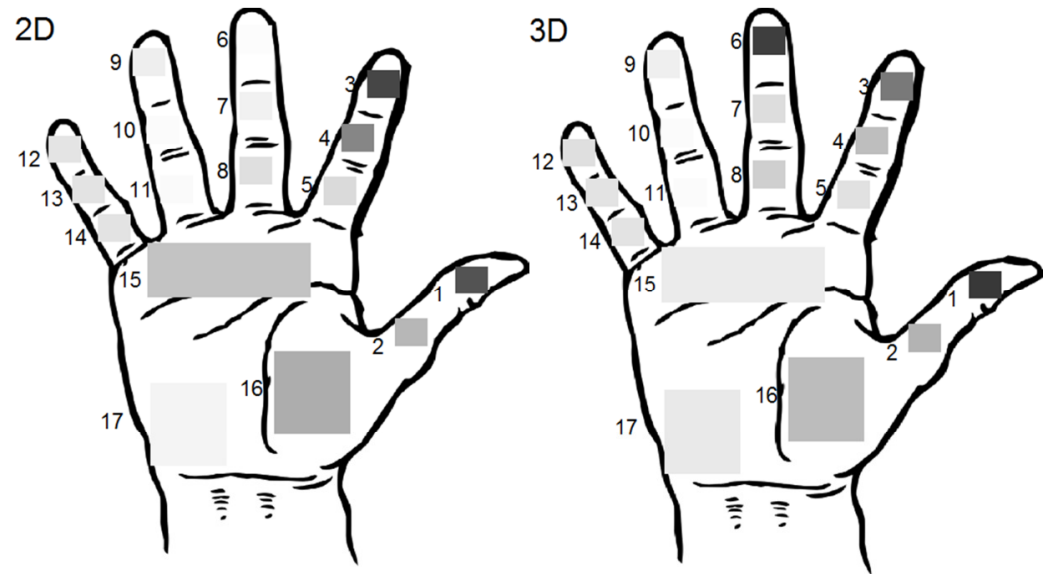

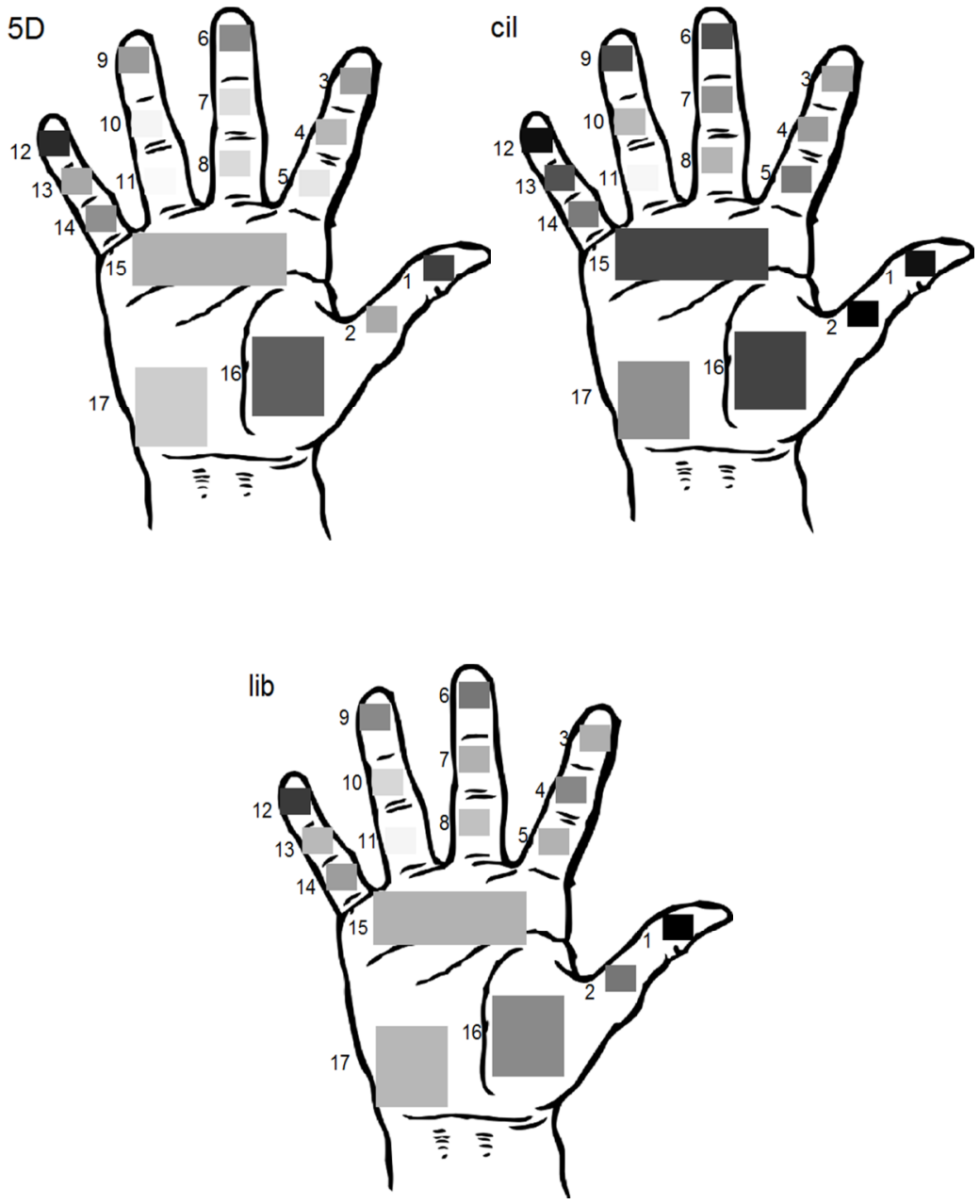

Figura 4.13. Presiones medias en las distintas zonas sensibles, para cada tipo de agarre (gradación desde $0 \mathrm{kPa}$ (blanco) a $16.7 \mathrm{kPa}$ (negro))

Tabla 4.I: Valores de p obtenidos de los ANOVAS sobre las contribuciones de cada sensor para el experimento ED con los factores 'Sujeto' (Suj), 'Diámetro' (Dia), 'Tipo de agarre' (TipA) y sus interacciones.

\begin{tabular}{cccccccccc}
\hline Factor & S1 & S2 & S3 & S4 & S5 & S6 & S7 & S8 & S9 \\
\hline Suj & 0.000 & 0.000 & 0.000 & 0.000 & 0.000 & 0.000 & 0.000 & 0.000 & 0.000 \\
Dia & 0.000 & 0.000 & 0.093 & 0.000 & 0.000 & 0.000 & 0.000 & 0.000 & 0.000 \\
TipA & 0.000 & 0.000 & 0.000 & 0.000 & 0.000 & 0.000 & 0.000 & 0.000 & 0.000 \\
Suj x Dia & 0.000 & 0.000 & 0.000 & 0.000 & 0.000 & 0.000 & 0.000 & 0.000 & 0.000 \\
Suj x TipA & 0.000 & 0.000 & 0.000 & 0.000 & 0.000 & 0.000 & 0.000 & 0.000 & 0.000 \\
Dia x TipA & 0.000 & 0.278 & 0.000 & 0.000 & 0.000 & 0.000 & 0.009 & 0.000 & 0.001 \\
\hline
\end{tabular}


Capítulo 4. Efecto del diámetro y peso en el agarre de objetos cilíndricos

\begin{tabular}{ccccccccc}
\hline Factor & S10 & S11 & S12 & S13 & S14 & S15 & S16 & S17 \\
\hline Suj & 0.000 & 0.000 & 0.000 & 0.000 & 0.000 & 0.000 & 0.000 & 0.000 \\
Dia & 0.704 & 0.002 & 0.772 & 0.009 & 0.001 & 0.000 & 0.000 & 0.000 \\
TipA & 0.000 & 0.000 & 0.000 & 0.000 & 0.000 & 0.000 & 0.000 & 0.000 \\
Suj x Dia & 0.000 & 0.000 & 0.002 & 0.000 & 0.000 & 0.146 & 0.000 & 0.000 \\
Suj x TipA & 0.000 & 0.000 & 0.000 & 0.000 & 0.000 & 0.000 & 0.000 & 0.000 \\
Dia x TipA & 0.540 & 0.004 & 0.635 & 0.000 & 0.059 & 0.000 & 0.000 & 0.002 \\
\hline
\end{tabular}

Tabla 4.m: Valores de $p$ obtenidos de los ANOVAS para las contribuciones de cada sensor para el experimento EP con los factores 'Sujeto' (Suj), 'Peso' (Pes), 'Tipo de agarre' (TipA) y sus interacciones.

\begin{tabular}{cccccccccc}
\hline Factor & S1 & S2 & S3 & S4 & S5 & S6 & S7 & S8 & S9 \\
\hline Suj & 0.000 & 0.000 & 0.000 & 0.000 & 0.000 & 0.000 & 0.000 & 0.000 & 0.000 \\
Pes & 0.000 & 0.095 & 0.000 & 0.267 & 0.007 & 0.000 & 0.079 & 0.066 & 0.160 \\
TipA & 0.000 & 0.000 & 0.000 & 0.000 & 0.000 & 0.000 & 0.000 & 0.000 & 0.000 \\
Suj x Pes & 0.003 & 0.000 & 0.000 & 0.006 & 0.000 & 0.006 & 0.000 & 0.000 & 0.000 \\
Suj x TipA & 0.000 & 0.000 & 0.000 & 0.000 & 0.000 & 0.000 & 0.000 & 0.000 & 0.000 \\
Pes x TipA & 0.014 & 0.053 & 0.000 & 0.748 & 0.885 & 0.000 & 0.000 & 0.000 & 0.887 \\
\hline
\end{tabular}

\begin{tabular}{ccccccccc}
\hline Factor & S10 & S11 & S12 & S13 & S14 & S15 & S16 & S17 \\
\hline Suj & 0.000 & 0.000 & 0.000 & 0.000 & 0.000 & 0.000 & 0.000 & 0.000 \\
Pes & 0.003 & 0.093 & 0.186 & 0.136 & 0.000 & 0.065 & 0.130 & 0.595 \\
TipA & 0.000 & 0.000 & 0.000 & 0.000 & 0.000 & 0.000 & 0.000 & 0.000 \\
Suj x Pes & 0.000 & 0.008 & 0.027 & 0.000 & 0.000 & 0.000 & 0.001 & 0.002 \\
Suj x TipA & 0.000 & 0.000 & 0.000 & 0.000 & 0.000 & 0.000 & 0.000 & 0.000 \\
Pes x TipA & 0.000 & 0.000 & 0.000 & 0.000 & 0.000 & 0.000 & 0.000 & 0.823 \\
\hline
\end{tabular}

Las tablas 4.n, 4.o, 4.p, 4.q muestran ANOVAS similares para los experimentos EP y ED, pero agrupando los sensores por dedos o por zonas. Analizando estas tablas, puede observarse que la MSF de la mayor parte de las zonas contribuyen de forma significativamente diferente según cambian los factores y sus interacciones. No se observa cambio significativo en los dedos anular y meñique y la palma al variar el peso (EP) y en los dedos medio y meñique al variar el diámetro (ED).

Tabla 4.n: Valores de $p$ obtenidos de los ANOVAS para las contribuciones en cada dedo para el experimento ED con los factores 'Sujeto' (Suj), 'Peso' (Pes), 'Tipo de agarre'

(TipA) y sus interacciones. 
Análisis de la distribución de presiones en la mano humana durante el agarre

\begin{tabular}{ccccccc}
\hline Factor & Pulgar & Índice & Medio & Anular & Meñique & Palma \\
\hline Suj & 0.000 & 0.000 & 0.000 & 0.000 & 0.000 & 0.000 \\
Dia & 0.000 & 0.001 & 0.678 & 0.000 & 0.912 & 0.000 \\
TipA & 0.000 & 0.000 & 0.000 & 0.000 & 0.000 & 0.000 \\
Suj x Dia & 0.000 & 0.000 & 0.000 & 0.000 & 0.000 & 0.000 \\
Suj x TipA & 0.000 & 0.000 & 0.000 & 0.000 & 0.000 & 0.000 \\
Dia x TipA & 0.000 & 0.000 & 0.000 & 0.000 & 0.000 & 0.000 \\
\hline
\end{tabular}

Tabla 4.o: Valores de $p$ obtenidos de los ANOVAS para las contribuciones en cada zona para el experimento ED con los factores 'Sujeto' (Suj), 'Peso' (Pes), 'Tipo de agarre'

(TipA) y sus interacciones.

\begin{tabular}{ccccccc}
\hline Factor & $\begin{array}{c}\text { Pulgar } \\
\text { distal }\end{array}$ & $\begin{array}{c}\text { Pulgar } \\
\text { proximal }\end{array}$ & $\begin{array}{c}\text { Falanges } \\
\text { distales }\end{array}$ & $\begin{array}{c}\text { Falanges } \\
\text { medias }\end{array}$ & $\begin{array}{c}\text { Falanges } \\
\text { proximales }\end{array}$ & Palma \\
\hline Suj & 0.000 & 0.000 & 0.000 & 0.000 & 0.000 & 0.000 \\
Dia & 0.000 & 0.001 & 0.001 & 0.000 & 0.000 & 0.000 \\
TipA & 0.000 & 0.000 & 0.000 & 0.527 & 0.000 & 0.000 \\
Suj x Dia & 0.000 & 0.000 & 0.000 & 0.000 & 0.000 & 0.000 \\
Suj x TipA & 0.000 & 0.000 & 0.000 & 0.000 & 0.000 & 0.000 \\
Dia x TipA & 0.000 & 0.000 & 0.000 & 0.000 & 0.000 & 0.000 \\
\hline
\end{tabular}

Tabla 4.p: Valores de $p$ obtenidos de los ANOVAS para las contribuciones en cada dedo para el experimento EP con los factores 'Sujeto' (Suj), 'Peso' (Pes), 'Tipo de agarre'

(TipA) y sus interacciones.

\begin{tabular}{ccccccc}
\hline Factor & Pulgar & Índice & Medio & Anular & Meñique & Palma \\
\hline Suj & 0.000 & 0.000 & 0.000 & 0.000 & 0.000 & 0.000 \\
Pes & 0.000 & 0.001 & 0.022 & 0.215 & 0.747 & 0.453 \\
TipA & 0.000 & 0.000 & 0.000 & 0.000 & 0.000 & 0.000 \\
Suj x Pes & 0.000 & 0.000 & 0.000 & 0.000 & 0.000 & 0.000 \\
Suj x TipA & 0.000 & 0.000 & 0.000 & 0.000 & 0.000 & 0.000 \\
Pes x TipA & 0.000 & 0.000 & 0.000 & 0.000 & 0.000 & 0.000 \\
\hline
\end{tabular}


Capítulo 4. Efecto del diámetro y peso en el agarre de objetos cilíndricos

Tabla 4.q: Valores de p obtenidos de los ANOVAS para las contribuciones en cada zona para el experimento EP con los factores 'Sujeto' (Suj), 'Peso' (Pes), 'Tipo de agarre'

(TipA) y sus interacciones.

\begin{tabular}{ccccccc}
\hline Factor & $\begin{array}{c}\text { Pulgar } \\
\text { distal }\end{array}$ & $\begin{array}{c}\text { Pulgar } \\
\text { proximal }\end{array}$ & $\begin{array}{c}\text { Falanges } \\
\text { distales }\end{array}$ & $\begin{array}{c}\text { Falanges } \\
\text { medias }\end{array}$ & $\begin{array}{c}\text { Falanges } \\
\text { proximales }\end{array}$ & Palma \\
\hline Suj & 0.000 & 0.000 & 0.000 & 0.000 & 0.000 & 0.000 \\
Pes & 0.000 & 0.245 & 0.000 & 0.970 & 0.001 & 0.453 \\
TipA & 0.000 & 0.000 & 0.000 & 0.000 & 0.000 & 0.000 \\
Suj x Pes & 0.000 & 0.000 & 0.000 & 0.000 & 0.000 & 0.000 \\
Suj x TipA & 0.000 & 0.000 & 0.000 & 0.000 & 0.000 & 0.000 \\
Pes x TipA & 0.000 & 0.000 & 0.000 & 0.000 & 0.000 & 0.000 \\
\hline
\end{tabular}

La tabla 4.r muestra los coeficientes de los componentes principales obtenidos del análisis PCA, agrupando las zonas sensibles por posición distal-proximal y palma. Cada columna de la tabla corresponde a una de las zonas de la mano, mientras que cada fila corresponde a un componente principal, ordenados en función de porcentaje de variabilidad explicado. Se observa que con dos componentes principales se explica el $90 \%$ de la varianza de la MGF en el agarre. El primer componente principal corresponde principalmente a la coordinación de las falanges distales, el segundo a las mediales y el tercero a las proximales, mientras que el cuarto considera el reparto entre la palma y el resto de zonas de los dedos.

La figura 4.14 muestra el coeficiente de correlación entre el agarre libre y cada uno de los otros tipos, por separado para cada cilindro, obtenido a partir de la información en los diferentes sensores de las tablas 4.e a 4.i. Se observa que para los cilindros $\mathrm{c} 1, \mathrm{c} 2$ y c3 el agarre libre presenta la mayor correlación con el 5D, superior siempre al $80 \%$. Para los cilindros c4, c5, c6 y c7 la correlación es similar para el agarre $5 \mathrm{D}$ y para el cilíndrico, siendo algo mayor con el $5 \mathrm{D}$ en el c6 y con el cilíndrico en el resto, en los que el peso es mayor $(c 4, c 5)$ o el diámetro máximo (c7). 
Análisis de la distribución de presiones en la mano humana durante el agarre

Tabla 4.r. Coeficientes de los componentes principales ( $P C)$, agrupando las zonas sensibles por posición distal-proximal y palma.

\begin{tabular}{|c|l|l|l|c|c|}
\hline & \multicolumn{3}{|c|}{ Coeficientes por zonas } & \multirow{2}{*}{$\begin{array}{c}\text { Varianza } \\
\text { explicada } \\
\text { acumulada }\end{array}$} \\
\hline PC & $\begin{array}{l}\text { Falanges } \\
\text { distales }\end{array}$ & $\begin{array}{l}\text { Falanges } \\
\text { mediales }\end{array}$ & $\begin{array}{l}\text { Falanges } \\
\text { proximales }\end{array}$ & Palma & $71.4 \%$ \\
\hline 1 & 0.8331 & -0.1928 & -0.1406 & 0.4990 & $89.9 \%$ \\
\hline 2 & -0.1979 & 0.7543 & -0.3391 & 0.5262 & $99.7 \%$ \\
\hline 3 & -0.1704 & -0.0239 & 0.8413 & 0.5124 & $100 \%$ \\
\hline 4 & -0.4876 & -0.6272 & -0.3967 & 0.4600 & 100 \\
\hline
\end{tabular}

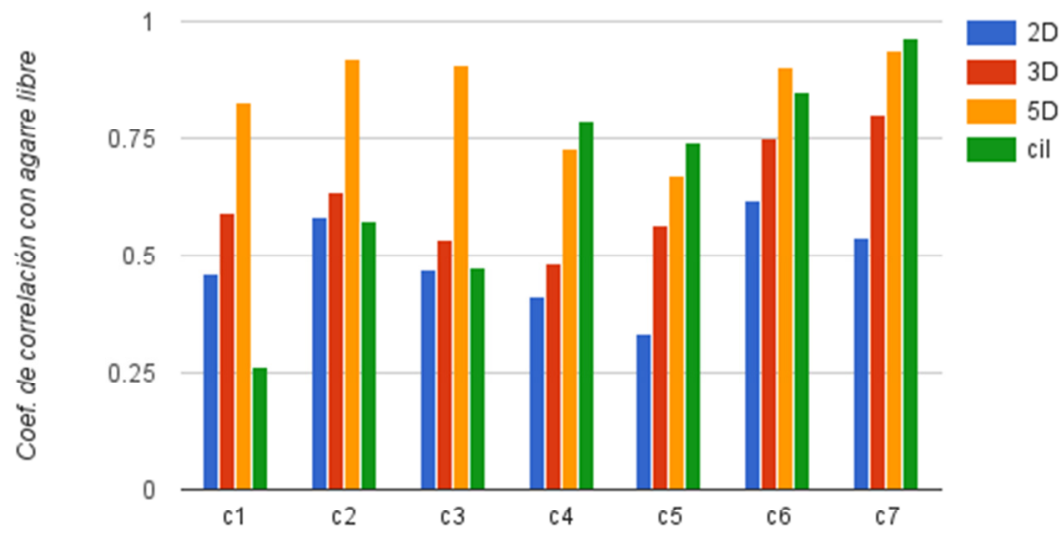

Figura 4.14. Coeficiente de correlación entre agarre libre y los demás tipos para cada cilindro 


\section{4.- Discusión}

En este capítulo se analiza en profundidad la distribución de fuerzas en el agarre de cilindros de diferentes pesos y diámetros, empleando varios tipos de agarre incluido el agarre libre seleccionado por el sujeto.

El error de repetibilidad de $0.54 \mathrm{~N}$ obtenido en los ensayos se considera aceptable, confirmando la validez de los sensores para este tipo de medidas, indicando que los sujetos realizan MGF y MSF similares al realizar distintas repeticiones de la misma tarea tras los ensayos previos de familiarización no registrados.

EI ANOVA realizado sobre la fuerza total de agarre del experimento EP (tabla 4.b) muestra que todos los factores ('Sujeto', 'Peso', 'Tipo de agarre', y sus interacciones) tienen un efecto estadísticamente significativo sobre la MGF. Observando el posterior análisis post-hoc de Tukey (figuras 4.5, 4.6, 4.7), puede observarse que hay dos grupos de sujetos ( 1 y $2 ; 3,4,5$ y 6 ) que realizan fuerzas estadísticamente similares. El factor más significativo para explicar la variabilidad en la fuerza de agarre es el tipo de agarre y no el peso. Esto se debe a que la fuerza empleada para el agarre cilíndrico es significativamente mayor que las empleadas en los demás agarres (figura 4.7), posiblemente porque el sujeto asocia este agarre a la realización de una mayor fuerza (de hecho la instrucción dada fue coger el cilindro como si fuera el mango de un martillo). No obstante, considerando el resto de agarres, se observa igualmente que la fuerza con el agarre 5D y libre es significativamente superior a la empleada con los agarres 2D y 3D, efecto que se podría explicar por una menor efectividad en el agarre, al no poder conseguir oposiciones tan efectivas entre el pulgar o la palma y el resto de dedos, cuando el número de estos es mayor. Al mismo tiempo esto permite incrementar el margen de seguridad del agarre dando preferencia a la estabilidad del mismo, efecto que puede confirmarse por el hecho de que las fuerzas sean mayores para el agarre libre que para el 5D.

Observando la figura 4.6, se observa que la fuerza de agarre aumenta con el peso del cilindro, aunque este aumento no es directamente proporcional. Domalain et al. (Domalain, Vigouroux, Danion, Sevrez, \& Berton, 2008b) muestra una relación peso/fuerza de agarre similar a la obtenida en este 
Análisis de la distribución de presiones en la mano humana durante el agarre

ensayo. Algunos estudios previos, sin embargo, indican que la fuerza de agarre es casi linealmente proporcional al peso del objeto manipulado (Gao, Latash, \& Zatsiorsky, 2005; Kinoshita et al., 1995; Monzee et al., 2003). Posiblemente la no linealidad en la función observada en nuestro caso se deba a que uno de los agarres es cilíndrico lo que afecta al valor de la fuerza media realizada para cada cilindro, ya que es posible realizar fuerzas de agarre más elevadas en los cilindros de diámetros más pequeños. Por otra parte, los cilindros más pesados se manipulen con un menor coeficiente de seguridad, ya que éste se optimiza de manera que no se deslice el objeto de la mano que lo sujeta (Westling \& Johansson, 1984a), pero puede ocurrir que para objetos ligeros se mayore al no producirse fatiga muscular aun con una mayor fuerza de agarre, mientras que dicha fuerza de agarre se optimice para pesos mayores, ajustándola más a la estrictamente necesaria para impedir que el objeto deslice. Otro posible motivo de la no proporcionalidad entre la fuerza de agarre y el peso del objeto puede ser que se reduzca el coeficiente de seguridad con el que se manipula el cilindro durante el transporte cuando el peso del objeto es más elevado. Ha habido estudios sobre la variación del coeficiente de seguridad como consecuencia de la rugosidad de las superficies (Westling \& Johansson, 1984b) o debido a la edad y la experiencia (Forssberg, Eliasson, Kinoshita, Westling, \& Johansson, 1995), pero poco se ha estudiado acerca de la variación del coeficiente de seguridad cuando se manipulan diversos objetos con pesos distintos, con lo que faltarían estudios para confirmar la hipótesis de que la fuerza de agarre no es linealmente proporcional al peso como consecuencia de la reducción del coeficiente de seguridad.

De forma similar, el ANOVA sobre la fuerza total de agarre del experimento ED (tabla 4.c) muestra que todos los factores ('Sujeto', 'Diámetro', 'Tipo de agarre', y sus interacciones) tienen un efecto estadísticamente significativo sobre la fuerza total de agarre. El efecto más importante es el de nuevo el tipo de agarre. Se mantiene la tendencia vista en el experimento EP, donde la menor fuerza de agarre se realiza con 2D, luego 3D y $\mathbf{5 D}$. La fuerza de agarre realizada con el agarre libre vuelve a ser mayor que la realizada con 5D, pero inferior a la ejercida cuando se efectúa un agarre cilíndrico. La mayor fuerza del agarre cilíndrico es debida a que es el único agarre de potencia. El segundo efecto más importante es el del sujeto. El análisis post-hoc de Tukey (figuras $4.8,4.9$ y 4.10 ) indica de nuevo que los sujetos 1 y 2 hacen una fuerza superior al resto y por otra parte no se observan diferencias significativas en la fuerza 
media para los cilindros de diámetros 50,65 y $90 \mathrm{~mm}$, pero sí una mayor fuerza para el de diámetro $35 \mathrm{~mm}$. La fuerza para el agarre cilíndrico, como se ha visto, es mucho mayor que la realizada con el otro tipo de agarres, por lo que el hecho de que la fuerza de agarre sea mayor para $35 \mathrm{~mm}$ parece indicar un diámetro óptimo para el agarre de potencia. De hecho el diámetro de 35 $\mathrm{mm}$ es cercano al $20 \%$ del tamaño medio de las manos empleadas en este ensayo, valor que fue el que obtuvieron Kong et al. (Y. K. Kong \& Lowe, 2005) como diámetro óptimo para conseguir la mayor fuerza de agarre en mangos de herramientas. Sin embargo, analizando únicamente el agarre 2D, el ANOVA sobre la MGF mostró que el factor "Diámetro" era significativo (tabla 4.e) y un posterior análisis post-hoc de Tukey señala que la MGF aumenta con el diámetro del cilindro manipulado (figura 4.11), tal como exponen Domalain et al. (Domalain et al., 2008a). Por tanto, la fuerza de agarre realizada en agarres de potencia cambia con el diámetro de forma diferente a la realizada en agarres de precisión como el 2D.

En cuanto a la contribución de las diferentes zonas de la mano al agarre, en las tablas 4.e - 4.i puede comprobarse que la contribución del pulgar baja a medida que aumenta el peso (los cilindros del c2 al c5 están ordenados por peso, del más ligero al más pesado), para todos los agarres prescritos (2D, 3D, 5D y cil). La tabla 4.j muestra que los dedos de mayor contribución son el pulgar, índice y meñique. Esto es debido a que el pulgar actúa como dedo oponible, interviniendo de forma preferente en todas las acciones de agarre y a que el índice es el segundo dedo más utilizado, ya que interviene en todos los tipos de agarre. La elevada contribución del meñique en el agarre con cinco dedos, libre y cilíndrico puede explicarse debido a que es el dedo más lateral, con lo que es el encargado de realizar el momento de equilibrio para evitar que el cilindro gire. Además, cabe destacar la gran contribución de la palma en el agarre cilíndrico, lo que puede justificar que se realice una fuerza muy superior a la del resto de agarres, aparte de que al prescribir un agarre de potencia, el sujeto tiende a realizar instintivamente una fuerza superior a la que realizaría con un agarre de precisión.

Las tablas 4.e - 4.i muestran que al aumentar el diámetro, la contribución del pulgar (zonas S1 y S2) también crece, sobre todo la de la zona distal (S1), reduciéndose la participación de la palma (ver figuras 4.12 c y $4.12 \mathrm{~d}$ ). Esto es debido a la dificultad para abarcar con la mano los cilindros de mayor diámetro 
Análisis de la distribución de presiones en la mano humana durante el agarre

de una forma apropiada, lo que dificulta el contacto de parte de la palma en los agarres cilíndricos y libre. Además, con el fin de asegurar el equilibrio entre fuerzas y controlar el movimiento del cilindro durante el agarre, al aumentar el diámetro del mismo, se hace necesario reducir la participación de las falanges proximales y medias a costa de las distales, que pueden situarse en posiciones más cercanas a una oposición diametral de fuerzas en el cilindro.

La tabla 4.k muestra que la mayor contribución a la fuerza de agarre total se produce en las falanges distales en todos los casos, lo que se explica debido a la tendencia al agarre tipo pinza aunque se utilicen varios dedos. La siguiente zona en importancia es la proximal, lo que puede explicarse debido a la gran contribución de esa zona del pulgar.

El efecto del peso y el diámetro del cilindro en la contribución a la fuerza de agarre por dedos y por zonas distal-proximal se muestra en la figura 4.12. Se observa que existe un aumento en la contribución del índice y medio como consecuencia del aumento del peso del cilindro, en detrimento de la contribución del pulgar (figura 4.12 (a)). La figura 4.12 (c) y (d) muestra que el aumento del diámetro del cilindro implica un incremento en la contribución de las zonas distales de la mano a la fuerza total de agarre.

La figura 4.13 muestra las presiones medias en las distintas zonas sensibles durante el transporte de los cilindros en función del tipo de agarre. Faria et al. (Faria, Martins, Lobo, \& Dias, 2012) realizaron una serie de ensayos en la que se realizaba una tarea de traslado a distintos objetos cotidianos, utilizando distintos tipos de agarres y el mismo sensor que en este ensayo. Comparando respectivamente los agarres 2D, 5D y cil con los agarres primitivos 1,5 y 3 descritos en ese ensayo puede comprobarse que la distribución de presiones en ambos casos es similar, ya que se utiliza el mismo agarre y se realiza la misma tarea. No obstante, nuestros resultados aportan información cualitativa adicional a la del trabajo de Faria et al. ya que ellos sólo distinguían entre tres niveles de presión (nulo, bajo, alto) en cada sensor.

Los resultados de los ANOVAS sobre la CGF (tablas 4.I y 4.m) muestran que la mayor parte de los factores afectan de forma significativa sobre la contribución porcentual de las distintas zonas, al igual que las interacciones entre los factores. Esto lleva a la conclusión por una parte de que la mano tiene un alto grado de especialización y es capaz de adaptar la fuerza de agarre a las 
características del objeto manipulado y, por otra, que cada sujeto es específico en su forma de agarrar, posiblemente como consecuencia de su anatomía y desarrollo neurológico. El hecho de que el factor 'Peso' peso no resulte significativo sobre la fuerza en gran parte de los sensores (S2, S4, S7, S8, S9, S11, S12, S13, S15 y S17) es coherente con algunos estudios previos, que indican que el valor de la fuerza se escala en función del peso, pero la contribución a la fuerza de agarre total es la misma (Domalain et al., 2008a; Hermsdörfer et al., 2011a).

El análisis de componentes principales ha mostrado que el mayor porcentaje de varianza en los resultados puede explicarse fundamentalmente por la contribución de las zonas distales (71.38\%). La segunda componente principal presenta coeficientes elevados en las falanges mediales y la palma, explicando un $18 \%$ adicional de la varianza. Estos resultados indican que en la manipulación de cilindros dentro de los rangos de diámetro y peso considerados en este ensayo las zonas más importantes para la manipulación son las puntas de los dedos.

El análisis del coeficiente de correlación entre el agarre libre y los otros tipos de agarre para cada uno de los cilindros (figura 4.14) permite afirmar que para los cilindros de pesos y diámetros pequeños, por debajo de los 500 gr y $50 \mathrm{~mm}$, se utiliza un agarre de 5 dedos, mientras que para pesos o diámetros más elevados, el agarre libre utiliza los 5 dedos pero tiende a asemejarse a un agarre cilíndrico de potencia.

Este ensayo presenta algunas limitaciones que hay que considerar en el análisis y comparación de los resultados. Por una parte, el grupo de sujetos es heterogéneo, ya que abarca tanto hombres como mujeres de distintas edades, y su número es reducido, lo que podría condicionar los valores medios objetivos promediados entre sujetos. Esta disparidad de sujetos podría explicar el hecho de que el factor 'Sujeto' haya sido estadísticamente significativo en todos los análisis realizados. Parte de este efecto del sujeto también podría estar relacionado con la diferente adaptación de las zonas sensibles del guante sensor a la mano del sujeto, ya que varía ligeramente en función del tamaño de la mano. Además, ha de tenerse en cuenta que una parte de la fuerza de la mano no está siendo registrada ya que el sensor, aunque cubre la mayor parte de la mano, no cubre su totalidad. 


\section{5.- Conclusiones}

En este capítulo se ha estudiado la contribución de las diferentes zonas de la mano a la fuerza total de agarre en el transporte de objetos cilíndricos de diámetros entre 35 y $90 \mathrm{~mm}$ y pesos entre 193 y $1117 \mathrm{~g}$. Se han realizado 5 tipos de agarres: 3 de precisión (tipo pinza con 2, 3 y 5 dedos), 1 de potencia (cilíndrico) y uno libre (sin dar indicaciones al sujeto acerca de cómo debía realizarlo). A partir del presente ensayo, pueden obtenerse las siguientes conclusiones:

- La repetibilidad de los ensayos con la metodología seguida se considera suficiente para abordar el análisis de las fuerzas de agarre y la contribución de las diferentes zonas de la mano.

- El sujeto que realiza el ensayo, el tipo de agarre y el peso y el diámetro de los cilindros afectan de forma estadísticamente significativa a la fuerza de agarre total en la manipulación del cilindro, lo que indica que el proceso de agarre es muy dependiente de las características del objeto y también del propio aprendizaje y anatomía del sujeto.

- La fuerza de agarre aumenta en promedio con el peso del cilindro, aunque no de forma directamente proporcional.

- La menor fuerza de agarre total en el transporte se realiza con el agarre tipo pinza con dos dedos, siendo ésta similar a la que se ejerce con el agarre con tres dedos. Cuando se incrementa el número de dedos crece la fuerzas de agarre. La mayor fuerza de agarre se produce con el agarre cilíndrico.

- El dedo que aporta una contribución más elevada a la fuerza de agarre es el pulgar, oscilando entre el $25 \%$ y el $40 \%$ de la fuerza de agarre total. Su contribución a la fuerza total de agarre decrece con el peso del cilindro y aumenta con su diámetro, para los rangos analizados. EI incremento de participación del pulgar al aumentar el diámetro se compensa con una reducción de la participación de la palma.

- Las zonas distales de los dedos son las que más contribuyen globalmente a la fuerza total de agarre para los objetos analizados, siendo esta contribución mayor para los cilindros de menor peso y para los de mayor diámetro. 
- La variación del peso del cilindro transportado no tiene un efecto estadísticamente significativo en la contribución de gran parte de las zonas de la mano, lo que indica una tendencia a realizar un escalado de las fuerzas proporcional en la mayor parte de las zonas de la mano, aunque no en todas.

- La coordinación entre las zonas de la mano en el reparto de la fuerza de agarre indica una coordinación de las falanges distales con la palma como modo principal de agarre para los casos analizados, con ajustes de menor importancia en las falanges medias y en las proximales.

- Para los cilindros analizados, el agarre libre seleccionado por el usuario es similar al 5D cuando el peso del cilindro es inferior a $500 \mathrm{gr}$ y su diámetro es igual o inferior a $50 \mathrm{~mm}$. Para diámetros superiores o pesos más elevados el agarre libre es intermedio entre el cilíndrico y el 5D. 
5.- Efecto de la tarea en el agarre en la manipulación de botellas 



\section{1.- Introducción}

Aunque varios estudios han medido las fuerzas de agarre ejercidas por la mano, la mayoría de ellos se basan en el agarre con las puntas de los dedos o bien utilizan dispositivos específicos en lugar de objetos reales (Aoki et al., 2006; McDowell et al., 2012; Radwin et al., 1992; Reilmann et al., 2001; Santello \& Soechting, 2000). Otros estudios utilizan objetos funcionales, tales como botellas, pero solamente analizan la cinemática o la posición de la mano en el agarre (Ansuini et al., 2008; Crajé et al., 2011). De esta forma, hay pocos estudios acerca de la distribución de las fuerzas de agarre en las distintas zonas de la mano durante la manipulación funcional de un objeto (Pylatiuk et al., 2006) y esto se puede explicar en cierta medida por la dificultad de encontrar sensores apropiados y no invasivos. Pylatiuk et al. (Pylatiuk et al., 2006) analizaron una manipulación funcional de botellas utilizando sensores de fuerza discretos especialmente diseñados para ese experimento que se colocaban en la mano, los cuales tenían $9 \mathrm{~mm}$ de diámetro y $3 \mathrm{~mm}$ de grosor. En un estudio más reciente, Hermsdörfer et al. (Hermsdörfer et al., 2011a) analizaron las fuerzas de agarre producidas como consecuencia de la manipulación de varios objetos de la vida diaria, aunque únicamente midieron las fuerzas de contacto de las puntas de tres dedos que ejecutaban el agarre.

El problema de la redundancia motriz en la producción de fuerza por la combinación de varios dedos ha sido remarcado por estudios previos (V M Zatsiorsky et al., 1998), de manera que la misma fuerza de agarre total se puede producir con diferentes contribuciones de los dedos individuales, lo que se conoce como la contribución de fuerzas (force sharing). Sin embargo, la contribución de fuerzas en las tareas cotidianas no se ha estudiado en profundidad. Poco se sabe acerca del efecto del sujeto, las características del objeto o de las tareas realizadas en la distribución de fuerzas que se produce entre los dedos en un agarre funcional.

El objetivo del presente estudio fue profundizar en el conocimiento de los agarres más usuales utilizados en actividades de la vida diaria (AVD). La manipulación de botellas u objetos similares es una AVD típica que es incluida en los protocolos de evaluación de la capacidad de agarre (Colin M. Light et al., 2002). Específicamente, se realizó la caracterización de la fuerza de agarre y la contribución de las distintas zonas de la mano a la misma durante la ejecución 
de dos tareas habituales con botellas, transporte y vertido de líquido. Se cuantificó la fuerza total y su distribución en las distintas áreas de la mano, analizándose el efecto de varios factores: el sujeto que ejecutaba la tarea; la tarea realizada, esto es, transporte y vertido; las características de la botella (forma y tamaño); y la cantidad de líquido en la botella. 


\section{2.- Materiales y métodos}

En el presente estudio participaron cinco sujetos diestros (tres hombres y dos mujeres) con edades entre 26 y 45 años. Ninguno de ellos había tenido ninguna lesión ni traumatismo en el brazo, mano o sus articulaciones. Los sujetos dieron su consentimiento informado al experimento, el protocolo del cual fue aprobado por el comité ético de la universidad.

Los objetos que se manipularon fueron cuatro botellas (figura 5.1): una botella de vidrio (B1) y tres de plástico (B2, B3 y B4). Cada botella se manipuló con dos pesos distintos, ya que la tarea se realizó con dos niveles diferentes de llenado (N1 y N2), tal como muestra la tabla 5.a.

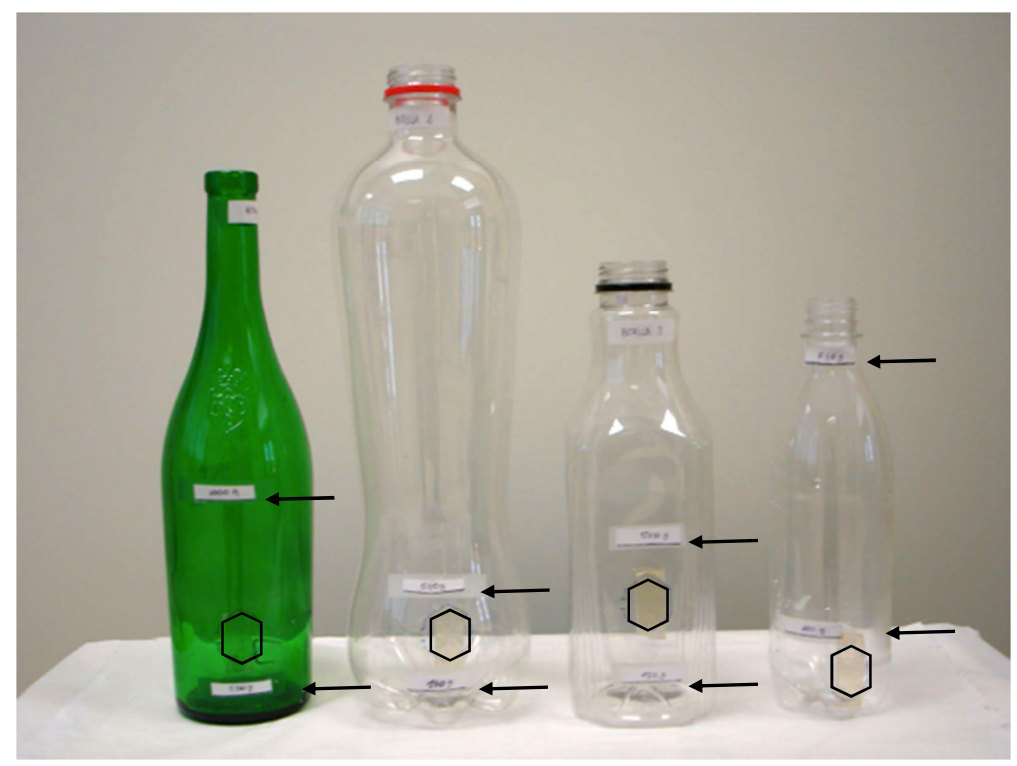

Figura 5.1: Botellas utilizadas en el experimento. De izquierda a derecha: B1, B2, B3 y $B 4$. Se ha remarcado con un contorno la localización de los sensores de posición. Las flechas indican los dos niveles a los que se llenaban las botellas.

Tabla 5.a: Características de las botellas: altura (h), diámetro (d), peso de la botella en vacío (WO) y peso total con los distintos niveles de llenado (W1,W2).

\begin{tabular}{ccccccc}
\hline Botella & $\mathbf{h}(\mathbf{m m})$ & $\mathbf{d}(\mathbf{m m})$ & Material & W0 $(\mathbf{g})$ & $\mathbf{W 1}(\mathbf{g})$ & $\mathbf{W} \mathbf{( g )}$ \\
\hline B1 & 300 & 80 & Vidrio & 523.5 & 550 & 1000 \\
B2 & 350 & 80 & PET & 49.0 & 150 & 550 \\
B3 & 245 & 75 & PET & 44.5 & 150 & 550 \\
B4 & 222 & 65 & PET & 28.5 & 150 & 550 \\
\hline
\end{tabular}


Para el ensayo los sujetos estaban sentados en una silla de altura ajustable en frente de la mesa, con el codo al mismo nivel que el tablero de la mesa. Se les pidió que realizaran dos tareas usando su mano derecha: la tarea T1 consistía en trasladar una botella desde la posición inicial B (figura 5.2) hasta la posición C, situada a $150 \mathrm{~mm}$ de B en dirección anterior. La tarea T2 consistía en coger la botella situada en la posición $B$ (figura 5.2), verter todo su contenido en un contenedor cilíndrico situado en $\mathrm{D}$, a $300 \mathrm{~mm}$ de $\mathrm{B}$, y devolver la botella vacía al punto $\mathrm{B}$. El contenedor tenía una altura de $150 \mathrm{~mm}$ y un diámetro de 150 $\mathrm{mm}$. Al inicio y final de ambas tareas, los sujetos tenían la mano derecha en la posición $\mathrm{A}$. Se les indicó que realizaran cada tarea a velocidad natural, pero no se les dio más indicaciones respecto al tipo de agarre ni se fijaron más restricciones. Cada combinación de botella, nivel de llenado y tarea se repitió cinco veces consecutivas, precedidas de cinco repeticiones de entrenamiento. El orden de las botellas fue aleatorio para cada sujeto. Todas las combinaciones de nivel de llenado y tarea para una misma botella se realizaron consecutivamente en orden aleatorio. Todos los experimentos para un mismo sujeto se realizaron en la misma sesión. La tabla 5.b muestra el resumen de experimentos realizados para cada sujeto, con las combinaciones de botella, tarea y nivel de llenado.

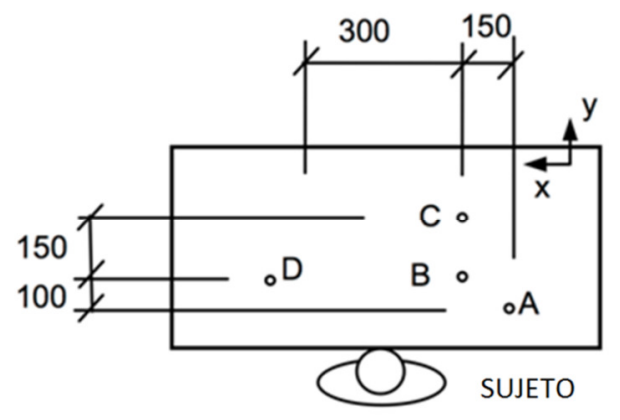

Figura 5.2. Disposición de la mesa y el sujeto para los experimentos (vista en planta): A es la posición inicial y final de la mano del sujeto, B es la posición inicial de la botella, $C$ es la posición final de la botella en la tarea T1 y D es la posición del contenedor donde se verterá el agua en la tarea $T 2$. 
Análisis de la distribución de presiones en la mano humana durante el agarre

Tabla 5.b. Combinación de parámetros para cada experimento.

\begin{tabular}{cccc}
\hline Experimento & Botella & Tarea & $\begin{array}{c}\text { Nivel de } \\
\text { Ilenado }\end{array}$ \\
\hline 1 & $\mathrm{~B} 1$ & $\mathrm{~T} 2$ & $\mathrm{~N} 2$ \\
2 & $\mathrm{~B} 1$ & $\mathrm{~T} 1$ & $\mathrm{~N} 2$ \\
3 & $\mathrm{~B} 1$ & $\mathrm{~T} 2$ & $\mathrm{~N} 1$ \\
4 & $\mathrm{~B} 1$ & $\mathrm{~T} 1$ & $\mathrm{~N} 1$ \\
5 & $\mathrm{~B} 2$ & $\mathrm{~T} 2$ & $\mathrm{~N} 2$ \\
6 & $\mathrm{~B} 2$ & $\mathrm{~T} 1$ & $\mathrm{~N} 2$ \\
7 & $\mathrm{~B} 2$ & $\mathrm{~T} 2$ & $\mathrm{~N} 1$ \\
8 & $\mathrm{~B} 2$ & $\mathrm{~T} 1$ & $\mathrm{~N} 1$ \\
9 & $\mathrm{~B} 3$ & $\mathrm{~T} 2$ & $\mathrm{~N} 2$ \\
10 & $\mathrm{~B} 3$ & $\mathrm{~T} 1$ & $\mathrm{~N} 2$ \\
11 & $\mathrm{~B} 3$ & $\mathrm{~T} 2$ & $\mathrm{~N} 1$ \\
12 & $\mathrm{~B} 3$ & $\mathrm{~T} 1$ & $\mathrm{~N} 1$ \\
13 & $\mathrm{~B} 4$ & $\mathrm{~T} 2$ & $\mathrm{~N} 2$ \\
14 & $\mathrm{~B} 4$ & $\mathrm{~T} 1$ & $\mathrm{~N} 2$ \\
15 & $\mathrm{~B} 4$ & $\mathrm{~T} 2$ & $\mathrm{~N} 1$ \\
16 & $\mathrm{~B} 4$ & $\mathrm{~T} 1$ & $\mathrm{~N} 1$ \\
\hline
\end{tabular}

Para registrar los datos, los sujetos fueron instrumentados con el sistema Finger TPS, cuyas características se detallan en el apartado 3.2 de esta tesis. La frecuencia de muestreo escogida fue de $40 \mathrm{~Hz}$. La figura 5.3 muestra la posición de cada sensor en la mano: cinco sensores en las falanges distales de cada dedo, incluido el pulgar (denominados como Index, Middle, Ring, Little y Thumb), dos sensores adicionales en las falanges proximales del índice y del dedo medio (denominados como Index2 y Middle2), y un sensor en la palma de la mano (denominado como Palm). La calibración se realizó mediante el procedimiento descrito en el apartado 3.2.

Las botellas fueron instrumentadas con un sensor magnético de posición (Fastrak Polhemus, Colchester, VT) para registrar su posición. El sensor receptor se fijó a la botella (el contorno se puede apreciar en la figura 5.1) y el transmisor se fijó a la mesa para que los ejes $X, Y, Z$ correspondieran a los movimientos mediales, anteriores y verticales, respectivamente. 


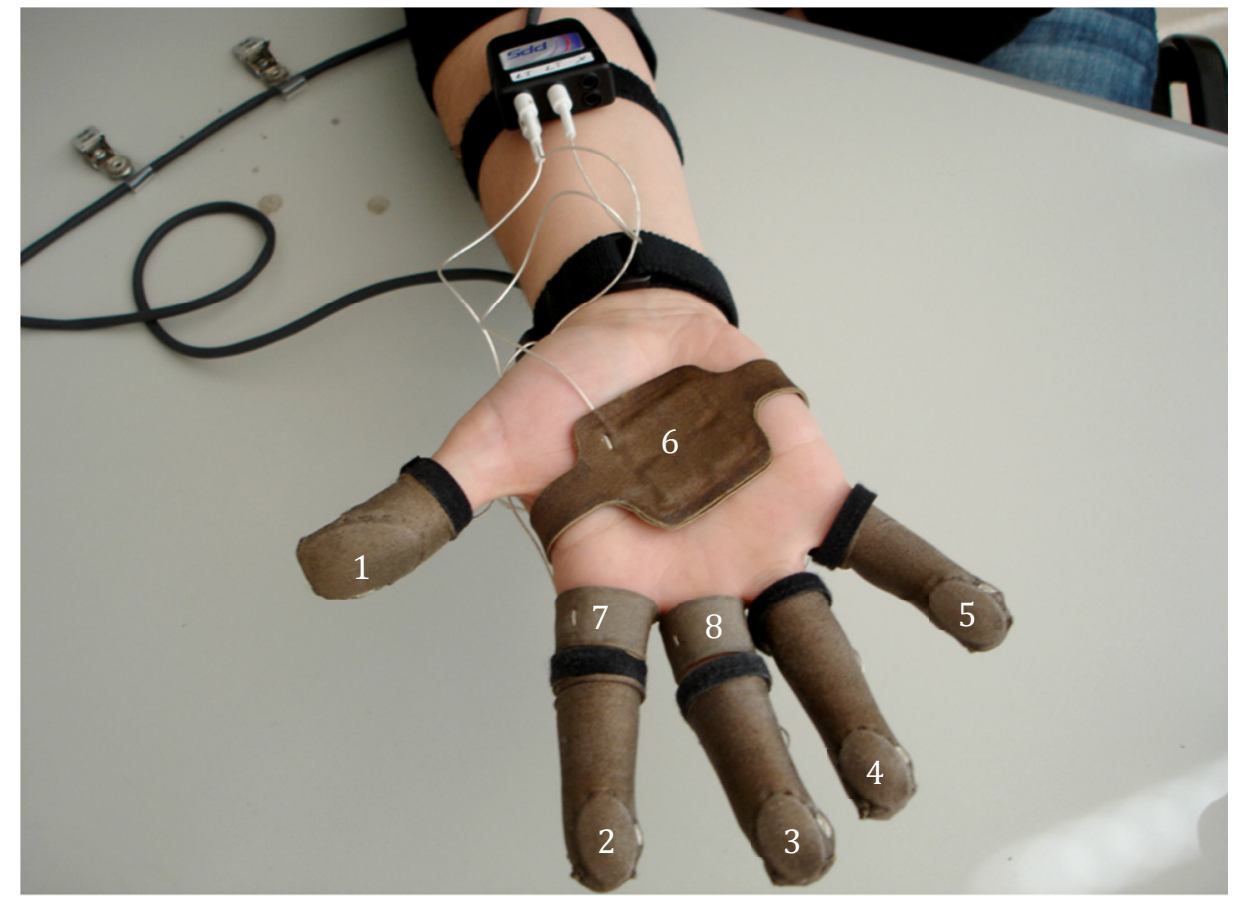

Figura 5.3. Disposición de los sensores Finger TPS en la mano del sujeto: Thumb (1), Index (2), Middle (3), Ring (4), Little (5), Palm (6), Index2 (7), Middle2 (8)

Las señales de presión, fuerza y posición se analizaron utilizando Matlab, después de reducir el rizado con un filtro paso-bajo del tipo forward-backward, que permitía el paso de frecuencias entre $0-20 \mathrm{~Hz}$. Los datos de los diferentes intentos se sincronizaron utilizando los instantes con las derivadas positivas y negativas máximas (en valor absoluto) de la señal del sensor Thumb, correspondiendo estos instantes de pendiente positiva y negativa máxima, respectivamente, a las fases de carga y descarga de la botella. El tiempo se normalizó al rango 0-1 para permitir comparar los distintos intentos independientemente del tiempo absoluto que hubiese costado realizarlos, situando los instantes de referencia de carga y descarga en los tiempos normalizados 0.3 y 0.7, respectivamente. La fuerza de agarre (GF) se calculó en cada instante sumando las fuerzas de todos los sensores. El valor medio de la fuerza de cada sensor $i\left(\mathrm{MSF}_{\mathrm{i}}, i=1, \ldots, 8\right)$ en el intervalo normalizado 0.4-0.6 se utilizó como el valor representativo cuando la botella se estaba manipulando.

Respecto al análisis estadístico, la repetibilidad de las medidas en las cinco repeticiones se comprobó mediante el error cuadrático medio (RMSE) en un 
análisis de varianza (ANOVA) sobre MSF con el factor 'sujeto $\mathrm{x}$ botella $\mathrm{x}$ tarea $\mathrm{x}$ nivel de llenado $x$ sensor'. El efecto de los diferentes factores en la fuerza total de agarre se investigó mediante la realización de un ANOVA con los factores 'sujeto', 'botella', 'tarea' y 'nivel de llenado'. El efecto de estos mismos cuatro factores en la fuerza en cada zona de la mano se analizó con distintos ANOVAS para cada sensor con MSF como variable dependiente.

La contribución relativa a la fuerza de agarre de cada zona de la mano se analizó mediante ANOVAS similares, siendo la variable dependiente la contribución media a la fuerza de agarre (CGF) de cada sensor, entre los instantes 0.4 y 0.6 de tiempo y conservando los mismos factores independientes. Para ambos ANOVAs, se realizaron análisis post-hoc de Tukey para determinar posibles agrupamientos en las variables 'botella' y 'sujeto'.

Además, para poder hallar posibles patrones en el comportamiento del agarre, se realizó un análisis de los componentes principales.

Para todos los análisis se consideró un nivel de significación del 5\%. 


\section{3.- Resultados}

La figura 5.4 muestras los desplazamientos típicos de la botella durante las dos tareas. Para la tarea T1, la coordenada Y muestra una transición suave desde el estado inicial hasta el final, separados $150 \mathrm{~mm}$, la coordenada vertical $Z$ sigue una curva de campana con un levantamiento máximo inferior a $50 \mathrm{~mm}$ y la posición $X$ permanece aproximadamente constante. Para la tarea T2, la posición $\mathrm{Z}$ sigue una curva de campana excéntrica a causa de una menor velocidad en el ascenso (vaciado de líquido) respecto al descenso de la botella, la posición $\mathrm{X}$ muestra un perfil con forma de $\mathrm{S}$ debido a la rotación que sufre la botella al verter el agua, mientras que la posición $\mathrm{Y}$ es aproximadamente constante con una pequeña oscilación debida a una ligera rotación de la botella. La excentricidad de la curva de la posición en $\mathrm{Z}$ aumenta con el nivel de llenado de la botella. La media de tiempo para realizar T1 fue de $1.08 \mathrm{~s}$ (SD 0.21) para el nivel de llenado N1 y de $1.22 \mathrm{~s}$ (SD 0.24) para N2. Para realizar T2, la media de tiempo fue $4.75 \mathrm{~s}$ (SD 1.39) para N1 y $8.47 \mathrm{~s}(2.17 \mathrm{~s}$ ) para N2.

Tarea T1

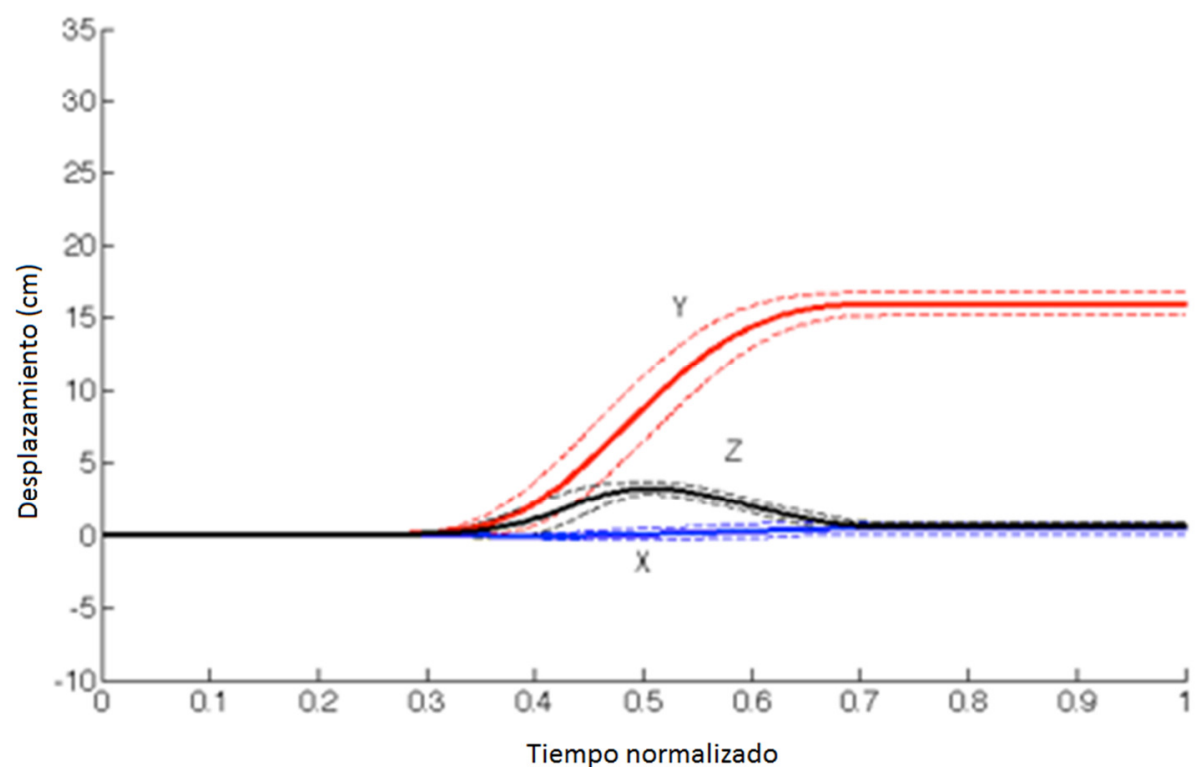




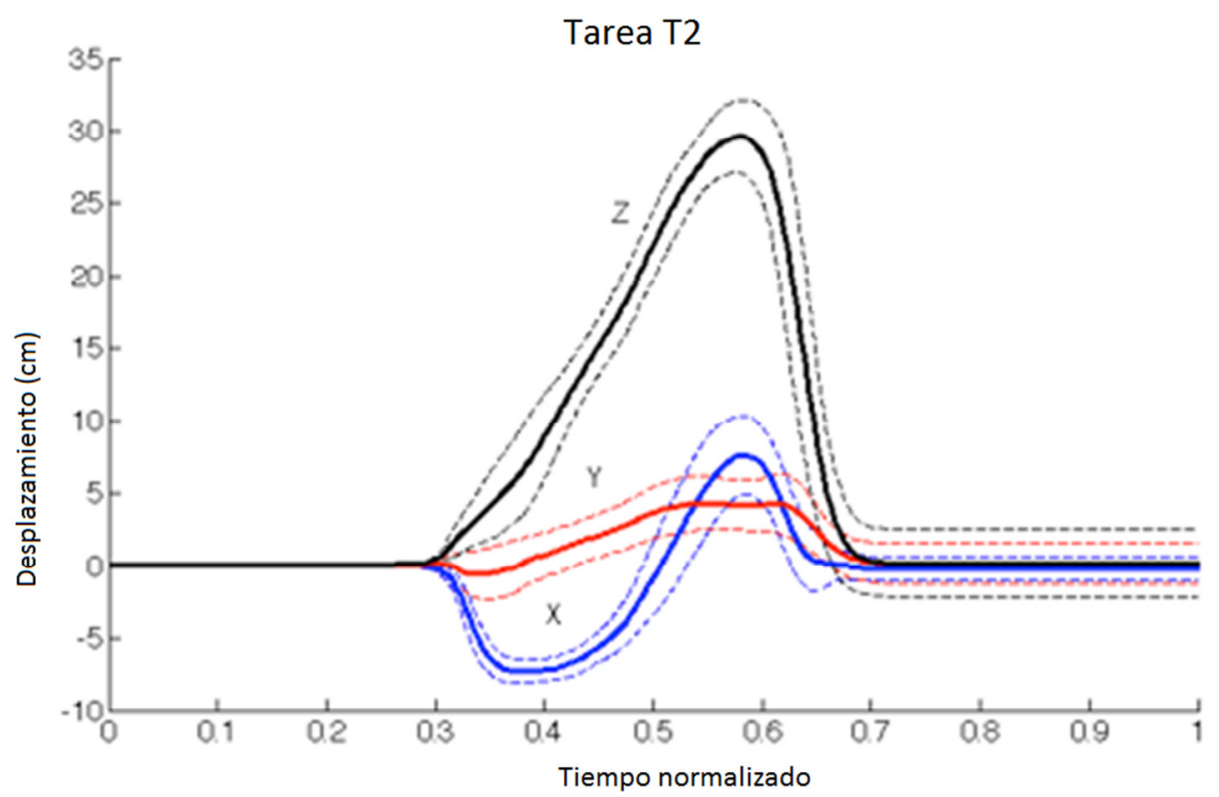

Figura 5.4. Desplazamientos medios (línea sólida) y desviación típica (línea de puntos) del sensor de la botella para un sujeto con la botella B2 y el nivel de llenado N1, en ambas tareas (a la izquierda, tarea de transporte, T1; a la derecha, tarea de vertido,

T2)

En la figura 5.5 se muestra la evolución de la GF normalizada para cada tarea, promediada para todas las pruebas. La normalización de la GF se ha realizado fijando el valor máximo de la fuerza a 100 (en porcentaje) en cada prueba. En ambas tareas se puede observar el mismo patrón, en el que se distinguen tres fases: un aumento rápido de GF durante la fase de carga, un descenso en GF durante la manipulación (más acusado en T2 que en T1) y un descenso rápido de GF durante la fase de descarga. También se observa un cambio en el valor de GF en T2 en el momento de la máxima inclinación de la botella al final del vertido (alrededor del instante normalizado 0.6), siendo este cambio más acusado para la botella más pesada (B1). 

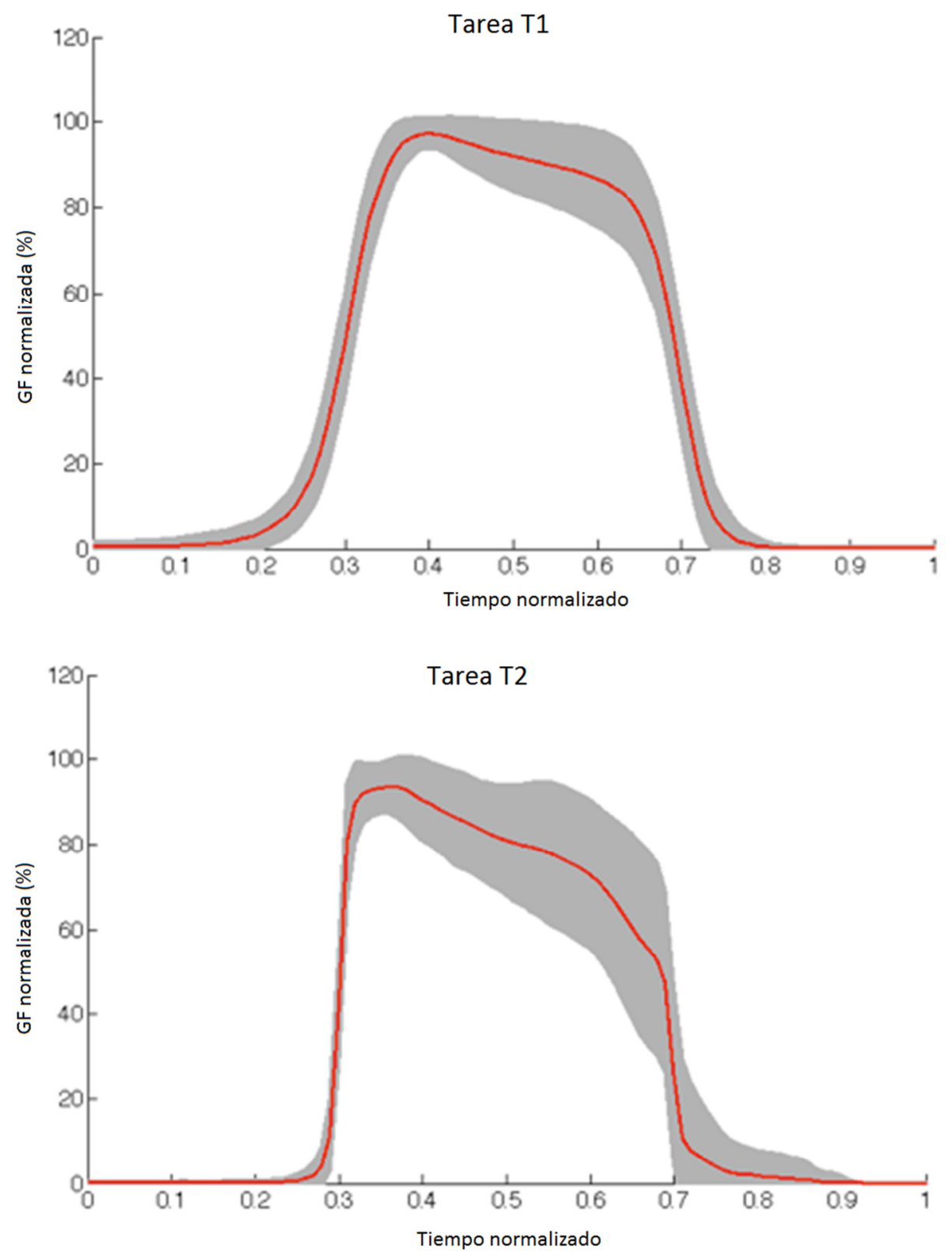

Figura 5.5: Valores medios y desviación típica de la GF normalizada en ambas tareas: arriba, tarea de transporte, $T 1$; abajo, tarea de vertido, T2. Se ha realizado una normalización de fuerzas tomando el valor máximo como 100 en todas las pruebas. 
El error de repetibilidad asociado a las diferentes cinco repeticiones de cada combinación de factores, obtenido a partir del RMSE del ANOVA del MSF con el factor 'sujeto $x$ botella $x$ tarea $x$ nivel de llenado $x$ sensor', fue de $0.88 \mathrm{~N}$.

La tabla 5.c muestra los resultados del ANOVA para MGF con los factores 'sujeto', 'botella', 'nivel de llenado', 'tarea' y sus interacciones simples. Todos los factores, a excepción de la tarea, muestran un efecto significativo en MGF. La mayor influencia en el valor es la asociada al sujeto, seguido de la botella. Las interacciones de los factores también tienen un efecto significativo en MGF, a excepción de la interacción 'sujeto x nivel de llenado'.

Tabla 5.c. Resultados del ANOVA para MGF con los factores sujeto (Suj), botella (Bot), nivel de llenado (Niv) y tarea (Tar) y sus interacciones.

\begin{tabular}{llllll}
\hline Factor & $\begin{array}{l}\text { Suma } \\
\text { cuadrados }\end{array}$ & $\begin{array}{l}\text { Grados de } \\
\text { libertad }\end{array}$ & $\begin{array}{l}\text { Cuadrado } \\
\text { medio }\end{array}$ & F & P \\
\hline Suj & 22664.3 & 4 & 5666.07 & 414.92 & 0.0000 \\
Niv & 1573.2 & 1 & 1573.18 & 115.2 & 0.0000 \\
Bot & 9419.4 & 3 & 3139.79 & 229.92 & 0.0000 \\
Tar & 2 & 1 & 1.99 & 0.15 & 0.7030 \\
Suj x Niv & 83.6 & 4 & 20.91 & 1.53 & 0.1926 \\
Suj x Bot & 8309.9 & 12 & 692.49 & 50.71 & 0.0000 \\
Suj x Tar & 4239.6 & 4 & 1059.90 & 77.62 & 0.0000 \\
Niv x Bot & 542.7 & 3 & 180.89 & 13.25 & 0.0000 \\
Niv x Tar & 165.1 & 1 & 165.10 & 12.09 & 0.0006 \\
Bot x Tar & 754.6 & 3 & 251.54 & 18.42 & 0.0000 \\
Error & 4957.1 & 363 & 13.66 & & \\
Total & 52711.4 & 399 & & & \\
\hline
\end{tabular}

El análisis post-hoc de Tukey para los ANOVAS mostró que dos de los sujetos realizaron una MGF similar (12.8 N y $12.1 \mathrm{~N}$ ), mientras que la de los otros tres sujetos era significativamente distinta ( $20.3 \mathrm{~N}, 26.9 \mathrm{~N}$ y $31.1 \mathrm{~N})$. Los mismos análisis indican que la variación entre las botellas B2, B3 y B4 no afecta de forma significativa en el MGF (18.5 N, 17,4 N y $17.8 \mathrm{~N}$, respectivamente), mientras que en la botella B1 se ejerció una MGF significativamente superior (29.1 N), en consonancia con su mayor peso. La MGF media para los niveles de llenado N1 y N2 fue de 18.7 N y 22.6 N, respectivamente. También se observó que la botella B1 con el nivel de llenado N1 se manipuló con una MGF superior $(28.5 \mathrm{~N})$ a la realizada para manipular las botellas B2, B3 y B4 con el nivel de llenado N2 (20.1 N), aunque el peso neto de todos los objetos fuera el mismo. 
La tabla 5.d resume los valores $\mathrm{p}$ obtenidos de los distintos ANOVAS para CGF en cada sensor, indicando de esta manera la significación estadística de cada factor. Los factores 'sujeto' y 'botella' tienen un efecto significativo en la CGF para todos los sensores. El factor 'nivel de Ilenado' solo afecta a la CGF de algunos sensores, como Thumb, Index y Middle2. El factor 'tarea' afecta significativamente a la CGF de todos los sensores, con la excepción de Middle y Little.

Tabla 5.d. Valores de p obtenidos de los ANOVAS para CGF con los factores sujeto (Suj), botella (Bot), nivel de llenado (Niv) y tarea (Tar).

\begin{tabular}{lllllllll}
\hline Factor & Thumb & Index & Middle & Ring & Little & Palm & Index2 & Middle2 \\
\hline Suj & 0.000 & 0.000 & 0.000 & 0.000 & 0.000 & 0.000 & 0.000 & 0.000 \\
Niv & 0.006 & 0.000 & 0.865 & 0.011 & 0.443 & 0.384 & 0.940 & 0.000 \\
Bot & 0.000 & 0.000 & 0.000 & 0.000 & 0.000 & 0.000 & 0.000 & 0.000 \\
Tar & 0.000 & 0.000 & 0.085 & 0.000 & 0.944 & 0.000 & 0.025 & 0.000 \\
Suj x Niv & 0.000 & 0.000 & 0.000 & 0.002 & 0.041 & 0.001 & 0.013 & 0.000 \\
Suj x Bot & 0.000 & 0.000 & 0.000 & 0.000 & 0.000 & 0.000 & 0.000 & 0.000 \\
Suj x Tar & 0.000 & 0.000 & 0.000 & 0.000 & 0.000 & 0.000 & 0.000 & 0.000 \\
Niv x Bot & 0.584 & 0.007 & 0.322 & 0.000 & 0.196 & 0.040 & 0.113 & 0.009 \\
Niv x Tar & 0.531 & 0.209 & 0.012 & 0.001 & 0.314 & 0.261 & 0.013 & 0.370 \\
Bot x Tar & 0.001 & 0.175 & 0.002 & 0.151 & 0.000 & 0.002 & 0.000 & 0.011 \\
\hline
\end{tabular}

La figura 5.6 muestra la MSF y la CGF para cada sensor, promediada sobre todos los sujetos y repeticiones, para cada combinación de botella, tarea y nivel de llenado, así como los valores medios para cada tarea. La fuerza registrada por Thumb fue la mayor entre los distintos sensores representando alrededor del $30-40 \%$ de la GF, seguida por la registrada por Middle, con una contribución cercana a la tercera parte de la medida por Thumb. Los sensores Index, Ring, Little y Palm registraron un promedio de fuerzas cercano a la mitad del medido por Middle. Las contribuciones de los dedos índice y medio, teniendo en cuenta los registros de los sensores situados tanto en la parte distal como en la proximal, fueron similares para ambos dedos, con un valor aproximado del $18 \%$. El sensor Little es el que registró una contribución menor en promedio, siendo de un $8 \%$ de la CGF. 

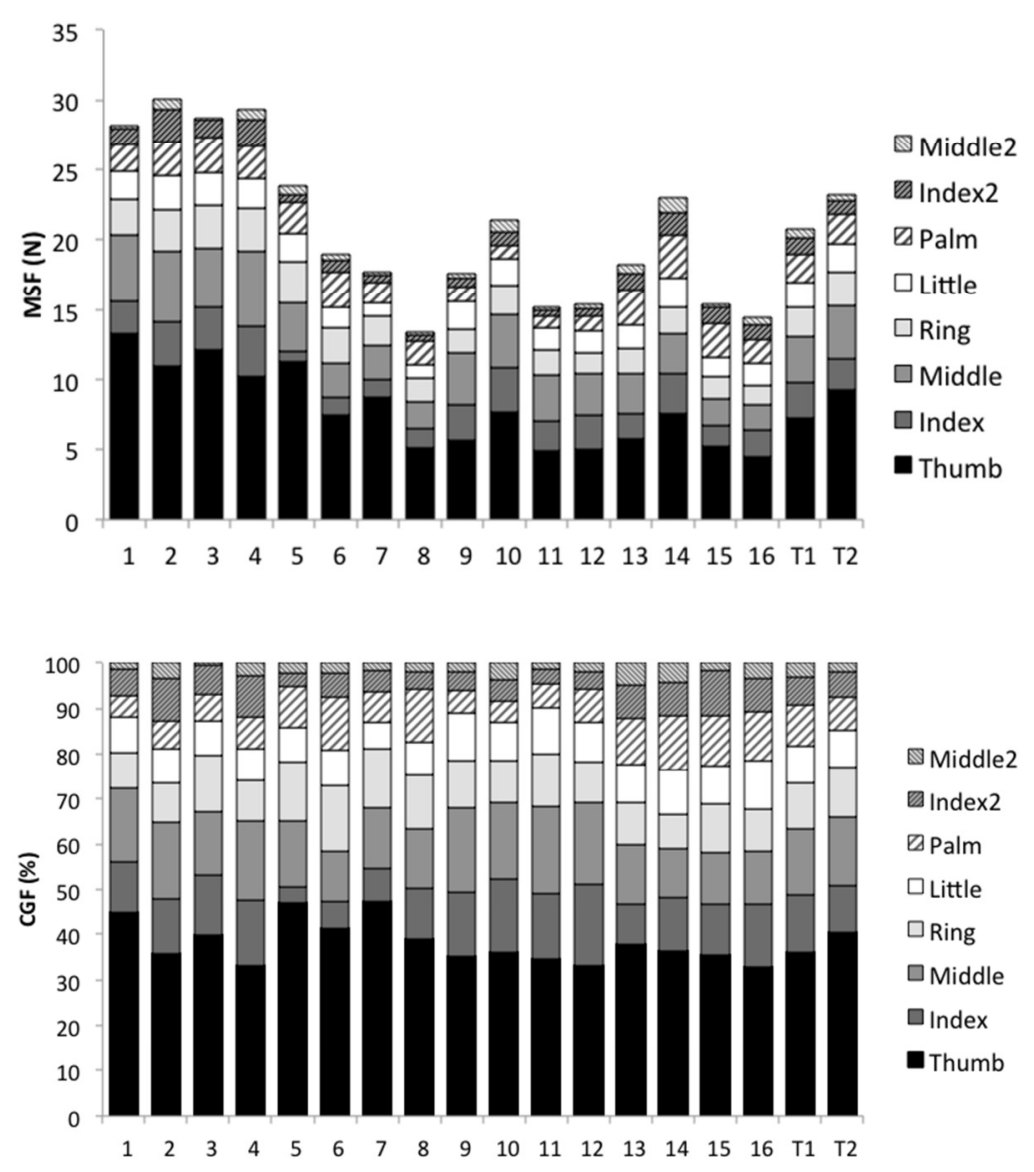

Figura 5.6. MSF (encima) y CGF (debajo) de cada sensor para cada experimento, promediado para todos los sujetos y repeticiones. Las dos últimas barras corresponden a los valores medios de las tareas $T 1$ y $T 2$.

La tabla 5.e muestra, por filas, los coeficientes cada uno de los componentes principales, obtenidos a partir de un análisis de componentes principales (PCA). Estos PC están ordenados de forma decreciente en cuanto a la parte de varianza explicada, de manera que el primero es el que explica la mayor parte de la varianza (un 72.1\%). Este PC está fuertemente correlacionado con el sensor Thumb. El segundo componente explica un $13.6 \%$ adicional, mostrando una actividad simultánea de los sensores Index 2, Ring y Little, es decir actividad desplazada hacia la parte cubital de la mano. El tercer PC indica un actividad principalmente del dedo índice (Index, Index 2) y del anular (Ring), más desplazada hacia la zona radial de la mano respecto al anterior PC. 
Capítulo 5. Efecto de la tarea en el agarre en la manipulación de botellas

Tabla 5.e. Coeficientes de los PC para cada sensor y la varianza asociada a cada PC

\begin{tabular}{|l|l|l|l|l|l|l|l|l|l|}
\hline PC & Thumb & Index & Middle & Ring & Little & Palm & Index 2 & Middle 2 & Varianza \\
\hline 1 & 0.9336 & -0.2808 & -0.2139 & 0.0062 & 0.0427 & -0.0375 & -0.0133 & -0.0183 & 0.7211 \\
\hline 2 & 0.0486 & 0.2202 & 0.0803 & 0.6012 & 0.4819 & -0.0176 & -0.5888 & -0.0455 & 0.8577 \\
\hline 3 & 0.2214 & 0.6987 & -0.0728 & 0.3728 & -0.5064 & 0.0898 & 0.2319 & 0.0169 & 0.9077 \\
\hline 4 & 0.0770 & 0.4870 & -0.1780 & -0.5457 & 0.0894 & -0.5724 & -0.2990 & -0.0485 & 0.9541 \\
\hline 5 & 0.1019 & 0.3574 & -0.0837 & -0.3601 & 0.4618 & 0.6893 & 0.1082 & 0.1584 & 0.9736 \\
\hline 6 & 0.2453 & 0.1016 & 0.9479 & -0.1451 & 0.0195 & -0.0619 & 0.0606 & -0.0452 & 0.9890 \\
\hline 7 & -0.0218 & 0.0961 & -0.0683 & 0.1861 & 0.5079 & -0.3154 & 0.6695 & -0.3812 & 0.9962 \\
\hline 8 & 0.0066 & 0.0014 & 0.0247 & 0.1281 & 0.1730 & -0.2900 & 0.2154 & 0.9069 & 1.0000 \\
\hline
\end{tabular}




\section{4.- Discusión}

La evolución en el tiempo de la fuerza total de agarre durante la tarea de transporte (figura 5.5) es similar a la obtenida por otros en tareas de elevación con dos dedos y con cinco dedos(Johansson \& Westling, 1984; Santello \& Soechting, 2000). Observando la figura 4.6, también se puede afirmar que dicha evolución es parecida a la tarea de transporte de cilindros del ensayo expuesto en el capítulo anterior. La fuerza de agarre necesaria para transportar la botella se alcanza en un intervalo de tiempo muy pequeño desde que se inicia el movimiento, y se reduce después del periodo de aceleración vertical para mejorar la eficiencia. En la tarea de vertido, esta reducción es aún más pronunciada que en la tarea de transporte, lo que se puede atribuir a la disminución de peso que sufre la botella durante el vertido. Además, esta reducción es mayor después del momento de mayor inclinación de la botella, cuando se requiere una menor precisión en la manipulación al haber finalizado el vertido.

El error de repetibilidad de $0.88 \mathrm{~N}$ confirma la idoneidad de los sensores para este tipo de medidas. Además, implica que los sujetos mantienen MGF y MSF similares al realizar una repetición de una tarea de forma consecutiva con las mismas condiciones. El ANOVA de la MGF (tabla 5.c) mostró que los sujetos son el factor que más afectan en la fuerza de agarre total, obteniéndose conclusiones similares a las de Kuo (Kuo et al., 2013). Esto puede ser debido a que cada sujeto selecciona coeficientes de seguridad distintos durante la manipulación, aunque las diferencias en el tamaño de la mano también pueden afectar a las posturas de prensión y también pueden explicar parte de este efecto. Los sujetos también afectan de forma significativa a la contribución que hacen las diferentes zonas de la mano a la fuerza de agarre (tabla 5.d), indicando que la manipulación es altamente dependiente del sujeto.

El peso y las características de la botella también tienen un efecto significativo en la fuerza de agarre, tal como se puede ver en la tabla 5.c. Un mayor nivel de llenado implica un mayor peso de la botella, lo que se traduce en un aumento de la fuerza de agarre para todos los sujetos, lo cual es lógico. Esto explica el motivo por el que la interacción sujeto y nivel de llenado no es significativa en el ANOVA: ante un aumento de peso, todos los sujetos reaccionan igual 
(aumentando la fuerza de agarre). Sin embargo, es remarcable que la fuerza de agarre es proporcionalmente mayor para las botellas más ligeras (figura 5.6). Las botellas más pesadas son manipuladas con coeficientes de seguridad menores, lo que concuerda con anteriores trabajos(Westling \& Johansson, 1984b). Posiblemente esto se deba a que los sujetos tiendan a manipular los objetos más pesados (o aparentemente más pesados) con un menor coeficiente de seguridad para reducir la fatiga muscular, o bien que los sujetos utilizan fuerzas mayores que las necesarias para mover objetos más ligeros. El material de la botella también parece tener un papel determinante en la fuerza de agarre, ya que la botella de vidrio se manipula con una fuerza superior que la de las botellas de plástico, aunque tengan el mismo peso. El motivo puede ser el distinto coeficiente de rozamiento, así como la menor rigidez de las botellas de plástico respecto a la de vidrio, lo que provoca que se manipulen las de plástico con una fuerza menor para que no haya deformaciones en la misma.

Además, estudios previos han demostrado que la fuerza de agarre depende del tamaño y del material de la botella, de manera que si la botella parece más pesada que otra manipulada anteriormente, la fuerza de agarre será mayor, independientemente del peso real de ambas(Buckingham, Cant, \& Goodale, 2009)(Cole, 2008)(Li et al., 2009). Las características de la botella también tienen un efecto significativo en la contribución de las diferentes zonas de la mano a la fuerza total de agarre (tabla 5.d), debido a que distintos tamaños y geometrías pueden implicar configuraciones distintas de contacto entre la mano y la botella, junto con la necesidad de utilizar distintas estrategias de intercambio de fuerzas para mejorar la estabilidad de la botella. Nuestros resultados sugieren que un incremento del nivel de llenado (y por tanto, del peso) no puede ser compensado únicamente escalando la fuerza de agarre, sino que requiere además una variación en la contribución de la fuerza de cada área.

Nuestros resultados muestran que las botellas se manejan con fuerzas totales de agarre similares independientemente de la tarea realizada, transporte o vertido (tabla 5.c), pero la contribución de la mayor parte de las áreas de la mano a esa fuerza de agarre es significativamente diferente (tabla 5.d). La contribución del pulgar a la fuerza de agarre es superior para la tarea de vertido, ya que el pulgar está situado en la parte baja de la botella mientras se 
vierte el líquido en el contenedor. El pulgar tiene que aumentar su contribución para contrarrestar la fuerza de la gravedad, lo que no ocurre con los otros dedos, localizados en la parte de arriba de la botella. La contribución de las zonas distales de los dedos medio y meñique no cambian significativamente con la tarea, debido probablemente a que esas zonas de la mano se utilizan sobre todo para mantener el equilibrio y control de la inclinación de la botella durante la tarea de vertido.

El agarre humano es complejo, tal como se aprecia al observar en los ANOVAS, tanto para la MGF como para la CFG, ya que la mayor parte de las interacciones entre factores son significativas. Como anteriormente se ha explicado, el hecho de que la interacción entre el sujeto y el nivel de llenado no salga significativa para MGF indica que ante una variación en el nivel de llenado ( $y$, por tanto, en el peso total de la botella) todos los sujetos reaccionan igual, esto es, si la botella es más pesada, todos aumentan la fuerza de agarre y, si es más ligera, todos la reducen(Vladimir M Zatsiorsky \& Latash, 2008). De la misma manera, las interacciones entre el nivel de llenado y los factores botella o tarea fueron no significativas respecto a la contribución del pulgar (registrado por el sensor Thumb), lo que se interpreta en el sentido de que la contribución del pulgar siempre crece cuando el contenido de la botella aumenta, independientemente de la tarea o el tipo de botella manipulado.

Tal como se ha mostrado, la mayor contribución a la fuerza total de agarre corresponde a la medida por el sensor Thumb, lo que implica que el pulgar es el dedo que más fuerza ejerce, conclusión presentada por otros estudios (Olafsdottir, Zatsiorsky, \& Latash, 2005; Pylatiuk et al., 2006). De nuestros resultados se desprende además que la contribución total del dedo índice es similar a la del dedo medio (considerando la suma de las dos zonas medidas, la distal y la proximal), mientras que los dedos anular y meñique y la zona de la palma realizan una contribución menor, lo que también concuerda con otro estudio con objetos y tareas similares (Pylatiuk et al., 2006). La estrategia de contribución de la fuerza para ambas tareas (figura 5.6b, últimas dos barras) muestra una contribución ligeramente superior de los dedos pulgar y anular en la tarea de vertido, mientras que en la tarea de transporte hay una mayor contribución de la palma y del dedo índice. Pylatiuk et al. (Pylatiuk et al., 2006) también concluyeron resultados similares cuando compararon una tarea de elevación frente a otra que simulaba una tarea de vertido usando varios tipos 
diferentes de sensores de fuerza. Nuestros resultados confirman dicha conclusión con tareas reales y objetos de la vida diaria.

En el PCA se determina que la primera componente principal consigue explicar la mayor parte de la varianza en la distribución de esfuerzos de agarre (72,1\%), correspondiendo al esfuerzo realizado por el pulgar de forma independiente, ya que el coeficiente que presenta el sensor Thumb es elevado (0.934). La segunda componente principal explica un $13,7 \%$ de varianza adicional, correspondiendo al esfuerzo coordinado de los dedos anular (coeficiente de 0.601 en Ring), índice ( 0.220 en Index y -0.589 en Index 2) y meñique (coeficiente de 0.482 en Little), que funcionarían como una única entidad que se opone al pulgar para conseguir el agarre. El valor negativo de Index 2 significa que la zona proximal del dedo índice disminuye su fuerza cuando aumenta en los dedos anular y meñique y parte distal del índice. El tercer componente principal corresponde a una mayor actividad en la parte más radial de la mano (índice principalmente con menor contribución del dedo anular). El resultado parece indicar que la actividad del pulgar, siempre presente para las tareas analizadas, es compensada con una mayor actividad en la zona cubital de la mano (PC2) o en la zona radial (PC3) dependiendo de la tarea. Es interesante observar que para las tareas realizadas el dedo medio no parece actuar de forma coordinada con el resto en la estrategia de agarre. Probablemente su contribución es bastante común independientemente del objeto o la tarea, siendo los dedos más radiales o cubitales los que actúan de forma diferenciada en función del objeto o tarea para ayudar al dedo medio en la oposición al pulgar.

Aunque el presente estudio contribuye a un mejor entendimiento de la distribución de fuerzas de agarre en dos actividades cotidianas de la vida diaria, tiene algunas limitaciones que se deben considerar. El sistema de medida Finger TPS usado en los ensayos solamente detecta fuerzas normales y está limitado a ciertas áreas de la mano. Otras zonas de la mano que no estén recubiertas por los sensores pueden contribuir a la fuerza total de agarre sin que dicha contribución quede registrada. A pesar de eso, los ocho sensores utilizados en el presente trabajo para detectar dichas fuerzas cubrían las principales zonas de la mano utilizadas en el agarre de las botellas empleadas. La calibración del sensor puede afectar a la comparación de resultados entre sujetos. Además, la localización de los sensores para cada sujeto puede ser 
ligeramente diferente como consecuencia de la diferente antropometría de la mano. Por otro lado, el cambio de la retroalimentación aferente como consecuencia de los sensores puede afectar a las fuerzas ejercidas para manipular los objetos. En este trabajo, nuestra investigación se ha limitado a cuatro botellas distintas con dos niveles de llenado, con intervalos de peso entre $150 \mathrm{~g}$ y $1000 \mathrm{~g}$, lo que es representativo de la mayoría de agarres de precisión utilizados en actividades de la vida diaria. Solo se han analizado dos tareas, transporte y vertido, y el tipo de agarre se seleccionó de forma libre por el sujeto. En cambio, otras tareas pueden implicar un tipo de agarre distinto que no ha sido analizado en el presente estudio, lo que se debe tener en cuenta en el momento de extrapolar las conclusiones obtenidas a otras actividades. 


\section{5.- Conclusiones}

En este capítulo se ha estudiado la fuerza de agarre y la contribución de las diferentes zonas de la mano en la realización de dos tareas (transporte y vertido) manipulando 4 tipos distintos de botellas, con pesos entre $1000 \mathrm{~g}$ y $150 \mathrm{~g}$.

Las conclusiones obtenidas a partir de este ensayo son las siguientes:

- La repetibilidad de los ensayos se considera suficiente para realizar el análisis de la MGF y de las CFG de cada zona usando la metodología empleada.

- La evolución en el tiempo de la fuerza total de agarre de la tarea T1 (de transporte de la botella) es similar a la del transporte de cilindros, expuesta en el capítulo anterior.

- El sujeto, el tipo de botella, el peso de la botella y la tarea realizada afectan de forma estadísticamente significativa a la GF en la manipulación de la botella. Se llega por tanto a la misma conclusión obtenida en el ensayo expuesto en el capítulo anterior: las características del objeto manipulado y del sujeto que lo manipula afectan de forma significativa al proceso de agarre, variando la GF con la que se manipula.

- Para distintos niveles de llenado (pesos distintos) se realizan fuerzas diferentes, aunque las botellas más pesadas son manipuladas con coeficientes de seguridad menores, por lo que la fuerza no aumenta con el peso de forma lineal sino con un coeficiente menor que uno.

- La MGF en la manipulación de las botellas es similar independientemente de la tarea que se realice; las CGF sí que cambian en función de la tarea realizada. Para la tarea de vertido, la contribución del pulgar es superior que para la de transporte.

- La mayor CGF corresponde al pulgar, seguido por el índice y el dedo medio. Los dedos anular y meñique, así como la palma, proporcionan una contribución menor.

- El mayor porcentaje de varianza en los resultados de MGF es debido fundamentalmente en primer lugar a la contribución del pulgar. La variabilidad explicada por el dedo medio es baja, siendo los dedos índice, anular y meñique los que cambian su contribución para ayudar 
Análisis de la distribución de presiones en la mano humana durante el agarre

al medio en la oposición al pulgar, con una actuación más desplazada hacia la zona cubital o hacia la zona radial de la mano, dependiendo de la tarea o el objeto manipulado. 



\section{6.- Caracterización del agarre en la realización de tareas cotidianas}





\section{1.- Introducción}

En el presente capítulo se analiza la fuerza de agarre y la contribución a la misma de las distintas zonas de la mano realizada al ejecutar tareas de la vida diaria, superando las limitaciones en cuanto al tipo de objeto y a las tareas analizadas de los trabajos presentados en los capítulos anteriores, en los que se analizaba el transporte de cilindros de laboratorio y las tareas de transporte y vaciado con botellas.

Existen trabajos previos que en lugar de utilizar objetos cotidianos reales para estudiar el agarre, han utilizado objetos de laboratorio (Dong, Wu, Welcome, \& McDowell, 2008; Edgren et al., 2004; N.J. Seo \& Armstrong, 2011; Na Jin Seo \& Armstrong, 2008) o instrumentados (Ghali, Thalanki Anantha, Chan, \& Chau, 2013; Hooke, Park, \& Shim, 2008; R W McGorry \& Lin, 2007; Shim et al., 2010) con el fin de extrapolar los resultados obtenidos a los objetos reales.

El interés del estudio de las fuerzas de agarre sobre objetos reales consiste en que permite obtener resultados que estén influenciados en la menor medida posible por el parecido del objeto instrumentado o del equipo de laboratorio con el objeto real. Además, la variedad de tareas realizadas con la mano humana viene condicionada sobre todo por el objeto que se manipula y la tarea que se realiza con el mismo, durante las actividades de la vida diaria.

Un estudio de Vergara et al. (Vergara, Sancho-Bru, Gracia-Ibáñez, \& PérezGonzález, 2014) muestra que los agarres más comunes en las actividades de la vida diaria (AVD) en número de usos por día son el de tipo pinza, no prensil, cilíndrico, pinza lateral y lumbrical, siendo los que ocupan mayor porcentaje de tiempo diario el de pinza, el oblicuo, el lumbrical y el cilíndrico.

En este capítulo se analizó la fuerza de agarre y la contribución a la misma de las distintas zonas de la mano en la realización de 21 actividades representativas de la vida diaria. 


\section{2.- Materiales y métodos}

En el estudio participaron 22 sujetos diestros (12 mujeres y 10 hombres) con edades entre 21 y 58 años. Ninguno de ellos había tenido ninguna lesión ni traumatismo en el brazo, mano o sus articulaciones. Los sujetos dieron su consentimiento informado al experimento, el protocolo del cual fue aprobado por el comité ético de la universidad.

Se realizaron un total de 21 tareas distribuidas entre 5 escenarios (Puerta, Mesa de lectura, Mesa de comida, Lavabo, Zona de limpieza y Zona de Planchado) para las que se utilizaron varios objetos. En la figura 6.1 se muestran los distintos escenarios y en la figura 6.2, los objetos que se encontraban en cada uno de ellos.

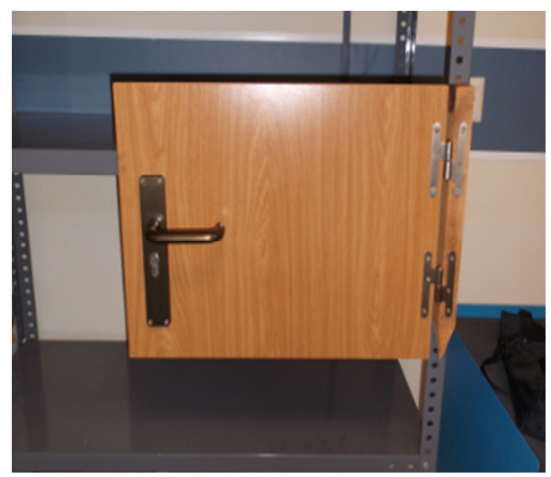

Escenario 1: Puerta

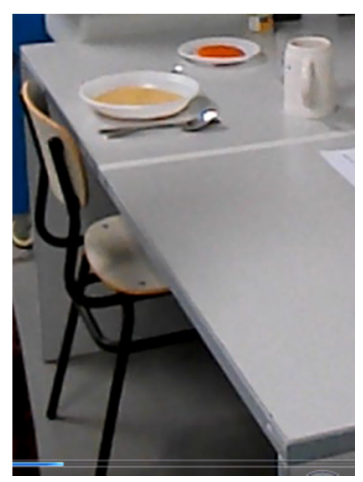

Escenario 3: Mesa de comida

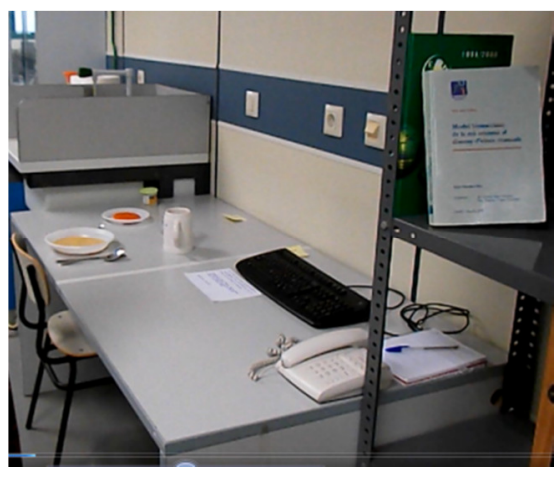

Escenario 2: Mesa de lectura

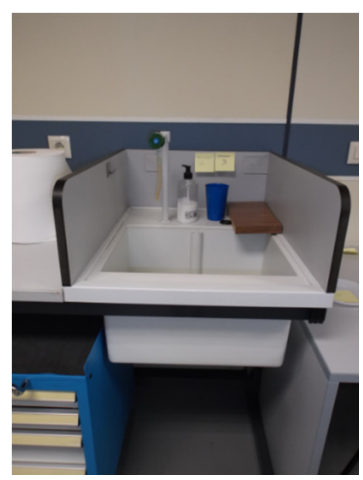

Escenario 4: Lavabo 


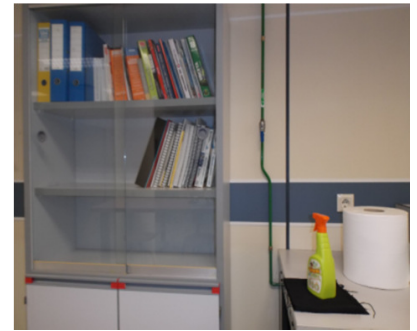

Escenario 5: Zona de limpieza

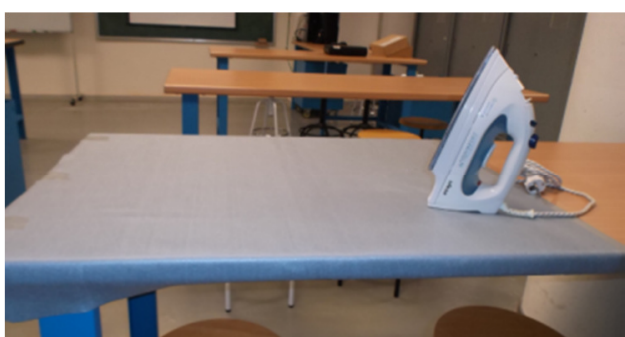

Escenario 6: Zona de planchado Figura 6.1: Escenarios para realizar las actividades

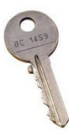

(a)

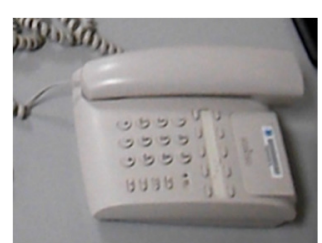

(e)

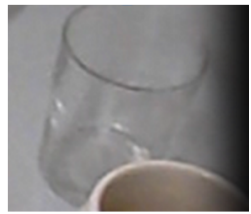

(i)

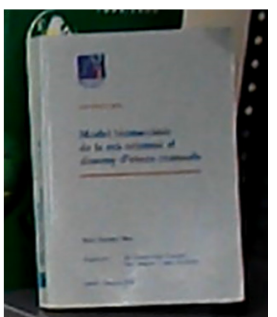

(b)

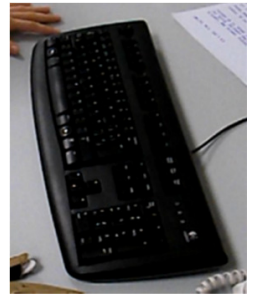

(f)

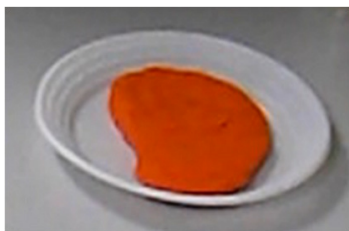

(j)

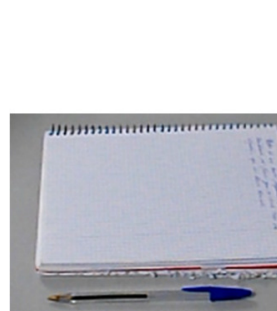

(c)

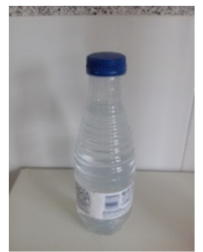

(g)

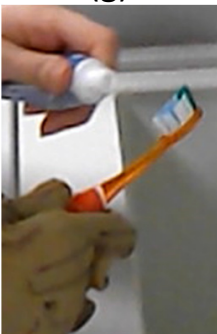

(k)

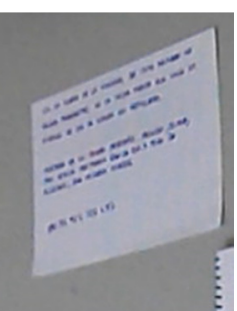

(d)

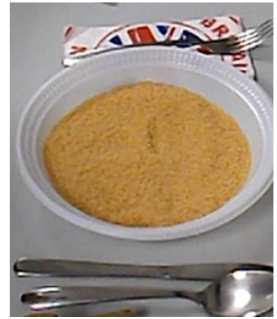

(h)

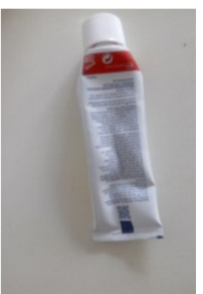

(I) 


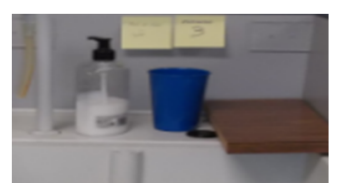

(m)

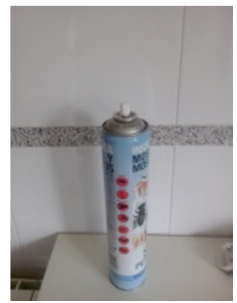

(q)

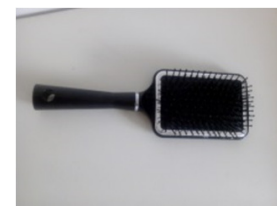

(n)

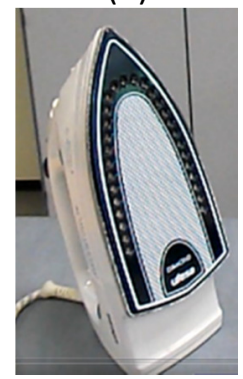

(r)

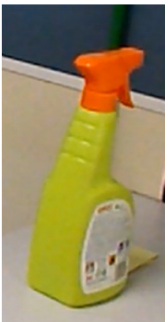

(o)

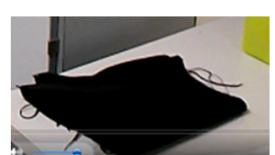

(p)

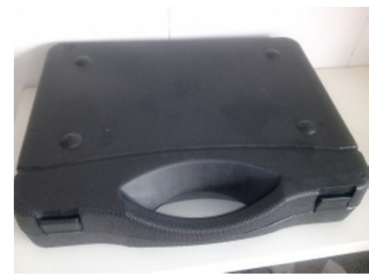

(s)

Figura 6.2: Objetos en cada escenario. Escenario 1: (a) Ilave; escenario 2: (b) libro, (c) libreta/bolígrafo, (d) modelo de texto escrito, (e) teléfono, (f) teclado; escenario 3: (g) botella de agua, (h) plato y cubiertos, (i) vaso, (j) bistec de plastilina; escenario 4: ( $k$ ) cepillo de dientes, (I) tubo de pasta de dientes, $(m)$ vaso del cepillo de dientes, ( $n$ ) cepillo de pelo; escenario 5: (o) pulverizador de limpieza, (p) trapo, (q) aerosol insecticida; escenario 6: (r) plancha, (s) maletín.

Para registrar los datos, la mano del sujeto se instrumentó con el sistema Grip 4256E, de Tekscan Inc., descrito en el capítulo 3. La frecuencia de muestreo empleada fue de $50 \mathrm{~Hz}$.

Para facilitar la colocación en la mano, el sensor se montó cosido sobre un guante de algodón siguiendo las recomendaciones del fabricante. Una vez puesto el guante sobre la mano del sujeto, se recubría el mismo con otro guante transparente delgado de polietileno de baja densidad para proteger el sensor y, encima de este, se colocaba otro guante de látex para fijar la posición del sensor, evitar el contacto directo con el objeto a manipular y asegurar un coeficiente de rozamiento más constante en el contacto mano-objeto (figura 6.3). 


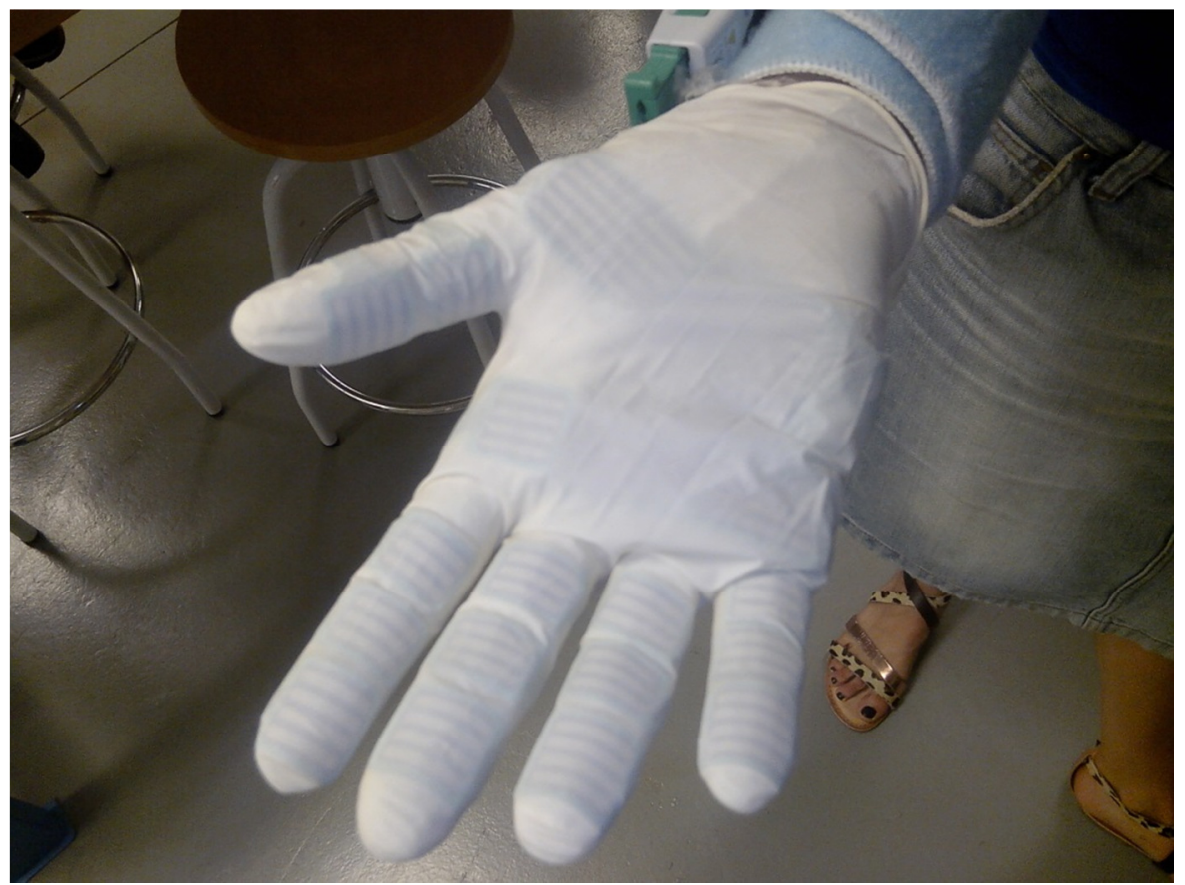

Figura 6.3: Sensor Grip 4256-E (Tekscan, Inc.) cosido a un guante de algodón y recubierto por un guante de LDPE y otro de látex para fijarlo.

La posición inicial del sujeto variaba en función de la tarea a realizar, habiendo dos posibilidades: De pie y Sentado. En la posición De pie el sujeto estaba de pie delante del objeto a manipular con los brazos relajados colgando a sus lados, de manera que no hubiese una presión previa en el sensor. En la posición Sentado el sujeto estaba sentado en una silla delante del objeto a manipular. Las manos estaban a ambos lados del sujeto, de manera que no estuvieran en contacto con nada.

En la tabla 6.a se muestran las tareas realizadas, con una breve descripción en la que se indican las etapas, el escenario donde se realizó, la postura inicial, la clasificación CIF (Who, 2001) y el tipo o tipos de agarre previsto según análisis visual previo de las tareas. 
Tabla 6.a. Tareas realizadas en el experimento

\begin{tabular}{|c|c|c|c|c|c|c|}
\hline Tarea & $\begin{array}{c}\text { Descripción } \\
\text { (etapas) }\end{array}$ & Escenario & $\begin{array}{c}\text { Material } \\
\text { necesario }\end{array}$ & $\begin{array}{c}\text { Postura } \\
\text { inicial }\end{array}$ & CIF & $\begin{array}{c}\text { Tipos de } \\
\text { agarre }\end{array}$ \\
\hline $\begin{array}{c}\text { T01 - Abrir } \\
\text { con llave }\end{array}$ & $\begin{array}{l}\text { Coger llave - } \\
\text { introducir llave } \\
\text { - girar llave } \\
\text { 180o horario - } \\
\text { girar llave } \\
\text { posición } \\
\text { original - sacar } \\
\text { llave - dejar } \\
\text { llave }\end{array}$ & Puerta & Llave & De pie & $\begin{array}{l}\text { Capítulo } 4 \text { - } \\
\text { Movilidad. } \\
\text { Llevar, mover y } \\
\text { usar objetos. - } \\
\text { d440 Uso fino } \\
\text { de la mano }\end{array}$ & $\begin{array}{c}\text { Pinza } \\
\text { lateral }\end{array}$ \\
\hline $\begin{array}{c}\text { T02 - Abrir } \\
\text { puerta }\end{array}$ & $\begin{array}{c}\text { Coger } \\
\text { picaporte - } \\
\text { girar picaporte } \\
\text { a tope - abrir } \\
\text { puerta - cerrar } \\
\text { puerta - } \\
\text { devolver } \\
\text { picaporte a la } \\
\text { posición } \\
\text { original }\end{array}$ & Puerta & $\begin{array}{l}\text { Puerta con } \\
\text { picaporte }\end{array}$ & De pie & $\begin{array}{l}\text { Capítulo } 4 \text { - } \\
\text { Movilidad. } \\
\text { Llevar, mover y } \\
\text { usar objetos. - } \\
\text { d445 Uso de la } \\
\text { mano y el brazo }\end{array}$ & Oblicuo \\
\hline $\begin{array}{c}\text { T03 - Coger } \\
\text { libro }\end{array}$ & $\begin{array}{l}\text { Coger libro de } \\
\text { la estantería } \\
\text { con la mano } \\
\text { derecha y } \\
\text { dejarlo en la } \\
\text { mesa en } \\
\text { posición para } \\
\text { lectura }\end{array}$ & $\begin{array}{l}\text { Mesa de } \\
\text { lectura }\end{array}$ & $\begin{array}{c}\text { Libro, } \\
\text { estantería, } \\
\text { mesa }\end{array}$ & De pie & $\begin{array}{l}\text { Capítulo 4 - } \\
\text { Movilidad. } \\
\text { Llevar, mover y } \\
\text { usar objetos. - } \\
\text { d430 Levantar y } \\
\text { llevar objetos }\end{array}$ & Lumbrical \\
\hline $\begin{array}{c}\text { T04- } \\
\text { Escribir }\end{array}$ & $\begin{array}{c}\text { Coger bolígrafo } \\
\text { y escribir texto } \\
\text { indicado, } \\
\text { dejando el } \\
\text { bolígrafo al } \\
\text { acabar } \\
\end{array}$ & $\begin{array}{l}\text { Mesa de } \\
\text { lectura }\end{array}$ & $\begin{array}{c}\text { Mesa, folio, } \\
\text { bolígrafo }\end{array}$ & Sentado & $\begin{array}{l}\text { Capítulo } 1 \text { - } \\
\text { Aplicación del } \\
\text { conocimiento - } \\
\text { d170 Escribir }\end{array}$ & $\begin{array}{c}\text { Pinza } \\
\text { especial }\end{array}$ \\
\hline $\begin{array}{c}\text { T05- } \\
\text { Contestar } \\
\text { teléfono }\end{array}$ & $\begin{array}{l}\text { Coger auricular } \\
\text { con la derecha } \\
\text { - llevarlo a la } \\
\text { oreja durante } 3 \\
\text { segundos - } \\
\text { colgar auricular }\end{array}$ & $\begin{array}{l}\text { Mesa de } \\
\text { lectura }\end{array}$ & $\begin{array}{c}\text { Mesa, } \\
\text { teléfono }\end{array}$ & Sentado & $\begin{array}{c}\text { Capítulo } 3 \text { - } \\
\text { Conversación y } \\
\text { utilización de } \\
\text { aparatos y } \\
\text { técnicas de } \\
\text { comunicación - } \\
\text { d360 Utilización } \\
\text { de dispositivos } \\
\text { y técnicas de } \\
\text { comunicación }\end{array}$ & $\begin{array}{l}\text { Agarre de } \\
\text { precisión } \\
\text { de } \\
\text { potencia } \\
\text { intermedia }\end{array}$ \\
\hline $\begin{array}{c}\text { T06- } \\
\text { Marcar } \\
\text { teléfono }\end{array}$ & $\begin{array}{l}\text { Marcar con la } \\
\text { mano derecha } \\
\text { una serie de } \\
\text { números } \\
\text { indicados }\end{array}$ & $\begin{array}{l}\text { Mesa de } \\
\text { lectura }\end{array}$ & $\begin{array}{l}\text { Mesa, } \\
\text { teléfono }\end{array}$ & Sentado & $\begin{array}{c}\text { Capítulo } 3 \text { - } \\
\text { Conversación y } \\
\text { utilización de } \\
\text { aparatos y } \\
\text { técnicas de } \\
\text { comunicación - } \\
\text { d360 Utilización } \\
\text { de dispositivos } \\
\text { y técnicas de } \\
\text { comunicación }\end{array}$ & No prensil \\
\hline
\end{tabular}




\begin{tabular}{|c|c|c|c|c|c|c|}
\hline $\begin{array}{c}\text { T07- } \\
\text { Teclear } \\
\text { ordenador }\end{array}$ & $\begin{array}{l}\text { Marcar con } \\
\text { ambas manos } \\
\text { un texto } \\
\text { indicado }\end{array}$ & $\begin{array}{l}\text { Mesa de } \\
\text { lectura }\end{array}$ & $\begin{array}{l}\text { Mesa, } \\
\text { teclado }\end{array}$ & Sentado & $\begin{array}{c}\text { Capítulo 3- } \\
\text { Conversación y } \\
\text { utilización de } \\
\text { aparatos y } \\
\text { técnicas de } \\
\text { comunicación- } \\
\text { d360 Utilización } \\
\text { de dispositivos } \\
\text { y técnicas de } \\
\text { comunicación }\end{array}$ & No prensil \\
\hline $\begin{array}{c}\text { T08-Servir } \\
\text { agua }\end{array}$ & $\begin{array}{c}\text { Coger botella } \\
\text { con la izquierda } \\
\text { - abrir tapón } \\
\text { con la derecha } \\
\text { - dejar tapón } \\
\text { en la mesa - } \\
\text { servir medio } \\
\text { vaso de agua - } \\
\text { dejar botella en } \\
\text { la mesa }\end{array}$ & $\begin{array}{l}\text { Mesa de } \\
\text { comida }\end{array}$ & $\begin{array}{c}\text { Mesa, } \\
\text { botella de } \\
\text { agua, vaso }\end{array}$ & Sentado & $\begin{array}{c}\text { Capítulo 5- } \\
\text { Autocuidado - } \\
\text { d560 Beber }\end{array}$ & $\begin{array}{c}\text { Pinza, } \\
\text { cilíndrico }\end{array}$ \\
\hline $\begin{array}{c}\text { T09 - Beber } \\
\text { agua }\end{array}$ & $\begin{array}{c}\text { Coger vaso - } \\
\text { beber agua - } \\
\text { dejar vaso }\end{array}$ & $\begin{array}{l}\text { Mesa de } \\
\text { comida }\end{array}$ & Mesa, vaso & Sentado & $\begin{array}{c}\text { Capítulo 5- } \\
\text { Autocuidado - } \\
\text { d560 Beber }\end{array}$ & Cilíndrico \\
\hline $\begin{array}{c}\text { T10-Comer } \\
\text { sopa (agua) }\end{array}$ & $\begin{array}{l}\text { Coger cuchara } \\
\text { - tomar } 3 \\
\text { cucharadas de } \\
\text { agua - dejar } \\
\text { cuchara en el } \\
\text { plato }\end{array}$ & $\begin{array}{l}\text { Mesa de } \\
\text { comida }\end{array}$ & $\begin{array}{c}\text { Mesa, plato, } \\
\text { cuchara }\end{array}$ & Sentado & $\begin{array}{l}\text { Capítulo 5 - } \\
\text { Autocuidado - } \\
\text { d550 Comer }\end{array}$ & $\begin{array}{c}\text { Agarre de } \\
\text { precisión } \\
\text { de } \\
\text { potencia } \\
\text { intermedia }\end{array}$ \\
\hline $\begin{array}{l}\text { T11 - Cortar } \\
\text { con cuchillo }\end{array}$ & $\begin{array}{l}\text { Coger cuchillo y } \\
\text { tenedor - } \\
\text { cortar } 3 \text { trozos } \\
\text { de carne - } \\
\text { dejar cuchillo y } \\
\text { tenedor en el } \\
\text { plato }\end{array}$ & $\begin{array}{l}\text { Mesa de } \\
\text { comida }\end{array}$ & $\begin{array}{l}\text { Mesa, plato, } \\
\text { plastilina, } \\
\text { cuchillo, } \\
\text { tenedor }\end{array}$ & Sentado & $\begin{array}{c}\text { Capítulo 5- } \\
\text { Autocuidado - } \\
\text { d550 Comer }\end{array}$ & $\begin{array}{c}\text { Agarre de } \\
\text { precisión } \\
\text { de } \\
\text { potencia } \\
\text { intermedia }\end{array}$ \\
\hline $\begin{array}{l}\text { T12- } \\
\text { Pinchar con } \\
\text { tenedor }\end{array}$ & $\begin{array}{c}\text { Coger tenedor } \\
\text { con la derecha } \\
\text { - pinchar } 3 \\
\text { veces y acercar } \\
\text { los pedazos a la } \\
\text { boca - dejar } \\
\text { tenedor en el } \\
\text { plato }\end{array}$ & $\begin{array}{l}\text { Mesa de } \\
\text { comida }\end{array}$ & $\begin{array}{l}\text { Mesa, plato, } \\
\text { plastilina, } \\
\text { tenedor }\end{array}$ & Sentado & $\begin{array}{c}\text { Capítulo 5- } \\
\text { Autocuidado - } \\
\text { d550 Comer }\end{array}$ & $\begin{array}{c}\text { Agarre de } \\
\text { precisión } \\
\text { de } \\
\text { potencia } \\
\text { intermedia }\end{array}$ \\
\hline $\begin{array}{l}\text { T13 - Abrir y } \\
\text { cerrar grifo }\end{array}$ & $\begin{array}{c}\text { Coger grifo - } \\
\text { abrirlo } 2 \\
\text { segundos - } \\
\text { cerrar grifo }\end{array}$ & Lavabo & Grifo & De pie & $\begin{array}{c}\text { Capítulo 5 - } \\
\text { Autocuidado - } \\
\text { d520 Cuidado } \\
\text { de partes del } \\
\text { cuerpo }\end{array}$ & $\begin{array}{c}\text { Pinza } \\
\text { especial }\end{array}$ \\
\hline $\begin{array}{c}\text { T14- } \\
\text { Cepillarse los } \\
\text { dientes }\end{array}$ & $\begin{array}{l}\text { Coger cepillo } \\
\text { del vaso - } \\
\text { cepillarse los } \\
\text { dientes } 5 \\
\text { segundos - } \\
\text { dejar cepillo en } \\
\text { el vaso }\end{array}$ & Lavabo & $\begin{array}{l}\text { Vaso, cepillo } \\
\text { de dientes }\end{array}$ & De pie & $\begin{array}{l}\text { Capítulo 5- } \\
\text { Autocuidado - } \\
\text { d520 Cuidado } \\
\text { de partes del } \\
\text { cuerpo }\end{array}$ & $\begin{array}{c}\text { Agarre de } \\
\text { precisión } \\
\text { de } \\
\text { potencia } \\
\text { intermedia }\end{array}$ \\
\hline
\end{tabular}




\begin{tabular}{|c|c|c|c|c|c|c|}
\hline $\begin{array}{l}\text { T15-Abrir } \\
\text { bote de } \\
\text { pasta y } \\
\text { poner al } \\
\text { cepillo }\end{array}$ & $\begin{array}{l}\text { Coger tubo con } \\
\text { la mano } \\
\text { derecha - } \\
\text { pasarlo a la } \\
\text { izquierda - } \\
\text { quitar tapón } \\
\text { con la derecha } \\
\text { - dejar tapón - } \\
\text { coger bote con } \\
\text { la derecha y } \\
\text { cepillo con la } \\
\text { izquierda - } \\
\text { poner pasta - } \\
\text { dejar bote }\end{array}$ & Lavabo & $\begin{array}{l}\text { Vaso, tubo } \\
\text { de pasta de } \\
\text { dientes, } \\
\text { cepillo de } \\
\text { dientes }\end{array}$ & De pie & $\begin{array}{l}\text { Capítulo 5 - } \\
\text { Autocuidado - } \\
\text { d520 Cuidado } \\
\text { de partes del } \\
\text { cuerpo }\end{array}$ & $\begin{array}{l}\text { Pinza } \\
\text { especial }\end{array}$ \\
\hline $\begin{array}{c}\text { T16- } \\
\text { Peinarse }\end{array}$ & $\begin{array}{c}\text { Abrir cajón - } \\
\text { coger cepillo - } \\
\text { peinarse } 5 \\
\text { segundos - } \\
\text { dejar cepillo- } \\
\text { cerrar cajón } \\
\end{array}$ & Lavabo & $\begin{array}{l}\text { Cepillo del } \\
\text { pelo, cajón }\end{array}$ & De pie & $\begin{array}{l}\text { Capítulo 5 - } \\
\text { Autocuidado - } \\
\text { d520 Cuidado } \\
\text { de partes del } \\
\text { cuerpo }\end{array}$ & Cilíndrico \\
\hline $\begin{array}{l}\text { T17-Echar } \\
\text { pulverizador } \\
\text { de limpieza }\end{array}$ & $\begin{array}{c}\text { Coger } \\
\text { pulverizador - } \\
\text { hacer tres } \\
\text { disparos - } \\
\text { dejar } \\
\text { pulverizador }\end{array}$ & $\begin{array}{c}\text { Zona } \\
\text { limpieza }\end{array}$ & Pulverizador & De pie & $\begin{array}{c}\text { Capítulo 6- } \\
\text { Vida doméstica } \\
\text { - Tareas del } \\
\text { hogar - d640 } \\
\text { Realizar los } \\
\text { quehaceres de } \\
\text { la casa }\end{array}$ & $\begin{array}{l}\text { Cilíndrico, } \\
\text { no prensil }\end{array}$ \\
\hline $\begin{array}{c}\text { T18- } \\
\text { Limpiar con } \\
\text { trapo }\end{array}$ & $\begin{array}{c}\text { Coger trapo- } \\
\text { limpiar cristal - } \\
\text { dejar trapo }\end{array}$ & $\begin{array}{c}\text { Zona } \\
\text { limpieza }\end{array}$ & Trapo & De pie & $\begin{array}{c}\text { Capítulo 6- } \\
\text { Vida doméstica } \\
\text { - Tareas del } \\
\text { hogar - d640 } \\
\text { Realizar los } \\
\text { quehaceres de } \\
\text { la casa } \\
\end{array}$ & No prensil \\
\hline $\begin{array}{l}\text { T19- Rociar } \\
\text { aerosol } \\
\text { insecticida }\end{array}$ & $\begin{array}{l}\text { Coger aerosol } \\
\text { con la derecha } \\
\text { llevándolo a la } \\
\text { altura de la } \\
\text { cabeza - } \\
\text { apretar medio } \\
\text { segundo- } \\
\text { dejar el aerosol }\end{array}$ & $\begin{array}{c}\text { Zona } \\
\text { limpieza }\end{array}$ & $\begin{array}{c}\text { Aerosol } \\
\text { insecticida }\end{array}$ & De pie & $\begin{array}{c}\text { Capítulo } 6 \text { - } \\
\text { Vida doméstica } \\
\text { - Tareas del } \\
\text { hogar - d640 } \\
\text { Realizar los } \\
\text { quehaceres de } \\
\text { la casa }\end{array}$ & $\begin{array}{l}\text { Cilíndrico, } \\
\text { no prensil }\end{array}$ \\
\hline $\begin{array}{c}\text { T20- } \\
\text { Planchar }\end{array}$ & $\begin{array}{l}\text { Coger plancha } \\
\text { - planchar } 5 \\
\text { segundos - } \\
\text { dejar plancha }\end{array}$ & $\begin{array}{l}\text { Zona de } \\
\text { planchado }\end{array}$ & Plancha & De pie & $\begin{array}{c}\text { Capítulo 6- } \\
\text { Vida doméstica } \\
\text { - Tareas del } \\
\text { hogar - d640 } \\
\text { Realizar los } \\
\text { quehaceres de } \\
\text { la casa }\end{array}$ & Oblicuo \\
\hline $\begin{array}{c}\text { T21- } \\
\text { Manipular } \\
\text { maletín }\end{array}$ & $\begin{array}{l}\text { Coger maletín } \\
\text { del suelo - } \\
\text { ponerlo en la } \\
\text { mesa tumbado }\end{array}$ & $\begin{array}{l}\text { Zona de } \\
\text { planchado }\end{array}$ & Maletín & De pie & $\begin{array}{l}\text { Capítulo 4- } \\
\text { Movilidad. } \\
\text { Llevar, mover y } \\
\text { usar objetos. - } \\
\text { d430 Levantar y } \\
\text { llevar objetos }\end{array}$ & Gancho \\
\hline
\end{tabular}


Para la realización de ensayo participaban dos operadores: uno explicaba las tareas al sujeto e iba indicando las etapas para su realización; el otro registraba los datos del guante sensitivo en el ordenador y los tiempos necesarios para facilitar la sincronización posterior entre distintos sujetos y la segmentación necesaria entre distintas etapas dentro de la tarea.

El sujeto ejecutaba la tarea una única vez, a velocidad natural, tras una demostración previa del operador. Las tareas se realizaron siempre en el orden mostrado en la tabla 6.a.

Los datos registrados se procesaron mediante Matlab para obtener valores de fuerza total, presión máxima, presión media y superficie de contacto, en cada una de las zonas sensibles.

Para un mejor análisis de los resultados se realizó un preprocesado de los datos experimentales. En primer lugar, los datos se filtraron utilizando un filtro paso bajo $(0-20 \mathrm{~Hz})$ de primer orden de desfase temporal nulo, para reducir el rizado de las medidas experimentales. El tiempo se normalizó y se sincronizaron las tareas de los distintos sujetos para poder compararlos independientemente del tiempo que había tardado cada uno en realizar la tarea completa y cada etapa de la misma.

Para cada tarea se eliminaron también los registros de los sujetos con valores atípicos. El parámetro de comparación empleado para ello fue la fuerza de agarre media (MGF), comparando la de cada sujeto con la de toda la población de sujetos. La MGF se calculó tomando el promedio de la fuerza de agarre (GF) desde el inicio al final de la tarea (tiempos normalizados de 0 a 1). Para detectar los valores atípicos se utilizó el método del rango intercuartil, descrito en el apartado 3.2.3.2.

La sincronización temporal de las tareas se realizó de forma manual, examinando las gráficas de evolución temporal de la fuerza de agarre (GF) y los tiempos medidos de inicio de cada etapa dentro de cada tarea. A partir de este análisis, se determinaron unos instantes singulares dentro de la tarea que eran comunes para la mayoría de sujetos, como por ejemplo máximos relativos de fuerza de agarre, que correspondían a un momento concreto de la tarea. Esos puntos utilizados para sincronizar las gráficas se llamarán puntos de sincronismo (PDS). Dichos PDS se hicieron coincidir en la escala de tiempo 
normalizado, asignándoles un valor de tiempo normalizado promedio del de los sujetos que presentaban dichos PDS. Los registros de los datos de cada sujeto se interpolaron adecuadamente para definir el registro temporal en tiempo normalizado asegurando la coincidencia de los PDS. Si algún sujeto no presentaba la singularidad, su registro se normalizó al tiempo total sin considerar la sincronización con los PDS. En algunas tareas no se apreciaron instantes singulares en la mayoría de los sujetos, por lo que esas tareas no se sincronizaron, aunque sí se realizó la normalización temporal.

Una vez realizada la sincronización de las medidas para los diferentes sujetos se analizó la evolución temporal promedio de la GF y de la GF normalizada para cada tarea, así como su desviación típica. La contribución de las diferentes zonas de la mano en cada tarea se analizó utilizando el parámetro de contribución a la fuerza de agarre (CGF) de cada sensor, obtenido promediando para todos los sujetos y posteriormente realizando un promedio durante todo el ensayo. Aparte de analizar la contribución de cada sensor, se realizaron análisis para obtener la contribución conjunta de cada zona de la mano por dedos: pulgar (S1, S2); índice (S3, S4, S5); medio (S6, S7, S8); anular $(S 9, S 10, S 11)$; meñique $(S 12, S 13, S 14)$; y palma $(S 15, S 16, S 17)$. También se analizó la contribución conjunta por zonas en función de su posición distalproximal: distal (S1, S3, S6, S9, S12), medial (S4, S7, S10, S13), proximal (S2, S5, $\mathrm{S} 8, \mathrm{~S} 11)$ y palma $(\mathrm{S} 15, \mathrm{~S} 16, \mathrm{~S} 17)$. Asimismo se analizaron las correlaciones entre las diferentes tareas con el fin de determinar la similitud entre ellas desde el punto de vista de la distribución de las fuerzas de agarre.

Otro parámetro interesante analizado fue la presión requerida (PR), que es una primera aproximación de la presión mínima necesaria que ha de haber entre una determinada zona de la mano y el objeto manipulado para llevar a cabo una determinada tarea. Para obtenerla se calculó la presión máxima de cada sensor a lo largo de todas las tareas, para cada sujeto, y se tomó el valor mínimo de dichos valores.

Se calcularon las matrices de correlaciones entre tareas considerando la CGF de las zonas sensibles para determinar cuáles estaban correlacionadas. El objetivo fue determinar si tareas con el mismo tipo de agarre presentan una fuerte correlación, y también si distintos tipos de agarre usados en diferentes tareas estaban correlacionados entre sí. 
Con el fin de determinar si el género del sujeto (hombre o mujer) implicaba cambios estadísticamente significativos sobre la fuerza de agarre, la contribución de las distintas zonas de la mano a la misma, la presión realizada o la superficie de contacto de la mano con los objetos, se realizaron cuatro ANOVAS y un MANOVA. En los cuatro ANOVAS la variable independiente fue el género del sujeto, siendo la MGF para toda la tarea, la presión máxima, la presión media y la superficie de contacto las cuatro variables dependientes para cada uno de los cuatro ANOVAS. En el MANOVA, se tomó la CGF como variable dependiente, siendo nuevamente el género la variable independiente. 


\section{3.- Resultados}

Una vez analizados los datos para realizar la sincronización de las tareas, se comprobó que en las tareas T01, T04, T12, T14, T15, T18, T20 no se podían establecer PDS claramente definidos. Para el resto de tareas se muestran los PDS, detallando a qué momento de la tarea corresponden. Entre paréntesis se indica el instante que se ha tomado, en tiempo normalizado, para definir el PDS.

- Tarea T02: La sincronización se ha realizado en dos puntos: el punto 1 (0.37) se ha considerado al inicio del contacto entre la mano y el picaporte, en el momento de carga al coger el picaporte (se ha tomado el instante de la máxima GF en esa etapa); y el punto 2 (0.56) se ha definido para el inicio de la fase de descarga al soltar el picaporte.

- Tarea T03: La sincronización se ha realizado en la fase de carga producida al separar el libro del estante (0.39). En este instante se suele producir la máxima GF de toda la tarea, aunque no ha sido así para todos los sujetos.

- Tarea T05: Se ha sincronizado en dos puntos: el punto 1 (0.37) corresponde al instante de mayor fuerza tras coger el teléfono. El punto 2 (0.56) se ha tomado al iniciarse la fase de descarga como consecuencia de dejar el teléfono en la base.

- Tarea T06: Se ha sincronizado en el momento en el que se pulsaba cada dígito del número de teléfono, mediante el máximo relativo de la GF.

- Tarea T07: Al igual que la tarea 6 , se ha sincronizado con las pulsaciones de las teclas.

- Tarea T08: Se sincronizó en el momento de abrir el tapón de la botella (0.21), que correspondía al mayor valor de fuerza de agarre en el tramo inicial de la tarea.

- Tarea T09: Se sincronizó en dos puntos. El punto 1 se tomó en el instante de máxima GF inicial (0.20), que correspondía a la elevación del vaso. El punto 2 se tomó en el instante de descenso del vaso (0.77) una vez se había bebido el contenido. 
- Tarea T10: Se sincronizó en 3 puntos $(0.37,0.56,0.77)$, correspondientes a los instantes de máxima GF debida al ascenso de la cuchara.

- Tarea T11. Se sincronizó en 3 puntos, que correspondían a los instantes de máxima GF debido al corte producido por el cuchillo.

- Tarea T13. Se sincronizó en 2 puntos. El punto 1 (0.29) se determinó en el instante de máxima GF debida a la apertura del grifo y el punto 2 (0.72) en el instante de máxima GF debida al inicio de cerrar el grifo.

- Tarea T16. Se sincronizó en dos puntos, en los instantes de apertura (0.13) y cierre del cajón (0.90)

- Tarea T17. Se sincronizó en 3 puntos, correspondientes a los tres disparos del pulverizador $(0.42,0.50,0.58)$. Para determinar estos instantes se comprobó la máxima fuerza de agarre en esos instantes, comparándola con la fuerza máxima de las zonas distales del índice y medio.

- Tarea T19. La sincronización se realizó en un punto, en el instante del disparo (0.52)

- Tarea T21. La sincronización se realizó a partir de dos puntos: el de máxima GF debido a la elevación del maletín (0.38) y al de máxima GF debido al giro del maletín para orientarlo y poderlo colocar encima de la mesa (0.54).

La tabla 6.b muestra un resumen de los ensayos realizados por tareas, donde se pueden ver la cantidad de valores atípicos detectados, la MGF y su desviación típica, y la PR. Se observa que las fuerzas medias durante las diferentes actividades se sitúan por debajo de los $40 \mathrm{~N}$, siendo las más exigentes las tareas T02 (abrir puerta), T20 (planchar) y T21 (manipular maletín). Por otra parte las tareas que requieren mayores presiones de contacto son la T16 (peinarse) y la T20 (planchar), con presiones requeridas superiores a los $400 \mathrm{kPa}$. 
Tabla 6.b. Cantidad de valores atípicos, MGF (SD) y PR para todas las tareas.

\begin{tabular}{|c|c|c|c|}
\hline Tarea & Valores atípicos & MGF (SD) (N) & PR (kPa) \\
\hline T01 & 2 & $4.36(2.87)$ & 128.9 \\
\hline T02 & 0 & $29.72(18.86)$ & 140.7 \\
\hline T03 & 1 & $3.84(2.75)$ & 145.3 \\
\hline T04 & 1 & $4.33(2.78)$ & 171.6 \\
\hline T05 & 1 & $10.22(7.27)$ & 217.0 \\
\hline T06 & 1 & $2.39(2.13)$ & 45.3 \\
\hline T07 & 0 & $2.47(1.71)$ & 99.7 \\
\hline T08 & 2 & $4.88(2.55)$ & 160.2 \\
\hline T09 & 1 & $3.73(2.24)$ & 170.3 \\
\hline T10 & 0 & $3.71(1.96)$ & 214.1 \\
\hline T11 & 1 & $7.63(4.52)$ & 238.2 \\
\hline T12 & 0 & $4.22(2.58)$ & 222.8 \\
\hline T13 & 1 & $11.58(9.61)$ & 125.5 \\
\hline T14 & 0 & $6.32(4.86)$ & 229.9 \\
\hline T15 & 0 & $4.03(2.90)$ & 236.5 \\
\hline T16 & 0 & $8.37(6.63)$ & 435.1 \\
\hline T17 & 3 & $6.19(3.41)$ & 349.9 \\
\hline T18 & 0 & $3.51(1.94)$ & 197.9 \\
\hline T19 & 0 & $13.45(8.43)$ & 263.1 \\
\hline T20 & 0 & $32.52(21.76)$ & 426.3 \\
\hline T21 & 0 & $32.81(23.15)$ & 254.9 \\
\hline
\end{tabular}

La tabla 6.c muestra los valores máximos de fuerza a los que se ve sometida cada zona de la mano realizando las diferentes tareas. Para ello se toma el valor de $\mathrm{SF}_{\mathrm{i}}$ (promediado para todos los sujetos) en cada instante de tiempo y para cada tarea. Posteriormente se selecciona el máximo de dichos valores. Por otra parte se muestra también la presión media más alta para dicho sensor de entre todas las tareas e instantes de tiempo. En la tabla se indica también en qué tarea se producen. Se observa que la tarea T19 (rociar aerosol) es la que exige mayores fuerzas en las zonas distales de pulgar, índice y meñique, así como la región hipotenar. La tarea T21 (manipular maletín) exige las mayores fuerzas en todas las zonas distal y medial del dedo medio y en la zona medial y proximal del índice. La tarea T02 (abrir puerta) es la que exige mayores fuerzas en la zona proximal del dedo medio y las zonas medial y proximal del anular y meñique, así como en las zonas distal y tenar de la palma. Las mayores presiones medias se observan en los dedos índice y medio y aparecen en tareas con agarre cilíndricos o gancho, como la T16 (peinarse), T21 (manipular maletín) y T02. La zona con una mayor fuerza de contacto es la zona palmar distal, en concreto para la tarea T02. 
Tabla 6.c. Valores máximos de SFi y de presión media para cada sensor.

\begin{tabular}{|c|c|c|c|c|c|c|}
\hline Sensor & $\mathrm{SF}_{\mathrm{i}}$ máxima $(\mathrm{N})$ & Tarea & $\mathrm{t}_{\text {norm }}$ & $\mathrm{P}_{\text {med }}(\mathrm{kPa})$ & Tarea & $\mathrm{t}_{\text {norm }}$ \\
\hline S1 & 2.92 & $\mathrm{~T} 19$ & 0.47 & 66.6 & $\mathrm{~T} 19$ & 0.26 \\
\hline S2 & 2.20 & $\mathrm{~T} 08$ & 0.21 & 60.4 & $\mathrm{~T} 08$ & 0.19 \\
\hline S3 & 5.41 & $\mathrm{~T} 19$ & 0.54 & 110.2 & $\mathrm{~T} 19$ & 0.54 \\
\hline S4 & 4.16 & $\mathrm{~T} 21$ & 0.47 & 68.3 & $\mathrm{~T} 11$ & 0.60 \\
\hline S5 & 4.76 & $\mathrm{~T} 21$ & 0.55 & 89.6 & $\mathrm{~T} 21$ & 0.55 \\
\hline S6 & 8.53 & $\mathrm{~T} 21$ & 0.55 & 105.0 & $\mathrm{~T} 16$ & 0.12 \\
\hline S7 & 13.88 & $\mathrm{~T} 21$ & 0.48 & 130.4 & $\mathrm{~T} 21$ & 0.54 \\
\hline S8 & 11.06 & $\mathrm{~T} 02$ & 0.35 & 134.7 & $\mathrm{~T} 02$ & 0.35 \\
\hline S9 & 8.75 & $\mathrm{~T} 20$ & 0.57 & 63.6 & $\mathrm{~T} 20$ & 0.34 \\
\hline S10 & 5.45 & $\mathrm{~T} 02$ & 0.35 & 63.1 & $\mathrm{~T} 02$ & 0.35 \\
\hline S11 & 1.70 & $\mathrm{~T} 02$ & 0.35 & 32.3 & $\mathrm{~T} 02$ & 0.35 \\
\hline S12 & 1.31 & $\mathrm{~T} 19$ & 0.53 & 29.4 & $\mathrm{~T} 20$ & 0.65 \\
\hline S13 & 0.53 & $\mathrm{~T} 02$ & 0.45 & 21.1 & $\mathrm{~T} 11$ & 0.52 \\
\hline S14 & 1.54 & $\mathrm{~T} 02$ & 0.35 & 30.0 & $\mathrm{~T} 02$ & 0.34 \\
\hline S15 & 29.54 & $\mathrm{~T} 02$ & 0.34 & 92.6 & $\mathrm{~T} 08$ & 0.15 \\
\hline S16 & 10.61 & $\mathrm{~T} 02$ & 0.34 & 64.0 & $\mathrm{~T} 02$ & 0.35 \\
\hline S17 & 8.61 & $\mathrm{~T} 19$ & 0.53 & 62.7 & $\mathrm{~T} 19$ & 0.56 \\
\hline
\end{tabular}

La evolución temporal de fuerza total de agarre (GF) y fuerza de agarre normalizada para cada tarea se muestran en la figura 6.4, como promedio de los diferentes sujetos (con la desviación típica mostrada en gris). La tarea más exigente en cuanto a máxima fuerza de agarre durante la tarea es la T02, correspondiente a girar el picaporte de la puerta para abrirla, con una máxima GF promedio en torno a los $100 \mathrm{~N}$, seguida de la de mover el maletín, con una fuerza de agarre media en torno a los $80 \mathrm{~N}$. Entre las menos exigentes desde el punto de vista de fuerza máxima están la T01 (coger llave), la T04 (escribir) y las T06 (marcar teléfono) y T07 (teclear ordenador).

En la figura 6.4 puede apreciarse también que la desviación típica es superior en las figuras que muestran la GF frente a las que muestran la GF normalizada. 

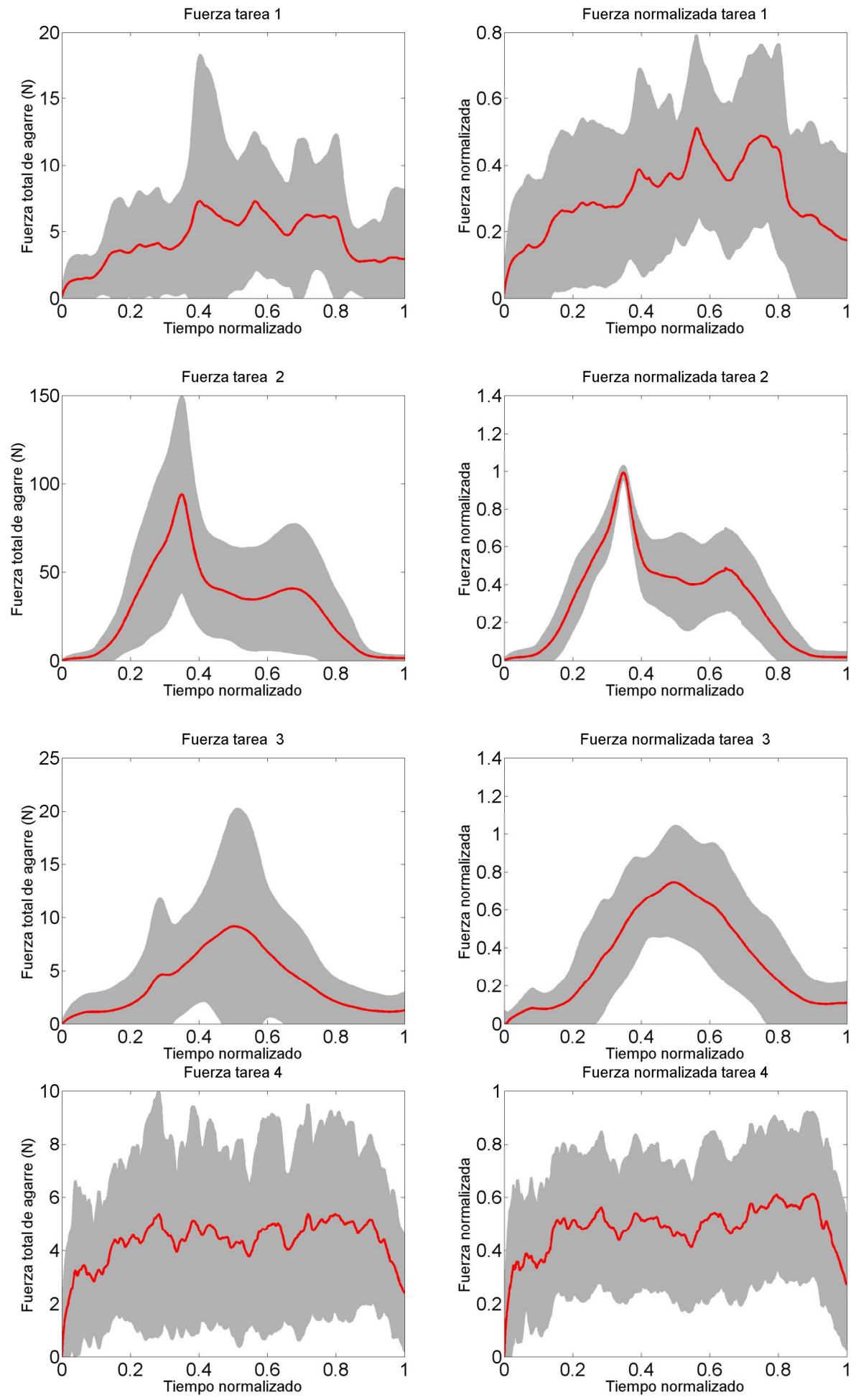

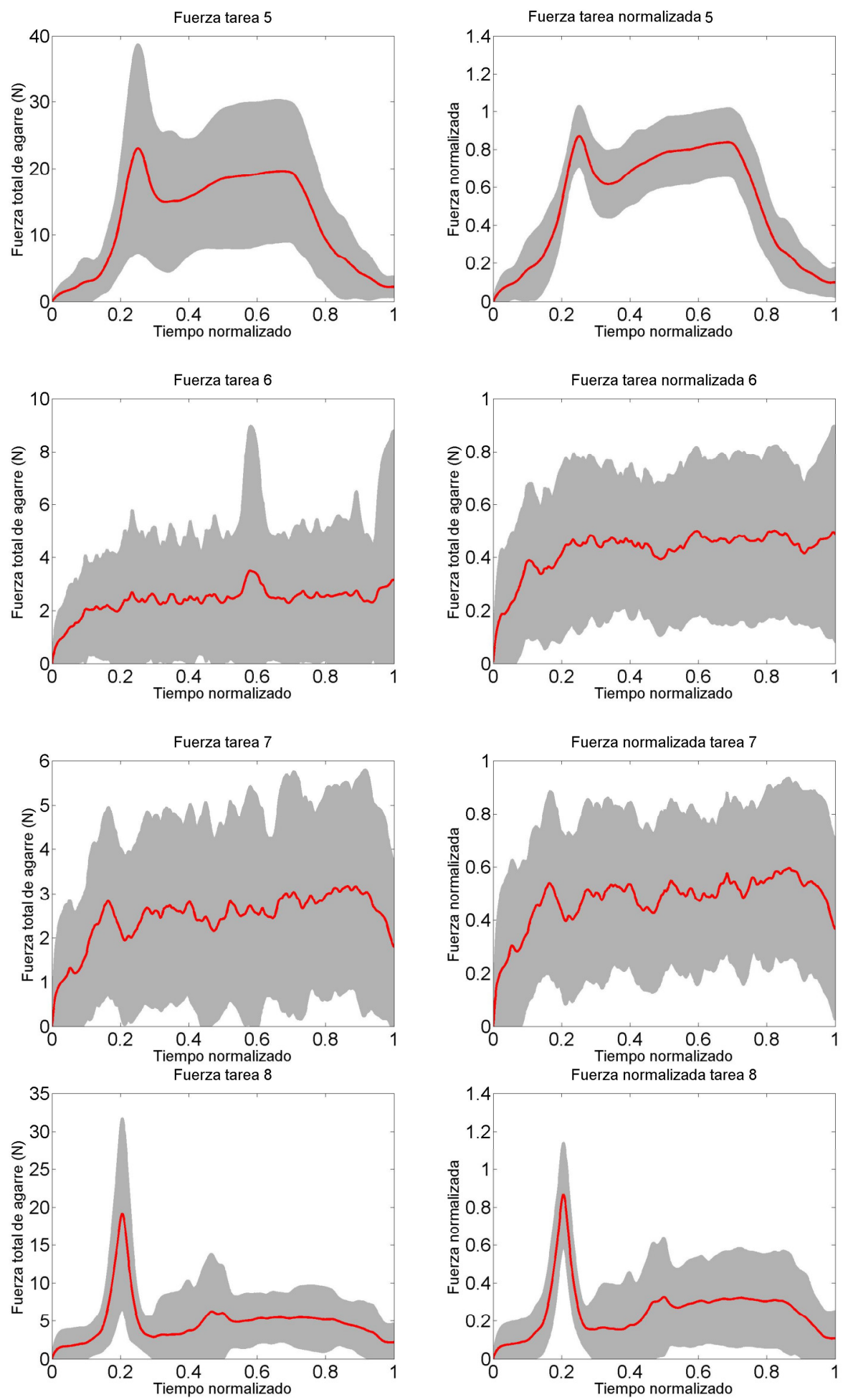

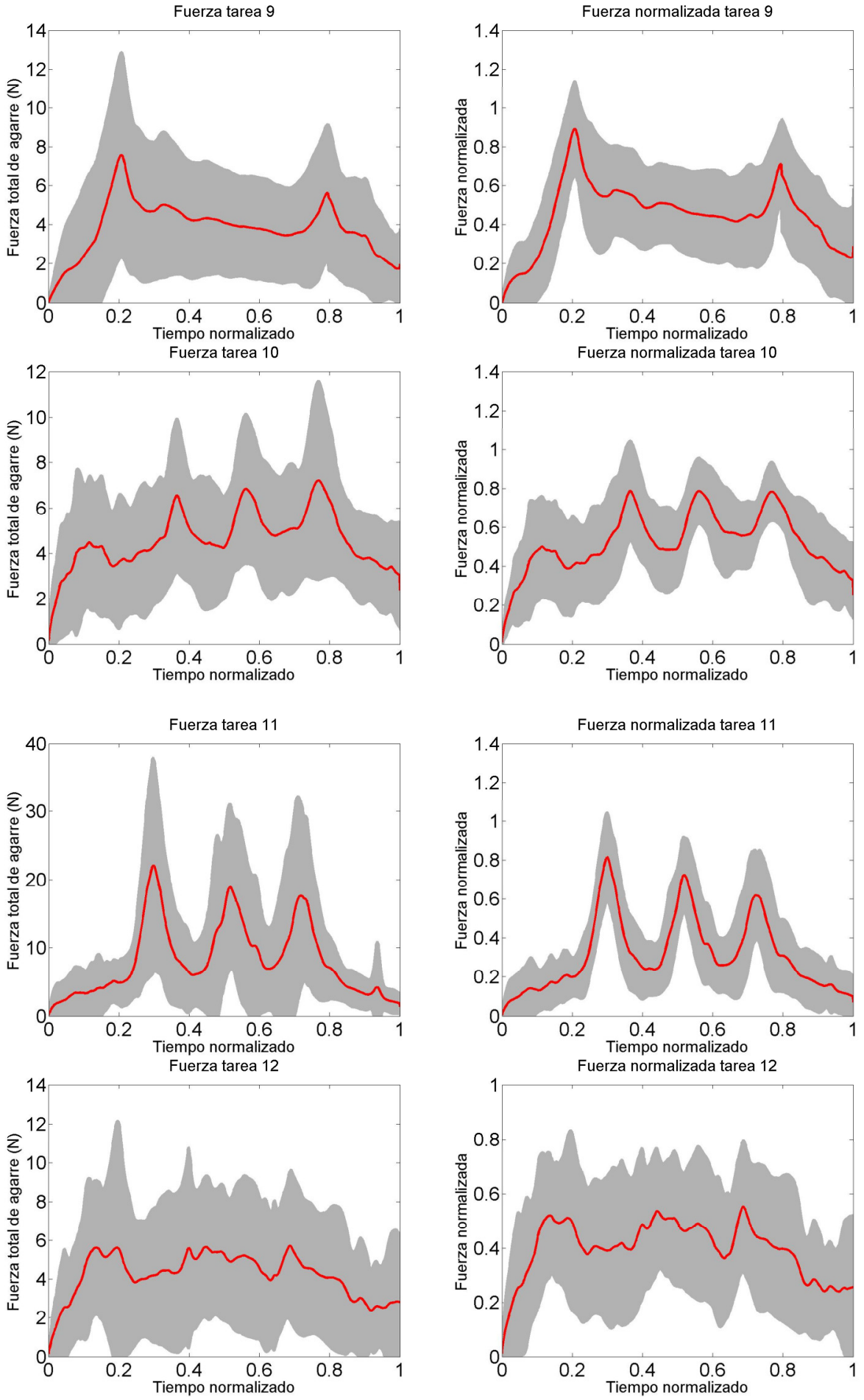

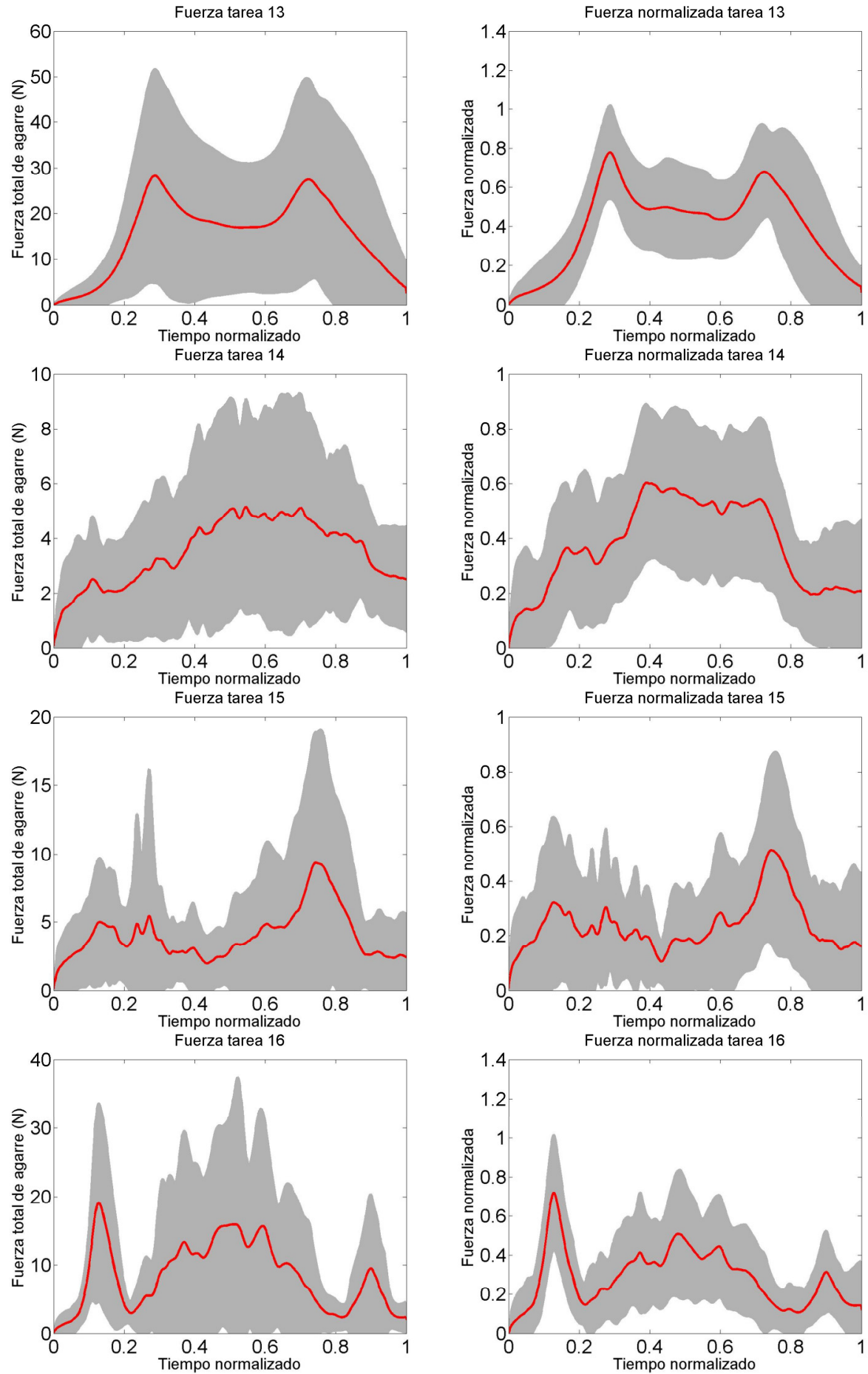

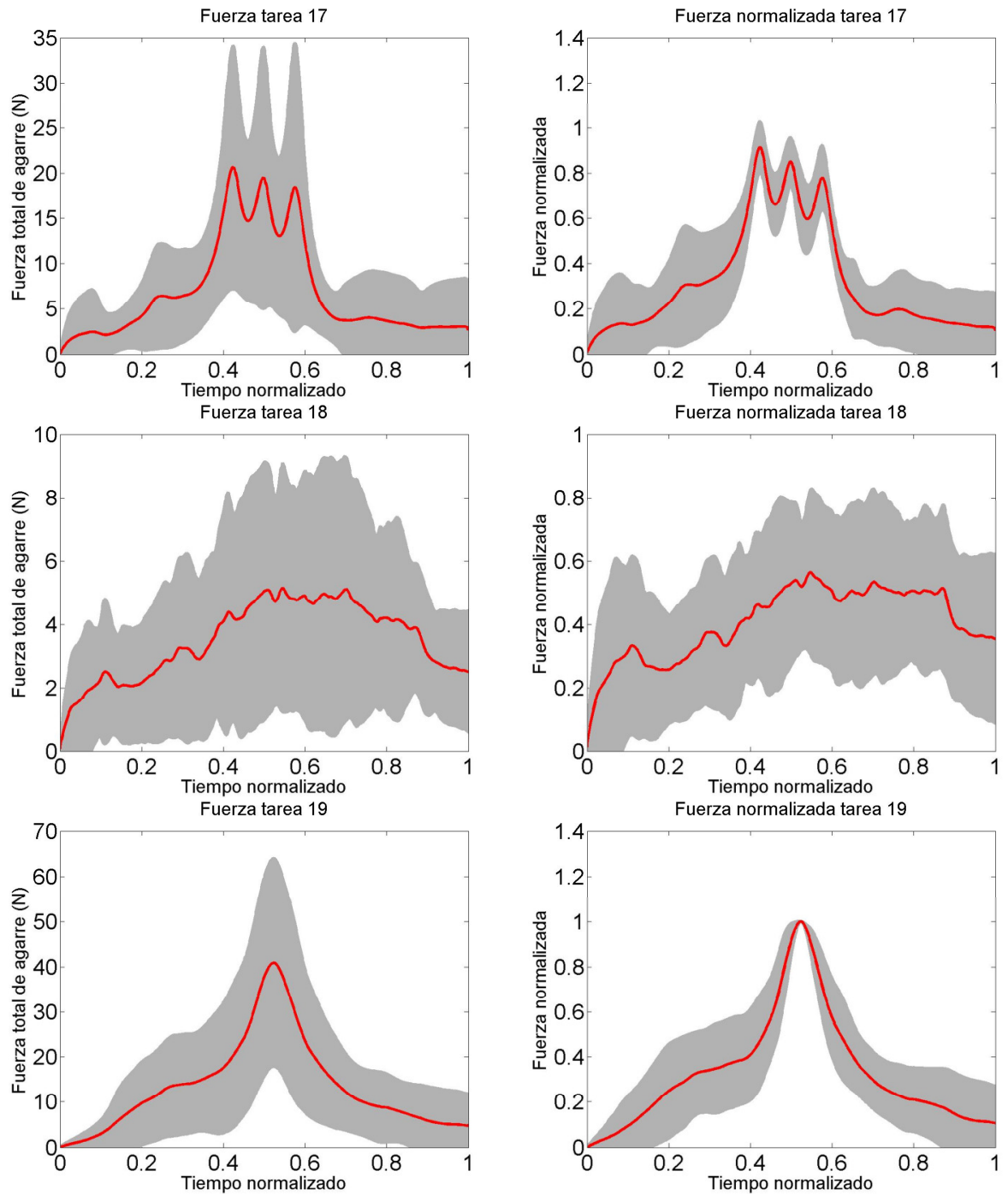

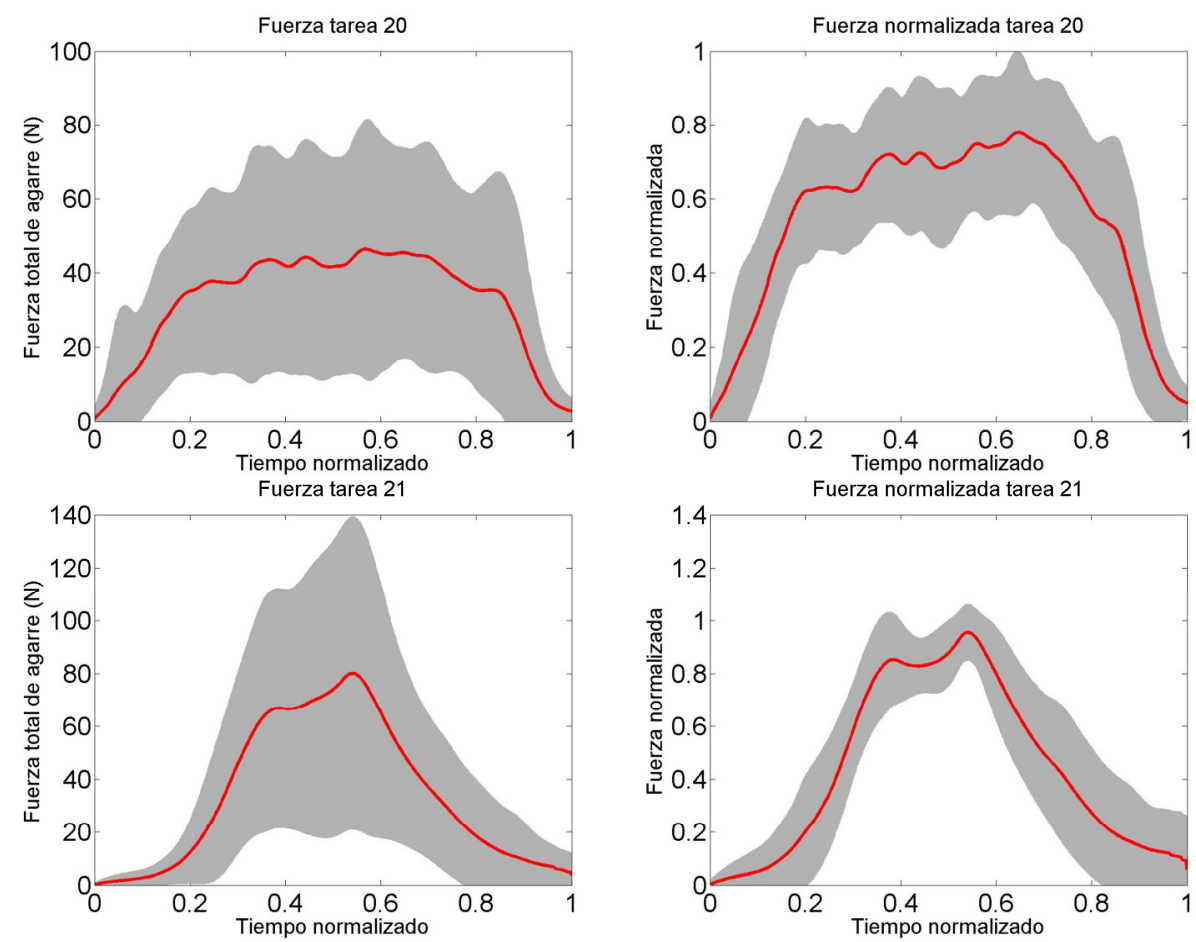

Figura 6.4. Valores medios y desviación típica de la GF y de la GF normalizada en todos los sujetos para todas las tareas

La tabla 6.d muestra la contribución de cada sensor para cada tarea (CGF). Las tareas se han agrupado en función del tipo de agarre principal.

Tabla 6.d: Contribución de cada sensor a cada tarea agrupada por tipo de agarre principal

\begin{tabular}{|c|c|c|c|c|c|c|c|}
\hline \multirow[b]{2}{*}{ Zona } & \multirow{2}{*}{$\begin{array}{c}\begin{array}{c}\text { Pinza } \\
\text { lateral }\end{array} \\
\text { CGF T01 } \\
(\%) \\
\end{array}$} & \multicolumn{3}{|c|}{ Pinza especial } & \multicolumn{3}{|c|}{ No prensil } \\
\hline & & CGF T04 (\%) & CGF T13 (\%) & CGF T15 (\%) & CGF T06(\%) & CGF T07(\%) & CGF T18 (\%) \\
\hline S1 & 9.5 & 4.0 & 10.1 & 6.9 & 3.1 & 6.3 & 4.3 \\
\hline S2 & 4.6 & 10.1 & 7.2 & 4.0 & 10.8 & 6.0 & 3.7 \\
\hline S3 & 12.1 & 11.4 & 5.7 & 19.2 & 39.3 & 33.5 & 27.2 \\
\hline S4 & 11.5 & 1.8 & 4.0 & 3.4 & 0.5 & 0.5 & 0.2 \\
\hline S5 & 2.9 & 0.3 & 2.2 & 1.2 & 0.0 & 0.0 & 0.5 \\
\hline S6 & 3.1 & 5.8 & 3.9 & 3.0 & 1.9 & 1.1 & 2.0 \\
\hline S7 & 4.5 & 3.5 & 10.1 & 6.4 & 2.8 & 3.3 & 1.3 \\
\hline S8 & 4.4 & 1.8 & 3.7 & 1.2 & 0.5 & 1.3 & 0.6 \\
\hline S9 & 10.6 & 7.2 & 8.4 & 14.3 & 12.4 & 7.6 & 19.2 \\
\hline S10 & 0.2 & 1.3 & 0.2 & 0.2 & 0.1 & 0.8 & 0.3 \\
\hline S11 & 0.0 & 0.2 & 0.1 & 0.0 & 0.0 & 0.0 & 0.0 \\
\hline
\end{tabular}


Capítulo 6. Caracterización del agarre en la realización de tareas cotidianas

\begin{tabular}{|c|c|c|c|c|c|c|c|}
\hline S12 & 0.2 & 0.0 & 0.0 & 0.1 & 0.0 & 0.1 & 0.8 \\
\hline S13 & 0.0 & 0.1 & 0.0 & 0.1 & 0.0 & 0.0 & 0.0 \\
\hline S14 & 0.0 & 0.4 & 0.0 & 0.3 & 0.0 & 0.0 & 0.1 \\
\hline S15 & 11.7 & 15.9 & 29.5 & 13.6 & 20.4 & 31.0 & 21.4 \\
\hline S16 & 23.0 & 36.1 & 14.1 & 23.7 & 7.9 & 8.0 & 17.0 \\
\hline S17 & 1.4 & 0.4 & 0.5 & 2.6 & 0.1 & 0.4 & 1.2 \\
\hline
\end{tabular}

\begin{tabular}{|c|c|c|c|c|c|c|c|}
\hline & \multicolumn{5}{|c|}{ Agarre de precisión de potencia intermedia } & \multicolumn{2}{|c|}{ Oblicuo } \\
\hline Zona & CGF T05(\%) & CGF T10 (\%) & CGF T11 (\%) & CGF T12 (\%) & CGF T14 (\%) & CGF T02 (\%) & CGF T20 (\%) \\
\hline S1 & 2.8 & 9.2 & 3.4 & 4.2 & 5.2 & 2.3 & 1.2 \\
\hline S2 & 3.1 & 2.0 & 2.3 & 3.2 & 4.1 & 3.2 & 3.7 \\
\hline S3 & 10.5 & 19.5 & 15.6 & 12.8 & 13.0 & 5.6 & 6.5 \\
\hline S4 & 1.3 & 3.2 & 2.7 & 4.4 & 5.2 & 2.8 & 0.8 \\
\hline S5 & 0.7 & 0.6 & 0.5 & 0.4 & 0.6 & 2.8 & 1.0 \\
\hline S6 & 3.5 & 0.7 & 1.5 & 2.3 & 2.3 & 3.3 & 9.1 \\
\hline S7 & 9.2 & 4.3 & 9.1 & 7.5 & 7.9 & 9.9 & 8.7 \\
\hline S8 & 4.1 & 2.2 & 1.7 & 0.1 & 1.3 & 11.3 & 3.2 \\
\hline S9 & 18.5 & 5.7 & 10.2 & 15.2 & 14.1 & 7.2 & 18.0 \\
\hline S10 & 0.2 & 0.5 & 1.4 & 0.3 & 0.7 & 2.8 & 2.0 \\
\hline $\mathrm{S} 11$ & 0.0 & 0.0 & 0.1 & 0.0 & 0.1 & 0.7 & 0.1 \\
\hline S12 & 1.0 & 0.0 & 0.2 & 0.1 & 0.3 & 0.1 & 0.9 \\
\hline S13 & 0.2 & 0.2 & 0.6 & 1.2 & 0.7 & 0.3 & 0.4 \\
\hline S14 & 0.1 & 0.1 & 0.4 & 0.7 & 0.6 & 0.4 & 0.2 \\
\hline S15 & 13.3 & 14.2 & 17.2 & 17.1 & 19.0 & 30.5 & 17.0 \\
\hline S16 & 11.5 & 36.1 & 26.3 & 29.7 & 23.5 & 12.7 & 19.5 \\
\hline S17 & 20.0 & 0.8 & 7.2 & 0.8 & 1.3 & 3.9 & 7.4 \\
\hline
\end{tabular}

\begin{tabular}{|c|c|c|c|c|c|c|c|}
\hline & \multicolumn{5}{|c|}{ Cilíndrico } & Gancho & Lumbrical \\
\hline Zona & CGF T08(\%) & CGF T09(\%) & CGF T16 (\%) & CGF T17 (\%) & CGF T19 (\%) & CGF T21 (\%) & CGF T03 (\%) \\
\hline S1 & 11.9 & 6.7 & 5.0 & 5.4 & 10.1 & 1.6 & 5.3 \\
\hline S2 & 8.2 & 5.1 & 4.7 & 7.6 & 1.7 & 1.8 & 6.8 \\
\hline S3 & 11.5 & 7.6 & 12.8 & 16.2 & 11.7 & 8.5 & 12.9 \\
\hline S4 & 4.0 & 1.3 & 3.8 & 1.9 & 0.1 & 3.7 & 1.6 \\
\hline S5 & 1.3 & 0.7 & 2.3 & 0.2 & 0.2 & 5.6 & 0.5 \\
\hline S6 & 5.2 & 8.6 & 10.5 & 10.6 & 5.9 & 4.6 & 3.5 \\
\hline S7 & 5.6 & 6.3 & 11.0 & 4.0 & 5.1 & 13.8 & 4.9 \\
\hline S8 & 1.1 & 0.2 & 2.0 & 0.2 & 1.2 & 7.5 & 2.2 \\
\hline S9 & 10.3 & 21.2 & 16.6 & 12.8 & 16.9 & 13.6 & 14.4 \\
\hline S10 & 0.5 & 0.1 & 0.7 & 0.2 & 0.3 & 3.5 & 0.2 \\
\hline S11 & 0.0 & 0.0 & 0.0 & 0.0 & 0.0 & 0.4 & 0.0 \\
\hline S12 & 0.2 & 0.2 & 0.4 & 0.2 & 1.0 & 0.3 & 0.9 \\
\hline S13 & 0.0 & 0.0 & 0.5 & 0.0 & 0.1 & 0.3 & 0.0 \\
\hline S14 & 0.1 & 0.0 & 0.1 & 0.2 & 0.2 & 0.1 & 0.1 \\
\hline S15 & 21.2 & 19.8 & 8.0 & 17.8 & 16.4 & 15.6 & 15.8 \\
\hline S16 & 17.2 & 21.6 & 20.3 & 15.6 & 14.1 & 15.0 & 28.5 \\
\hline S17 & 1.7 & 0.5 & 1.3 & 6.7 & 14.9 & 4.1 & 2.4 \\
\hline
\end{tabular}


La figura 6.5 muestra un gráfico acumulado de la contribución de las diferentes zonas sensibles para todas las tareas. Puede observarse que la mayor contribución se da en la zona de la palma (S15, S16 y S17), seguido de la zona distal del índice (S3) y del dedo medio (S6, S7). Destaca la elevada contribución de la zona distal del dedo anular (S9). Las zonas que muestran una menor contribución son las pertenecientes al dedo meñique $(\mathrm{S} 12, \mathrm{~S} 13, \mathrm{~S} 14)$ y a las zonas medial y proximal del dedo anular (S10, S11).

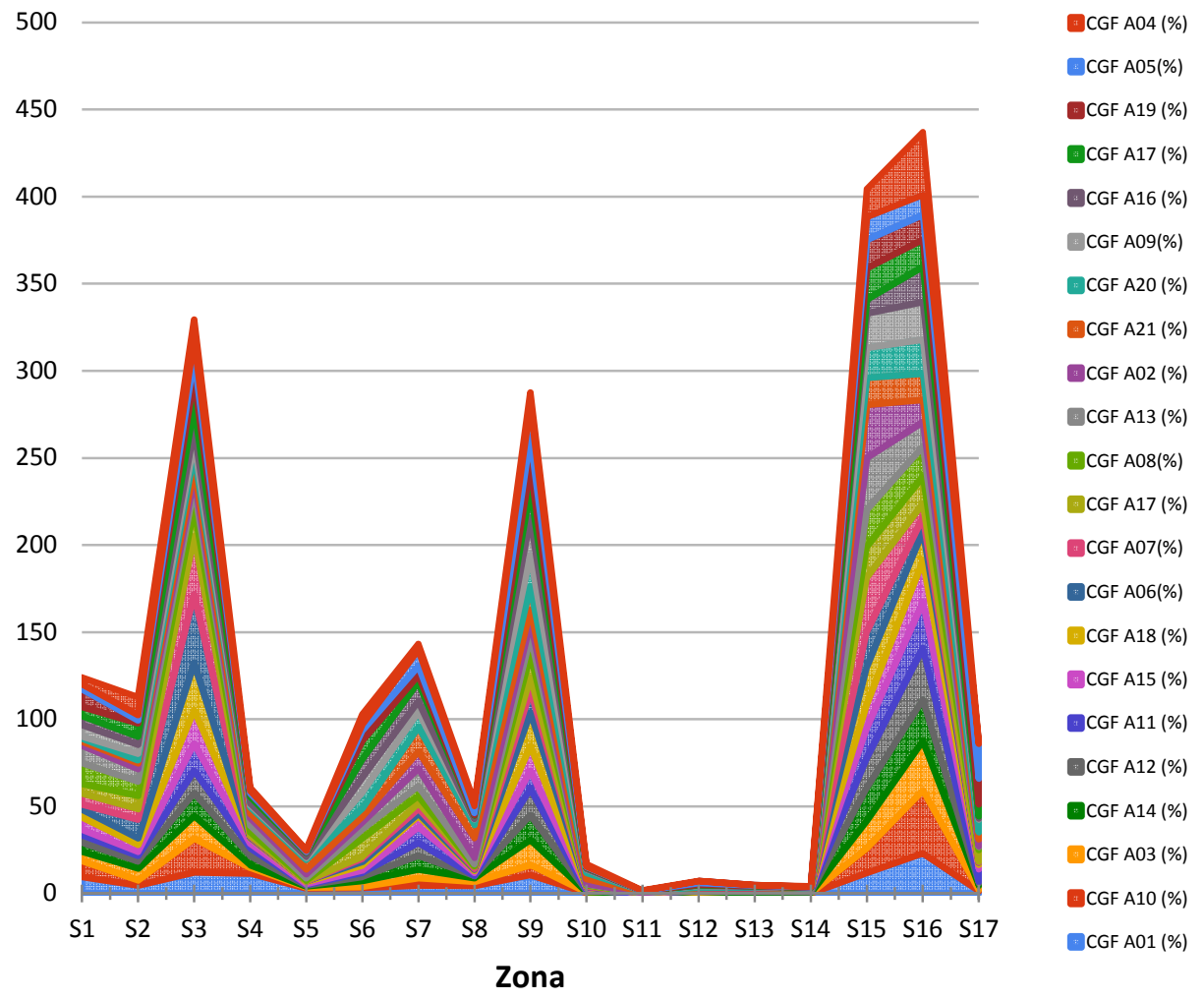

Figura 6.5. Contribución acumulada para todas las tareas de las distintas zonas sensibles del sensor

La matriz de correlaciones entre las distintas tareas, obtenida comparando los valores de CGF en los diferentes sensores, puede verse en la tabla 6.e, donde se puede observar que algunas parejas de tareas presentan coeficientes de correlación elevados. La mayor correlación (0.98) se observa entre la tarea T12 (pinchar con tenedor) y T14 (cepillar dientes) al igual que entre T12 y T03 
(coger libro). No obstante, se observan varias parejas de tareas con correlaciones igualmente altas (iguales o superiores a 0.95 ).

Tabla 6.e. Coeficientes de correlación entre todas las tareas considerando todas las zonas sensibles.

\begin{tabular}{|c|c|c|c|c|c|c|c|c|c|c|c|c|c|c|c|c|c|c|c|c|c|}
\hline & T01 & T02 & T03 & T04 & T05 & T06 & T07 & T08 & T09 & T10 & T11 & $\mathrm{T} 12$ & T13 & T14 & T15 & T16 & T17 & $\mathrm{T} 18$ & T19 & $\mathrm{T} 20$ & T21 \\
\hline T01 & 1.00 & 0.53 & 0.9 & 0.86 & 0.46 & 0.52 & 0.54 & 0.84 & 0.79 & 0.91 & 0.85 & 0.91 & 0.66 & 0.90 & 0.90 & 0.81 & 0.74 & 0.73 & 0.64 & 0.70 & 0.69 \\
\hline T02 & & 1.00 & 0.61 & 0.56 & 0.52 & 0.43 & 0.65 & 0.75 & 0.67 & 0.50 & 0.67 & 0.63 & 0.91 & 0.72 & 0.55 & 0.43 & 0.64 & 0.59 & 0.58 & 0.71 & 0.80 \\
\hline T03 & & & 1.00 & 0.95 & 0.61 & 0.59 & 0.60 & 0.87 & 0.91 & 0.93 & 0.94 & 0.98 & 0.71 & 0.96 & 0.96 & 0.87 & 0.86 & 0.82 & 0.75 & 0.87 & 0.77 \\
\hline T04 & & & & 1.00 & 0.42 & 0.46 & 0.49 & 0.80 & 0.80 & 0.94 & 0.89 & 0.92 & 0.65 & 0.88 & 0.86 & 0.78 & 0.76 & 0.67 & 0.58 & 0.76 & 0.65 \\
\hline T05 & & & & & 1.00 & 0.45 & 0.45 & 0.54 & 0.64 & 0.42 & 0.69 & 0.59 & 0.47 & 0.62 & 0.63 & 0.60 & 0.71 & 0.63 & 0.9 & 0.79 & 0.70 \\
\hline T06 & & & & & & 1.00 & 0.94 & 0.66 & 0.51 & 0.57 & 0.62 & 0.55 & 0.49 & 0.63 & 0.74 & 0.54 & 0.77 & 0.9 & 0.55 & 0.44 & 0.47 \\
\hline T07 & & & & & & & 1.00 & 0.76 & 0.56 & 0.59 & 0.66 & 0.58 & 0.68 & 0.69 & 0.72 & 0.47 & 0.79 & 0.89 & 0.61 & 0.49 & 0.54 \\
\hline T08 & & & & & & & & 1.00 & 0.88 & 0.79 & 0.83 & 0.85 & 0.91 & 0.91 & 0.86 & 0.74 & 0.89 & 0.82 & 0.77 & 0.77 & 0.71 \\
\hline T09 & & & & & & & & & 1.00 & 0.72 & 0.82 & 0.90 & 0.79 & 0.92 & 0.85 & 0.87 & 0.87 & 0.79 & 0.80 & 0.94 & 0.81 \\
\hline T10 & & & & & & & & & & 1.00 & 0.92 & 0.92 & 0.60 & 0.89 & 0.92 & 0.77 & 0.74 & 0.74 & 0.61 & 0.67 & 0.64 \\
\hline T11 & & & & & & & & & & & 1.00 & 0.96 & 0.70 & 0.95 & 0.94 & 0.82 & 0.84 & 0.82 & 0.78 & 0.84 & 0.82 \\
\hline T12 & & & & & & & & & & & & 1.00 & 0.72 & 0.98 & 0.95 & 0.88 & 0.82 & 0.81 & 0.73 & 0.87 & 0.81 \\
\hline T13 & & & & & & & & & & & & & 1.00 & 0.80 & 0.65 & 0.55 & 0.73 & 0.65 & 0.64 & 0.71 & 0.75 \\
\hline T14 & & & & & & & & & & & & & & 1.00 & 0.95 & 0.86 & 0.86 & 0.86 & 0.76 & 0.87 & 0.85 \\
\hline T15 & & & & & & & & & & & & & & & 1.00 & 0.89 & 0.88 & 0.91 & 0.78 & 0.8 & 0.76 \\
\hline T16 & & & & & & & & & & & & & & & & 1.00 & 0.81 & 0.74 & 0.70 & 0.85 & \begin{tabular}{|l|l|} 
\\
\end{tabular} \\
\hline T17 & & & & & & & & & & & & & & & & & 1.00 & 0.89 & 0.86 & 0.85 & 0.71 \\
\hline T18 & & & & & & & & & & & & & & & & & & 1.00 & 0.77 & 0.73 & 0.69 \\
\hline T19 & & & & & & & & & & & & & & & & & & & 1.00 & 0.83 & 0.69 \\
\hline T20 & & & & & & & & & & & & & & & & & & & & 1.00 & 0.88 \\
\hline T21 & & & & & & & & & & & & & & & & & & & & & 1.00 \\
\hline
\end{tabular}

Con el fin de clarificar los resultados, puede utilizarse la información de la tabla 6.d para agrupar los resultados por dedos y por zonas (tablas 6.f y 6.h). Se observa que las zonas con mayor contribución promedio en la agrupación por dedos son la palma, el índice y el pulgar, mientras que en la agrupación por zonas se observa igualmente la mayor participación de la palma y la contribución claramente superior de las zonas distales de los dedos respecto a las medias y proximales. 
Las tablas 6.g y 6.i muestran los coeficientes de correlación entre tareas para dichas agrupaciones, observándose que para la mayor parte de las parejas de tareas el coeficiente de correlación es superior a 0.9, siendo la tareas T06 (marcar teléfono) la que presenta peores correlaciones para la agrupación por dedos y la T02 (abrir puerta) la que presenta peores correlaciones en la agrupación por zonas.

Tabla 6.f. Contribución por dedos (en \%)

\begin{tabular}{|c|c|c|c|c|c|c|}
\hline & Pulgar & Índice & Medio & Anular & Meñique & Palma \\
\hline Tarea T01 & 14.1 & 26.5 & 8.9 & 10.8 & 0.2 & 36.1 \\
\hline Tarea T02 & 5.4 & 11.3 & 21.2 & 10.7 & 0.7 & 47.1 \\
\hline Tarea T03 & 12.1 & 15.0 & 7.0 & 14.6 & 0.9 & 46.6 \\
\hline Tarea T04 & 14.0 & 13.4 & 5.2 & 8.5 & 0.5 & 52.3 \\
\hline Tarea T05 & 5.9 & 12.5 & 13.2 & 18.7 & 1.3 & 44.7 \\
\hline Tarea T06 & 13.9 & 39.7 & 3.3 & 12.5 & 0.0 & 28.3 \\
\hline Tarea T07 & 12.3 & 34.0 & 4.5 & 8.4 & 0.1 & 39.4 \\
\hline Tarea T08 & 20.1 & 16.9 & 6.6 & 10.7 & 0.2 & 40.1 \\
\hline Tarea T09 & 11.8 & 9.5 & 6.4 & 21.3 & 0.1 & 41.9 \\
\hline Tarea T10 & 12.0 & 23.2 & 6.4 & 6.2 & 0.3 & 51.0 \\
\hline Tarea T11 & 5.6 & 18.7 & 10.7 & 11.6 & 1.1 & 50.6 \\
\hline Tarea T12 & 7.3 & 17.6 & 7.5 & 15.5 & 1.9 & 47.6 \\
\hline Tarea T13 & 17.3 & 12.0 & 13.8 & 8.6 & 0.0 & 44.1 \\
\hline Tarea T14 & 9.2 & 18.8 & 9.1 & 14.8 & 1.6 & 43.8 \\
\hline Tarea T15 & 11.0 & 23.7 & 7.4 & 14.5 & 0.4 & 39.8 \\
\hline Tarea T16 & 9.7 & 18.8 & 13.0 & 17.3 & 1.0 & 29.5 \\
\hline Tarea T17 & 13.0 & 18.4 & 4.3 & 13.0 & 0.3 & 40.1 \\
\hline Tarea T18 & 8.0 & 27.9 & 1.9 & 19.5 & 0.8 & 39.6 \\
\hline Tarea T19 & 11.8 & 12.0 & 6.3 & 17.2 & 1.2 & 45.4 \\
\hline Tarea T20 & 5.0 & 8.3 & 12.0 & 20.1 & 1.5 & 43.8 \\
\hline Tarea T21 & 3.3 & 17.8 & 21.2 & 17.5 & 0.6 & 34.7 \\
\hline Promedio & 10.6 & 18.8 & 9.0 & 13.9 & 0.7 & 42.2 \\
\hline
\end{tabular}


Tabla 6.g. Coeficientes de correlación entre todas las tareas considerando los dedos.

\begin{tabular}{|c|c|c|c|c|c|c|c|c|c|c|c|c|c|c|c|c|c|c|c|c|c|}
\hline & T01 & T02 & T03 & T04 & T05 & T06 & T07 & T08 & T09 & T10 & T11 & T12 & T13 & T14 & T15 & T16 & T17 & T18 & T19 & T20 & $\mathrm{T} 21$ \\
\hline T01 & .00 & 0.76 & 0.89 & 0.88 & 0.80 & 0.88 & 0.98 & 0.92 & 0.78 & 0.96 & 0.90 & 0.89 & 0.85 & 0.92 & 0.98 & 0.91 & 0.95 & 0.93 & 0.84 & 0.73 & 0.76 \\
\hline T02 & & 1.00 & 0.90 & $0.89 \mid$ & 0.95 & 0.39 & 0.67 & 0.80 & 0.85 & 0.86 & 0.94 & 0.91 & 0.92 & 0.91 & 0.83 & 0.85 & 0.83 & 0.70 & 0.88 & 0.93 & 0.92 \\
\hline T03 & & & 1.00 & 0.99 & 0.96 & 0.60 & 0.82 & 0.95 & 0.96 & 0.96 & 0.97 & 0.99 & 0.95 & 0.99 & 0.95 & 0.90 & 0.98 & 0.89 & 0.99 & 0.94 & 0.81 \\
\hline T04 & & & & 1.00 & 0.92 & 0.57 & 0.82 & 0.97 & 0.92 & 0.97 & 0.96 & 0.96 & 0.97 & 0.96 & 0.92 & 0.84 & 0.97 & 0.83 & 0.97 & 0.89 & 0.75 \\
\hline T05 & & & & & 1.00 & 0.48 & 0.72 & 0.84 & 0.96 & 0.88 & 0.96 & 0.97 & 0.90 & 0.96 & 0.90 & 0.92 & 0.90 & 0.83 & 0.96 & 0.99 & 0.92 \\
\hline T06 & & & & & & 1.00 & 0.93 & 0.67 & 0.47 & 0.72 & 0.62 & 0.63 & 0.49 & 0.67 & 0.81 & 0.72 & 0.73 & 0.85 & 0.54 & 0.39 & 0.50 \\
\hline T07 & & & & & & & 1.00 & 0.85 & 0.69 & 0.92 & 0.85 & 0.84 & 0.75 & 0.87 & 0.94 & 0.84 & 0.90 & 0.93 & 0.77 & 0.64 & 0.68 \\
\hline T08 & & & & & & & & 1.00 & 0.89 & 0.95 & 0.89 & 0.91 & 0.95 & 0.92 & 0.93 & 0.84 & 0.97 & 0.84 & 0.93 & 0.80 & 0.68 \\
\hline T09 & & & & & & & & & 1.00 & 0.85 & 0.90 & 0.94 & 0.89 & 0.94 & 0.88 & 0.88 & 0.93 & 0.84 & 0.99 & 0.96 & 0.79 \\
\hline T10 & & & & & & & & & & 1.00 & 0.97 & 0.96 & 0.93 & 0.97 & 0.97 & 0.87 & 0.97 & 0.89 & 0.92 & 0.83 & 0.77 \\
\hline T11 & & & & & & & & & & & 1.00 & 0.99 & 0.92 & 0.99 & 0.95 & 0.91 & 0.95 & 0.88 & 0.95 & 0.93 & 0.88 \\
\hline T12 & & & & & & & & & & & & 1.00 & 0.91 & 1.00 & 0.96 & 0.92 & 0.97 & 0.92 & 0.98 & 0.95 & 0.85 \\
\hline T13 & & & & & & & & & & & & & 1.00 & 0.92 & 0.87 & 0.83 & 0.92 & 0.73 & 0.93 & 0.87 & 0.78 \\
\hline T14 & & & & & & & & & & & & & & 1.00 & 0.98 & 0.94 & 0.98 & 0.92 & 0.97 & 0.93 & 0.86 \\
\hline T15 & & & & & & & & & & & & & & & 1.00 & 0.95 & 0.98 & 0.97 & 0.93 & 0.85 & 0.82 \\
\hline T16 & & & & & & & & & & & & & & & & 1.00 & 0.91 & 0.92 & 0.89 & 0.88 & 0.93 \\
\hline T17 & & & & & & & & & & & & & & & & & 1.00 & 0.94 & 0.96 & 0.87 & 0.76 \\
\hline T18 & & & & & & & & & & & & & & & & & & 1.00 & 0.87 & 0.79 & 0.75 \\
\hline T19 & & & & & & & & & & & & & & & & & & & 1.00 & 0.96 & 0.80 \\
\hline T20 & & & & & & & & & & & & & & & & & & & & 1.00 & 0.89 \\
\hline T2 & & & & & & & & & & & & & & & & & & & & & \\
\hline
\end{tabular}

Tabla 6.h. Contribución por zonas (en \%)

\begin{tabular}{|c|c|c|c|c|}
\hline & Distal & Medial & Proximal & Palma \\
\hline Tarea T01 & 35.6 & 16.1 & 12.0 & 36.1 \\
\hline Tarea T02 & 18.6 & 15.8 & 18.4 & 47.1 \\
\hline Tarea T03 & 37.0 & 6.6 & 9.6 & 46.6 \\
\hline Tarea T04 & 28.3 & 6.6 & 12.7 & 52.3 \\
\hline Tarea T05 & 36.3 & 10.8 & 8.0 & 44.7 \\
\hline Tarea T06 & 56.8 & 3.4 & 11.3 & 28.3 \\
\hline Tarea T07 & 48.7 & 4.5 & 7.3 & 39.4 \\
\hline Tarea T08 & 39.0 & 10.1 & 10.7 & 40.1 \\
\hline Tarea T09 & 44.4 & 7.6 & 5.9 & 41.9 \\
\hline Tarea T10 & 35.0 & 8.2 & 5.6 & 51.0 \\
\hline Tarea T11 & 30.6 & 13.7 & 4.9 & 50.6 \\
\hline
\end{tabular}


Análisis de la distribución de presiones en la mano humana durante el agarre

\begin{tabular}{|c|c|c|c|c|}
\hline Tarea T12 & 34.5 & 13.4 & 4.3 & 47.6 \\
\hline Tarea T13 & 28.2 & 14.3 & 13.2 & 44.1 \\
\hline Tarea T14 & 34.8 & 14.5 & 6.7 & 43.8 \\
\hline Tarea T15 & 43.4 & 10.0 & 6.6 & 39.8 \\
\hline Tarea T16 & 45.2 & 16.0 & 9.0 & 29.5 \\
\hline Tarea T17 & 45.2 & 6.2 & 8.3 & 40.1 \\
\hline Tarea T18 & 53.5 & 1.9 & 4.9 & 39.6 \\
\hline Tarea T19 & 45.7 & 5.5 & 3.3 & 45.4 \\
\hline Tarea T20 & 35.7 & 12.0 & 8.3 & 43.8 \\
\hline Tarea T21 & 28.5 & 21.3 & 15.4 & 34.7 \\
\hline Promedio & 38.3 & 10.4 & 8.9 & 42.2 \\
\hline
\end{tabular}

Tabla 6.i. Coeficientes de correlación entre todas las tareas considerando las zonas de la mano.

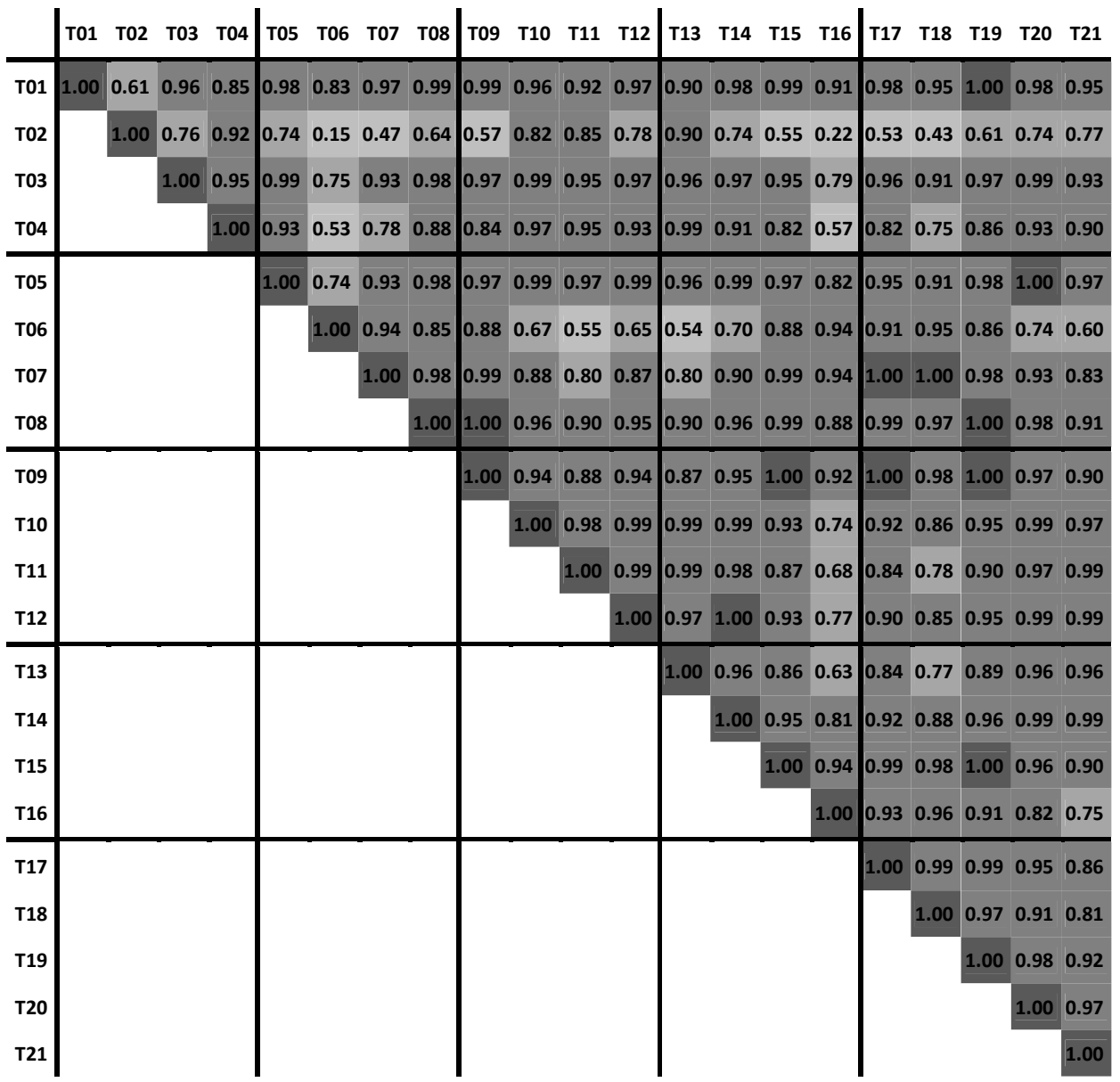


La figura 6.6 muestra la presión media registrada por cada zona sensible en cada tarea, como promedio de todos los sujetos y como promedio en toda la tarea, indicando el nivel de presión que se exige a las diferentes zonas de la mano en cada una de las actividades analizadas.
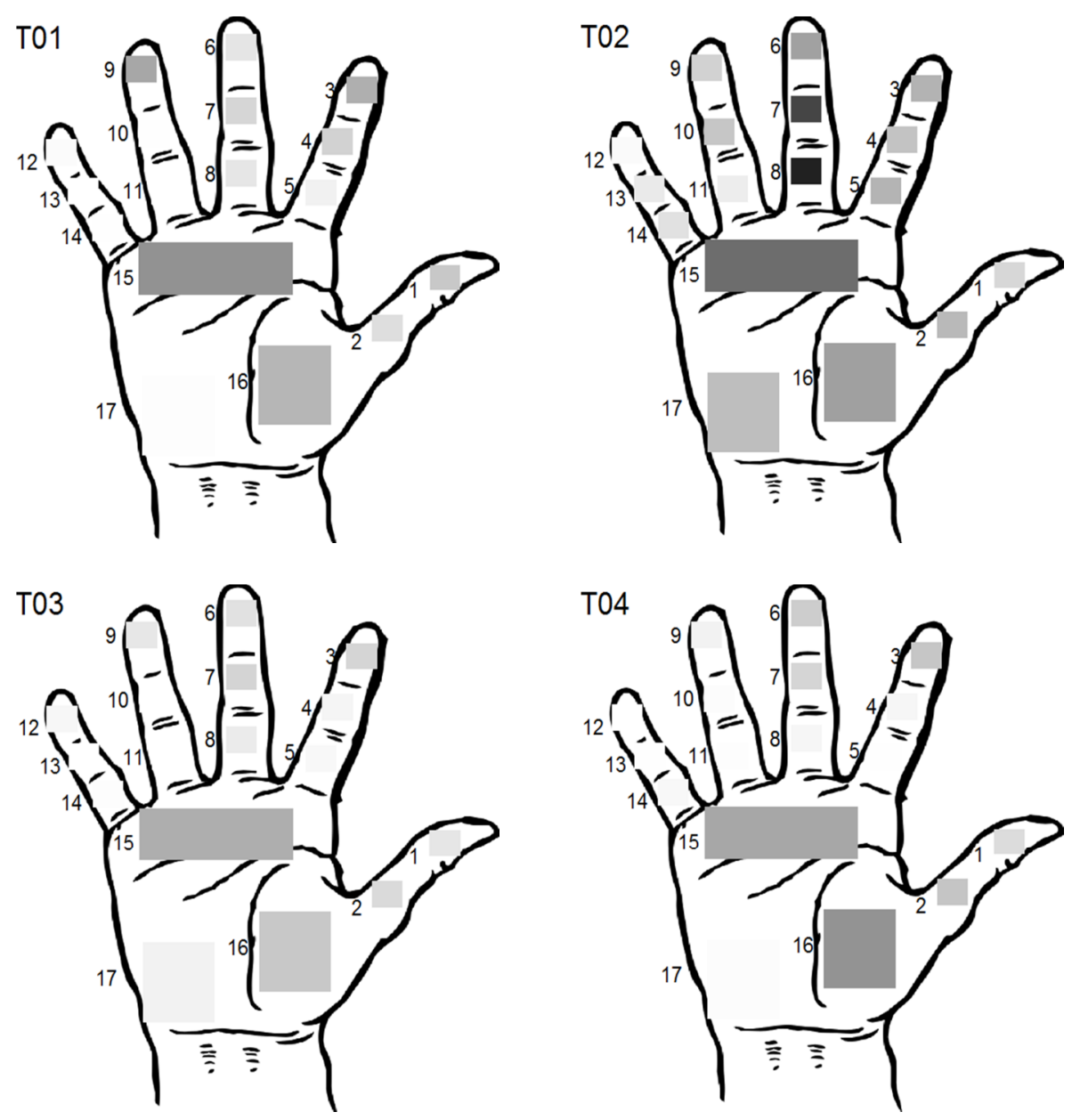

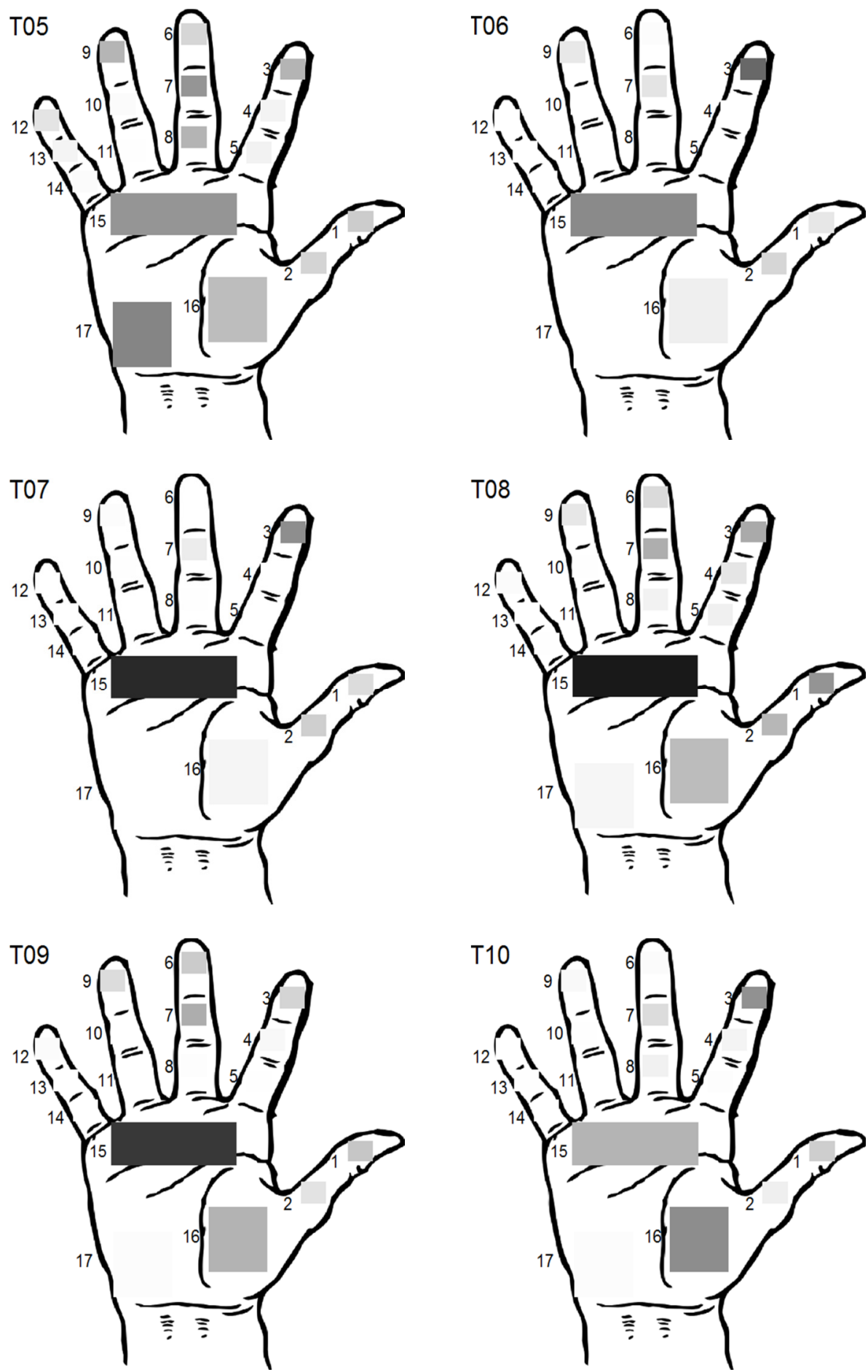

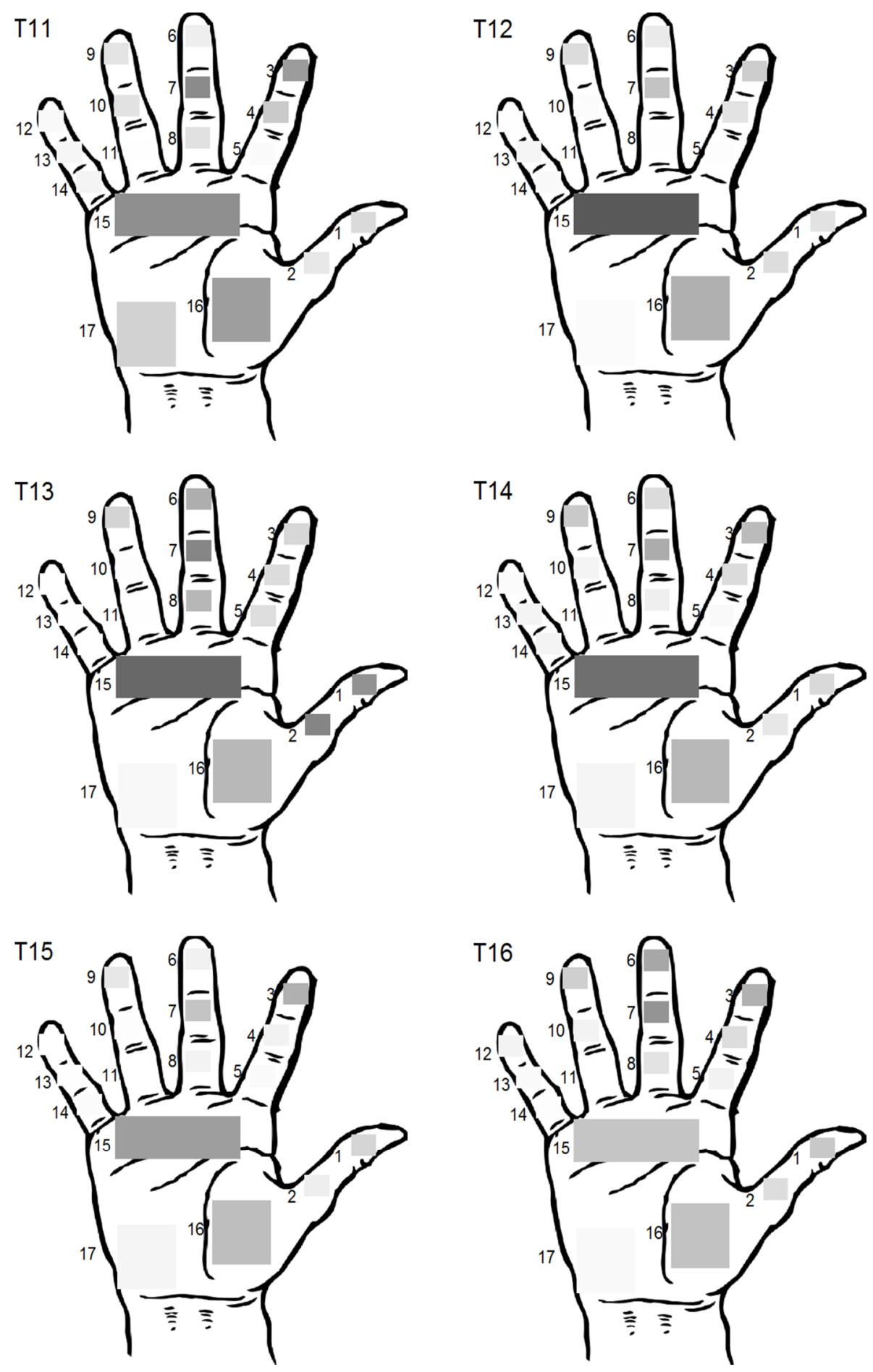

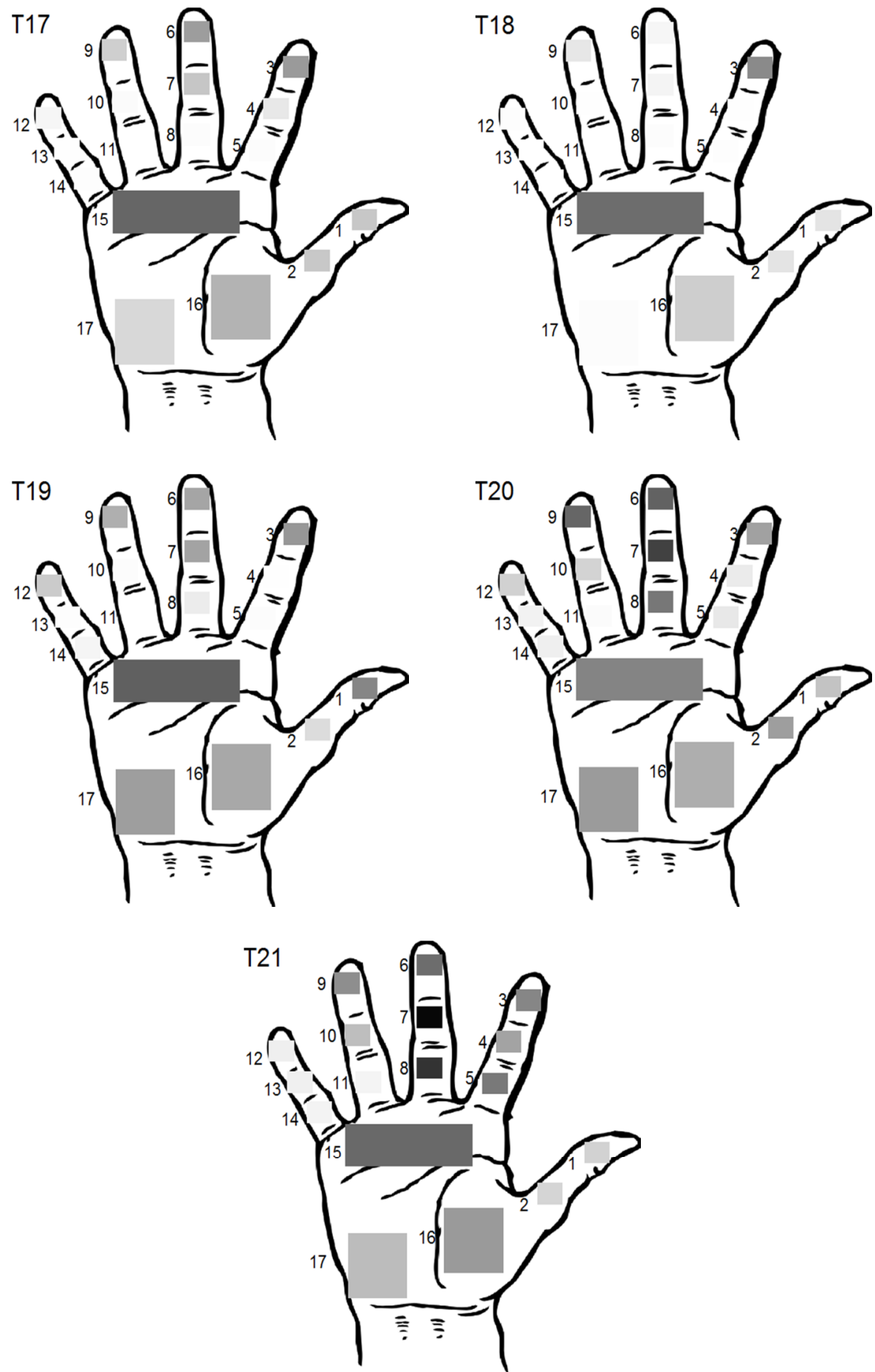

Figura 6.6. Presiones medias (promediadas en toda la tarea y para todos los sujetos) en las distintas zonas sensibles (escala de grises de 0, blanco a $60 \mathrm{kPa}$, negro). 
La tabla 6.j muestra el valor de $p$ de los ANOVAS realizados sobre la presión máxima, presión media, superficie de contacto y MGF, y el valor de $p$ del MANOVA sobre la CGF. En todos los casos el factor independiente es el 'Género' (hombre o mujer). Los ANOVAS realizados muestran que no hay diferencia estadísticamente significativa en la MGF con la que los hombres y las mujeres realizan las tareas, ni tampoco en los valores de presión media y superficie de contacto. Únicamente en la tarea T18 (limpiar con trapo) se observa un cambio estadísticamente significativo entre la presión máxima realizada por los hombres y la realizada por las mujeres.

Los resultados del MANOVA muestran sólo cuatro tareas en las que la distribución de fuerzas, representada por la CGF, es significativamente distinta entre hombres y mujeres (tareas T04 (escribir), T14 (cepillarse los dientes), T16 (peinarse) y T18 (limpiar con trapo).

Tabla 6.j. Valor de p de los ANOVAS sobre la presión máxima, presión media, superficie total y MGF, y MANOVA sobre la CGF. En todos IOS ANOVAS y el MANOVA el factor independiente es el 'Género'.

\begin{tabular}{|c|c|c|c|c|c|}
\hline Tarea & Presión máxima & Presión media & Superficie total & MGF & CGF \\
\hline T01 & 0.1136 & 0.0761 & 0.7763 & 0.2039 & 0.6916 \\
\hline T02 & 0.0728 & 0.4236 & 0.3450 & 0.0667 & 0.2617 \\
\hline T03 & 0.0702 & 0.4992 & 0.4888 & 0.8239 & 0.2030 \\
\hline T04 & 0.4976 & 0.4753 & 0.7257 & 0.7672 & 0.2286 \\
\hline T05 & 0.793 & 0.4994 & 0.2411 & 0.4604 & 0.0441 \\
\hline T06 & 0.3614 & 0.1543 & 0.1116 & 0.9141 & 0.4251 \\
\hline T07 & 0.8408 & 0.4065 & 0.1388 & 0.9238 & 0.1297 \\
\hline T08 & 0.2524 & 0.2002 & 0.3323 & 0.1307 & 0.6980 \\
\hline T09 & 0.9804 & 0.9275 & 0.3860 & 0.3271 & 0.7891 \\
\hline T10 & 0.8342 & 0.7705 & 0.3744 & 0.9010 & 0.6737 \\
\hline T11 & 0.3553 & 0.4901 & 0.6411 & 0.3064 & 0.2855 \\
\hline T12 & 0.9445 & 0.9151 & 0.2174 & 0.7490 & 0.1351 \\
\hline T13 & 0.9232 & 0.5261 & 0.3697 & 0.5382 & 0.3062 \\
\hline T14 & 0.5434 & 0.9121 & 0.9701 & 0.5095 & 0.0202 \\
\hline T15 & 0.5736 & 0.5595 & 0.6398 & 0.8118 & 0.3426 \\
\hline T16 & 0.3056 & 0.3296 & 0.5660 & 0.9479 & 0.0485 \\
\hline T17 & 0.1074 & 0.0658 & 0.7287 & 0.2028 & 0.0366 \\
\hline T18 & 0.0350 & 0.1142 & 0.2158 & 0.5048 & 0.0459 \\
\hline T19 & 0.3194 & 0.3334 & 0.6472 & 0.3698 & 0.4975 \\
\hline T20 & 0.3034 & 0.0999 & 0.3512 & 0.2266 & 0.3993 \\
\hline T21 & 0.5578 & 0.3695 & 0.8611 & 0.4859 & 0.0362 \\
\hline
\end{tabular}


Respecto a la tarea T06, la fuerza media realizada por todos los sujetos en el instante de presionar la tecla del teléfono, calculada como el promedio de la fuerza ejercida en cada una de las 13 pulsaciones realizadas por cada sujeto es de $3.08 \mathrm{~N}$ (2.74). La tabla 6.k muestra la fuerza media realizada por cada sujeto y la desviación típica intrasujeto.

Tabla 6.k: Fuerza media en las 13 pulsaciones al apretar cada tecla del teléfono y desviación típica entre teclas para cada sujeto en la tarea 6.

\begin{tabular}{|c|c|c|}
\hline Sujeto & Fuerza media (N) & Desviación típica (N) \\
\hline 1 & 6.42 & 5.96 \\
\hline 2 & 5.12 & 1.52 \\
\hline 3 & 7.24 & 2.21 \\
\hline 4 & 0.72 & 0.23 \\
\hline 5 & 4.15 & 1.79 \\
\hline 6 & 7.96 & 0.93 \\
\hline 7 & 5.97 & 0.84 \\
\hline 8 & 6.21 & 3.79 \\
\hline 10 & 1.53 & 1.44 \\
\hline 11 & 0.51 & 0.10 \\
\hline 12 & 6.60 & 1.46 \\
\hline 13 & 1.24 & 0.26 \\
\hline 14 & 2.71 & 0.99 \\
\hline 15 & 3.60 & 1.33 \\
\hline 16 & 0.46 & 0.22 \\
\hline 17 & 1.91 & 0.02 \\
\hline 18 & 0.65 & 0.70 \\
\hline 19 & 0.13 & 0.18 \\
\hline 20 & 0.22 & 0.12 \\
\hline 21 & 1.26 & 0.85 \\
\hline 22 & 0.50 & 0.34 \\
\hline
\end{tabular}

Las tareas T16 (peinarse), T17 (echar pulverizador de limpieza) y T19 (rociar aerosol) presentaban contribuciones claramente diferentes en función de la etapa que se estaba realizando. La CFG promediada durante cada etapa se muestra en la tabla 6.I. La tarea 16 se ha dividido en la apertura del cajón (de 0 a 0.20 en tiempo normalizado), peinarse $(0.20$ a 0.81 ) y cierre de cajón ( $0.81-$ 1); la tarea 17 se ha dividido en los intervalos en los que se efectuaban los disparos con el pulverizador de limpieza (de 0.40 a 0.60 ) y los que no se 
realizaban (de 0 a 0.40 y de 0.60 a 1); la misma división se ha realizado para la tarea 19 , siendo el intervalo de tiempo en el que se disparaba de 0.50 a 0.55 y el resto, el intervalo sin disparo.

Tabla 6.I. Contribución para las tareas T16, T17, T19 en distintos intervalos (en \%)

\begin{tabular}{|c|c|c|c|c|c|c|c|}
\hline Sensor & $\begin{array}{c}\text { CGF T16 } \\
\text { (Apertura } \\
\text { cajón) }\end{array}$ & $\begin{array}{c}\text { CGF T16 } \\
\text { (Peinarse) }\end{array}$ & $\begin{array}{c}\text { CGF T16 } \\
\text { (cierre } \\
\text { cajón) }\end{array}$ & $\begin{array}{c}\text { CGF T17 } \\
\text { (sin } \\
\text { disparo) }\end{array}$ & $\begin{array}{c}\text { CGF T17 } \\
\text { (con } \\
\text { disparo) }\end{array}$ & $\begin{array}{c}\text { CGF A 19 } \\
\text { (sin } \\
\text { disparo) }\end{array}$ & $\begin{array}{c}\text { CGF T19 } \\
\text { (con } \\
\text { disparo) }\end{array}$ \\
\hline S1 & 2.589 & 5.969 & 4.960 & 5.701 & 2.417 & 7.879 & 7.618 \\
\hline S2 & 1.924 & 3.630 & 7.815 & 8.226 & 4.606 & 1.659 & 1.312 \\
\hline S3 & 16.715 & 9.153 & 18.932 & 19.057 & 4.876 & 11.719 & 14.764 \\
\hline S4 & 7.794 & 1.622 & 5.952 & 1.538 & 3.486 & 0.071 & 0.008 \\
\hline S5 & 1.326 & 3.437 & 0.132 & 0.243 & 0.482 & 0.200 & 0.926 \\
\hline S6 & 26.269 & 4.350 & 14.409 & 7.051 & 26.557 & 5.681 & 6.671 \\
\hline S7 & 4.948 & 15.212 & 4.015 & 4.184 & 2.986 & 4.116 & 1.961 \\
\hline S8 & 0.823 & 2.952 & 0.160 & 0.278 & 0.192 & 1.215 & 1.121 \\
\hline S9 & 17.153 & 16.405 & 18.390 & 13.675 & 10.326 & 18.840 & 15.034 \\
\hline S10 & 0.706 & 1.088 & 0.059 & 0.236 & 0.402 & 0.266 & 0.035 \\
\hline S11 & 0.001 & 0.015 & 0.000 & 0.001 & 0.000 & 0.006 & 0.002 \\
\hline S12 & 0.115 & 0.627 & 0.036 & 0.317 & 0.413 & 3.080 & 2.066 \\
\hline S13 & 0.008 & 0.763 & 0.214 & 0.005 & 0.035 & 0.047 & 0.157 \\
\hline S14 & 0.107 & 0.141 & 0.025 & 0.226 & 0.011 & 0.212 & 0.319 \\
\hline S15 & 10.345 & 7.710 & 8.446 & 19.575 & 12.832 & 16.981 & 9.296 \\
\hline S16 & 8.544 & 24.935 & 15.881 & 15.804 & 11.732 & 14.005 & 5.614 \\
\hline S17 & 0.634 & 1.992 & 0.574 & 3.884 & 18.648 & 14.024 & 33.087 \\
\hline
\end{tabular}




\section{4.- Discusión}

Aunque existen estudios en la literatura en los que se han realizado ensayos con objetos cotidianos de la vida diaria para determinar las fuerzas de agarre y la contribución a la misma por parte de las distintas zonas de la mano, en general se trata de pocos objetos y/o pocas tareas realizadas (Faria et al., 2012; Hermsdörfer et al., 2011b; Komi, Roberts, \& Rothberg, 2007). El trabajo que se presenta en este capítulo describe un estudio realizado utilizando una gran variedad de objetos de la vida diaria. Además, los 22 sujetos que realizaron el ensayo no se limitaron a realizar un agarre estático de los objetos sino que realizaron una manipulación sobre ellos para desarrollar una tarea cotidiana de la vida diaria. Los datos conseguidos mediante este ensayo (distribución de presiones durante el agarre de los objetos, fuerza necesaria para el correcto manejo de los mismos y la contribución de las distintas zonas de la mano a dicha fuerza) aportan información interesante para su uso en el diseño de prótesis de mano humana y de robots manipuladores de servicio.

El valor de fuerza de agarre promedio durante la tarea para las diferentes tareas analizadas se sitúa en valores inferiores a $40 \mathrm{~N}$, siendo máximo en las tareas T20 (planchar) y T21 (manipular maletín). Por otra parte las presiones requeridas alcanzan un valor máximo de $435.1 \mathrm{kPa}$, correspondiente a la tarea T16. No obstante, analizando la evolución temporal de la fuerza de agarre en las diferentes tareas se observa que el valor máximo de dicha fuerza se sitúa en torno a los $100 \mathrm{~N}$ (tarea T02, figura 6.4). Estos resultados pueden servir para fijar un requisito aproximado para la fuerza de agarre que debe suministrar y para las presiones de contacto que debe soportar una prótesis o robot de servicio manipulador para realizar estas tareas, representativas de la vida diaria. Tal como se ha indicado en el apartado 2.4, Belter et al. (Belter et al., 2013) recomendaban un valor de fuerza de agarre para prótesis de mano de 65 $\mathrm{N}$, que es superior al valor de 40 obtenido como promedio durante las tareas, pero inferior al valor pico observado en la tarea T02 correspondiente a la apertura de una puerta, con lo cual podría resultar insuficiente para dicha tarea u otras similares.

En cuanto al análisis de las fuerzas necesarias para el agarre por zonas de la mano, los resultados de este ensayo indican lo siguiente: 
- Las zonas sensibles S1, S3, S12 y S17, que corresponde a la zonas distales del pulgar, índice y meñique y a la eminencia tenar registran los valores más elevados de fuerza en la tarea T19, en la que se rocía aerosol insecticida. Estos valores máximos se producen entre los tiempos normalizados $0.47-0.54$, que corresponde al momento inmediatamente anterior al disparo, debido a que la mano se reajusta para sujetar mejor un objeto liso y esbelto como es el aerosol y evitar que gire al efectuar el disparo.

- La zona proximal del dedo pulgar presenta valores máximos de fuerza y presión al inicio de la tarea T08 (entre 0.19 y 0.21 en tiempo normalizado), según la tabla 6.c. Esto corresponde a la fase de desenroscar el tapón, que resulta especialmente exigente para esta zona.

- En el dedo medio e índice se producen fuerzas máximas en varias zonas durante la ejecución de la tarea T21 (manipular maletín), en torno a los tiempos normalizados 0.47-0.55 (tabla 6.c). Esto ocurre en el instante correspondiente al volteo del maletín para orientarlo de manera que se pueda situar en la mesa. En ese instante, se utiliza el dedo medio como pivote para realizar este giro, lo que explica la elevada fuerza registrada.

- Las zonas sensibles S8, S10, S11, S13, S14, S15 y S16, correspondientes a zonas de los dedos medio, anular y meñique y la eminencia tenar y seno palmar distal, registran su fuerza máxima en la tarea T02 durante la apertura de la puerta, entre los instantes normalizados $0.34-0.45$. Se puede destacar el elevado valor de las fuerzas en las zonas de la palma durante esta tarea.

- Las zonas sensibles S4 y S13 presenta valores máximos de presión para la tarea T11 (cortar con cuchillo) pero los valores máximos de fuerza se tan en otras tareas, como se ha comentado.

El análisis de la contribución a la fuerza de agarre de las diferentes zonas de la mano para este ensayo, indica que la mayor contribución corresponde a la palma de la mano y las zonas distales de los dedos. Sin embargo, la contribución relativa del pulgar y de la palma en estos ensayos es ligeramente diferente a la observada en los ensayos con cilindros en el capítulo 4. También se observa una menor participación del meñique en comparación con aquellos ensayos. La explicación a esto no está totalmente clara, pero el análisis de los 
resultados de los experimentos de este capítulo indica que la mayor participación de la palma puede tener que ver con los contactos que se producen entre los dedos y la palma o de la palma con superficies de trabajo durante el desarrollo de algunas de las tareas. Por ejemplo al marcar las teclas del teléfono se encogen los dedos y éstos contactan con la palma de la mano o al escribir se apoya la palma en la mesa.

La tabla 6.e muestra que hay ciertas tareas que presentan un coeficiente de correlación elevado en la contribución de las diferentes zonas al agarre. La fuerte correlación de la tarea T01 con la T10, T12, T14 y T15 indica que el agarre de la llave es similar al agarre realizado con la cuchara, tenedor, cepillo de dientes y tubo de pasta de dientes. La tarea T02 y T13 están fuertemente correlacionadas ya que en ambas se emplea un agarre cilíndrico, en un caso para manejar el pomo de la puerta y en el otro para abrir y cerrar el grifo. Las tareas relacionadas con ingerir alimentos (T10, T11 y T12) también presentan una fuerte correlación, debido a que las zonas utilizadas para manipular los cubiertos son similares. Cabe resaltar que se observan patrones similares en tipos de agarres clasificados como diferentes en la tabla 6.a, lo cual indica que la clasificación de tipos de agarre en base a observaciones visuales puede ser válida desde el punto de vista cinemático (posturas) pero llevar a engaño en el caso dinámico (reparto de fuerzas en la mano). Los altos coeficientes de correlación obtenidos entre tareas cuando se agrupan las zonas sensibles por zonas de la mano o por dedos indica que pese a la variedad de tareas el reparto por dedos o por zonas es bastante similar, presentando patrones comunes.

La tabla 6.I muestra cómo cambia la CGF en función de la etapa en las tareas 16 (peinarse), 17 (echar pulverizador de limpieza) y 19 (pulverizar aerosol insecticida). En la tarea 16 se aprecia una mayor contribución de las zonas distales de los dedos índice, medio y anular en la apertura y cierre del cajón que durante el peinado, ya que estas zonas se utilizan para efectuar un agarre tipo gancho del cajón para abrirlo y cerrarlo. Durante el peinado se observa una contribución superior de las zonas mediales y proximales de los dedos índice y medio, así como en la región hipotenar, debida al agarre cilíndrico del mango del cepillo. La región hipotenar también presenta una contribución elevada durante el cierre del cajón, ya que esta zona contacta en el mismo durante el cierre. 
La tabla 6.I muestra también cómo el disparo del pulverizador de limpieza se produce fundamentalmente con la zona distal del dedo medio, ya que presenta la mayor variación de contribución respecto al intervalo sin disparo. También aumenta la contribución de la región tenar como parte opositora a la fuerza ejercida por el dedo medio durante el disparo. Algo similar ocurre en la tarea T19, donde aumenta la contribución de la zona S3, correspondiente a la zona distal del dedo índice (que está directamente implicada en el disparo) y, como consecuencia de esto, también aumenta la contribución de la zona hipotenar (S17).

Existen algunos estudios previos acerca de la contribución de cada zona de la mano en función del tipo de agarre, pero estudian dicha contribución mediante una única tarea (Faria et al., 2012). Otros estudios analizan las zonas de contacto de la mano en cada agarre pero sin considerar la contribución de cada una de esas zonas (Gonzalez, Gosselin, \& Bachta, 2014). La tabla 6.d muestra que dicha contribución no depende únicamente del tipo de agarre efectuado sino también de la tarea realizada con el objeto. En el estudio presentado en el capítulo anterior se llegaba a una conclusión similar, ya que la contribución de las distintas zonas de la mano a la fuerza de agarre dependía de la tarea que se realizara con la botella, aunque el agarre realizado era similar (figura 5.6). De esta manera, aunque el tipo de agarre influye en las zonas de contacto de la mano con el objeto manipulado, los valores concretos de la CGF varían en función de la tarea realizada con el objeto manipulado.

Las tareas T08 y T09, que corresponden a la de llenar un vaso de agua y a la de beber un vaso con agua, pueden compararse a la tarea T2 del capítulo anterior, en la que se vaciaba el agua de una botella en un recipiente. Aunque en ambas tareas se traslada un recipiente con agua que se vierte en otro, las diferencias entre la tarea T08 y la tarea T2 se deben fundamentalmente a dos motivos: por un lado, en la tarea 8 se abre el tapón mientras que en la T2 ya estaba abierto y, por otro, no se vierte toda la cantidad de líquido. Pese a estas diferencias, comparando esta tarea con la tarea de vertido de líquido expuesta en el capítulo anterior, examinando las figuras 5.5 y 6.4, puede verse cómo en los tramos comunes (mientras la botella está en la mano derecha, entre 0 0.15 y $0.27-1$, en tiempo normalizado), la GF sigue la misma tendencia en los dos casos, ya que la fuerza aumenta rápidamente durante la fase de carga para permanecer sensiblemente constante durante el transporte. 
Por otro lado, la tarea T09 también es similar a la tarea T2, ya que en ambas se toma un recipiente, se vacía el contenido y se deposita en otro sitio. Examinando las figuras 5.5 y 6.4, puede apreciarse que en ambos casos hay un aumento de la GF brusco en el momento de coger el recipiente (fase de carga). En la tarea T09 se observa además un máximo relativo de GF en el tiempo normalizado 0.77 que no se aprecia de forma tan marcada en la tarea T2, aunque en esta última también se apreciaba un incremento justo al final para algunos sujetos y/o botellas, que queda reflejado en la curva media de la figura 5.5 como un cambio de pendiente. Este máximo relativo corresponde al inicio del descenso del vaso una vez se ha bebido el contenido. Las diferencias entre ambas curvas pueden atribuirse a las diferencias en la tarea, ya que aunque se traslada un recipiente y se vacía, en la tarea T2 no se varía la altura de forma importante, mientras que en la tarea T09 de este capítulo, sí. Cuando se finaliza la tarea de beber hay un instante en el que ha de recolocarse el vaso y empezar a bajarlo, lo que exige una mayor GF para impedir que se caiga, ya que se realizan aceleraciones mayores y esto hace que se incremente la GF para mantener la estabilidad.

La figura 6.4 muestra cómo en la tarea T04, correspondiente a escribir un texto con un bolígrafo, la variación de la GF entre sujetos es muy acusada. Esto puede ser debido a que no se ha conseguido una buena sincronización a pesar de que el tiempo se ha normalizado, ya que es probable que cuando un sujeto esté haciendo una GF elevada al apretar para escribir, otro esté en ese mismo instante haciendo una menor GF al estar cambiando de palabra. A esto se une el hecho de que la escritura es una habilidad aprendida y existen varios estilos, lo que conlleva varias formas de coger el bolígrafo (Bailey, 1988). Por otra parte, en la escritura se produce el efecto de redundancia motriz, lo que implica que la misma fuerza pueda realizarse colocando los dedos de distintas maneras (Hooke et al., 2008; Shim et al., 2010). Los valores de GF obtenidos en este experimento son similares a los mostrados por Hooke et al. (Hooke et al., 2008). La contribución por zonas muestra que el máximo porcentaje corresponde a la eminencia hipotenar, siendo este valor anormalmente elevado, al igual que el seno palmar. Seguramente estas zonas no presentan un valor elevado debido al contacto con el bolígrafo sino que estos valores registrados se deben al apoyo de la mano con la mesa durante la escritura y con otros dedos de la mano al adoptar la postura para escribir. Los valores altos de la zona distal y media del dedo anular parecen confirmar la existencia 
de contacto entre esta zona del dedo y el seno palmar. La zona distal del índice tiene una contribución elevada, lo que parece lógico al ser una de las zonas de contacto de la mano con el bolígrafo. La zona distal del pulgar debería tener un valor de contribución mayor, ya que tiene solamente un 3.98\%. En esta zona posiblemente el sensor no ha captado toda la fuerza de contacto al presionar el bolígrafo en un área que no estaba recubierta por sensor. El elevado valor del pulgar proximal muestra cómo el bolígrafo también apoya en esa zona durante la escritura.

En la tarea T06, que consistía en marcar un número de teléfono, puede observarse que los resultados obtenidos muestran una gran dispersión entre sujetos en el valor ejercido para presionar una tecla en un teléfono convencional. Analizando cada sujeto por separado, puede observarse como la desviación típica dentro de cada sujeto no es elevada, aunque sí que lo es entre sujetos. Tal como se puede observar en la tabla 6.d, la mayor contribución es la debida a la zona distal del dedo índice. Es lógico, ya que es la parte empleada por la mayor parte de sujetos para presionar las teclas. La zona proximal del pulgar y, en menor medida, la zona distal del mismo dedo, también tienen una contribución significativa. Esto es debido a que algunos sujetos utilizaban también este dedo para marcar los números que se encuentran más próximos a él, aunque se les indicó que utilizaran la zona distal del dedo índice. También es remarcable el porcentaje de contribución de la zona distal del dedo anular (12.5\%), que se debe a dos motivos: por una lado, este dedo se utilizó para marcar números más próximos a la zona cubital de la mano del sujeto; y por otro, algunos sujetos encogían los dedos medio, anular y meñique para marcar, con lo que esta zona contactaba con el seno palmar (al igual que las zonas distal y medial del dedo medio, que también muestran una contribución elevada). Este contacto se certifica al observar elevados valores de contribución del seno palmar (20.4\%) y de la eminencia tenar $(7.9 \%)$, producidos por el contacto con las zonas antes mencionadas.

En la tarea T07, en la que se tecleaba un texto en el ordenador, se han obtenido valores que muestran una dispersión muy grande, al igual que ha ocurrido con otras tareas. El motivo puede ser similar al de la tarea 4: resulta muy complicado realizar una sincronización, a pesar de normalizar el tiempo, por lo que es probable que cuando un sujeto esté pulsando una tecla, en el mismo instante de tiempo normalizado otro sujeto esté preparándose para 
pulsarla. Examinando la contribución por zonas de la mano, la tabla 6.h muestra que la contribución mayor es la de la zona distal (48.8 \%) ya que se utilizan las zonas distales de los dedos para presionar las teclas. Además, en la tabla 6.d puede observarse que la contribución mayor se da en la zona índice distal (33.5\%). Esto se debe a dos factores: por un lado, hay sujetos que no utilizan todos los dedos para escribir, pero todos utilizan el índice; y por otro lado, es el dedo con el que resulta más cómodo realizar la presión, por lo que con este dedo se realiza más fuerza de la necesaria para presionar la tecla. La contribución de la palma también es elevada, con un 39.4\% (tabla 6.h), donde destaca la zona del seno palmar con un $31.0 \%$ (tabla 6.d). No se debe a que se hayan pulsado teclas con esta zona, sino a que algunos sujetos la apoyan para escribir en el teclado. El pulgar también presenta una contribución elevada (12.3 \%, tabla 6.f) debido a que es el dedo utilizado para pulsar la barra espaciadora y, normalmente, se realiza un esfuerzo mayor al de una tecla con una letra o número al ser una tecla más alargada). Las zonas proximales de los dedos tienen una contribución muy baja $(0.00 \%$ en el índice, $1.33 \%$ en el medio, $0.01 \%$ en el anular y $0.00 \%$ en el meñique), lo que resulta lógico ya que esas zonas ni impactan con el teclado ni se encuentran en contacto con ninguna zona mientras se escribe.

Respecto a la tarea T21, que consistía en elevar un maletín, la figura 6.4 muestra que la tendencia en las fuerzas es similar en todos los sujetos, aunque la dispersión entre sujetos es elevada, motivo por el cual en las fuerzas normalizadas puede observarse una tendencia similar y poca dispersión, mientras que en el caso de las fuerzas totales, la dispersión es mayor. La contribución de los dedos índice y medio es elevada, ya que con estos dedos se efectúa el agarre tipo gancho, mientras que la contribución del pulgar es baja, ya que no interviene en este tipo de agarre.

Los valores de GF de la tarea 11 son más bajos que los registrados en la literatura para cortes con cuchillo, pero hay que tener en cuenta que en nuestra tarea se cortaba plastilina, que tiene menor resistencia mecánica que la carne. Sin embargo, la relación entre los valores máximo y medio (aproximadamente igual a 3) sí que es similar a los valores mostrados en la literatura (Raymond W. McGorry et al., 2003). 
Los ANOVAS y el MANOVA realizados indican que el género del sujeto no implica cambios estadísticamente significativos ni en la GF, presión máxima, presión media ni en la superficie de contacto. Estudios previos indican que los hombres son capaces de realizar una fuerza de agarre máxima superior a la de las mujeres (Morse, Jung, Bashford, \& Hallbeck, 2006; Nicolay \& Walker, 2005), aunque no es comparable a este caso al tratarse de agarres de precisión o de potencia intermedia. Lo mismo ocurre con un estudio de Eksioglu et al. (Eksioglu \& Kizilaslan, 2008), que predice una mayor fuerza en el agarre de un volante durante la conducción por parte de los hombres que de las mujeres, aunque el agarre de un volante es un agarre de potencia.

Este ensayo tiene algunas limitaciones que se han de considerar. Por una parte, el sensor utilizado Grip 4256E, si bien incluye muchos sensores, no es capaz de registrar todas las zonas de contacto entre mano y objeto, por lo que puede existir un cierto error en los valores de fuerza de agarre, que debe añadirse al propio error experimental. Otra limitación relacionada con el sensor empleado es la diferente adaptación del mismo a los diferentes tamaños de mano de los sujetos. El sensor se ha utilizado montado sobre un guante y recubierto por dos guantes más, uno de LDPE y otro de látex. Aunque el uso de tres guantes reduce algo la sensibilidad y movilidad de los sujetos, Rock et al. determinaron que la GF no se modifica de forma estadísticamente significativa para tareas por debajo de las capacidades máximas del sujeto (Rock et al., 2001). Por otra parte, cada sujeto realizó una única ejecución de la tarea en este ensayo, tras ver la demostración de cómo debía ejecutarla. Esta única ejecución no debería afectar a los resultados según estudios previos (A. Hamilton et al., 1994; V Mathiowetz et al., 1984). Por otra parte, los resultados de los capítulos anteriores, que muestran una buena repetibilidad en los resultados entre las diferentes ejecuciones de una misma tarea por parte de un sujeto, confirman esta idea. 


\section{5.- Conclusiones}

En este capítulo se ha estudiado la dinámica del agarre de diversos objetos mediante la realización de 21 actividades de la vida diaria. Gran parte de los resultados de este trabajo pueden ser útiles para contribuir a la mejora del diseño de prótesis de mano humana y de robots manipuladores de servicio. Cabe destacar las siguientes conclusiones:

- Se ha podido comprobar que distintas tareas realizadas con el mismo tipo de agarre no mostraban la misma contribución de las distintas zonas de la mano a la fuerza de agarre, por lo que se ha concluido que dicha contribución no depende únicamente del tipo de agarre sino también de la tarea realizada durante la manipulación del objeto.

- Asimismo, se ha concluido que tareas con un tipo de agarre clasificado como diferente, presentan fuertes correlaciones teniendo en cuenta la contribución de los distintos sensores. Esto parece indicar que la clasificación de agarres basada en la postura puede no ser válida desde el punto de vista de la distribución de fuerzas de agarre en la mano.

- Se ha determinado que la fuerza de agarre, la superficie de contacto durante el agarre y las presiones máximas y medias realizadas durante el manejo de los distintos objetos son, en general, independientes del género del sujeto.

- Para el conjunto de tareas de la vida diaria analizadas, la mayor contribución a la fuerza de agarre es realizada por la palma y las zonas distales de los dedos, especialmente la del dedo índice. 
Capítulo 6. Caracterización del agarre en la realización de tareas cotidianas

$-228-$ 
7.- Conclusiones y desarrollos futuros 



\section{1- Conclusiones}

Este trabajo se ha centrado en caracterizar el agarre humano, determinando la fuerza total, la contribución a dicha fuerza realizada por las distintas zonas de la mano y las presiones que se producían en dichas zonas, con el fin de aportar datos que permitan mejorar el diseño de prótesis de mano humana, de robots manipuladores y la ergonomía de objetos y mangos.

Para conseguir estos objetivos, se ha realizado una búsqueda bibliográfica exhaustiva sobre la anatomía de la mano, los aspectos neurofisiológicos del agarre humano, las diferentes taxonomías existentes de agarre, las prótesis de mano y robots manipuladores existentes, la ergonomía del agarre, y las diferentes técnicas de medición del agarre. Además, se han realizado tres ensayos experimentales para obtener resultados acerca de la fuerza que se realiza en el agarre de objetos y la contribución de las diferentes zonas de la mano a la misma. Dichos ensayos realizados han permitido, además de obtener conclusiones sobre la dinámica del agarre humano en diferentes tareas y con diversos objetos cotidianos, poner a punto protocolos de ensayo adecuados para la investigación en este campo, utilizando tecnologías relativamente nuevas disponibles para la medida de fuerzas y presiones de contacto entre la mano y el objeto. Los tres ensayos han abordado el estudio de la dinámica del agarre con diferentes niveles de abstracción en los objetos, crecientes desde un primer ensayo con objetos abstractos cilíndricos hasta un último ensayo en el que se han analizado 21 tareas típicas de la vida diaria, utilizando otros tantos objetos de uso cotidiano. Por todo ello se puede afirmar que, según nuestro conocimiento, esta tesis constituye uno de los trabajos más extensos sobre análisis de las presiones y fuerzas de contacto en el agarre humano.

Las conclusiones de la tesis se han ido exponiendo de forma detallada en cada uno de los capítulos de la tesis. No obstante, se resumen a continuación las conclusiones principales:

- Los sistemas de medida de presión Finger TPS (finger Profile Systems) y Grip 4256E (Tekscan) utilizados en esta tesis se consideran sistemas válidos para el estudio de la dinámica del agarre humano. Comparativamente el sistema Finger TPS resulta algo menos invasivo 
que el Grip 425E, aunque éste último presenta la ventaja de recoger información de presión de mayor superficie de la mano y con una mayor resolución espacial, al disponer de un número muy elevado de sensores individuales. Para el uso de ambos sistemas se recomienda el uso de guantes exteriores de látex o similar que aseguren uniformidad en el coeficiente de rozamiento en el contacto entre las diferentes partes de la mano y el objeto, independientemente de la posición de los sensores. En el caso del sistema Grip 4256E se recomienda el uso de un guante fino y holgado de polietileno para proteger el sensor antes de la colocación del guante de látex.

- En los ensayos realizados se ha comprobado que la repetibilidad del agarre por parte de un mismo sujeto en condiciones similares (misma tarea y objetos) en la misma sesión es aceptable, siendo pequeño el error producido debido a las distintas repeticiones ejecutadas por un mismo sujeto.

- Se ha podido comprobar que la dinámica del proceso de agarre es compleja y dependiente de la mayor parte de los factores implicados, tales como el sujeto, las características del objeto manipulado y la tarea realizada. La variabilidad asociada al sujeto es alta lo que indica que el aprendizaje del sujeto y/o sus características anatómicas tienen una influencia importante en la dinámica del agarre. No obstante, no se ha confirmado como significativo el factor género del sujeto.

- La fuerza de agarre usada en el transporte de objetos cilíndricos, aumenta con el peso de los mismos, aunque no de forma directamente proporcional. Los resultados de la tesis indican que el margen de seguridad en el transporte de objetos de menor peso es más elevado que para objetos más pesados. En contraste, los resultados de la tesis indican que en el caso de objetos con el mismo peso, aquellos con apariencia de más pesados se manipulan con una mayor fuerza de agarre. La variación del peso del objeto transportado no tiene un efecto estadísticamente significativo en la contribución de gran parte de las zonas de la mano, lo que indica una tendencia a realizar un escalado de las fuerzas proporcional en la mayor parte de las zonas de la mano, aunque no en todas. 
- Comparando agarres de precisión con diferente número de dedos, la menor fuerza de agarre total en el transporte de objetos cilíndricos se realiza con el agarre tipo pinza con dos dedos, siendo ésta similar a la que se ejerce con el agarre con tres dedos. Cuando se incrementa el número de dedos crecen la fuerzas de agarre.

- Para el agarre de objetos cilíndricos, cuando el usuario selecciona el agarre de forma libre o natural, utiliza agarres de precisión con cinco dedos si el peso del cilindro es inferior a 500 g y su diámetro es igual o inferior a $50 \mathrm{~mm}$. Para diámetros superiores o pesos más elevados el agarre seleccionado es intermedio entre un agarre cilíndrico de potencia y un agarre de precisión con cinco dedos.

- La contribución a la fuerza de agarre por parte de las distintas zonas de la mano es dependiente de la tarea que se realiza, lo que se ha confirmado para el caso de objetos cotidianos aunque el tipo de agarre utilizado para ellos sea aparentemente similar o incluso cuando la manipulación es con el mismo objeto, como se ha comprobado en la manipulación de botellas.

- Las zonas de la mano con mayor contribución media al agarre en las actividades cotidianas son la palma y las zonas distales de los dedos. La contribución de las zonas distales crece para cilindros de mayor diámetro y para aquellos de menor peso. La contribución del meñique es muy dependiente de la tarea. Así, se han obtenido contribuciones relativamente altas del meñique para la manipulación de precisión de cilindros, pero valores bajos en conjunto en las tareas de la vida cotidiana analizadas. Asimismo, el pulgar presenta una mayor contribución en las tareas de manipulación de cilindros que en el conjunto de tareas cotidianas analizadas.

- En el estudio del agarre con diferentes objetos en tareas cotidianas se ha comprobado que tareas con tipos de agarre clasificados visualmente como diferentes, presentan fuertes correlaciones en la distribución de la fuerza de agarre entre las distintas zonas de la mano, lo que indica que las clasificaciones de tipos de agarre basadas en la postura de la mano pueden no ser válidas desde el punto de vista de la distribución de fuerzas de agarre en la mano.

Durante el desarrollo de esta tesis se ha colaborado en el desarrollo de algunos de los proyectos de investigación en marcha en el grupo de Biomecánica y 
Ergonomía de la Universitat Jaume I y se han realizado algunas contribuciones a congresos del ámbito de biomecánica. Asimismo se están elaborando artículos para publicación en revistas internacionales indexadas, uno de las cuales está actualmente en proceso de revisión. La información específica se indica a continuación:

- Proyecto: Caracterización biomecánica de la planificación y la postura en la manipulación de objetos por la mano humana. Fechas: Ene. 2010-Dic. 2011. Fundació Bancaixa- Universitat Jaume I. Referencia: P1-1B2009-40.

- Proyecto: Análisis y caracterización biomecánica del agarre humano en actividades cotidianas. Fechas: Ene. 2011-Dic. 2013. Ministerio de Ciencia e Innovación. Referencia: DPI2010-18177.

- Congreso internacional: A. Pérez-González, J. Cepriá, F.J. Andrés, J.L. Sancho (2015). Force sharing for different grasp types when transporting a cylinder. Abstracts of the 21th Congress of the European Society of Biomechanics. Prague, 2015.

- Congreso nacional: Cepriá Bernal, J., Pérez González, A.,Mora, M.C.,Sancho-Bru, J. (2014) Fuerza de agarre en dos tareas de manipulación con botellas. Actas de la IV Reunión del Capítulo Nacional de la Sociedad Europea de Biomecánica. Valencia.

- Revista indexada JCR: Javier Cepriá-Bernal, Antonio Pérez-González, Marta C. Mora, Joaquín L. Sancho-Bru. Grip force and force sharing in two different manipulation tasks with bottles. Ergonomics (en revisión). 


\section{2.- Desarrollos futuros}

El trabajo realizado en esta tesis ha permitido contribuir a un mejor conocimiento de la dinámica del agarre humano, aunque a partir de él se abren posibles líneas de trabajo futuro. Algunas de las que se proponen son las siguientes:

- Extensión del análisis realizado sobre el agarre en tareas cotidianas a un mayor número de objetos y tareas, con el fin de disponer de una base de datos suficientemente amplia para servir de referencia fiable en el diseño de manipuladores antropomorfos y prótesis o en el diseño de productos y herramientas. Con el fin de analizar la reproducibilidad de los resultados, también sería conveniente repetir los mismos ensayos con los mismos sujetos en más de una sesión experimental, lo que permitiría al mismo tiempo una mejor caracterización de los sistemas de medida.

- Aplicación de la metodología experimental utilizada en esta tesis al estudio de la fuerza de agarre durante el uso de herramientas manuales, tales como sierras, destornilladores, martillos, etc. El análisis de las fuerzas de contacto empleadas durante el uso de dichas herramientas así como su distribución en la mano permitiría obtener datos muy útiles con el fin de mejorar el diseño ergonómico de los mangos de dichas herramientas.

- Diseño de objetos sensorizados internamente y/o superficialmente para facilitar el estudio de la dinámica del agarre. Dado que las prótesis o manipuladores artificiales tienen diseños con diferente número de grados de libertad y capacidades que la mano humana, sería muy interesante disponer de un conjunto de objetos sensorizados que permitan analizar comparativamente las fuerzas de agarre realizadas sobre los mismos por parte de sujetos sanos y de sujetos usando prótesis, o bien de robots manipuladores de servicio. El diseño y desarrollo de un conjunto suficientemente amplio de objetos sensorizados, de modo que recojan información de la dinámica del agarre es un reto interesante y no resuelto. Disponer de estos objetos facilitaría la comparación de las capacidades prensiles de la mano 
humana frente a otros sistemas artificiales, permitiendo ensayos menos invasivos para el sujeto y más fieles al agarre real.

- Diseño y construcción de un prototipo de manipulador antropomorfo, con capacidades prensiles similares a la mano humana. En esta línea ya se ha empezado a trabajar en el grupo de Biomecánica y Ergonomía en el que se enmarca esta tesis. Para el diseño cinemático y dinámico de dicho manipulador y para su facilitar su control se considerarán los datos de fuerza de agarre y contribución de las diferentes zonas de la mano obtenidos en la presente tesis.

- Estudio comparativo de las diferencias entre la fuerza de agarre y su distribución producida por sujetos zurdos y por sujetos diestros. Se trata de un campo poco estudiado y del que se derivaría información valiosa para las prótesis enfocadas hacia los sujetos zurdos, que forman aproximadamente el $10 \%$ de la población. 
Bibliografía 
Agashe, H. A., \& Contreras-Vidal, J. L. (2013). Decoding the evolving grasping gesture from electroencephalographic (EEG) activity. Conference Proceedings : ... Annual International Conference of the IEEE Engineering in Medicine and Biology Society. IEEE Engineering in Medicine and Biology Society. Conference, 2013, 5590-3. http://doi.org/10.1109/EMBC.2013.6610817

Agins, H. J., Harder, V. S., Lautenschlager, E. P., \& Kudrna, J. C. (2003). Effects of sterilization on the Tekscan digital pressure sensor. Medical Engineering \& Physics, 25(9), 775-780. http://doi.org/10.1016/S13504533(03)00119-X

Amazon. (2013). Calibre hidráulico Preston. Retrieved September 1, 2015, from http://www.amazon.com/Preston-Baseline-Hydraulic-PinchGauge/dp/B00QZ7WCL2

Andalucía, J. de. (n.d.). Estructura ósea de la mano.

Ansuini, C., Giosa, L., Turella, L., Altoè, G., \& Castiello, U. (2008). An object for an action, the same object for other actions: effects on hand shaping. Experimental Brain Research. Experimentelle Hirnforschung. Expérimentation Cérébrale, 185(1), 111-119. Retrieved from http://dx.doi.org/10.1007/s00221-007-1136-4

Aoki, T., Niu, X., Latash, M. L., \& Zatsiorsky, V. M. (2006). Effects of friction at the digit-object interface on the digit forces in multi-finger prehension. Experimental Brain Research, 172(4), 425-438. Retrieved from papers2://publication/uuid/5A2E8B73-EF20-417F-BC9B-9C6E2156AC50

Argall, B. D., Argall, B. D., Chernova, S., Chernova, S., Veloso, M., Veloso, M., ... Browning, B. (2009). A survey of robot learning from demonstration. Robotics and Autonomous Systems, 57(5), 469-483. http://doi.org/10.1016/j.robot.2008.10.024

Ascari, L., Bertocchi, U., Corradi, P., Laschi, C., \& Dario, P. (2009). Bio-inspired grasp control in a robotic hand with massive sensorial input. Biological Cybernetics, 100(2), 109-128. Retrieved from papers2://publication/uuid/2321FA58-FA35-42E1-A4B6-9A15315F9CC9 
Augurelle, A.-S., Smith, A. M., Lejeune, T., \& Thonnard, J.-L. (2003). Importance of cutaneous feedback in maintaining a secure grip during manipulation of hand-held objects. Journal of Neurophysiology, 89(2), 665-671. http://doi.org/10.1152/jn.00249.2002

Bachus, K. N., DeMarco, A. L., Judd, K. T., Horwitz, D. S., \& Brodke, D. S. (2006). Measuring contact area, force, and pressure for bioengineering applications: Using Fuji Film and TekScan systems. Medical Engineering and Physics, 28(5), 483-488. http://doi.org/10.1016/j.medengphy.2005.07.022

BACORN, R. W., \& KURTZKE, J. F. (1953). Colles' fracture; a study of two thousand cases from the New York State Workmen's Compensation Board. The Journal of Bone and Joint Surgery. American Volume, 35-A(3), 643-658.

Bailey, C. A. (1988). Handwriting: Ergonomics, Assessment and Instruction. British Journal of Special Education, 15(2), 65-71. http://doi.org/10.1111/j.1467-8578.1988.tb00318.x

Balogun, J. A., Akomolafe, C. T., \& Amusa, L. O. (1991). Grip strength: effects of testing posture and elbow position. Archives of physical medicine and rehabilitation (Vol. 72).

Bebionic. (n.d.). Bebionic Hand. Retrieved October 4, 2015, from http://es.bebionic.com/

Belter, J. T., Segil, J. L., Dollar, A. M., \& Weir, R. F. (2013). Mechanical design and performance specifications of anthropomorphic prosthetic hands: a review. Journal of Rehabilitation Research and Development, 50(5), 599618. http://doi.org/10.1682/JRRD.2011.10.0188

Bicchi, A. (2000). Hands for dexterous manipulation and robust grasping: A difficult road toward simplicity. IEEE Transactions on Robotics and Automation, 16(6), 652-662. http://doi.org/10.1109/70.897777

Bioinstrumentación. (n.d.). Mano híbrida. Retrieved from http://bioinstrumentacion.eia.edu.co/WebEstudiantes/2005II/ManoRob otica/P2.JPG 
Blackwell, J. R., Kornatz, K. W., \& Heath, E. M. (1999). Effect of grip span on maximal grip force and fatigue of flexor digitorum superficialis. Applied Ergonomics, 30(5), 401-405. http://doi.org/10.1016/S00036870(98)00055-6

Bluethmann, W., Ambrose, R., Diftler, M., Askew, S., Huber, E., Goza, M., ... Magruder, D. (2003). Robonaut: A robot designed to work with humans in space. Autonomous Robots, 14(2-3), 179-197. http://doi.org/10.1023/A:1022231703061

Bock, O. (n.d.). Myo hand.

Bohannon, R. W., Bear-Lehman, J., Desrosiers, J., Massy-Westropp, N., \& Mathiowetz, V. (2007). Average grip strength: a meta-analysis of data obtained with a Jamar dynamometer from individuals 75 years or more of age. Journal of Geriatric Physical Therapy (2001), 30(1), 28-30.

Bohannon, R. W., Peolsson, A., Massy-Westropp, N., Desrosiers, J., \& BearLehman, J. (2006). Reference values for adult grip strength measured with a Jamar dynamometer: a descriptive meta-analysis. Physiotherapy. http://doi.org/10.1016/j.physio.2005.05.003

Bolton, W. (2010). Mecatrónica (4 ed.). Alfaomega.

Bourbonnais, D., Frak, V., Pilon, J.-F., \& Goyette, M. (2008). An instrumented cylinder measuring pinch force and orientation. Journal of Neuroengineering and Rehabilitation, 5, 2. http://doi.org/10.1186/17430003-5-2

Bowers, R. (2002). El Maravilloso mundo de las prótesis cosméticas. inMotion, 12.

Brand, P. W., \& Hollister, A. (1992). Clinical Mechanics of the Hand (2 Edición). St. Louis: Mosby Year Book.

Bridgwater, L. B., Ihrke, C. A., Diftler, M. A., Abdallah, M. E., Radford, N. A., Rogers, J. M., ... Linn, D. M. (2012). The robonaut 2 hand - Designed to do work with tools. In Proceedings - IEEE International Conference on Robotics and Automation (pp. 3425-3430). http://doi.org/10.1109/ICRA.2012.6224772 
BROCK, O., FAGG, A., GRUPEN, R., PLATT, R., ROSENSTEIN, M., \& SWEENEY, J. (2005). A FRAMEWORK FOR LEARNING AND CONTROL IN INTELLIGENT HUMANOID ROBOTS. International Journal of Humanoid Robotics. http://doi.org/10.1142/S0219843605000491

Brodke, D. S., Gollogly, S., Alexander Mohr, R., Nguyen, B. K., Dailey, a T., \& Bachus aK. (2001). Dynamic cervical plates: biomechanical evaluation of load sharing and stiffness. Spine, 26(12), 1324-1329. http://doi.org/10.1097/00007632-200106150-00010

Buckingham, G., Cant, J. S., \& Goodale, M. A. (2009). Living in a material world: how visual cues to material properties affect the way that we lift objects and perceive their weight. Journal of Neurophysiology, 102, 3111-3118. http://doi.org/10.1152/jn.00515.2009

Buckley, D. (n.d.). Mano Stranford/JPL. Retrieved from http://www.davidbuckley.net/RS/HandResearch.htm

Budgeon, M. K., Latash, M. L., \& Zatsiorsky, V. M. (2008). Digit force adjustments during finger addition/removal in multi-digit prehension. Experimental Brain Research, 189(3), 345-359. http://doi.org/10.1007/s00221-008-1430-9

Buis, A. W., \& Convery, P. (1997). Calibration problems encountered while monitoring stump/socket interface pressures with force sensing resistors: techniques adopted to minimise inaccuracies. Prosthetics and Orthotics International, 21(3), 179-182. http://doi.org/10.3109/03093649709164552

Butterfass, J., Grebenstein, M., Liu, H., \& Hirzinger, G. (2001). DLR-Hand II: next generation of a dextrous robot hand. Proceedings 2001 ICRA. IEEE International Conference on Robotics and Automation (Cat. No.01CH37164), 1. http://doi.org/10.1109/ROBOT.2001.932538

Butterfass, J., Hirzinger, G., Knoch, S., \& Liu, H. (1998). DLR's multisensory articulated hand. I. Hard- and software architecture. Proceedings. 1998 IEEE International Conference on Robotics and Automation (Cat. No.98CH36146), 3. http://doi.org/10.1109/ROBOT.1998.680625 
Carbone, G., \& González, A. (2011). A numerical simulation of the grasp operation by LARM Hand IV: A three finger robotic hand. Robotics and Computer-Integrated Manufacturing, 27(2), 450-459. http://doi.org/10.1016/j.rcim.2010.09.005

Ceccarelli, M., Nava, N., Jáuregui, J. M., Parada, J., \& Carbones, G. (2004). Diseño y experimentación de un dedo articulado antropomorfo con un grado de libertad para una mano robótica. Iberoamericana de Igeniería Mecánica, 8(12), 15-24.

Centri. (2014). Mano Myo. Retrieved October 4, 2015, from emo.org.es/es/catalog/detail/533/mano-mioelectrica-myo

Chandler, R., Clauser, D., McMconville, J., Reynolds, H., \& Young, J. (1975). Investigation of inertial properties of the human hand. US Department of Transportation, DOT HS-801.

Chang, L. Y., \& Matsuoka, Y. (2006). A kinematic thumb model for the ACT hand. In Proceedings - IEEE International Conference on Robotics and Automation (Vol. 2006, pp. 1000-1005). http://doi.org/10.1109/ROBOT.2006.1641840

Chkeir, A., Jaber, R., Hewson, D. J., \& Duchene, J. (2012). Reliability and validity of the Grip-Ball dynamometer for grip-strength measurement. In Proceedings of the Annual International Conference of the IEEE Engineering in Medicine and Biology Society, EMBS (pp. 1996-1999). http://doi.org/10.1109/EMBC.2012.6346348

Clarkson, H. M. (2000). Musculoskeletal assessment: joint range of motion and manual muscle strength. Williams \& Wilkins.

Coldham, F., Lewis, J., \& Lee, H. (2006). The Reliability of One vs. Three Grip Trials in Symptomatic and Asymptomatic Subjects. Journal of Hand Therapy, 19(3), 318-327. http://doi.org/10.1197/j.jht.2006.04.002

Cole, K. J. (2008). Lifting a familiar object: Visual size analysis, not memory for object weight, scales lift force. Experimental Brain Research, 188, 551557. http://doi.org/10.1007/s00221-008-1392-y

Computer History. (n.d.). Mano UTAH-MIT. Retrieved September 12, 2015, 
Análisis de la distribución de presiones en la mano humana durante el agarre

from http://www.computerhistory.org/collections/accession/102693567)

Crajé, C., Lukos, J. R., Ansuini, C., Gordon, A. M., Santello, M., \& Craj e, C. e line. (2011). The effects of task and content on digit placement on a bottle. Experimental Brain Research. Experimentelle Hirnforschung. Expérimentation Cérébrale, 212(1), 119-24. http://doi.org/10.1007/s00221-011-2704-1

Cutkosky, M. R. (1989). On grasp choice, grasp models, and the design of hands for manufacturing tasks. IEEE Transactions on Robotics and Automation, 5(3), 269-279. http://doi.org/10.1109/70.34763

Cutkosky, M., \& Wright, P. (1986). Modeling manufacturing grips and correlations with the design of robotic hands. Proceedings. 1986 IEEE International Conference on Robotics and Automation, 3, 1533-1539. http://doi.org/10.1109/ROBOT.1986.1087525

Davitt, J. S., Beals, T. C., \& Bachus, K. N. (2001). The effects of medial and lateral displacement calcaneal osteotomies on ankle and subtalar joint pressure distribution. Foot Ankle Int, 22(11), 885-889.

DeMarco, A. L., Rust, D. A., \& Bachus, K. N. (2000). Measuting contact pressure and contact area in orthopedic applications: Fuji Film vs. Tekscan. In. Proceedings of 46th Annual Meeting, Orthopaedic Research Society, Orlando, FL, 36(11), $1659-1668$.

DLR. (n.d.). Mano DLR-Hand. Retrieved September 12, 2015, from http://www.dlr.de/rmc/rm/en/desktopdefault.aspx/tabid3975/6161_read-243/

Domalain, M., Vigouroux, L., Danion, F., Sevrez, V., \& Berton, E. (2008a). Effect of object width on precision grip force and finger posture. Ergonomics, 51(9), 1441-1453. http://doi.org/10.1080/00140130802130225

Domalain, M., Vigouroux, L., Danion, F., Sevrez, V., \& Berton, E. (2008b). Effect of object width on precision grip force and finger posture. Ergonomics, 51(9), 1441-1453. http://doi.org/10.1080/00140130802130225

Dong, R. G., Wu, J. Z., Welcome, D. E., \& McDowell, T. W. (2008). A new approach to characterize grip force applied to a cylindrical handle. 
Medical Engineering and Physics, 30(1), 20-33. http://doi.org/10.1016/j.medengphy.2007.01.002

Dorador, J., Ríos, P., Flores, R., \& Juárez, A. (2004). Diseño de prótesis inteligentes. Departamento de Ingeniería Mecatrónica.

Drewniak, E. I., Crisco, J. J., Spenciner, D. B., \& Fleming, B. C. (2007). Accuracy of circular contact area measurements with thin-film pressure sensors. Journal of Biomechanics, 40(11), 2569-2572. http://doi.org/10.1016/j.jbiomech.2006.12.002

Dubousset, J. F. (1981). The Hand. Volumen I, capitulo 6: The Digital Joints. Philadelphia: Saunders Company.

Duvinage, M., Castermans, T., \& Dutoit, T. (2011). Control of a lower limb active prosthesis with eye movement sequences. 2011 IEEE Symposium on Computational Intelligence, Cognitive Algorithms, Mind, and Brain (CCMB), 1-7. http://doi.org/10.1109/CCMB.2011.5952116

Edgren, C. S., Radwin, R. G., \& Irwin, C. B. (2004). Grip force vectors for varying handle diameters and hand sizes. Human Factors, 46(2), 244-251. http://doi.org/10.1518/hfes.46.2.244.37337

Edoarado. (2011). Planos anatómicos. Retrieved October 4, 2015, from https://upload.wikimedia.org/wikipedia/commons/thumb/d/dc/Planos_a nat\%C3\%B3micos.svg/507px-Planos_anat\%C3\%B3micos.svg.png

Einot, I., \& Gabriel, K. R. (1975). A Study of the Powers of Several Methods of Multiple Comparisons. Journal of the American Statistical Association, 70(351), 574-583.

Eksioglu, M. (2004). Relative optimum grip span as a function of hand anthropometry. International Journal of Industrial Ergonomics, 34(1), 112. http://doi.org/10.1016/j.ergon.2004.01.007

Eksioglu, M., \& Kizilaslan, K. (2008). Steering-wheel grip force characteristics of drivers as a function of gender, speed, and road condition. International Journal of Industrial Ergonomics, 38(3-4), 354-361. http://doi.org/10.1016/j.ergon.2008.01.004

Ekvall, S., \& Kragic, D. (2004). Interactive grasp learning based on human 
demonstration. Robotics and Automation, 2004. Proceedings. ICRA '04.

2004 IEEE International Conference on.
http://doi.org/10.1109/ROBOT.2004.1308798

EMO. (2014). Catálogo EMO.

Exner, C. E. (2001). Development of hand skills. Occupational therapy for children.

Eyler, D. L., \& Markee, J. E. (1954). The anatomy and function of the intrinsic musculature of the fingers. J. Bone and Joint Surgery, 36A(1), 1-18.

Fahrer, M., \& Tubiana, R. (1981). The Hand, chapter 26: The Hypothenar Eminence. Philadelphia: W.B. Saunders Company.

Faria, D. R., Martins, R., Lobo, J., \& Dias, J. (2012). Extracting data from human manipulation of objects towards improving autonomous robotic grasping. Rob Auton Syst, 60(3), 396-410. http://doi.org/10.1016/j.robot.2011.07.020

Feix, T., Pawlik, R., Schmiedmayer, H.-B., Romero, J., \& Kragi, D. (2009). A comprehensive grasp taxonomy. Robotics, Science and Systems Conference: Workshop on Understanding the Human Hand for Advancing Robotic Manipulation, 2-3.

Ferguson-Pell, M., Hagisawa, S., \& Bain, D. (2001). Evaluation of a sensor for low interface pressure applications. Medical Engineering and Physics, 22(9), 657-663. http://doi.org/10.1016/S1350-4533(00)00080-1

Fischer, G. W. (1969). A Treatise of the Topographical Anatomy of the Long Finger and Biomechanical Invesigation of its Interjoint Movement. Ann Arbor, Michigan: University Microfilms.

Flanagan, J. R., Burstedt, M. K. O., \& Johansson, R. S. (1999). Control of Fingertip Forces in Multidigit Manipulation. J Neurophysiol, 81(4), 17061717. Retrieved from http://jn.physiology.org/content/81/4/1706.long

Flanagan, J. R., \& Tresilian, J. R. (1994). Grip-load force coupling: a general control strategy for transporting objects. Journal of Experimental Psychology. Human Perception and Performance, 20(5), 944-957. http://doi.org/10.1037/0096-1523.20.5.944 
Flanagan, J. R., \& Wing, A. M. (1997). Effects of surface texture and grip force on the discrimination of hand-held loads. Perception \& Psychophysics, 59, 111-118. http://doi.org/10.3758/BF03206853

Flanagan, J. R., Wing, A. M., Allison, S., \& Spenceley, A. (1995). Effects of surface texture on weight perception when lifting objects with a precision grip. Perception \& Psychophysics, 57, 282-290. http://doi.org/10.3758/BF03213054

Forssberg, H., Eliasson, A. C., Kinoshita, H., Westling, G., \& Johansson, R. S. (1995). Development of human precision grip - IV.Tactile adaptation of isometric finger forces to the frictional condition. Experimental Brain Research, 104(2), 323-330. http://doi.org/10.1007/BF00242017

Frykman, G. (1967). Fracture of the distal radius including sequelae: shoulderhand-finger syndrome, disturbance of the distal radio-ulnar joint and impairment of nerve function. A clinical and experimental study. Acta Orthopaedica Scandinavica, 108.

Fuji. (n.d.). Fuji Film. Retrieved October 2, 2015, from http://www.fujifilm.com/products/prescale/prescalefilm/

Gaiser, I., Schulz, S., Kargov, A., Klosek, H., Bierbaum, A., Pylatiuk, C., ... Dillmann, R. (2008). A new anthropomorphic robotic hand. In 2008 8th IEEE-RAS International Conference on Humanoid Robots, Humanoids 2008 (pp. 418-422). http://doi.org/10.1109/ICHR.2008.4755987

Gao, F., Latash, M. L., \& Zatsiorsky, V. M. (2005). Internal forces during object manipulation. Experimental Brain Research, 165, 69-83. http://doi.org/10.1007/s00221-005-2282-1

García-Villapando, J. A., Castillo-Morales, A., Ramírez Guzmán, M. E., RendónSánchez, G., \& Larqué-Saavedra, M. U. (2001). Comparación de los procedimientos de Tukey, Duncan, Dunnett, HSU y Bechhofer para la selección de medias. Agrociencia, 35, 79-86.

Ghali, B., Thalanki Anantha, N., Chan, J., \& Chau, T. (2013). Variability of Grip Kinetics during Adult Signature Writing. PLOS ONE, 8(5). http://doi.org/10.1371/journal.pone.0063216 
Gonzalez, F., Gosselin, F., \& Bachta, W. (2014). Analysis of Hand Contact Areas and Interaction Capabilities During Manipulation and Exploration. IEEE Transactions on Haptics, 7(4), 415-429. http://doi.org/10.1109/TOH.2014.2321395

Greis, P. E., Scuderi, M. G., Mohr, A., Bachus, K. N., \& Burks, R. T. (2002). Glenohumeral articular contact areas and pressures following labral and osseous injury to the anteroinferior quadrant of the glenoid. Journal of Shoulder and Elbow Surgery, 11(5), 442-451. http://doi.org/10.1067/mse.2002.124526

Grichting, B., Hediger, V., Kaluzny, P., \& Wiesendanger, M. (2000). Impaired proactive and reactive grip force control in chronic hemiparetic patients. Clinical Neurophysiology, 111(9), 1661-1671. http://doi.org/10.1016/S1388-2457(00)00355-2

Hamilton, A., Balnave, R., \& Adams, R. (1994). Grip strength testing reliability. J Hand Ther, 7(3), 163-170. Retrieved from http://www.ncbi.nlm.nih.gov/entrez/query.fcgi?cmd=Retrieve\&db=Pub Med\&dopt=Citation\&list_uids $=7951708$

Hamilton, G. F., McDonald, C., \& Chenier, T. C. (1992). Measurement of grip strength: validity and reliability of the sphygmomanometer and jamar grip dynamometer. The Journal of Orthopaedic and Sports Physical Therapy, 16(5), 215-219. http://doi.org/10.2519/jospt.1992.16.5.215

Harris, M. L., Morberg, P., Bruce, W. J., \& Walsh, W. R. (1999). An improved method for measuring tibiofemoral contact areas in total knee arthroplasty: a comparison of K-scan sensor and Fuji film. Journal of Biomechanics, 32(9), 951-8. http://doi.org/DOI: 10.1016/S00219290(99)00072-X

Hermsdörfer, J., Li, Y., Randerath, J., Goldenberg, G., Eidenmüller, S., \& Eidenmuller, S. (2011a). Anticipatory scaling of grip forces when lifting objects of everyday life. Experimental Brain research.Experimentelle Hirnforschung.Experimentation Cerebrale, 212(1), 19-31. http://doi.org/10.1007/s00221-011-2695-y

Hermsdörfer, J., Li, Y., Randerath, J., Goldenberg, G., Eidenmüller, S., \& 
Eidenmuller, S. (2011b). Anticipatory scaling of grip forces when lifting objects of everyday life. Experimental Brain research.Experimentelle Hirnforschung.Experimentation Cerebrale, 212(1), 19-31. http://doi.org/10.1007/s00221-011-2695-y

Hirukawa, H., Kanehiro, F., Kaneko, K., Kajita, S., Fujiwara, K., Kawai, Y., ... Inoue, H. (2004). Humanoid robotics platforms developed in HRP. In Robotics and Autonomous Systems (Vol. 48, pp. 165-175). http://doi.org/10.1016/j.robot.2004.07.007

Hooke, A. W., Park, J., \& Shim, J. K. (2008). The forces behind the words: Development of the Kinetic Pen. Journal of Biomechanics, 41, 2060-2064. http://doi.org/10.1016/j.jbiomech.2008.03.036

HRP. (n.d.). HRP-4C. Retrieved September 12, 2015, from https://radiocontempo.wordpress.com/2009/03/16/

Hsiao, H., Guan, J., \& Weatherly, M. (2002). Accuracy and precision of two inshoe pressure measurement systems. Ergonomics, 45(8), 537-555. http://doi.org/10.1080/00140130210136963

Hu, Y., Osu, R., Okada, M., Goodale, M. A., \& Kawato, M. (2005). A model of the coupling between grip aperture and hand transport during human prehension. Experimental Brain Research, 167(2), 301-304. http://doi.org/10.1007/s00221-005-0111-1

Human Grasping Database. (2007). Taxonomy comparison. Retrieved October 5, 2015, from http://grasp.xief.net/documents/taxonomy_comparison.pdf Imaeda, R., An, K. N., \& W.P., C. (1992). Functional anatomy and biomechanics of the thumb. Hand Clinics.

Johansson, R. S., \& Westling, G. (1984). Roles of glabrous skin receptors and sensorimotor memory in automatic control of precision grip when lifting rougher or more slippery objects. Experimental Brain Research. Experimentelle Hirnforschung. Experimentation Cerebrale, 56, 550-564. http://doi.org/10.1007/BF00237997

Jones, L. A., \& Lederman, S. J. (2006). Human Hand Function. The Journal of 
Hand Surgery European Volume (Vol. 32).

http://doi.org/10.1016/j.jhse.2007.04.015

Junta de beneficencia. (n.d.). Prótesis mecánica. Retrieved from https://www.juntadebeneficencia.org.ec/attachments/article/1028/prot esis_meadows.jpg

Kamakura, N., Matsuo, M., Ishii, H., Mitsuboshi, F., \& Miura, Y. (1980). Patterns of static prehension in normal hands. The American Journal of Occupational Therapy. : Official Publication of the American Occupational Therapy Association, 34(7), 437-445. http://doi.org/10.5014/ajot.34.7.437

Kaneko, K., Harada, K., Kanehiro, F., Miyamori, G., \& Akachi, K. (2008). Humanoid robot HRP-3. In 2008 IEEE/RSJ International Conference on Intelligent Robots and Systems, IROS (pp. 2471-2478). http://doi.org/10.1109/IROS.2008.4650604

Kaneko, K., Kanehiro, F., Morisawa, M., Akachi, K., Miyamori, G., Hayashi, A., \& Kanehira, N. (2011). Humanoid robot HRP-4 - Humanoid robotics platform with lightweight and slim body. In IEEE International Conference on Intelligent Robots and Systems (pp. 4400-4407). http://doi.org/10.1109/IROS.2011.6048074

Kaneko, K., Kanehiro, F., Morisawa, M., Tsuji, T., Miura, K., Nakaoka, S., ... Yokoi, K. (2011). Hardware improvement of cybernetic human HRP-4C for entertainment use. In IEEE International Conference on Intelligent Robots and Systems (pp. 4392-4399). http://doi.org/10.1109/IROS.2011.6048061

Kapandji, I. A. (1996). Fisiología Articular. Miembro superior. (5 edición). Editorial Médica Panamericna, Madrid.

Kapandji, I. A. (2006). Funktionelle Anatomic der Gelenke. Schematisierte und kommentierte Zeichnungen zur menschlischen Biomechanik. Thieme Georg Verlag.

Kargov, A., Pylatiuk, C., Martin, J., Schulz, S., \& Döderlein, L. (2004). A comparison of the grip force distribution in natural hands and in 
prosthetic hands. Disabil Rehabil, 26(12), 705-711. Retrieved from papers2://publication/uuid/8E07EB1A-8F3F-49BC-BA7F-47599B385A35

Kawasaki, H., Komatsu, T., \& Uchiyama, K. (2002). Dexterous anthropomorphic robot hand with distributed tactile sensor: Gifu hand II. IEEE/ASME Transactions on Mechatronics, 7(3), 296-303. http://doi.org/10.1109/TMECH.2002.802720

Kellor, M., Frost, J., Silberberg, N., Iversen, I., \& Cummings, R. (1971). Hand strength and dexterity. Occupational Therapy International, 25, 77-83.

Kemp, C. C., Edsinger, A., \& Torres-Jara, E. (2007). Challenges for robot manipulation in human environments [Grand challenges of robotics]. IEEE Robotics Automation Magazine, 14(1), 20. Retrieved from papers2://publication/uuid/2C9988A1-973D-49CC-9D74-066127BAF295

Kinoshita, H., Kawai, S., \& Ikuta, K. (1995). Contributions and co-ordination of individual fingers in multiple finger prehension. Ergonomics, 38, 12121230. http://doi.org/10.1080/00140139508925183

Komi, E. R., Roberts, J. R., \& Rothberg, S. J. (2007). Evaluation of thin, flexible sensors for time-resolved grip force measurement. Proceedings of the Institution of Mechanical Engineers, Part C: Journal of Mechanical Engineering Science, 221(12), 1687-1699. Retrieved from papers2://publication/uuid/33AEF976-31B6-4A74-8127-B85D4D76182A

Kong, Y. K., \& Lowe, B. D. (2005). Optimal cylindrical handle diameter for grip force tasks. International Journal of Industrial Ergonomics, 35(6), 495507. http://doi.org/10.1016/j.ergon.2004.11.003

Kong, Y.-K., Lee, K.-S., Kim, D.-M., \& Jung, M.-C. (2011). Individual finger contribution in submaximal voluntary contraction of gripping. Ergonomics, 54(11), 1072-1080. http://doi.org/10.1080/00140139.2011.620176

Kong, Y.-K., Seo, M.-T., \& Kang, H.-S. (2014). Evaluation of total grip strength and individual finger forces on opposing (A-type) handles among Koreans. Ergonomics, 57(1), 108-15. http://doi.org/10.1080/00140139.2013.851284 
Koreamed. (2012). Dinamómetro digital de pinza. Retrieved September 1, 2015 from http://synapse.koreamed.org/DOlx.php?id=10.5535/arm.2012.36.3.394\& vmode=PUBREADER

Kuijt-Evers, L. F. M., Groenesteijn, L., De Looze, M. P., \& Vink, P. (2004). Identifying factors of comfort in using hand tools. Applied Ergonomics, 35(5), 453-458. http://doi.org/10.1016/j.apergo.2004.04.001

Kuo, L.-C., Chen, S.-W., Lin, C.-J., Lin, W.-J., Lin, S.-C., \& Su, F.-C. (2013). The force synergy of human digits in static and dynamic cylindrical grasps. PloS One, 8(3), e60509. http://doi.org/10.1371/journal.pone.0060509

Laschi, C., Dario, P., Carrozza, M. C., Guglielmelli, E., Teti, G., Taddeucci, D., ... Anna, S. (2000). Grasping and Manipulation in Humanoid Robotics. Science And Technology.

Lee, S., Kong, Y., Lowe, B., \& Song, S. (2009). Handle grip span for optimising finger-specific force capability as a function of hand size. Ergonomics, 52(5), 601-608. Retrieved from http://www.tandfonline.com/doi/abs/10.1080/00140130802422481

Li, Y., Randerath, J., Bauer, H., Marquardt, C., Goldenberg, G., \& Hermsdörfer, J. (2009). Object properties and cognitive load in the formation of associative memory during precision lifting. Behavioural Brain Research, 196, 123-130. http://doi.org/10.1016/j.bbr.2008.07.031

Lidstrom, A. (1959). Fractures of the distal end of the radius. Acta Orthopaedica Scandinavica, 41.

Light, C. M., Chappell, P. H., \& Kyberd, P. J. (2002). Establishing a standardized clinical assessment tool of pathologic and prosthetic hand function: Normative data, reliability, and validity. Archives of Physical Medicine and Rehabilitation, 83(6), 776-783. http://doi.org/10.1053/apmr.2002.32737

Light, C. M., Chappell, P. H., Kyberd, P. J., \& Ellis, B. S. (1999). A critical review of functionality assessment in natural and prosthetic hands. British Journal of Occupational Therapy.

Lovchik, C. S., \& Diftler, M. A. (1999). The Robonaut hand: a dexterous robot 
hand for space. Proceedings 1999 IEEE International Conference on

Robotics and Automation (Cat. No.99CH36288C), 2. http://doi.org/10.1109/ROBOT.1999.772420

Lowe, B. D. (2001). Precision grip force control of older and younger adults, revisited. Journal of occupational rehabilitation (Vol. 11).

Manis, R. P., \& Santos, V. J. (2015). Independent digit contributions to rotational manipulation in a three-digit pouring task requiring dynamic stability. Experimental Brain Research, 233(7), 2195-2204. http://doi.org/10.1007/s00221-015-4289-6

Martin, J. R., Latash, M. L., \& Zatsiorsky, V. M. (2009). Interaction of finger enslaving and error compensation in multiple finger force production. Experimental Brain Research. Experimentelle Hirnforschung. Experimentation Cerebrale, 192, 293-298. http://doi.org/10.1007/s00221-008-1615-2

Mason, M. T., \& Salisbury, J. K. (1985). Robot hands and the mechanics of manipulation. MA: MIT Press.

Massy-Westropp, N., Rankin, W., Ahern, M., Krishnan, J., \& Hearn, T. C. (2004). Measuring grip strength in normal adults: Reference ranges and a comparison of electronic and hydraulic instruments. Journal of Hand Surgery, 29(3), 514-519. http://doi.org/10.1016/j.jhsa.2004.01.012

Mathiowetz, V. (2002). Comparison of Rolyan and Jamar dynamometers for measuring grip strength. Occupational Therapy International, 9(3), 201209.

Mathiowetz, V., Weber, K., Volland, G., \& Kashman, N. (1984). Reliability and validity of grip and pinch strength evaluations. The Journal of Hand Surgery, 9(2), 222-226. http://doi.org/http://dx.doi.org/10.1016/S03635023(84)80146-X

Matsuda, S., Williams, V. G., Whiteside, L. A., \& White, S. E. (1995). A comparison of pressure sensitive film and digital electronic sensors to measure contact area and contact stress. Proceedings of 46th Annual Meeting, Orthopaedic Research Society, Orlando, FL. 
Mattar, E. (2013). A survey of bio-inspired robotics hands implementation: New directions in dexterous manipulation. Robotics and Autonomous Systems, 61(5), 517-544. http://doi.org/10.1016/j.robot.2012.12.005

McDonnell, M. N., Ridding, M. C., Flavel, S. C., \& Miles, T. S. (2005). Effect of human grip strategy on force control in precision tasks. Experimental Brain Research, 161, 368-373. http://doi.org/10.1007/s00221-004-20810

McDowell, T. W., Wimer, B. M., Welcome, D. E., Warren, C., \& Dong, R. G. (2012). Effects of handle size and shape on measured grip strength. International Journal of Industrial Ergonomics, 42(2), 199-205. http://doi.org/10.1016/j.ergon.2012.01.004

McGorry, R. W. (2001). A system for the measurement of grip forces and applied moments during hand tool use. Applied Ergonomics, 32(3), 271279. http://doi.org/10.1016/S0003-6870(00)00062-4

McGorry, R. W., Dowd, P. C., \& Dempsey, P. G. (2003). Cutting moments and grip forces in meat cutting operations and the effect of knife sharpness. Applied Ergonomics, 34(4), 375-382. http://doi.org/10.1016/S00036870(03)00041-3

McGorry, R. W., \& Lin, J.-H. (2007). Power grip strength as a function of tool handle orientation and location. Ergonomics, 50(9), 1392-403. http://doi.org/10.1080/00140130701340115

MEC. (n.d.). Músculos del pulgar. Retrieved from http://recursos.cnice.mec.es

Medicallexpo. (n.d.-a). Mano mioeléctrica. Retrieved from http://img.medicalexpo.es/images_me/photo-mg/protesis-miembrosuperior-protesis-parcial-mano-mioelectrica-multiarticuladas-adulto80284-5266677.jpg

Medicallexpo. (n.d.-b). Prótesis estética externa de la mano adulta. Retrieved from http://img.medicalexpo.es/images_me/photo-g/protesis-esteticaesterna-mano-adulto-80284-5265979.jpg

Micera, S., Carpaneto, J., \& Raspopovic, S. (2010). Control of hand prostheses using peripheral information. IEEE Reviews in Biomedical Engineering, 3, 
48-68. http://doi.org/10.1109/RBME.2010.2085429

Molina-Vilaplana, J., \& López-Coronado, J. (2007). Neural modelling of hand grip formation during reach to grasp. Neurocomputing, 71(1-3), 411. Retrieved from papers2://publication/uuid/C63AF437-9EE9-480B-827D9DF50D01C08A

Mombaur, K., \& Sreenivasa, M. N. (2010). HRP-2 plays the yoyo: From human to humanoid yoyo playing using optimal control. In Proceedings - IEEE International Conference on Robotics and Automation (pp. 3369-3376). http://doi.org/10.1109/ROBOT.2010.5509780

Momberger, N., Morgan, J. M., Bachus, K. N., \& West, J. R. (2000). Calcaneocuboid joint pressure after lateral column lengthening in a cadaveric planovalgus deformity model. Foot \& Ankle International / American Orthopaedic Foot and Ankle Society [and] Swiss Foot and Ankle Society, 21(9), 730-735.

Monzée, J., Lamarre, Y., \& Smith, A. M. (2003). The effects of digital anesthesia on force control using a precision grip. Journal of Neurophysiology, 89(2), 672-683. http://doi.org/10.1152/jn.00434.2001

Monzee, J., Lamarre, Y., Smith, A. M., Monzée, J., Lamarre, Y., \& Smith, A. M. (2003). The effects of digital anesthesia on force control using a precision grip. Journal of Neurophysiology, 89(2), 672-683. http://doi.org/DOI 10.1152/jn.00434.2001

Mora, M. C., Sancho-Bru, J. L., \& Perez-Gonzalez, A. (2012). Hand Posture Prediction using Neural Networks within a Biomechanical Model. International Journal of Advanced Robotic Systems, 9. http://doi.org/10.5772/52057

Morse, J. L., Jung, M. C., Bashford, G. R., \& Hallbeck, M. S. (2006). Maximal dynamic grip force and wrist torque: The effects of gender, exertion direction, angular velocity, and wrist angle. Applied Ergonomics, 37, 737742. http://doi.org/10.1016/j.apergo.2005.11.008

Napier. (1956). The prehensile movements of the human hand. The Journal of Bone and Joint Surgery, 38, 902-913. Retrieved from 
http://www.ncbi.nlm.nih.gov/entrez/query.fcgi?db=pubmed\&cmd=Retri eve\&dopt=AbstractPlus\&list_uids=1380342483412326293related:IRcs4Cz 2JxMJnpapers://c80d98e4-9a96-4487-8d06-8e1acc780d86/Paper/p424

Nicholas, J. W., Corvese, R. J., Woolley, C., \& Armstrong, T. J. (2012). Quantification of hand grasp force using a pressure mapping system. In Work (Vol. 41, pp. 605-612). http://doi.org/10.3233/WOR-2012-0217605

Nicolay, C. W., \& Walker, A. L. (2005). Grip strength and endurance: Influences of anthropometric variation, hand dominance, and gender. International Journal of Industrial Ergonomics, 35(7), 605-618. http://doi.org/10.1016/j.ergon.2005.01.007

Nof, S. Y. (1999). Handbook of industrial robotics ( $2^{\mathrm{a}}$ ed.). Robotic Industries Association.

Nowak, D. A., Glasauer, S., \& Hermsdörfer, J. (2004). How predictive is grip force control in the complete absence of somatosensory feedback? Brain, 127(1), 182-192. http://doi.org/10.1093/brain/awh016

Olafsdottir, H., Zatsiorsky, V. M., \& Latash, M. L. (2005). Is the thumb a fifth finger? A study of digit interaction during force production tasks. Experimental Brain Research. Experimentelle Hirnforschung. Experimentation Cerebrale, 160, 203-213. http://doi.org/10.1007/s00221-004-2004-0

Olier Caparroso, I., Avilés, O., \& Hernández Bello, J. (1999). Una introducción a la robótica industrial. Revista de La Facultad de Ingeniería, 8, 53-67.

Otto Bock. (n.d.). Mano Michelangelo. Retrieved from http://www.ottobock.com/cps/rde/xchg/ob_com_en/hs.xsl/49490.html

Parker, P., Englehart, K., \& Hudgins, B. (2006). Myoelectric signal processing for control of powered limb prostheses. Journal of Electromyography and Kinesiology, 16, 541-548. http://doi.org/10.1016/j.jelekin.2006.08.006

Pataky, T. C., Slota, G. P., Latash, M. L., \& Zatsiorsky, V. M. (2012). Radial force distribution changes associated with tangential force production in cylindrical grasping, and the importance of anatomical registration. 
Journal of Biomechanics, 45(2), 218-224. http://doi.org/10.1016/j.jbiomech.2011.11.006

Pérez-González, a, Jurado-Tovar, M., \& Sancho-Bru, J. (2011). Fuerzas de contacto entre mano y objeto en el agarre cilíndrico: comparación de dos técnicas de medición. XIX Congreso Nacional de Ingeniería Mecánica. Castellón de la Plana: XIX Congreso Nacional de Ingeniería Mecánica. Retrieved from http://www.xixcnim.uji.es/CDActas/Documentos/ComunicacionesPosters 101-16.pdf

Peters, M. J. H., Van Nes, S. I., Vanhoutte, E. K., Bakkers, M., Van Doorn, P. A., Merkies, I. S. J., \& Faber, C. G. (2011). Revised normative values for grip strength with the Jamar dynamometer. Journal of the Peripheral Nervous System, 16(1), 47-50. http://doi.org/10.1111/j.1529-8027.2011.00318.x

Pilon, J. F., De Serres, S. J., \& Feldman, A. G. (2007). Threshold position control of arm movement with anticipatory increase in grip force. Experimental Brain Research, 181(1), 49-67. http://doi.org/10.1007/s00221-007-09018

Pistohl, T., Schulze-Bonhage, A., Aertsen, A., Mehring, C., \& Ball, T. (2012). Decoding natural grasp types from human ECoG. Neurolmage, 59(1), 248-60. http://doi.org/10.1016/j.neuroimage.2011.06.084

Polliack, a a, Sieh, R. C., Craig, D. D., Landsberger, S., McNeil, D. R., \& Ayyappa, E. (2000). Scientific validation of two commercial pressure sensor systems for prosthetic socket fit. Prosthetics and Orthotics International, 24, 6373. http://doi.org/10.1080/03093640008726523

Pylatiuk, C., Kargov, A., Schulz, S., \& Döderlein, L. (2006). Distribution of grip force in three different functional prehension patterns. Journal of Medical Engineering \& Technology, 30(3), 176-82. http://doi.org/10.1080/03091900600565217

Quinayás Burgos, C. A. (2010). Diseño y construcción de una prótesis robótica de mano funcional adaptada a varios agarres. Universidad de Cauca.

Radwin, R. G., Oh, S., Jensen, T. R., \& Webster, J. G. (1992). External finger 
forces in submaximal five-finger static pinch prehension. Ergonomics, 35, 275-288. http://doi.org/10.1080/00140139208967813

Rajabally, Y. A., \& Narasimhan, M. (2013). Jamar hand-held grip dynamometry in chronic inflammatory demyelinating polyneuropathy. Journal of the Neurological Sciences, 325(1-2), 36-38. http://doi.org/10.1016/j.jns.2012.11.010

Ranney, D. A., Wells, R. P., \& Dowling, J. (1987). Lumbrical function: Interaction of lumbrical contraction with the elasticity of the extrinsic finger muscles and its effects on metacarpophalangeal equilibrium,. J. Hand Surgery, $12 A(4), 566-575$.

Reilmann, R., Gordon, A. M., \& Henningsen, H. (2001). Initiation and development of fingertip forces during whole-hand grasping. Experimental Brain Research. Experimentelle Hirnforschung. Experimentation Cerebrale, 140, 443-452. http://doi.org/10.1007/s002210100838

Roberts, H. C., Denison, H. J., Martin, H. J., Patel, H. P., Syddall, H., Cooper, C., \& Sayer, A. A. (2011). A review of the measurement of grip strength in clinical and epidemiological studies: Towards a standardised approach. Age and Ageing. http://doi.org/10.1093/ageing/afr051

robotnik. (n.d.). Mano Shadow. Retrieved from http://www.robotnik.es/web/wp-content/uploads/2014/07/shadowhand-manos-roboticas-robotnik_s03.jpg

Rock, K. M., Mikat, R. P., \& Foster, C. (2001). The Effects of Gloves on Grip Strength and Three-point Pinch. JOURNAL OF HAND THERAPY, 14, 286290.

Rouviere, H., \& Delmas, A. (2005). Anatomía humana descriptiva, topográfica y funcional. Elsevier (11th ed.).

RSJ. (n.d.). Gifu Hand II. Retrieved September 12, 2015, from http://www.rsj.or.jp/rij_e/?page_id=73

Salazar, A. (n.d.). Músculos del pulgar. Retrieved from http://myanatomy.tuars.com/Musculos.html 
Sancho-Bru, J. L. (2000). Model Biomecànic de la ma orientat al disseny d'eines manuals. Universitat Jaume I.

Sancho-Bru, J. L., Pérez-González, A., Vergara, M., \& Giurintano, D. J. (2003). A $3 \mathrm{D}$ biomechanical model of the hand for power grip. Journal of Biomechanical Engineering, 125(1), 78-83. http://doi.org/10.1115/1.1532791

Santello, M., \& Soechting, J. F. (2000). Force synergies for multifingered grasping. Experimental Brain Research, 133(4), 457-467. Retrieved from papers2://publication/uuid/09E8ACA4-FAD4-4E96-81E0-D1DB1C5001D2

Sartori, L., Straulino, E., \& Castiello, U. (2011). How objects are grasped: The interplay between affordances and end-goals. PLOS ONE, 6(9). http://doi.org/10.1371/journal.pone.0025203

Savescu, A. V., Latash, M. L., \& Zatsiorsky, V. M. (2008). A technique to determine friction at the finger tips. Journal of Applied Biomechanics, 24(1), 43-50. Retrieved from http://www.ncbi.nlm.nih.gov/pmc/articles/PMC2827180/

Schenck, R. R. (1964). Variations of extensor tendons of the fingers. J. Bone and Joint Surgery, 46A(1), 103-110.

Schlesinger, G. (1919). Der Mechanische Aufbau der Kunstlichen Glieder. Ersatzglieder und Arbeitshilfen, part II. Berlin: Springer.

Schmidt, R. T., \& Toews, J. V. (1970). Grip strength as measured by the Jamar dynamometer. Archives of Physical Medicine and Rehabilitation, 51, 321327.

Seo, N. J. (2009). Dependence of safety margins in grip force on isometric push force levels in lateral pinch. Ergonomics, 52(7), 840-847. http://doi.org/10.1080/00140130903160345

Seo, N. J., \& Armstrong, T. J. (2008). Investigation of grip force, normal force, contact area, hand size, and handle size for cylindrical handles. Human Factors, 50(5), 734-744. http://doi.org/Doi 10.1518/001872008×354192

Seo, N. J., \& Armstrong, T. J. (2011). Effect of elliptic handle shape on grasping strategies, grip force distribution, and twisting ability. Ergonomics. 
http://doi.org/10.1080/00140139.2011.606923

Shadow Robot. (n.d.). The Shadow Hand. Retrieved from http://www.shadowrobot.com/hand

Shih, R. H., Vasarhelyi, E. M., Dubrowski, A., \& Carnahan, H. (2001). The effects of latex gloves on the kinetics of grasping. International Journal of Industrial Ergonomics, 28(5), 265-273. http://doi.org/10.1016/S01698141(01)00021-X

Shim, J. K., Hooke, A. W., Kim, Y. S., Park, J., Karol, S., \& Kim, Y. H. (2010). Handwriting: Hand-pen contact force synergies in circle drawing tasks. Journal of Biomechanics, 43(12), 2249-2253. http://doi.org/10.1016/j.jbiomech.2010.04.033

Shin, H., Moon, S. W., Kim, G. S., Park, J. D., Kim, J. H., Jung, M. J., ... Oh, M. K. (2012). Reliability of the pinch strength with digitalized pinch dynamometer. Annals of Rehabilitation Medicine, 36(3), 394-399. http://doi.org/10.5535/arm.2012.36.3.394

Simanca, P. S., Avilés, O., \& Calle, G. (2005). Dedos para "grippers" robóticos Revisión bibliográfica. Scientia et Technica, XI, 97-102.

Smith, R. J. (1975). Intrinsic Muscles of the Fingers: Function, Dysfunction and Surgical Reconstruction (Vol. 24). A.A.O.S.: Instructional Course Lectures.

Solgaard, S., Kristiansen, B., \& Jensen, J. S. (1984). Evaluation of instruments for measuring grip strength. Acta Orthopaedica Scandinavica, 55(5), 569572. http://doi.org/10.3109/17453678408992963

Taylor, G. L., \& Schwart, R. J. (1955). The Anatomy and Mechanics of the Human Hand.

TekScan. (n.d.). I-Scan. Retrieved October 2, 2015, from https://www.tekscan.com/products-solutions/systems/i-scan-system

Thorngren, K. G., \& Werner, C. O. (1979). Normal grip strength. Acta Orthopaedica Scandinavica, 50(3), 255-259. http://doi.org/10.3109/17453677908989765

Torres Coscoyuela, M., González del Pino, J., Yáñez Calvo, J., \& Bartolomé del 
Valle, E. (1999). Estudio dinamométrico de la mano y el pulgar. Revista de Ortopedia Y Traumatología, 43, 321-326.

Touch Bionics. (n.d.). Prótesis i-limb. Retrieved from http://www.touchbionics.com/sites/default/files/image-gallery/i-limb ultra1.jpg

Trampisch, U. S., Franke, J., Jedamzik, N., Hinrichs, T., \& Platen, P. (2012). Optimal jamar dynamometer handle position to assess maximal isometric hand grip strength in epidemiological studies. Journal of Hand Surgery, 37(11), 2368-2373. http://doi.org/10.1016/j.jhsa.2012.08.014

Tsaousidis, N., \& Freivalds, A. (1998). Effects of gloves on maximum force and the rate of force development in pinch, wrist flexion and grip. International Journal of Industrial Ergonomics, 21(5), 353-360. http://doi.org/10.1016/S0169-8141(96)00086-8

Tubiana, R. (1981). The Hand, volumen I, Capitulo 4: Architecture and Functions of the Hand. Philadelphia: W.B. Saunders Company.

Tubiana, R., \& Valentin, P. (1964). The anatomy of the extensor apparatus of the fingers. Sur. Clin. North America, 44(4), 897-906.

Tyldesley, B., \& Grieve, J. I. (1996). Muscles, nerves, and movement: kinesiology in daily living. Blackwell Science.

Ugurlu, U., \& Özdogan, H. (2013). Conversion of grip strength scores between Jamar dynamometer and a modified sphygmomanometer in patients with rheumatoid arthritis. Isokinetics and Exercise Science, 21(4), 263272. http://doi.org/10.3233/IES-130493

Valentin, P. (1981). The Hand, volumen I, capitulo 23: Extrinsic Muscles of the Hand and Wrist: An Introduction (Vol. I). Philadelphia: Tubiana, R. W.B. Saunders Company.

Vergara, M., Sancho-Bru, J. L., Gracia-Ibáñez, V., \& Pérez-González, A. (2014). An introductory study of common grasps used by adults during performance of activities of daily living. Journal of Hand Therapy: Official Journal of the American Society of Hand Therapists, 27, 1-28. http://doi.org/10.1016/j.jht.2014.04.002 
Vern, P. (1992). Cumulative trauma disorders: a manual for muscoskeletal diseases of the upper limbs. London: Taylor $\backslash \&$ Francis.

Vincent Systems. (2011). Vincent Hand. Retrieved October 4, 2015, from http://vincentsystems.de/en

Vinjamuri, R., Weber, D. J., Mao, Z.-H., Collinger, J. L., Degenhart, A. D., Kelly, J. W., ... Wang, W. (2011). Toward Synergy-Based Brain-Machine Interfaces. Information Technology in Biomedicine, IEEE Transactions on, 15(5), 726736.

Retrieved

from

http://www.google.es/search?client=safari\&rls=10_7_4\&q=Toward+Syne rgy+Based+Brain+Machine+Interfaces\&ie=UTF-8\&oe=UTF-

8\&gws_rd=cr\&ei=kvYBUsqrBMnT7Ab5wIDAAQ

Von Schroeder, H. P., \& Botte, M. J. (1995). Anatomy of the extensor tendons of the fingers: Variations and multiplicity. J. Hand Surgery, 20(A), 27-34.

Wehbé, M. A. (1995). Anatomy of the extensor mechanism of the hand and wrist. Hand Clinics, 11(3), 361-366.

Weir, R. F., Troyk, P. R., DeMichele, G. A., Kerns, D. A., Schorsch, J. F., \& Maas, H. (2009). Implantable myoelectric sensors (IMESs) for intramuscular electromyogram recording. IEEE Transactions on Biomedical Engineering, 56, 159-171. http://doi.org/10.1109/TBME.2008.2005942

Westling, G., \& Johansson, R. S. (1984a). Factors influencing the force control during precision grip. Experimental Brain Research, 53(2), 277-84. http://doi.org/10.1007/BF00238156

Westling, G., \& Johansson, R. S. (1984b). Factors influencing the force control during precision grip. Experimental Brain Research, 53, 277-84. http://doi.org/10.1007/BF00238156

Who. (2001). The International Classification of Functioning, Disability and Health. World Health Organization, 18, 237. http://doi.org/10.1097/01.pep.0000245823.21888.71

Wilson, D. C., Niosi, C. a., Zhu, Q. a., Oxland, T. R., \& Wilson, D. R. (2006). Accuracy and repeatability of a new method for measuring facet loads in the lumbar spine. Journal of Biomechanics, 39(2), 348-353. 
http://doi.org/10.1016/j.jbiomech.2004.12.011

Wilson, D. R., Apreleva, M. V., Eichler, M. J., \& Harrold, F. R. (2003). Accuracy and repeatability of a pressure measurement system in the patellofemoral joint. Journal of Biomechanics, 36(12), 1909-1915. http://doi.org/10.1016/S0021-9290(03)00105-2

Wimer, B., Dong, R. G., Welcome, D. E., Warren, C., \& McDowell, T. W. (2009). Development of a new dynamometer for measuring grip strength applied on a cylindrical handle. Medical Engineering and Physics, 31(6), 695-704. http://doi.org/10.1016/j.medengphy.2009.01.009

Woodburn, J., \& Helliwell, P. S. (1996). Observations on the F-Scan in-shoe pressure measuring system. Clinical Biomechanics, 11(5), 301-304. http://doi.org/10.1016/0268-0033(95)00071-2

Yousef, H., Boukallel, M., \& Althoefer, K. (2011). Tactile sensing for dexterous in-hand manipulation in robotics - A review. Sensors and Actuators, A: Physical. http://doi.org/10.1016/j.sna.2011.02.038

Zaid, A. M., \& Yaqub, M. A. (2012). UTHM HAND: Kinematics behind the dexterous anthropomorphic robotic hand. In Communications in Computer and Information Science (Vol. 330 CCIS, pp. 119-127). http://doi.org/10.1007/978-3-642-35197-6_13

Zancolli, E., \& Cozzi, E. (1993). Atlas de Anatomía Quirúrgica de la Mano (Editorial). Buenos Aires.

Zatsiorsky, V. M., \& Latash, M. L. (2008). Multifinger prehension: an overview. Journal of Motor Behavior, 40(5), 446-476. Retrieved from http://dx.doi.org/10.3200/jmbr.40.5.446-476

Zatsiorsky, V. M., Li, Z. M., \& Latash, M. L. (1998). Coordinated force production in multi-finger tasks: finger interaction and neural network modeling. Biological Cybernetics, 79(2), 139-50. Retrieved from http://www.ncbi.nlm.nih.gov/pubmed/9791934

Zatsiorsky, V. M., Li, Z. M., \& Latash, M. L. (2000). Enslaving effects in multifinger force production. Experimental Brain Research. Experimentelle Hirnforschung. Experimentation Cerebrale, 131, 187-195. 
Análisis de la distribución de presiones en la mano humana durante el agarre

http://doi.org/10.1007/s002219900261 